\title{
Modulation of skeletal muscle plasticity by inflammation
}

Citation for published version (APA):

Langen, R. C. J. (2003). Modulation of skeletal muscle plasticity by inflammation. [Doctoral Thesis, Maastricht University]. Maastricht University. https://doi.org/10.26481/dis.20031212rl

Document status and date:

Published: 01/01/2003

DOI:

10.26481/dis.20031212rl

Document Version:

Publisher's PDF, also known as Version of record

\section{Please check the document version of this publication:}

- A submitted manuscript is the version of the article upon submission and before peer-review. There can be important differences between the submitted version and the official published version of record.

People interested in the research are advised to contact the author for the final version of the publication, or visit the DOI to the publisher's website.

- The final author version and the galley proof are versions of the publication after peer review.

- The final published version features the final layout of the paper including the volume, issue and page numbers.

Link to publication

\footnotetext{
General rights rights.

- You may freely distribute the URL identifying the publication in the public portal. please follow below link for the End User Agreement:

www.umlib.nl/taverne-license

Take down policy

If you believe that this document breaches copyright please contact us at:

repository@maastrichtuniversity.nl

providing details and we will investigate your claim.
}

Copyright and moral rights for the publications made accessible in the public portal are retained by the authors and/or other copyright owners and it is a condition of accessing publications that users recognise and abide by the legal requirements associated with these

- Users may download and print one copy of any publication from the public portal for the purpose of private study or research.

- You may not further distribute the material or use it for any profit-making activity or commercial gain

If the publication is distributed under the terms of Article $25 \mathrm{fa}$ of the Dutch Copyright Act, indicated by the "Taverne" license above, 
Modulation of skeletal muscle plasticity by inflammation 
Druk: Datawyse

ISBN: 90-5278-401-9

(C) Ramon Langen, Maastricht 2003

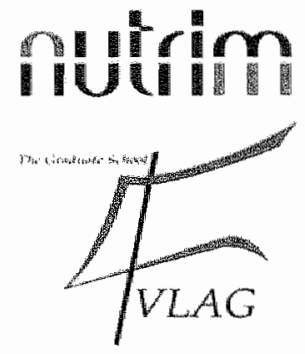

The study presented in this thesis was performed at the Nutrition and Toxicology Research Institute Maastricht (NUTRIM), which participates in the Graduate School VLAG (Food Technology, Agrobiotechnology, Nutrition, accredited by the Royal Netherlands Academy of Arts and Sciences (KNAW). 


\section{Modulation of skeletal muscle plasticity by inflammation}

\section{PROEFSCHRIFT}

ter verkrijging van de graad van doctor aan de Universiteit Maastricht, op gezag van de Rector Magnificus Prof. dr. A.C. Nieuwenhuijzen

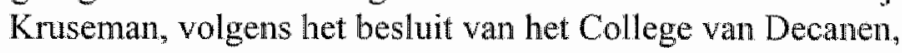

in het openbaar te verdedigen op vrijdag 12 december $2003 \mathrm{om} \mathrm{12:00} \mathrm{uur}$

door

Ramon Langen

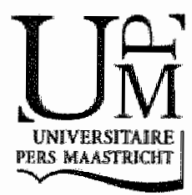




\section{Promotor}

Prof. Dr. E.F.M. Wouters

\section{Co-promotores}

Dr. Y.M.W. Janssen-Heininger (Department of Pathology, University of Vermont, USA) Dr. Ir. A.M.W.J. Schols

\section{Beoordelingscommissie}

Prof. Dr. M. Daemen (voorzitter)

Prof. Dr. M. Decramer (UZ Gasthuisberg, Leuven, België)

Prof. Dr. M. Hofker

Prof. Dr. M.B. Reid (Department of Physiology, University of Kentucky, USA)

Prof. Dr. G.J. van der Vusse

The studies described in this thesis were supported by a research grant from NUMICO Research BV. The publication of this thesis was financially supported by: Stichting Hornerheide, Stichting Pulmologie, NUMICO Research BV, Nutricia Nederland BV, Boehringer Ingelheim BV / Pfizer BV, AstraZeneca BV, Thermo Life Sciences Labsystems BV, Greiner Bio-One, tebu-bio, Sanyo, Beun-De Ronde BV. 
Chapter 1 General Introduction

Chapter 2 Direct effects of inflammation on skeletal muscle

Chapter 3 Enhanced myogenic differentiation by extracellular matrix is regulated at the early stages of myogenesis

Chapter $4 \quad$ Inflammatory cytokines inhibit myogenic differentiation through the activation of Nuclear Factor kappa B

Chapter 5 Tumor Necrosis Factor alpha inhibits myogenesis through redox dependent and independent pathways

Chapter 6 Tumor Necrosis Factor alpha inhibits myogenic differentiation through MyoD protein destabilization

Chapter 7 Inhibition of myogenic differentiation by Tumor Necrosis Factor alpha and Protein Kinase $\mathrm{A}$ is associated with aberrant regulation of MyoD protein stability

Chapter $8 \quad$ General discussion and future directions

Summary

Samenvatting

Dankwoord/Acknowledgements

Publications 


\section{CHAPTER 1}

General introduction 


\section{PACKGROUND}

Skeletal muscle atrophy is a prominent feature of chronic inflammatory disorders, such as Chronic Obstructive Pulmonary Disease (COPD), Chronic Heart Failure (CHF), Inflammatory Bowel Disease (IBD), and Rheumatoid Arthritis (RA)(1-4). The loss of muscle mass is a major contributor of muscle weakness, exercise impairment, and a decreased health status in these disorders (5-9). Besides, skeletal muscle atrophy is a predictor of mottality, independent of primary organ fallure $(2,10)$. As these distinct primary disease processes culminate in a shared pathology at the systemic level, it is hypothesized that a conserved mechanism is involved in the etiology of skeletal muscle atrophy associated with chronic inflammatory disorders. From a therapeutic perspective a generalized approach may then be implemented to reverse the systemic aspects of these diseases.

The etiology of skeletal muscle atrophy is still unclear. Remarkably a chronic, low-grade, systemic inflammatory response is a common feature of COPD, CHF, IBD, and RA (1119). This inflammatory response is characterized by elevated circulatory levels of proinflammatory cytokines and chemokines, such as Tumor Necrosis Factor alpha (TNF $\alpha$ ), Interleukin-1,-6 and $-8(\mathrm{LL}-1,1 \mathrm{~L}-6$, and IL -8$)$, and their receptors, as well as increased serum concentrations of acute phase proteins, such as C-reactive protein. Observations that administration of pro-inflammatory cytokines such as TNF $\alpha$ or IL- 1 in animal models is sufficient to cause acute muscle atrophy $(20,21)$, further support an important role for inflammatory mediators in the etiology of skeletal muscle atrophy.

Skeletal muscle is capable of remodelling following altered functional demand, injury, or disease. This adaptive response is referred to as muscle plasticity. Previous research has predominantly approached muscle atrophy from disturbances in protein metabolism. However, particularly in chronic conditions it is questionable whether skeletal muscle atrophy is solely the result of imbalances in protein metabolism, or whether muscle plasticity is affected at an additional level. Moreover, it remains to be determined whether inflammatory cytokines directly affect skeletal muscle, and if so, which intracellular signal transduction pathways are responsible for altering skeletal muscle plasticity.

\section{AIMS AND OUTLINE OF THE THESIS}

The overall aim of this work was to evaluate the direct effects of inflammatory mediators on skeletal muscle, and investigate potential mechanisms of inflammation-induced skeletal muscle atrophy.

An overview of the current literature regarding the effects of inflammatory mediators on skeletal muscle, their role in skeletal muscle atrophy in pathological conditions and experimental models, and potential mechanisms of inflammation-induced muscle atrophy is provided in Chapter 2. To test potential direct effects of inflammatory mediators on skeletal muscle in viro, a model of cultured skeletall muscle cells was adapted and optimised. In this system myogenic differentiation, or myogenesis, was characterised in Chapter 3. During this process single, undifferentiated skeletal muscle cells (myoblasts) 
cease to proliferate and attain biochemical and morphological features of differentiated muscle fibers (myotubes). To test the effects of inflammatory mediators on skeletal muscle, Tumor Necrosis Factor alpha (TNF $\alpha$ ) was chosen as model inflammatory mediator, as both clinical $(11,13,19,22)$ and experimental $(20,21)$ studies have suggested its involvement in skeletal muscle atrophy. The transcription factor Nuclear Factor kappa $B\left(N^{-}-k B\right.$ ) is a pivotal, intra-cellular integrator of inflammatory stimuli and responses (23). Therefore, the effect of the pro-inflammatory cytokines TNF $\alpha$ and Interleukin 1 (IL-1) on the activity of NF- $\mathrm{kB}$ was evaluated in Chapter 4, as well the effect on myogenic differentiation of myoblasts, or differentiation status of myotubes. In Chapter 5 TNF $\alpha$-induced signal transduction in skeletal muscle was further dissected. The role of oxidant production in NF$\mathrm{kB}$ activation was assessed, as well as the potential involvement of oxidative stress in TNF $\alpha$-mediated inhibition of myogenic differentiation. The biochemical differentiation of skeletal muscle involves the expression of muscle specific proteins, such as creatine kinase, myosin heavy chains, troponins, and myogenin. To investigate at which level the expression of these proteins was impaired by TNFa, the induction of a battery of muscle specific messenger ribonucleic acids (mRNA's) was assessed in Chapter 6. In addition, the effect of TNF $\alpha / N F-K B$ signalling on MyoD, a key myogenic regulator, which is involved in cell cycle exit and muscle specific gene expression during myogenic differentiation was evaluated. Importantly, the effect of TNF $\alpha$ on myogenic differentiation was also investigated in an in vivo (mouse) model of skeletal muscle regeneration. Protein Kinase A (PKA) is involved in multiple signal transduction pathways, including the regulation of myogenic differentiation (24). Work presented in Chapter 7 focussed on the potential involvement of Protein Kinase A (PKA) in TNF $\alpha$ dependent MyoD destabilization and inhibition of differentiation.

In Chapter 8 a model is presented of the etiology of skeletal muscle atrophy associated with inflammation, based on the experimental findings presented in this dissertation. Furthermore the implications of these findings and future investigations to verify their relevance from a clinical perspective are discussed in this chapter. 


\section{REFERENCES}

1. Schols, A. M., Slangen, J., Volovics, L., and Wouters, E. F. (1998) Weight loss is a reversible factor in the prognosis of chronic obstructive pulmonary disease. Am $J$ Respir Crit Care Med 157, 1791-1797

2. Anker, S. D., Ponikowski, P., Varney, S., Chua, T. P., Clark, A. L., Webb-Peploe, K. M., Harrington, D., Kox, W. J., Poole-Wilson, P. A., and Coats, A. J. (1997) Wasting as independent risk factor for mortality in chronic heart failure. Lancet 349, 10501053

3. Tjellesen, L., Nielsen, P. K., and Staun, M. (1998) Body composition by dual-energy X-ray absorptiometry in patients with Crohn's disease. Scand J Gastroenterol 33, 956-960

4. Roubenoff, R., Roubenoff, R. A., Ward, L. M., Holland, S. M., and Hellmann, D. B. (1992) Rheumatoid cachexia: depletion of lean body mass in rheumatoid arthritis. Possible association with tumor necrosis factor. $J$ Rheumatol 19, 1505-1510

5. Baarends, E. M., Schols, A. M., Mostert, R., and Wouters, E. F. (1997) Peak exercise response in relation to tissue depletion in patients with chronic obstructive pulmonary disease. Eur Respir J 10, 2807-2813

6. Mostert, R., Goris, A., Weling-Scheepers, C., Wouters, E. F., and Schols, A. M. (2000) Tissue depletion and health related quality of life in patients with chronic obstructive pulmonary disease. Respir Med 94, 859-867

7. Harrington, D., Anker, S. D., Chua, T. P., Webb-Peploe, K. M., Ponikowski, P. P., Poole-Wilson, P. A., and Coats, A. J. (1997) Skeletal muscle function and its relation to exercise tolerance in chronic heart failure. $J$ Am Coll Cardiol 30, 1758-1764

8. Brevinge, H., Berglund, B., Bosaeus, I.x Tolli, J., Nordgren, S., and Lundholm, K. (1995) Exercise capacity in patients undergoing proctocolectomy and small bowel resection for Crohn's disease. Br J Surg 82, 1040-1045

9. Stucki, G., Bruhlmann, P., Stoll, T., Stucki, S., Willer, B., and Michel, B. A. (1996) Low serum creatine kinase activity is associated with muscle weakness in patients with rheumatoid arthritis. J Rheumatol 23, 603-608

10. Marquis, K. Debigare, R., Lacasse, Y., LeBlanc, P., Jobin, J., Carrier, G., and Maltais, F. (2002) Midthigh muscle cross-sectional area is a better predictor of mortality than body mass index in patients with chronic obstructive pulmonary disease. Am J Respir Crit Care Med 166, 809-813

11. Di Francia, M., Barbier, D., Mege, I. L., and Orehek, J. (1994) Tumor necrosis factor-alpha levels and weight loss in chronic obstructive pulmonary disease. $A \mathrm{~m} J$ Respir Crit Care Med 150, 1453-1455

12. Schols, A. M., Butrman, W. A., Staal van den Brekel, A. J., Dentener, M. A., and Wouters, E. F. (1996) Evidence for a relation between metabolic derangements and increased levels of inflammatory mediators in a subgroup of patients with chronic obstructive pulmonary disease. Thorax 51, 819-824

13. Eid, A. A., Ionescu, A. A., Nixon, L. S., Lewis-Jenkins, V., Matthews, S. B., Griffiths, T. L... and Shale, D. J. (2001) Inflammatory response and body composition in chronic obstructive pulmonary disease. Am J Respir Crit Care Med 164, 1414- 
14. Levine, B., Kalman, J., Mayer, L., Fillit, H. M., and Packer, M. (1990) Elevated circulating levels of tumor necrosis factor in severe chronic heart failure. $N$ Engl J Med 323, 236-241

15. Ferrari, R., Bachetti, T., Confortini, R., Opasich, C., Febo, O., Corti, A., Cassani, G., and Visioli, O. (1995) Tumor necrosis factor soluble receptors in patients with various degrees of congestive heart failure. Circulation 92, 1479-1486

16. Murch, S. H., Lamkin, V. A., Savage, M. O., Walker-Smith, J. A., and MacDonald, T. T. (1991) Serum concentrations of tumour necrosis factor alpha in childhood chronic inflammatory bowel disease. Gut $32,913-917$

17. Mazlam, M. Z., and Hodgson, H. J. (1992) Peripheral blood monocyte cytokine production and acute phase response in inflammatory bowel disease. Gut 33, 773-778

18. Altomonte, L., Zoli, A., Mirone, L., Scolieri, P., and Magaro, M. (1992) Serum levels of interleukin-1b, tumour necrosis factor-a and interleukin- 2 in rheumatoid arthritis. Correlation with disease activity. Clin Rheumatol 11, 202-205

19. Roubenoff, R., Roubenoff, R. A., Cannon, J. G., Kehayias, J. J., Zhuang, H., Dawson-Hughes, B., Dinarello, C. A., and Rosenberg, I. H. (1994) Rheumatoid cachexia: cytokine-driven hypermetabolism accompanying reduced body cell mass in chronic inflammation. $J$ Clin Invest $93,2379-2386$

20. Fong, Y., Moldawer, L. L., Marano, M., Wei, H., Barber, A., Manogue, K., Tracey, K. J., Kuo, G., Fischman, D. A., Cerami, A., and et al. (1989) Cachectin/TNF or IL-1 alpha induces cachexia with redistribution of body proteins. Am J Physiol 256, R659665

21. Buck, M., and Chojkier, M. (1996) Muscle wasting and dedifferentiation induced by oxidative stress in a murine model of cachexia is prevented by inhibitors of nitric oxide synthesis and antioxidants. Embo $J 15,1753-1765$

22. Zhao, S. P., and Zeng, L. H. (1997) Elevated plasma levels of tumor necrosis factor in chronic heart failure with cachexia. Int J Cardiol 58, 257-261

23. Pahl, H. L. (1999) Activators and target genes of Rel/NF-kappaB transcription factors. Oncogene 18,6853-6866

24. Winter, B., Braun, T., and Arnold, H. H. (1993) cAMP-dependent protein kinase represses myogenic differentiation and the activity of the muscle-specific helix-loophelix transcription factors Myf-5 and MyoD.J Biol Chem 268, 9869-9878 


\title{
CHAPTER 2
}

\section{Direct effects of inflammation on skeletal muscle}

\begin{abstract}
Skeletal muscle is capable of producing inflammatory mediators, and signal transduction pathways including Nuclear Factor Kappa $\mathrm{B}(\mathrm{NF}-\mathrm{k} \cdot \mathrm{B})$ involved in the transcriptional regulation of these mediators, have also been identified in skeletal muscle. Irrespective of their origin, acute or chronic elevations of inflammatory mediators may culminate in pathology of skeletal muscle, resulting in muscle dysfunction and atrophy. The generation of Reactive Oxygen Species (ROS) that may accompany an inflammatory response is thought to contribute to muscle dysfunction, as ROS affect multiple components involving the transduction of an action potential into force development. Acute inflammatory conditions such as sepsis, are also associated with muscle catabolism. This condition may be consequent to decreased protein synthesis, which is apparent at the transcriptional and translational level of muscle protein expression. Alternatively, a cytokine-driven increase in protein degradation has been shown involving the ubiquitin proteasome pathway. Considering the slow progression of muscle wasting in chronic inflammatory conditions, muscle homeostasis may also be deregulated at levels other than protein metabolism. Loss of myonuclei by apoptosis and gain by muscle growth and regeneration has been described in experimental conditions. Certain cytokines may elicit apoptotic responses, and conversely, inhibit muscle regeneration. Eventually, such an imbalance in myonuclear turnover could result in muscle wasting.
\end{abstract}

Langen, R. C. J. Department of Respiratory Medicine, Mastricht University. European Respiratory Monograph 2003; 8: 68-85. 


\section{Introduction}

In this chapter the effects of inflammation on skeletal muscle will be discussed, as many mediators of inflammatory responses affect skeletal muscle, in a range of adaptive physiological responses and pathological processes. First, however, the infummatory response will be described with respect to its constituents; the various cell types and (secreted) factors involved.

Inflammation can be defined as the initial innate immune response, which is rapidly induced to control the spread of invading pathogens, and to allow the subsequent activation of the adaptive immune response, which includes more specialized cellular and humoral mediators that can destroy remaining pathogens. First, the alternative pathway of complement activation is responsible for opsonization of pathogens. Secondly, pathogens are recognized and engulfed by phagocytic cells, mainly tissue macrophages, and destroyed. However, the response of resident macrophages to invading pathogens is not limited to phagocytosis; these cells will also release various polypeptide and lipid mediators in order to recruit circulating neutrophils and monocytes to the site of infection. These include cytokines, chemokines, and arachidonic acid metabolites like prostaglandins and leukotriens. The recruitment of neutrophils and monocytes from the circulation is a complicated, but well described process. It involves the interaction between multiple cell types, including those of the infected tissue and the recruited leukocytes. The cytokine Tumor Necrosis Factor alpha (TNF $\alpha$ ), released by activated phagocytes, acts in a paracrine fashion by increasing vascular permeability, and inducing the expression of adhesion molecules on the cell surface of endothelial cells. This allows for diapedesis of neutrophils and monocytes to occur. Establishment of a chemokine gradient allows the extravasized leukocytes to migrate to the focus of infection (chemotaxis), where infectious organisms are effectively destroyed by the release of an array of aggravating compounds like proteolytic enzymes, reactive oxygen and -nitrogen species (ROS and RNS, respectively), hypochlorous acid, and through phagocytosis.

Although the various mediators of inflammatory responses discussed here are generally regarded for their ability to recruit and activate leukocytes, increasing evidence suggests that they affect skeletal muscle as part of physiological responses, but also as part of pathological conditions associated with deregulated inflammatory responses.

\section{Skeletal muscle in inflammatory conditions: innocent bystander ar active participant?}

Sources of inflammatory mediators that can affect skeletal muscle are resident macrophages, recruited monocytes and neutrophils, endothelial cells of the mictovasculature, but also skeletal myocytes themselves. Indeed, it has been demonstrated that skeletal muscle is capable of constitutive and inducible production of various cytokines and chemokines. Bartoccioni et al, demonstrated that cultured myoblasts isolated from human biopties constitutively secreted Interleukin 6 (IL-6), which could be augmented by the addition of TNF $\alpha$ (1). Likewise, De Rossi et al found that IL-6, Interleukin 1 alpha (IL10), and the chemokines Interleukin 8 (IL-8) and RANTES were produced constitutively by isolated human myoblasts, whereas IL-1/, TNF $\alpha$, and Monocyte Chemoatractant Protein-1 (MCP-1) were produced in an inducible fashion (2). In addition, in cultured human and rat 
myoblasts it has also been shown that constitutive expression of Interferon gamma (IFNy) and IL-6 (3,4), Intercellular Adhesion Molecule-1 (ICAM-1) (5, 6), and the cell surface receptors for TNF $\alpha$ (RI and R2), IL-1 (RI and R2) (3) could further be enhanced by treatment with proinflammatory cytokines. The expression of the anti-inflammatory cytokines $L-9,-10$, and $L$ - 15 was also induced in $\mathrm{C} 2 \mathrm{C} 12$ skeletal myocytes following treatment with TNFo (4). In an experimental sepsis model, the intravenous administration of the bacterial endotoxin lipopolysaccharide (LPS) to rats resulted not only in elevated circulatory levels of TNF $\alpha$, but also induced TNF $\alpha$ expression in the diaphragm muscle, as Was detected by Northern blot analysis (7). In a comparable study, induction of TNF-R2 and IL-6R mRNA was apparent in skeletal muscle (3). Evidence of increased expression of inflammatory mediators by skeletal muscle during pathological conditions in human subjects became apparent from a study in which TNF $\alpha$ mRNA in the vastus lateralis was elevated fourfold in diabetic patients compared to control subjects. Constitutive TNFa secretion by myotubes derived from sub-cultured muscle biopties was threefold higher in these same patients (8). In another study, IL-8 mRNA levels, measured by ribonuclease protection assay (RPA), were found to be elevated 12 fold in skeletal muscle of patients undergoing cardiopulmonary bypass (9). Immunohistochemical analysis of muscle tissue obtained from subjects with idiopathic inflammatory myopathy demonstrated reactivity suggestive of IL-1 $\alpha$, IL-1 $\beta$, Interleukin 2 (IL-2), TNF $\alpha$ and ICAM-1 $(10,11)$ production by skeletal muscle.

The inducible expression of many inflammatory cytokines and chemokines, and adhesion molecules is regulated to a large extent by the transcription factor nuclear factor kappa $B$ $(N F-k B$ ) (for review see (12)). Under normal conditions, $N F-k B$ is present within the cytoplasm in an inactive state, bound to its inhibitory protein $1 k B \alpha$ (Figure 1). Upon stimulation, for example TNFa binding to its receptor, an intracellular signaling cascade is initiated, resulting in the phosphorylation of $I k B \alpha$ on serine residues 32 and 36 by $1 k B$ kinase (IKK). Phosphorylation and subsequent ubiquitination of these residues target $1 K B \alpha$ for degradation by the $26 \mathrm{~S}$-proteasome complex. Once liberated from its inhibitory protein, $N F-K B$ translocates to the nucleus, where it binds to its cognate DNA sequence in promoter and enhancer elements of (inflammatory) genes that it regulates.

Most nucleated cells are known to be capable of $\mathrm{NF}_{-\kappa} \mathrm{B}$ activation, and skeletal muscle is no exception. The presence of various components of the $\mathrm{NF}-\mathrm{kB}$ signal transduction pathway has been demonstrated in skeletal myocytes in several studies. NF-kB dependent gene transcription and DNA binding by RelA-p50 heterodimers and p50-p50 homodimers has been described in response to TNF $\alpha$ in C2C12 myocytes and rat satellite cells (13-15). In addition, these studies showed that the inhibitors of $N F-\kappa B, I \kappa B \alpha$ and $I \kappa B \beta$, were present in myoblasts and myotubes and were degraded following TNF $\alpha$. Others have demonstrated activation of the $I K K$ complex responsible for $I K B \alpha$ degradation in L6 myocytes (16). A more upstream regulator responsible for the transduction of TNF $\alpha$ dependent $N F-K B$ signaling, the adaptor protein TNF Receptor Associated Factor-2 (TRAF2), was also demonstrated to exist in myocytes (17). 


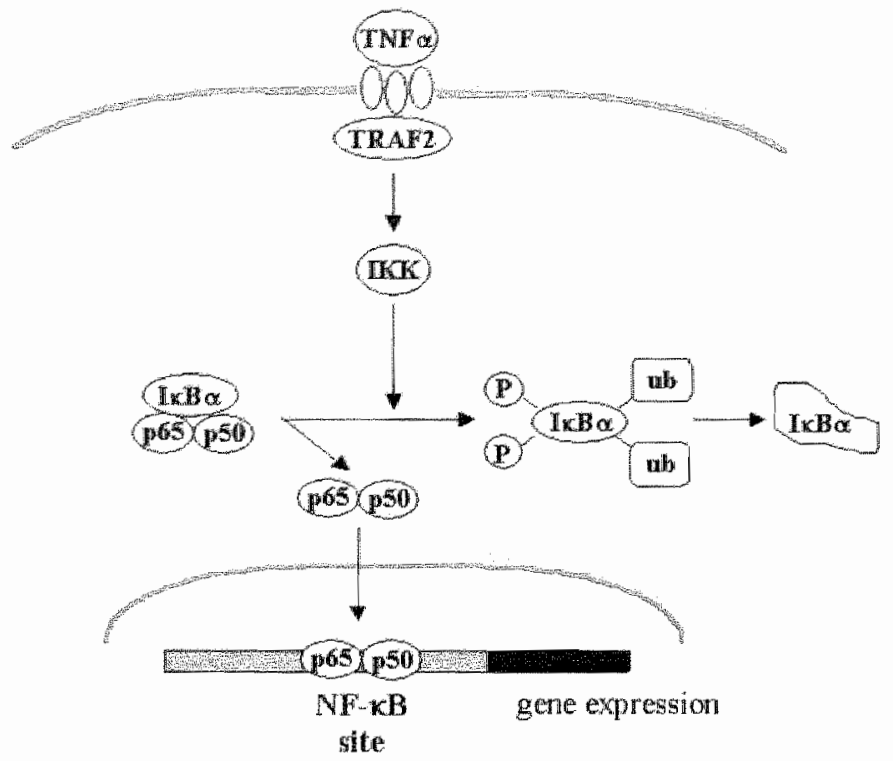

Figure 1: TNFa-induced

$\mathrm{NF} \cdot \mathrm{kB}$ signal transduction.

Binding of TNF $\alpha$ causes receptor trimerization and the recruitment of adaptor molecules, including TRAF2. This results in activation of the $\mathbb{I K K}$ complex, which subsequently phosphorylates IK $B \alpha$. Phosphorylated $I K B \alpha$ is ubiquinated and degraded by the proteasome, allowing released $N F-K B$ (here depicted as a p65/p50 heterodimer) to translocate to the nucleus. Here NF-kB binds to its cognate sites in (usually) promoters of genes which are transcriptionally regulated by $\mathrm{NF}-\mathrm{kB}$.

The finding that skeletal muscle is capable of activating $N F-K B$ and subsequent expression and secretion of inflammatory mediators, may suggest an active role for skeletal muscle in inflammatory responses. This may either be in response to the primary stimulus, or as an amplification step secondary to an inflammatory signal of local or systemic origin. This intrinsic ability of skeletal muscle to participate in inflammatory signaling merits further characterization and elucidation of the signaling pathways involved in order to understand the significance of these events in muscle physiology and pathology.

\section{Effects of acute systemic inflammation on muscle function and muscle mass}

Acute or chronic elavations in circulating inflammatory mediators, derived from a source elsewhere than muscle, may also culminate in pathology of skeletal muscle, resulting in muscle dysfunction and/or atrophy. The extent to which skeletal muscle is affected by inflammation may be determined by the magnitude and duration of an inflammatory response, its location, and the activation of an amplification signal by the skeletal muscle in response to an inflammatory stimulus.

Acute systemic inflammation, observed in sepsis has profound effects on multiple tissues, including skeletal musele. Respiratory and peripheral muscle dysfunction have been investigated extensively in sepsis. Initially, muscle contractile dysfunction in septic shock was believed to be the direct result of bacterial endotoxin, in particular lipopolysaccharide (LPS), a component of the cell wall of Gram negative bacteria. However, there is no clear evidence indicating a direct impact on muscle function. Rather, intermediary factors appear to be required, as the ex vivo contractility of isolated rat diaphragm was not affected by endotoxin (18). In fact, TNF $\alpha$, an inflammatory cytokine released systemically during septic 
shock, has been implicated in muscle contractile dysfunction in sepsis. Systemic infusion of TNFa in dogs for three hours resulted in a decline in diaphragm contractility (19). In addition, pre-injection of an anti-TNFo antibody partially prevented endotoxin-induced diaphragmatic hypocontractility in rats (7). Conflicting data have been obtained from studies addressing whether TNF $\alpha$ acts directly on the muscle contractile machinery. No change in force-frequency relationship was observed when isolated rat diaphragm was incubated with TNF $\alpha$ for 60 minutes (18). In contrast, studies in which isolated mouse diaphragms were incubated with TNF $\alpha$ for 150 minutes, revealed a decline in the forcefrequency relationship (20). The mechanism by which TNFo affects contractile function at the sub-cellular level is unclear, but may involve the generation of reactive oxygen species (ROS). This was suggested from studies in which infusion with oxygen radical scavengers, such as superoxide dismutase, catalase and dimethyl sulfoximine attenuated the decline in diaphragmatic force in response to endotoxin infusion $(21,22)$. In addition, studies using transgenic mice with cardiac specific over-expression of TNF $\alpha$ demonstrated a decteased force-frequency relationship of the diaphragm, which could partially be restored by incubation of isolated diaphragms with $\mathrm{N}$-acetyl cysteine (20).

Potential targets for ROS responsible for decreased force generation by striated muscle may include all of the components involwed in transduction of an action potential into force development. For example, ROS have been shown to partially inhibit the activity of the cell surface $\mathrm{Na}+\mathrm{K}+\mathrm{A}$-A TPase of isolated rat cardiomyocytes, which may result in impairment of action potential propagation (23). Muscle cell function may also become impaired by ROS through modification of sarcoplasmatic reticulum (SR) function, as critical thiol groups of the SR in close proximity to the calcium release channels were oxidized by various forms of oxidative stress, resulting in alterations in calcium release from the $\mathrm{SR}(24,25)$. SR function was also found to be affected by ROS through oxidative modifications affecting the SR calcium uptake pump $(26,27)$. In addition to interference with the transduction of action potential to force generation, enzymes responsible for the energy metabolism to fuel force generation may be the target of ROS. For example, inhibition of mitochondrial respiration through inactivation of NADH dehydrogenase, NADH oxidase, succinate dehydrogenase, and cytochrome oxidase by superoxide and hydrogen peroxide lias been reported (28). Finally, proteins of the contractile apparatus itself may be oxidized by ROS, which may impair force development, as the redox state of critical sulhydryl residues on the contractile proteins has been shown to be important (29). Potential sources of ROS in skeletal muscle during inflammation are NADPH oxidases of invading leukocytes (30), the cyclooxygenase pathway of arachidonic acid metabolism (31), and the mitochondrial electron transport (MET) chain (32). However, the only source of ROS reported to be activated in skeletal muscle following exposure to inflammatory cytokines (TNF $\alpha$ ) is the MET chain (32).

Besides causing muscle dysfunction, the acute rise in circulating inflammatory mediators associated with sepsis also results in a catabolic response that particularly affects skeletal muscle. During this condition, skeletal muscle protein degradation exceeds muscle protein synthesis. The amino acids liberated by this process are believed to serve in the liver as substrates for gluconeogenesis and direct oxidation, and for the synthesis of acute phase proteins. The shift in the balance of muscle protein metabolism responsible for the net catabolism observed in sepsis has been the focus of many studies, and both, reductions in 
protein synthesis and increases in proteolysis have been documented. Animal models in which LPS was utilized to induce experimental sepsis, have revealed a central role for the inflammatory cylokines TNFo and $\mathrm{L}_{-1}$ in the catabolic response that affects skeletal muscle during sepsis. For example, infusion of TNFo, or IL- 1 in rats was found to (synergistically) result in muscle wasting, similar to that observed following LPS (33-35). It was demonstrated that neutralization of TNFo, using TNF-binding protein (36), or IL-1 receptor antagonist (37) prevented sepsis-induced inhibition of protein synthesis. In vitro studies using human myocytes revealed that inflammatory cytokines can interfere with protein synthesis directly, as the presence of TNFa in the culture media inhibited serum or Insulin like Growth Factor-I (IGF-I) stimulated protein synthesis (38). Further evidence for a reduction in protein synthesis during sepsis was presented in studies revealing decreases at the translational level. Here, a reduction in $40 \mathrm{~S}$ initiation complex formation was evident in skeletal muscle of septic rats (39). In addition, reductions in $18 \mathrm{~S}, 28 \mathrm{~S}$, and ribosomal RNA, and importantly, in mRNA levels of muscle specific genes such as $\alpha$-actin and myosin heavy chain have been reported in skeletal muscle of rats following LPS, TNFa, or IL-I $(33,40)$. This seems to indicate that reductions in muscle protein synthesis during sepsis can result from defects localized at various steps of the protein synthesis machinery. These include the translational and $m$ RNA level, the latter implying regulation of mRNA stability, or alternatively, gene transcription.

In contrast, work by Bistrain and colleagues demonstrated that muscle proteolysis contributed to the wasting of muscle mass in sepsis, as the net protein catabolic rate in rats infused with TNFa or $1 \mathrm{~L}-1$ was elevated $(34,35)$. Protein degradation in skeletal muscle occurs through several proteolytic systems, including the lysosomal pathway, the calciumdependent proteases $\mu$ - and $\mathrm{m}$-calpain, and the $26 \mathrm{~S}$ ubiquitin-proteasome pathway. The latter is believed to catalyze the selective degradation of ubiquitin-tagged, short-lived (regulatory), and abnormal proteins (41). Ubiquitin is a 76 amino-acid, $9 \mathrm{kDa}$ peptide that is highly conserved and present in all eucaryotes, and the covalent binding of a poly-ubiquitin chain targets proteins for degradation through the cytosolic, ATP-dependent $26 \mathrm{~S}$ proteasome pathway. The conjugation of ubiquitin to proteins is a multistep process that involves three different enzymes. First, ubiquitin is activated by an E1 enzyme, and ransferred to an ubiquitin conjugating (E2) enzyme. Subsequent conjugation of ubiquitin (chains) to target proteins can occur directly, or in the presence of an ubiquitin ligase (E3). Substrate specificity in the ubiquitination process is conferred by the enzymes of the E2 and E3 class. With regard to its role in skeletal muscle protein degradation, extensive data implicates the activation of this proteolytic pathway during fasting conditions (for review see $(42,43))$. In septic rats, marked increases in total and myofibrillar protein breakdown occurred in the absence of alterations in the lysosomal and calcium-dependent proteases, but coincided with an increase in ATP-dependent proteolysis, ubiquitin conjugates and elevations in ubiquitin gene expression (44). Indeed, elevated ubiquitin gene expression and ubiquitin conjugation were reported in skeletal muscle following the administration of TNFa, IL-1 o* $I F N \gamma$ (45). Work using cultured murine myotubes demonstrated myosin heavy chain (MyHC) depletion following the addition of TNF $\alpha$ which could not be contributed to a decrease in MyHC synthesis, supporting a mechanism by which muscle protein degradation following inflammatory cytokines is responsible for depletion of muscle mass (14). These same authors demonstrated in a later study that the activation of $N F-k B$ is 
required for the TNF $\alpha$-induced MyHC depletion, and suggested that NF-KB dependent transcriptional up-regulation of certain components of the ubiquitin proteasome pathway was responsible for increased MyC degradation (46). Recently, the application of transcript profiling (cDNA array and differential display) on skeletal muscle of fasted mice and rats undergoing various muscle disuse protocols has resulted in the identification of a muscle specific ubiquitin protein ligase (E3 protein), which was markedly uparegulated under these conditions $(47,48)$. In addition to fasting, the mRNA of this protein, named Atrogin-1 by these authors, was also induced during other conditions associated with skeletal muscle wasting, including models of uncontrolled diabetes, renal failure, and cancer. The same protein, but now called Muscle Atrophy F-box (MAFbx) in the second study, was also increased at the mRNA level following treatment with dexamethasone, or IL-1, two known inducers of skeletal muscle wasting. The causal relationship between the up-regulation of MAFbx and subsequent muscle atrophy was conclusively demonstrated in this study, as the gastrocnemius muscle of MAFbx -1 - mice showed only $44 \%$ of the loss in muscle weight observed in wild type animals following a denervation protocol. In the same study, another ubiquitin ligase, Muscle RING Finger 1(MuRFl) was identified using the same approach. The increased expression of this $\mathrm{E} 3$ protein ligase mirrored that of MAFbx, although its induction following hind limb suspension, denervation and IL-1 administration was stronger than that of MAFbx. However, the MURFI -/-mouse was more susceptible to denervation induced muscle atrophy than the MAFbx null mouse, but demonstrated still a $36 \%$ sparing in muscle weight compared to wild type mouse. It would be interesting to subject the double null mouse to one of the atrophy protocols and investigate whether these two muscle E3 ligases operate in an additive fashion under these conditions. In addition, the use of these mice could provide insight in to what extent muscle wasting associated with inflammation is due to increased activity of the ubiquitin-proteasome pathway.

From this work it appears that a simultaneous augmentation of protein degradation and decline in protein synthesis are responsible for the net loss of muscle protein observed in acute inflammatory conditions like sepsis. Interestingly, the observation that TNF $\alpha$ or $L_{-}-1$ can recapitulate most of the effects of endotoxin with regard to increasing the protein degradation machinery, and reducing muscle protein synthesis, indicates that specific factors controlling these mechanisms may be regulated by these inflammatory cytokines.

\section{Effects of chromic inflammatory disease on skeletal muscle}

In contrast to the rapid dysfunction and depletion of skeletal muscle observed during acute inflammatory conditions, chronic low-grade elevations in circulating inflammatory mediators appear to result in a slow progression to a cachectic state.

Potential sources of inflammatory mediators are dependent on the primary disease. For example, in COPD circulating inflammatory mediators such as TNFa and IL-6 may have originated from the lung, or may have been released by activated circulating monocytes ( 49 51). In addition, transgenic animal models have demonstrated that organ specific production of inflammatory mediators results in spill-over into the circulation. For example, sustained elevations in circulatory TNF $\alpha$ levels could be detected in transgenic mice that expressed the human. TNF $\alpha$ gene under the control of a lung on cardiac specific promoter $(20,52)$. 
Specifically, in COPD there may be an alternative (or complementary) source of TNFa, since elevated levels of the cytokine and its receptors correlated with the occurrence of chronic hypoxemia, which may have stimulated TNF $\alpha$ production by affected tissues (53).

Associations between various circulating markers of inflammation, including TNF $\alpha$, IL-6, and their receptors, and the loss of fat free mass (i.e. muscle) have been made in chronic pathologic conditions, including COPD $(49,50,54)$. However, the elucidation of mechanisms responsible for the wasting of skeletal muscle in these conditions may be extremely complicated, as the depletion of skeletal muscle progresses very slowly. For example, imbalances in protein metabolism may be too small to be detected, as the wasting process progresses over periods of months or years.

Indeed, data offering insight the pathobiology of cachexia associated with chronic lowgrade inflammation is scarce in the literature, and mostlly restricted to experimental cancer models. For instance, some evidence for activation of the $26 \mathrm{~S}$-ubiquitin proteasome pathway, illustrated by increased expression of ubiquitin and ubiquitin-conjugation, was presented in studies analyzing hind limb muscles of hepatoma-bearing rats, as a model of cancer cachexia $(55,56)$. Interestingly, it was hypothesized that TNF $\alpha$ may be involved in this model of cachexia, which was supported by data demonstrating that intravenous administration of this cytokine also resulted in increased muscular ubiquitin conjugation and -mRNA levels $(57,58)$. Conversely, anti-TNF $\alpha$ treatment prevented the increased ubiquitin expression in this model (59). An alternative mechanism by which chronic inflammation may result in cachexia was proposed in a study in which TNF $\alpha$ secreting-, or control Chinese Hamster Ovary (CHO) cells were implanted in the muscle of nude mice (60). Over a period of 30 days, this resulted in extensive cachexia in the CHO-TNF $\alpha$ mice compared to the CHO-only controls. The data obtained in this study further suggested the involvement of oxidative stress caused by TNFo, which was responsible for deregulation of muscle specific gene transcription, as dietary supplementation with antioxidants attenuated weight loss, and corrected muscle specific gene expression.

Although most of the evidence regarding skeletal muscle wasting in acute inflammatory conditions appears to involve imbalances in protein metabolism, caution must be taken by extrapolating the findings of those studies and models to mechanisms of wasting in chronic inflammatory disease. In fact, considering the slow progression of muscle depletion in these chronic conditions, attention should also be focused towards the potential of deregulation of muscle homeostasis at levels other than protein and energy metabolism, e.g. the maintenance of functional skeletal muscle mass by muscle fiber apoptosis and regeneration.

\section{Inflammation and skeletal muscle apoptosis}

Cell death in multi-cellular organisms does not only occur as a result of external insults, but can in fact be desirable or even necessary, and is often manifested in such instances as apoptosis, or programmed cell death (PCD). Apoptosis, as opposed to cell necrosis, is an active process, which requires ATP and is governed by a well-conserved self-destruction machinery. Another difference from necrosis is that cells dying by an apoptotic mechanism will not induce an inflammatory reaction caused by the release of the intracellular content. In fact, the remainder of the cell is packaged in vesicles named apoptotic bodies, awaiting phagocytosis by macrophages. A cardinal role for apoptosis has emerged in embryogenesis, 
the control of cell number in proliferative tissues, immune regnlation and in the resolution of inflammatory responses. However, a potential role of apoptosis in chronic disease associated muscle atrophy has not been investigated until recently. This is quite remarkable, as apoptosis was originally described in the muscle of developing moth larvae (61). Considerable knowledge has accumulated on the regulation of apoptosis, mostly in mononucleated cells, but the actual process of PCD in multinucleated myofibers of skeletal muscle remains elusive.

Apoptosis can roughly be distinguished into two major pathways based on the PCD inducing signal (Figure 2, and reviewed by Hengartner (62)). The first is the receptor mediated apoptosis pathway, and is induced by receptor clustering upon ligand binding to receptors of some of the members of the TNF Receptor (TNF-R) super family. Best described here is the PCD-signaling by TNF-R1 (also p55 or CD120a) and Fas (also Apo or $C D-95$ ). Clustering (trimerization) of these receptors can result in the formation of a deathinducing signaling complex through the recruitment of adapter proteins. These include Fasassociated Death Domain (FADD), and TNF Receptor-associated Death Domain (TRADD). Their binding to the intracellular receptor domains results in the recruitment of (inactive) procaspase-8, yielding cleaved (active) caspase-8. The other major apoptotic pathway is the intracellular, or apoptosome pathway. Activation of this pathway may occur in response to xenobiotic agents (e.g. radiation, oxidative stress, hypoxia), exogenous proteins like hormones and cytokines. The name of this pathway refers to the central involvenent of the mitochondria in the execution of the apoptotic program, although it may still be activated through receptor signaling. Apoptotic stimuli converge at the level of this organelle, resulting in alterations in mitochondrial membrane integrity allowing the release of cytochrome $C$ into the cytoplasm. This is followed by the formation of the apoptosome, a complex constituted of apoptosis activating factor 1 (APAF-1), cytochrome $\mathrm{C}$ and procaspase-9, resulting in autocatalysis and activation of caspase-9. Caspases are a family of cysteine proteases, which reside in the cell in an inactive form. Activation of initiator caspases (caspase-8 and -9) results in proteolysis of, and subsequent activation of effector. caspases such as caspase-3. The receptor mediated and intracellular apoptotic pathway converge at this point and share most of the downstream signaling events, i.e. the activation of the executioners of apoptosis by the effector caspases (illustrated in Figure 2).

It is interesting to note that smaller cells containing less cytoplasm (thus fewer mitochondria) like lymphocytes, appear to utilize the direct, receptor-mediated rather than the apoptosome pathway. Whether this implies that large myofibers containing many mitochondria preferably utilize, or are even restricted to the apoptosome pathway remains to be determined. Arguing against this notion is a study that failed to demonstrate APAF 1 protein or mRNA in skeletal muscle of healthy human subjects, although the possibility remains that $\mathrm{APAF}-1$ expression is very low under baseline (healthy) conditions (63). To illustrate this, some studies suggest that an active disease process may be required in order to detect apoptosis-related proteins in skeletal muscle; in muscle of patients suffering from Becker and Duchenne muscular dystrophies expression of Fas could only be detected in a subset of the myofibers $(64,65)$. In the same study, the proportion of Fas-positive muscle fibers was higher (up to $50 \%$ ) in biopsies derived from patients with inflammatory myopathies (64). Interestingly, the Fas-positive fibers were smaller than the negative ones. Moreover, a high percentage of the Fas-positive fibers also stained for $\mathrm{Bcl}-2$, and no apoptosis could be detected in these biopsies. 


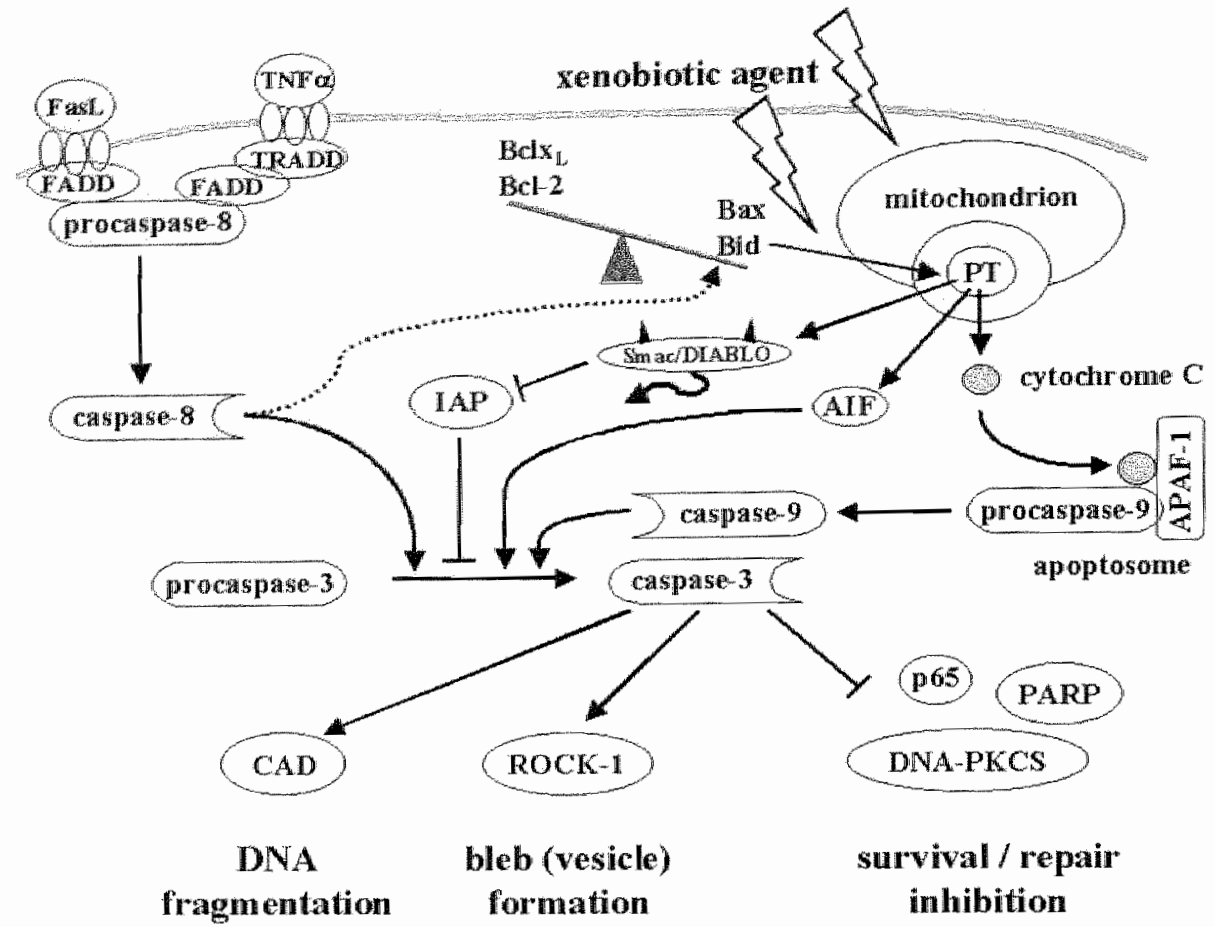

Figure 2: The receptor and apoptosome mediated apoptotic pathways.

Fas- or TNF-receptor clustering following ligand binding results in the recruitment of death domains (FADD and TRADD), and activation of caspase-8, which in turn activates caspase-3. Alternatively, xenobiotic apoptotic stimuli disfupt mitochondrial menbrane integrity, resulting in the release of cytochrome $C$ into the cytoplasm. Mitochondrial membrane integrity is altered by increased conductance of the permeability transition (PT) pore, which is govened by the ratio of pro- (Bax, Bak, Bad, Bid) and anti- (Bcl-2, Bcl- $x_{1}$ ) apoptotic members of the Bcl-2 family in the outer membrane of the mitochondria. Cytochrome $\mathrm{C}$ release results in the formation of the apoptosome, a complex constituted of apoptosis protense activating factor 1 (APAF-1), cylochrome $C$ and procaspase-9, iriggering autocatalysis and activation of caspase-9. In addition, the retease of at least wo other pro-apoptotic factors is controlled by the mitochondria. These include apoptosis inducing factor (AIF), which activates caspase-3, and the Smac/DLABLO protein, which blocks the inhibitory action of Inhibitor of Apoptosis Proteins (IAP) on caspase-3, thus sustaining activation of this effector caspase. The executioners of apoptosis that are activated by caspase- 3 include caspase activated DNase (CAD), which cleaves genomic DNA between nucleosomal units resulting in DNA fragmentation, and ROCK 1 , an enzyme involved in membrane bleb formation, which is required for the formation of apoptotic vesicles. In addition, a number of proteins involved in survival or repair, such as the NF- $\mathrm{KB}$ subunit 165 , or the DNA-repair enzyme DNA-PKCS, or associated factors like PARP are inactivated through cleavge by caspases. Cross-talk between the two pathways exists at various levels. For example parallel to, or instead of direct activation of caspase-3, TNF-RI (or Fas) mediated activation of caspase-8 can result in the formation and activation of the apoptosome. In this scenario (varying with cell type and duration of the apoptotic stimulus) the catalytic activity of caspase- 8 is directed against members of the Bcl-2 family (Bid), lipping the batance in favor of the pro-inpoptotic members (dotted line). Arrows indicate activation, whereas blunted arrows indicate inhibition. 
Potentially, Bcl-2 expression may have been induced to counteract the apoptotic stimulus, as $\mathrm{Bcl}-2$ is absent in normal adult myotibers. Alternatively, the $\mathrm{Bcl}-2$ reactivity was reminiscent of satellite cells that recently differentiated and fused, as $\mathrm{Bcl}-2$ expression transiently increases during myoblast differentiation (66). This scenario is further supported by increased expression of $\mathrm{N}-\mathrm{CAM}(\mathrm{CD} 56)$ on the $\mathrm{Bcl}-2$ reactive fibers, suggestive of muscle regeneration (64). The sensitivity of myofibers to apoptosis inducing ligands such as Fas-L and TNF $\alpha$ remains to be established. Treatment with TNF $\alpha$ did not result in cell death of fully differentiated myotubes (46), whereas two studies reported increased apoptosis in differentiating $\mathrm{C} 2 \mathrm{C} 12$ myoblasts when cultured in the presence of a combination of IGF-II and TNF $\alpha(67,68)$. In contrast, Guttridge et al. described a proliferative effect of TNF $\alpha$ when added to $\mathrm{C} 2 \mathrm{Cl} 2$ myoblasts under differentiation promoting conditions (15).

Evidence of some classical features of apoptosis in cultured skeletal myotubes has been described, including nuclear and cell shrinkage, DNA fragmentation and caspase-3 activation, which were observed following treatment with staurosporine, suggesting that differentiated skeletal muscle is capable of undergoing receptor-independent apoptosis mediated through the apoptosome pathway (69).

Further evidence of a functional apoptosome pathway in mature skeletal muscle was presented in a model of burn injury, in which caspase-9 activation (dependent on APAF-1) was demonstrated (70). In addition, the cleavage products of capase-1 and -3 , suggestive of their activation were detectable. In a model of cancer cachexia, activation of caspase-1, -3, $6,-8$ and -9 were documented in the gastrocnemius muscle, along with cytochrome $C$ release and PARP fragmentation (70). Interestingly, DNA fragmentation could not be detected in this study. Chronic heart failure (CHF) is another condition in which apoptosis in skeletal muscle is associated with muscle wasting. In a rat model of $\mathrm{CHF}$, the number of apoptotic nuclei correlated with a reduction in fiber cross-sectional area and muscle weight to body weight ratio, indicative of muscle atrophy (71). Moreover, a later study by the same group revealed a correlation between circulating TNF $\alpha$ and muscular apoptosis in this CHF model, suggesting a role for apoptosis in TNFo-associated muscle atrophy (72). Importantly, this response may be muscle fiber type specific, as this correlation could only be observed in the fast twitch tibialis anterior, but not the slow-twitch soleus muscle. In addition to a reduced muscle mass, the loss of myonuclei may also result in dysfunction of skeletal muscle. Indeed, apoptotic myonuclei were detected almost half of a patient population suffering from CHF, and the occurrence of apoptosis correlated with a reduced exercise capacity (73).

To comprehend the pathophysiological significance of the reported data here, it is important to realize that the detection of apoptotic nuclei in these disease models allows at best a snap shot of nuclei undergoing apoptosis, as most of the techniques visualize usually only one aspect of the apoptotic process. Therefore, a small number of apoptotic nuclei detected at one time point may contribute to a substantial loss of myonucleil, and thus muscle over a longer time period. Importantly, the ability of skeletal muscle to replace the lost myonuclei through the activation of satellite cells may ultimately determine whether a noyofiber will atrophy following an apoptotic stimulus. 


\section{Inflammation and keletal muscle regenerstion}

Following muscle injury resulting from muscle trauma, exposure to toxins, or modified muscle use, it is the adaptive response of skeletal muscle to regenerate damaged fibers. Skeletal muscle regeneration depends on the activation of the resident satellite cell population which involves proliferation of these quiescent muscle precursor cells to form a pool of myoblasts that differentiate and fuse with damaged segments of existing fibers, or form new myofibers. Regeneration to replace lost myonuclei is dependent on activation and proliferation of satellite cells, as fully differentiated and fused skeletal myocytes have lost the ability to undergo mitosis. Evidence that a proliferative response is required for complete muscle regeneration was provided in a study which demonstrated that local $\gamma$ irradiation of skeletal muscle (which prevents cell division due to DNA damage) following unloading-induced muscle atrophy resulted in incomplete muscle regeneration, as was evident from an impaired recovery in muscle weight, cross sectional area, and myonuclear number (74). Moreover, it has been suggested that age-associated muscle atrophy is consequent to an impaired regenerative response, which some authors attribute to satellite cell senescence (or reduced proliferative capacity) (75-77), or a decrease in absolute satellite cell number, whereas work by others implies that the defect is localized at the level of myogenic differentiation and fusion into myotubes (78). As these studies suggest an important role for satellite cells in the regeneration process, many investigators have focused their work on the activation of satellite cells. Accumulated evidence has revealed a conplex pattern in which multiple growth factors and cytokines, released by the myofibers themselves, or resident macrophages regulate satellite cell activation, proliferation and differentiation.

A prominent role for Hepatocyte Growth Factor (HGF) in the activation of satellite cells has been suggested, as the receptor for $\mathrm{HGF}^{*}$, cMet, is exclusively expressed on satellite cells and not on myofibers $(79,80)$. In fact HGF, which is produced instantly in response to muscle injury (81) has been shown to induce satellite cells proliferation and delay differentiation in witro and in wivo (82-84). In addition, various isoforms of Fibroblast Growth Factor (FGF) are up-regulated following muscle injury, suggesting a role of these factors in the regeneration process (85). in vitro work revealed that most FGF isoforms stimulate proliferation of myoblasts and inhibit myogenic differentiation (86). Importantly, proliferation of satellite cells is affected by various cytokines, which may have consequences for regeneration in inflammatory conditions. For example, Leukemia Inhibitory Factor (LIF) and IL-6 were both reported to enhance myoblast proliferation in virro $(87,88)$. A stimulatory effect on myoblast proliferation has also been described for TNFa (15). Incubation with TNFa under differentiation-inducing conditions caused sustained expression of cyclin D 1 , and hence sustained proliferation through preventing the
myoblasts from exiting the cell cycle.

bubsequent steps in satellite cell activation, myogenic differentiation and fusion, have also been shown to be regulated by growth factors and cytokines, mainly in in vitro studies. Both, FGF and Transforming Growth Factor $\beta$ (TGF $\beta$ ), inhibit the differentiation of Myoblasts, although TGF $\beta$ does not affect proliferation $(86,89,90)$.

Myogenic differentiation is a complex process, which requires cell cycle exit resulting in a mutual exclusion of proliferation and differentiation. Therefore, polypeptide growth factors
as FGF, which stimulate proliferation, may inhibit differentiation by antagonizing cell cycle 
exit. The Myogenic Regulatory Factors (MRFs) are part of a superfamily of basis helix loop helix (bHLH) transcription factors, and consist of MyoD (Myf-3), Myf-5, myogenin (Myf1), and MRF4 (Myf-6/Herculin) (for review see (91)). It is the activity of the MRFs which regulates, in concert with the Myocyte Enhancer Factor 2 family (MEF-2), the myogenesis program, which include the expression of muscle specific genes and fusion. MyoD is regarded as the master regulator, as MyoD -/- satellite cells are differentiation defective and the expression of MyoD in fibroblasts is sufficient to convert these cells into myoblasts, as evidenced by their ability to express muscle specific genes and fuse $(92,93)$. Muscle specific gene transcription by the MRFs occurs through their dimerization with the ubiquitously expressed bHLH proteins E12 and E47, and subsequent binding to cis-acting regulatory elements in the enhancer regions of muscle specific genes, called E-boxes. Formation of functional dimers conveys a regulatory mechanism for the control of the myogenic program. During proliferation E 12 and E47 are not available for dimerization to the MRFs, as they are occupied by transcriptionally inactive bHLH proteins called Intribitor of Differentiation (91). Conversely, TGF 3 appears to inhibit myogenic differentiation through repression of E-box dependent promoter activation by a physical interaction between MyoD and Smad 3, an intracellular effector of TGFB (90).

A double role exists for IGF-I, which inhibits differentiation and promotes myoblast proliferation at high doses, but promotes myogenesis at lower doses, even resulting in hypertrophy $(94,95)$. Finally, IGF-II has been implicated as a positive regulator of myoblast differentiation and survival (96).

Regulation of myogenic differentiation has been demonstrated to occur at many additional levels, and the discussion of all of these would be beyond the scope of this review. Recently evidence of regulation of myogenic differentiation by inflammatory cytokines has been presented. Using a myoblast cell line, Langen et al. demonstrated that the presence of TNF $\alpha$ or IL-1 during differentiation inhibited myogenesis markedly, as was evidenced by delayed myogenin expression, reductions in muscle specific gene products, and the inability to form multinucleated myotubes. Importantly, this inhibitory effect depended on the activation of $\mathbb{N F}-\mathrm{kB}$, as inhibition of this inflammatory transcription factor rendered the differentiating myoblasts insensitive to TNF $\alpha$ (13). Similar findings were reported by Guttidge ef al., who demonstrated that the inhibitory effect of $N F-\kappa B$ required new gene transcription, and therefore involved potentially an NF-KB controlled gene product (97). Moreover; the inhibitory effect occurred at the level of MyoD regulation, as MyoD mRNA levels decreased following TNFa. Further evidence supporting an inbibitory role of $N F-k B$ in muscle regeneration was apparent in a study by Thaloor et al, in which muscle regeneration following a standardized muscle injury protocol was stimulated by systemic administration of the NF- $-\mathrm{B}$ inhibitor curcumin (98). An opposite role for $T N F \alpha$ during myogenic differentiation was reported in a study by Li et al, in which the authors suggested that TNF $\alpha$ secreted by differentiating myoblasts, served as an autocrine factor required for myogenic differentiation (99). However, skeletal muscle of TNF $\alpha-$ - mice subjected to crush injury, demonstrated no impaiments in the regeneration process, which is not supporting a prominent role for this cytokine in successful differentiation (100). In another study it was postulated that $\mathrm{NF}-\mathrm{KB}$ activation was required for myogenic differentiation, as expression of a catalytically inactive mutant of $1 \mathrm{KK} \alpha$ interfered with the differentiation 
process (16). However, accumulating evidence suggests that activation of $\mathrm{NF}-\mathrm{kB}$ by inflammatory stimuli depends mainly on IKK $\beta$, whereas a major role for IKK $\alpha$ has been suggested in developmental processes, such as skin and skeletal formation (101), potentially through a secondary, evolutionary conserved NF- $\mathrm{kB}$ pathway $(102,103)$.

From these studies it becomes apparent that inflammation may interfere with muscle regeneration, although the multitude and spatio-temporal dependent secretion of growth factors and cytokines may complicate obtaining complete insight into how these polypeptides affect regeneration. However, elucidation of these regulatory mechanisms is very important, considering the potential for therapeutic strategies to enhance muscle regeneration to prevent or even reverse muscle atrophy.

\section{Conclusion}

From the work described here, it becomes clear that inflammation may disturb skeletal muscle function and homeostasis at multiple levels. Several important regulatory processes affecting muscle contractility and fatigability, muscle protein synthesis and degradation, and myofiber apoptosis and regeneration, which are modulated by inflammation have been identified. The challenge of future work will be the further elucidation of the (signaling) molecules and pathways induced and/or altered in skeletal muscle by inflammation. In addition, emphasis should be placed on the identification of critical regulatory molecules of these processes, which could be evaluated in patient material. This to verify their physiological and clinical relevance, and to develop therapeutic strategies to reverse the deleterious effects of inflammation on skeletal muscle. 


\section{REFERENCES}

1. Bartoccioni, E., Michaelis, D., and Hohlfeld, R. (1994) Constitutive and cytokineinduced production of interleukin-6 by human myoblasts. Immuntol Let $42,135-138$

2. De Rossi, M., Bernasconi, P., Baggi, F., de Waal Malefyt, R., and Mantegazza, R. (2000) Cytokines and chemokines are both expressed by human myoblasts: possible relevance for the immune pathogenesis of muscle inflammation. Int Immunof 12. $1329-1335$

3. Zhang, Y., Pilon, G., Marette, A., and Baracos, V. E. (2000) Cytokines and endotoxin induce cytokine receptors in skeletal muscle. Am I Physiol Endocminol Metab 279, E196-205

4. Alvarez, B., Quinn, L. S., Busquets, S., Lopez-Soriano, F. J., and Argiles, J. M. (2002) TNF-alpha modulates cytokine and cytokine receptors in $\mathrm{C} 2 \mathrm{Cl} 2$ myotubes. Cancer Lent 175, 181-185

5. Marino, M., Scuderi, F., Mazzarelli, P., Mannella, F., Provenzano, C., and Bartoccioni, E. (2001) Constitutive and cytokine-induced expression of MHC and intercellular adhesion molecule-1 (ICAM-1) on human myoblasts. I Newroimnunol $116,94-101$

6. Sen, C. K., Khanna, S., Reznick, A. Z., Roy, S., and Packer, L. (1997) Glutathione regulation of tumor necrosis factor-alpha-induced NF-kappa B activation in skeletal muscle-derived L6 cells. Biochem Biophys Res Commmn 237, 645-649

7. Shindoh, C., Hida, W., Ohkawara, Y., Yamauchi, K., Ohno, I., Takishima, T., and Shirato, K. (1995) TNF-alpha mRNA expression in diaphragm muscle after endotoxin administration. Am J Respir Crit Care Med 152, 1690-1696

8. Saghizadeh, M., Ong, J. M., Garvey, W. T., Henry, R. R., and Kern, P. A. (1996) The expression of TNE alpha by human muscle. Relationship to insulin resistance. $J$ Clin Invest $97,1111-1116$

9. Burns, S. A., Newburger, J. W., Xiao, M., Mayer, J. E., Jr., Walsh, A. Z., and Neufeld, E. J. (1995) Induction of interleukin-8 messenger RNA in heart and skeletal muscle during pediatric cardiopulmonary bypass. Circulation 92, II315-321

10. Tews, D. S., and Goebel, H. H. (1995) Expression of cell adhesion molecules in inflammatory myopathies. J Newroimmunol 59, 185-194

11. Tews, D. S., and Goebel, H. H. (1996) Cytokine expression profile in idiopathic intlammatory myopathies. I Neuropathol Exp Neurol $55,342-347$

12. Gilmore, T. D. (1999) The Rel/NF-kappaB signal transduction pathway: introduction. Oncogene 18,6842-6844

13. Langen, R. C., Schols, A. M., Kelders, M. C., Wouters, E. F., and Janssen-Heininger, Y. M. (2001) Inflammatory cytokines inhibit myogenic differentiation through activation of nuclear factor-kappaB. Faseb J15, 1169-1180

14. Li, Y. P., Schwartz, R. J., Waddell, I. D., Holloway, B. R., and Reid, M. B. (1998) Skelletal muscle myocytes undergo protein loss and reactive oxygen-mediated NF. $\mathrm{kappaB}$ activation in response to tumor necrosis factor alpha. Faseb $/ 12,871-880$

15. Guttridge, D. C., Albanese, C., Reuther, J. Y., Pestell, R. G., and Baldwin, A. S, Jr. (1999) NF-kappaB controls cell growth and differentiation through transcriptional regulation of cyclin D1. Mol Cell Biol 19,5785-5799 
16. Canicio, J., Ruiz-Lozano, P., Carrasco, M., Palacin, M., Chien, K., Zorzano, A., and Kaliman, P. (2001) Nuclear factor kappa B-inducing kinase and Ikappa B kinasealpha signal skeletal muscle cell differentiation. J Biol Chem 276, 20228-20233

17. MacLachlan, T. K., and Giordano, A. (1998) TRAF2 expression in differentiated muscle. I Cell Biochem 71, 461-466

18. Diaz, P. T., Julian, M. W., Wewers, M. D., and Clanton, T. L. (1993) Tumor necrosis factor and endotoxin do not directly affect in vitro diaphragm function. Am Rev Respir Dis 148,281-287

19. Wilcox, P. G., Wakai, Y., Walley, K. R., Cooper, D. I., and Road, J. (1994) Tumor necrosis factor alpha decreases in vivo diaphragm contractility in dogs. Am I Respir Crit Care Med 150, 1368-1373

20. Li, X., Moody, M. R., Engel, D., Walker, S., Clubb, F. J., Jr., Sivasubramanian, N., Mann, D. L., and Rell, M. B. (2000) Cardiac-specific overexpression of tumor necrosis factor-alpha causes oxidative stress and contractile dystunction in mouse diaphragm. Cinculation 102, 1690-1696

21. Supinski, G., Nethery, D., and DiMarco, A. (1993) Effect of free radical scavengers on endotoxin-induced respiratory muscle dysfunction. Am Rev Respir Dis 148, 13181324

22. Shindoh, C., Dimarco, A., Nethery, D., and Supinski, G. (1992) Effect of PEGsuperoxide dismutase on the diaphragmatic response to endotoxin. Am Rev Respir Dis 145, 1350-1354

23. Huang, W. H., Wang, Y., Askari, A., Zolotarjova, N., and Ganjeizadeh, M. (1994) Different sensitivities of the $\mathrm{Na}+\mathrm{K}(+)$-ATPase isoforms to oxidants. Biochim Biophys Acra $1190,108-114$

24. Favero, T. G., Zable, A. C., Bowman, M. B., Thompson, A., and Abramson, J. J. (1995) Metabolic end products inhibit sarcoplasmic reticulum Ca2+ release and [3H]ryanodine binding. I Appl Physiol 78, 1665-1672

25. Stoyanovsky, D. A., Salama, G, and Kagan, V. E. (1994) Ascorbate/iron activates $\mathrm{Ca}(2+)$-release channels of skeletal sarcoplasmic reticulum vesicles reconstituted in lipid bilayers. Arch Biochem Biophys 308, 214-221

26. Scherer, N. M., and Deamer, D. W. (1986) Oxidative stress impairs the function of sarcoplasmic reticulum by oxidation of sulfhydryl groups in the Ca2+-ATPase. Arch Biochem Biophys 246, 589-601

27. Eley, D. W., Eley, I. M.. Korecky, B., and Fliss, H. (1991) Impairment of cardiac contractility and sarcoplasmic reticulum Ca2+ ATPase activity by hypochlorous acid: reversal by dithiothreitol. Can J Physiol Pham acol 69, 1677-1685

28. Zhang, Y., Marcillat, O., Giulivi. C., Enster, L., and Davies, K. J. (1990) The oxidative inactivation of mitochondrial electron transport chain components and ATPase. I Biol Chem 265, $16330-16336$

29. Macfarlane, N. G., and Miller, D. J. (1992) Depression of peak force without altering calcium sensitivity by the superoxide anion in chemically skinned cardiac muscle of rat. Circ Res $70,1217 \cdot 1224$

30. Supinski, G., Stofan, D., Nethery, D., Szweda, L., and DiMarco, A. (1999) Apocynin improves diaphragmatic function after endotoxin administration. $J$ Appl Physiol 87 ,
$776-782$ 
31. Nethery, D., Callahan, L. A., Stofan, D. Mattera, R. DiMaroo, A., and Supmski, G. (2000) PLA(2) dependence of diaphragm mitochondrial fomation of reactive oxygen species. I Appl Physiol 89, 72-80

32. Li, Y. P., Atkins, C. M., Sweatt, J. D., and Reid, M. B. (1999) Mitochondria mediate tumor necrosis factor-alpha/NF-kappaB signaling in skeletal muscle myotubes. Antioxid Redox Signal 1, 97-104

33. Fong, Y., Moldawer, L. L., Marano, M., Wei, H., Barber, A., Manogue, K., Tracey, K. J., Kuo, G., Fischman, D. A., Cerami, A., and et al. (1989) Cachectin/TNF or IL-1 alpha induces cachexia with redistribution of body proteins. Am J Physiol $256, \mathrm{R} 659$ 665

34. Ling, P. R., Schwartz, J. H., and Bistrian, B. R. (1997) Mechanisms of host wasting induced by administration of cytokines in rats. Am J Physiol 272, E333-339

35. Flores, E. A., Bistrian, B. R., Pomposelli, J. J., Dinarello, C. A., Blackburn, G. L.* and Istfan, N. W. (1989) Infusion of tumor necrosis factor/cachectin promotes muscle catabolism in the rat. A synergistic effect with interleukin $1 . \mathrm{J}$ C/in Imest 83 , 1614-1622

36. Cooney, R., Kimball, S. R., Eckman, R., Maish, G., 3rd, Shumate, M., and Vary, T. C. (1999) TNF-binding protein ameliorates inhibition of skeletal muscle protein synthesis during sepsis. Am J Physiol 276, E611-619

37. Cooney, R., Owens, E., Jurasinski, C., Gray, K., Vannice, J., and Vary, T. (1994) Interleukin-1 receptor antagonist prevents sepsis-induced inhibition of protein synthesis. Am J Physiol 267, E636-641

38. Frost, R. A., Lang, C. H., and Gelato, M. C. (1997) Transient exposure of human myoblasts to tumor necrosis factor-alpha inhibits serum and insulin-like growth factor-I stimulated protein synthesis. Endocrinology 138, 4153-4159

39. Vary, T. C., Jurasinski, C., and Kimball, S. R. (1998) Reduced 40S initiation complex formation in skeletal muscle during sepsis. Mol Cell Biochem 178, 81-86

40. Hasselgren, P. O., Tricoli. J. V., Wieczorek, D., Stengerwald, K. A., Angeras, U., Hall-Angeras, M., and Fischer, J. E. (1991) Reduced levels of mRNA for myofibrillar proteins in skeletal muscle from septic rats. Life Sci 49, 753-760

41. Rechstemer, M. (1991) Natural substrates of the ubiquitin proteolytic pathway. Cel $66,615-618$

42. Argiles, J. M., and Lopez-Soriano, F. J. (1996) The ubiquitin-dependent proteolytic pathway in skeletal muscle: its role in pathological states. Thends Phamacol Sci 17 , $223-226$

43. Attaix, D., Taillandier, D., Temparis, $\mathrm{S}_{\text {. }}$ Larbaud, D., Aurousseau, E., Combaret, L., and Voisin, L. (1994) Regulation of ATP-ubiquitin-dependent proteolysis in muscle wasting. Reprod Nur Dev 34,583-597

44. Tiao, G., Fagan, J. M., Samuels, N., James, J. H., Hudson, K., Lieberman, M., Fischer, J. E., and Hasselgren, P. O. (1994) Sepsis stimulates nonlysosomal, energy dependent proteolysis and increases ubiquitin mRNA levels in rat skeletal muscle. $J$ Clin Invest $94,2255-2264$

45. Llovera, M., Carbo, N., Lopez-Soriano, J., Garcia-Martinez, C., Busquets, S., Alvarez, B., Agell, N., Costelli, P., Lopez-Soriano, F. J., Celada, A., and Argiles, J. M. (1998) Different cytokines modulate ubiquitin gene expression in rat skeletal muscle. Cancer Lett 133,83-87 
46. Li, Y. P., and Reid, M. B. (2000) NF-kappaB mediates the protein loss induced by TNF-alpha in differentiated skeletal muscle myotubes. Am I Physiol Regul Integr Comp Physiol 279, R1165-1170

47. Bodine, S. C., Latres, E., Baumhueter, S., Lai, V. K., Nunez, L., Clarke, B. A., Poueymirou, W. T., Panaro, F. J., Na, E., Dharmarajan, K., Pan, Z, Q., Valenzuela, D. M., DeChiara, T. M., Stitt, T. N., Yancopoulos, G. D., and Glass, D. J. (2001) Identification of ubiquitin ligases required for skeletal muscle atrophy. Science 294. 1704-1708

48. Gomes, M. D., Lecker, S. H., Jagoe, R. T., Navon, A., and Goldberg, A. L. (2001) Atrogin-1, a muscle-specific F-box protein highly expressed during muscle atrophy. Proc Natl Acad Sci U S A 98, 14440-14445

49. Di Francia, M., Barbier, D., Mege, J. L., and Orehek, J. (1994) Tumor necrosis factor-alpha levels and weight loss in chronic obstructive pulmonary disease. Am $J$ Respir Crit Care Med 150, 1453-1455

50. Eid, A. A., Ionescu, A. A., Nixon, L. S., Lewis-Jenkins, V., Matthews, S. B., Griffiths, T. L., and Shale, D. J. (2001) Inflammatory response and body composition in chronic obstructive pulmonary disease. Am $J$ Respir Crit Care Med 164, 14141418

51. de Godoy, I., Donahoe, M., Calhoun, W. J., Mancino, J., and Rogers, R. M. (1996) Elevated TNF-allpha production by peripheral blood monocytes of weight-losing COPD patients. Am J Respir Crit Care Med 153, 633-637

52. Fujita, M., Shannon, J. M., Irvin, C. G., Fagan, K. A., Cool, C., Augustin, A.. and Mason, R. J. (200I) Overexpression of tumor necrosis factor-alpha produces an increase in lung volumes and pulmonary hypertension. Am J Physiol Lung Cell Mol Physiol 280, L-39-49

53. Takabatake, N., Nakamura, H., Abe, S., Inoue, S., Hino, T., Saito, H., Yuki, H., Kato, S., and Tomoike, H. (2000) The relationship between chronic hypoxemia and activation of the tumor necrosis factor-alpha system in patients with chronic obstructive pulmonary disease. Am J Respir Crit Care Med 161, 1179-1184

54. Schols, A. M., Burman, W. A., Staal van den Brekel, A. J., Dentener, M. A., and Wouters, E. F. (1996) Evidence for a relation between metabolic derangements and increased levels of inflammatory mediators in a subgroup of patients with chronic obstructive pulmonary disease. 7 horax $51,819-824$

55. Llovera, M., Garcia-Martinez, C., Agell, N., Marzabal, M., Lopez-Soriano, F. J., and Argiles, J. M. (1994) Ubiquitin gene expression is increased in skeletal muscle of tumour-bearing rats. FEBS Lett $338,311-318$

56. Baracos, V. E., DeVivo, C., Hoyle, D. H., and Goldberg, A. L. (1995) Activation of the ATP-ubiquitin-proteasome pathway in skeletal muscle of cachectic rats bearing a
hepatoma. Am J Phywol $268, \mathbb{E} 996-1006$

57. Garcia-Martinez, C., Agell, N., Llovera, M., Lopez-Soriano, F. J., and Argiles, J. M. (1993) Tumour necrosis factor-alpha increases the ubiquitinization of rat skeletal
muscle proteins. FEBS Letr $323,211-214$ 58. Garcia-Martinez, C., Llovera, M., Agell, N., Lopez-Soriano, F. J., and Argiles, J. M.
(1994) Ubiquitin gene expression in skeletal muscle is increased by tumour necrosis
factor-alpha. Biochem Biophys Res Comm factor-alpha. Biochem Biophys Res Commun 201, 682-686 
59. Llovera, M., Carbo, N., Garcia-Martinez, C., Costelli, P., Tessitore, L., Baccino, F. M., Agell, N., Bagby, G. J., Lopez-Soriano, F. J, and Argiles, J. M. (1996) Anti-TNF treatment reverts increased muscle ubiquitin gene expression in tumour-bearing rats. Biochem Biophys Res Commun 221, 653-655

60. Buck, M., and Chojkier, M. (1996) Muscle wasting and dedifferentiation induced by oxidative stress in a murine model of cachexia is prevented by inhibitors of nitric oxide synthesis and antioxidants. Embo J 15, 1753-1765

61. Kerr, J. F., Wyllie, A. H., and Currie, A. R. (1972) Apoptosis: a basic biological phenomenon with wide-ranging implications in tissue kinetics. Br.J Cancer 26, 239257

62. Hengartner, M. O. (2000) The biochemistry of apoptosis. Nature 407, 770-776

63. Burgess, D. H., Svensson, M., Dandrea, T., Gronlund, K., Hammarquist, F., Orrenius, S., and Cotgreave, I. A. (1999) Human skeletal muscle cytosols are refractory to cytochrome c-dependent activation of type-II caspases and lack APAF1. Cell Death Differ 6, 256-26॥

64. Behrens, L., Bender, A., Johnson, M. A., and Hohlfeld, R. (1997) Cytotoxic mechanisms in inflammatory myopathies. Co-expression of Fas and protective $\mathrm{Bcl}-2$ in muscle fibres and inflammatory cells. Brain 120 (Pt 6), 929-938

65. Inukai, A., Kobayashi, Y., Ito, K., Doyu, M., Takano, A., Honda, H., and Sobue, G. (1997) Expression of Fas antigen is nol associated with apoptosis in human myopathies. Muscle Nerve 20, 702-709

66. Dominov, J. A., Dunn, J. J., and Miller, J. B. (1998) Bcl-2 expression identifies an early stage of myogenesis and promotes clonal expansion of muscle cells. $J$ Cell Biol $142,537-544$

67. Foulstone, E. J., Meadows, K. A., Holly, J. M., and Stewart, C. E. (2001) Insulin-like growth factors (IGF-I and IGF-II) inhibit $\mathrm{C} 2$ skeletal myoblast differentiation and enhance TNF alpha-induced apoptosis. $J$ Cell Physiol 189, 207-215

68. Meadows, K. A., Holly, J. M., and Stewart, C. E. (2000) Tumor necrosis factoralpha-induced apoptosis is associated with suppression of insulin-like growth factor binding protein-5 secretion in differentiating murine skeletal myoblasts. $J$ Cell Physiol 183, 330-337

69. McArdle, A., Maglara, A., Appleton, P., Watson, A. J., Grierson, I., and Jackson, M. J. (1999) Apoptosis in multinucleated skeletal muscle myotubes. Lab Invest 79, 1069-1076

70. Yasuhara, S., Kanakubo, E., Perez, M. E., Kaneki, M., Fujita, T., Okamoto, T., and Martyn, J. A. (1999) The 1999 Moyer award. Burn injury induces skeletal muscle apoptosis and the activation of caspase pathways in rats. I Bum Care Rehabil 20, 462-470

71. Libera, L. D., Zennaro, R., Sandri, M., Ambrosio, G. B., and Vescovo, G. (1999) Apoptosis and atrophy in rat slow skeletal muscles in chronic heart failure. Am J Physiol 277, C982-986

72. Dalla Libera, L., Sabbadini, R., Renken, C., Ravara, B., Sandri, M., Betto, R., Angelini, A., and Vescovo, G. (2001) Apoptosis in the skeletal muscle of rats with heart failure is associated with increased serum levels of TNF-alpha and sphingosine. $J$ Mol Cell Cardiol 33, 1871-1878 
73. Hambrecht, R., Adams, V., Gielen, S., Linke, A., Mobius-Winkler, S., Yu, J., Niebauer, J., Jiang, H., Fiehn, E., and Schuler, G. (1999) Exercise intolerance in patients with chronic heart failure and increased expression of inducible nitric oxide synthase in the skeletal muscle. I Am Coll Cardiol 33, 174-179

74. Mitchell, P. O., and Pavlath, G. K. (2001) A muscle precursor cell-dependent pathway contributes to muscle growth after atrophy. Am $J$ Physiol Cell Physiol 281 , C.1706-1715

75. Dodson, M. V., and Allen, R. E. (1987) Interaction of multiplication stimulating activity/rat insulin-like growth factor II with skeletal muscle satellite cells during aging. Mech Ageing Dev 39, 121-128

76. Gibson, M. C., and Schultz, E. (1983) Age-related differences in absolute numbers of skeletal muscle satellite cells. Muscle Nerve 6,574-580

77. Schultz, E, and Lipton, B. H. (1982) Skeletal muscle satellite cells: changes in proliferation potential as a function of age. Mech Ageing Dev 20, 377-383

78. Renaull, V., Piron-Hamelin, G., Forestier, C., DiDonna, S., Decary, S., Hentati, F., Saillant, G., Butler-Browne, G. S., and Mouly, V. (2000) Skeletal muscle regeneration and the mitotic clock. Exp Gerontol 35, 711-719

79. Comelison, D. D., and Wold, B. J. (1997) Single-cell analysis of regulatory gene expression in quiescent and activated mouse skeletal muscle satellite cells. Dev Biol 191, 270-283

80. Tatsumi, R., Anderson, J. E., Nevoret, C. J., Halevy, O., and Allen, R. E. (1998) $\mathrm{HGF} / \mathrm{SE}$ is present in normal adult skeletal muscle and is capable of activating Satellite cells. Dev Biol 194, 114-128

81. Jennische, E., Ekberg, S, and Matejka, G. L. (1993) Expression of hepatocyte growh factor in growing and regenerating rat skeletal muscle. Am J Physiol 265 , C $122 m 128$

82. Anastasi, S., Giordano, S., Sthandier, O., Gambarotta, G., Maione, R., Comoglio, P., and Amati, P. (1997) A natural hepatocyte growth factor/scatter factor autocrine loop in myoblast cells and the effect of the constitutive Met kinase activation on myogenic differentiation. " Cell Birol 137, 1057-1068

83. Gal-Levi, R., Leshem, Y., Aoki, S., Nakamura, T, and Halevy, O. (1998) Hepatocyte growth factor plays a dual rolle in regulating skeletal muscle satellite cell proliferation and differentiation. Biochim Biophys Acta 1402, 39-51

84. Miller, K. J., Thaloor, D., Matteson, S., and Pavlath, G. K. (2000) Hepatocyte growth factor affects satellite cell activation and differentiation in regemerating skeletal muscle. An of Physiol Cell Physiol 278, C174-181

85. Lefaucheur, J. P., and Sebille, A. (1995) Muscle regeneration following injury can be modified in vivo by immune neutralization of basic tibroblast growth factor, transforming growth factor beta 1 or insulin-like growth factor I. I Neuroimmmol $57,85-91$

86. Kastner, S., Elias, M. C., Rivera, A. J., and Yablonka-Reuveni, Z. (2000) Gene expression pattens of the fibroblast growth factors and their receptors during myogenesis of rat satellite cells. J Histochem Cytochem 48, 1079-1096

87. Austin, L., and Burgess, A. W. (1991) Stimulation of myoblast proliferation in culture by leukaemia inhibitory factor and other cytokines. J Neurol Sci 101, 193-197 
88. Austin, L., Bower, J., Kurek, J., and Vakakis, N. (1992) Effects of leukaemia inhibitory factor and other cytokines on murine and human myoblast proliferation. $J$ Neurol Sci $112,185-191$

89. Gospodarowicz, D., Weseman, J., Moran, J. S., and Lindstrom, I. (1976) Effect of fibroblast growth factor on the division and fusion of bovine myoblasts. I Cell Biol $70,395-405$

90. Liu, D., Black, B. L., and Derynck, R. (2001) TGF-beta inhibits muscle differentiation through functional repression of myogenic transcription factors by Snad3. Genes Dev 15, 2950-2966

91. Perry, R. L., and Rudnick, M. A. (2000) Molecular mechanisms regulating myogenic determination and differentiation. Front Biosci 5, D750-767

92. Comelison, D. D., Olwin, B. B., Rudnicki, M. A., and Wold, B. J. (2000) MyoD(-/-) satellite cells in single-fiber culture are differentiation defective and MRF4 deficient. Dev Biol 224, 122-137

93. Weintraub, H., Tapscott, S. J., Davis, R. L., Thayer, M. J., Adam, M. A., Lassar, A. B., and Miller, A. D. (1989) Activation of muscle-specific genes in pigment, nerve, fat, liver, and fibroblast cell lines by forced expression of MyoD. Proc Natl Acod Sci USA 86, 5434-5438

94. Florini, J. R., Ewton, D. Z., Falen, S. L., and Van Wyk, J. J. (1986) Biphasic concentration dependency of stimulation of myoblast differentiation by somatomedins. Am J Physiol $250, \mathrm{C} 771-778$

95. Musaro, A., McCullagh, K. J., Naya, F. J., Olson, E. N., and Rosenthal, N. (1999) $\mathbb{G G}-1$ induces skeletal myocyte hypertrophy through calcineurin in association with GATA-2 and NF-ATc1. Nawre 400,581-585

96. Stewart, C. E., and Rotwein, P. (1996) Insulin-like growth factor-II is an autocrine survival factor for differentiating myoblasts. J Biol Chem 271, 11330-11338

97. Guttridge, D. C., Mayo, M. W., Madrid, L. V., Wang, C. Y., and Baldwin, A. S., Jr. (2000) NF-kappaB-induced loss of MyoD messenger RNA: possible role in muscle decay and cachexia. Science 289,2363-2366

98. Thaloor, D., Miller, K. J., Gephart, J., Mitchell, P. O., and Pavlath, G. K. (1999) Systemic administration of the NF-kappaB inhibitor curcumin stimulates muscle regeneration after traumatic injury. $A m$ o Physiol 277, C320-329

99. Li, Y. P., and Schwartz, R. J. (2001) TNF-alpha regulates early differentiation of C2C 12 myoblasts in an autocrine fashion. Faseb J 15, 14.13-1415

100. Collins, R. A., and Grounds, M. D. (2001) The role of tumor nectosis factor-alpha (TNF-alpha) in skeletal muscle regeneration. Studies in TN/ ${ }^{*}$ alpha( $/-$ ) and TNF. alpha(-/-)/LT-alpha(-/-) mice. J Histochem Cylochem 49, 989-1001

101. Hu, Y., Baud, V., Delhase, M., Zhang, P., Deerinck, T., Ellisman, M., Johnson, R., and Karin, M. (1999) Abnomal morphogenesis but intact IKK activation in mice lacking the IKKalpha subunit of IkappaB kinase. Scrence 284, 316-320

102. Hu, Y., Baud, V., Oga, T., Kim, K. I., Yoshida, K., and Karin, M. (2001) \KKalpha controls formation of the epidermis independently of NF-kappaB. Narue 410,710 714

103. Senfteben, U., Cao, Y., Xiao, G., Greten, F. R., Krahn, G., Bonizzi, G., Chen, Y., Hu, Y., Fong, A., Sun, S. C., and Karin, M. (2001) Activation by IKKalpha of a 
second, evolutionary conserved, NF-kappa B signaling pathway. Science 293, $1495-$ 1499 


\title{
CHAPTER 3
}

\section{Enhanced myogenic differentiation by extracellular matrix is regulated at the early stages of myogenesis}

\begin{abstract}
Myogenic cell lines have been used extensively in the study of skeletal muscle development, regeneration, and homeostasis. To induce myogenic differentiation, culture media composed of a wide variety of growth factors and other additives have been used. Since the diversity in these components may modulate the differentiation process differentially, we describe a differentiation protocol that does not require the introduction of any factors to the differentiation media (DM), other than those present in the growth media. By culturing $\mathrm{C} 2 \mathrm{C} 12$ skeletal myocytes on a coating of diluted Matrigel, a soluble basement membrane, consisting of collagen IV, laminin, heparan sulfate proteoglycans and entactin, myogenic differentiation was accomplished by mere serum reduction. Assessment of myotube formation, creatine kinase activity, myosin heavy chain-fast and myogenin, demonstrated that the kinetics and extent of myogenic differentiation were superior using this protocol, compared to a commonly used differentiation protocol, in which an extracellular matrix is not provided and the DM contains horse serum. In addition, the elevated transactivation of a troponin- $I$ promoter reporter construct suggested that myogenesis was enhanced at the transcriptional level. Finally, assessment of genomic DNA content revealed that the Matrigel differentiation protocol resulted in lowered proliferation. This protocol may aid studies aimed at elucidating mechanisms of myogenic differentiation, where a homogeneous population of myotubes is preferred.
\end{abstract}

Ramon C.J. Langen", Annemie M.W.J. Schols, Marco C.J.M. Kelders". Emiel F.M. Wouters' and Yvonne M.W. Janssen-Heininger'. Departments of 'Respiratory Medicine, Masultich University, Maastrich, The Netherlands, and "Pathology, University of Vermont, Burlington VT, USA. In Fitro Cellukit and Developmental Biology-Animal 2003; 39: 163-169 


\section{INTRODUCTION}

The culture of skeletal myocytes has been used extensively in the study of skeletal muscle development, and to obtain insight in mechanisms of skeletal muscle homeostasis and disease at the cellular and molecular level. The use of these skeletal muscle precursor cells (satellite cells), or myogenic cell hines derived from these cells, has greatly facilitated these studies, since they exhibit a proliferative and differentiated phenotype, referred to as myoblasts and myotubes, respectively. Among established skeletal muscle cell lines capable of undergoing myogenic differentiation are the rat $\mathbb{L} 6$ cell line, and its mouse counterpart the $\mathrm{C} 2 \mathrm{C} / 2$ line. The $\mathrm{C} 2 \mathrm{C} 12$ myogenic cell line has been derived from the $\mathrm{C} 2$ line (1), which was originally isolated from injured mouse thigh skeletal muscle (2).

The irreverstble transition from the proliferation competent myoblast stage into fused, multinucleated myotubes, known as myogenic differentiation, has commonly been studied in wiro in the context of skeletal muscle development and regeneration $(3,4)$. In addition, various aspects of skeletal muscle homeostasis have been studied using myoblasts and differentiated myotubes from myogenic cell lines. These studies include growth factor-and cytokine-induced signal transduction $(5,6)$, insulin signaling $(7)$, and carbohydrate metabolism (8), providing valuable information that would have been complicated or impossible to obtain using organ tissue culture or intact animals. Furthermore, the use of skeletal muscle cell lines has provided substantial insight into the pathophysiology of certain disease states affecting skeletal muscle, including Duchenne"s muscular dystrophy (9), and muscle wasting associated with inflammation $(6,10-12)$. Finally, skeletal muscle cell lines have been used for the evaluation of a myriad of gene therapeutic approaches, including the application of engineered insulin-producing myotubes in insulin dependent diabetes mellitus (13).

Although the understanding of myogenic differentiation has increased dramatically over the last two decades, discrepancies in similar studies have been reported by different investigators and were ascribed to differences in culture conditions. Potentially confounding factors that may be responsible for the difficulties comparing data generated by different investigators include the use different culture protocols, and in particular the varied composition of differentiation media (DM). Many protocols use growth media (GM) and DM that contain completely unrelated growth factors. In addition, the multitude of growth lactors and other additives derived from sera, brain extracts and other sources found in various DM, may differentially affect one or more of the signaling pathways that are involved in the differentiation process, and therefore alter the kinetics or extent of myogenic differentiation. Not only may the use of a DM composed of a plenitude of additives complicate the comparison of related studies; when any aspect of the differentiation process itself is the focus, it will also obscure the interpretation of data obtained by that particular study.

Cells of the myogenic lineage have successfully been cultured on matrices of various compositions to achieve a higher degree of differentiation. One of the substrata used to provide muscle cells with an extracelhular matrix is Matrigel, a soluble basement membrane extract (14). Matrigel is composed of collagen IV, laminim, heparan sulfate proteoglycans and entaction, which also constitute the "natural" environment in which satellite cells are localized, known as the endomysium (15). 
The goal of the present study is to determine whether myogenic differentiation of $\mathrm{C} 2 \mathrm{C} 12$ cells is possible without the introduction of additional growth factors to the DM, other than present in the growth media, by providing skeletal muscle cells with a physiological matrix. Therefore, we compared the kinetics and degree of myogenic differentiation using this protocol, and a frequently used differentiation protocol that utilizes horse serum as an additive in the DM. In addition, we evaluated at which stage of myogenic differentiation Matrigel exerted its stimulatory effect on myogenesis.

\section{MATERIALS AND METHODS}

\section{Cell culture and induction of differentiation}

The murine skeletal muscle cell line $\mathrm{C} 2 \mathrm{C} 12$ was obtained from the American Type Culture Collection (ATCC \# CRL1772, Manassas, VA). These cells are able to undergo differentiation into spontaneously contracting myotubes upon growth factor withdrawal (2). Myoblasts were cultured in low glucose Dulbecco's Modified Eagle Medium (DMEM) containing antibiotics (50U/mL Penicillin and $50 \mu \mathrm{g} / \mathrm{ml}$ Streptomycin) and $9 \%(\mathrm{v} / \mathrm{v})$ Fetal Bovine Serum (FBS) (all from Life Technologies, Rockville, MD), referred to as growth media (GM). We used two different protocols comparatively in order to induce myogenic differentiation. In selected experiments, $60 \mathrm{~mm}$ dishes (Becton Dickinson Labware, Bedford, MA) were coated for $2 \mathrm{~h}$ at $37^{\circ} \mathrm{C}$ with diluted (1:50 in DMEM), growth factor reduced Matrigel (Becton Dickinson Labware, Bedford, MA), which contains collagen IV, laminin, heparan sulfate proteoglycan and entactin, which are constituents of the natural extracellular matrix of skeletal muscle fibers (14). Cells were plated at $10^{4} / \mathrm{cm}^{2}$ and cultured in GM for $24 \mathrm{~h}$, allowing them to reach $80 \%$ confluency. To induce differentiation in cells plated on Matrigell, cultures were washed twice in Hank's balanced salt solution (HBSS) and further cultured in low glucose DMEM, containing antibiotics and $0.5 \%$ heat inactivated FBS, referred to as Matrigel differentiation media (MFBS). Alternatively, differentiation of cells plated on plastic dishes was induced by the replacement of GM with low glucose DMEM, containing antibiotics and $2 \%$ heat inactivated horse serum (HS), referred to as the horse serum differentiation media protocol (UHS). Cells were examined with an inverted phase contrast microscope (Olympus CH40, Melville, NY), equipped with a camera (Nikon N6000).

\section{Assessment of myogenic differentiation}

As a morphological parameter of differentiation, the myogenic index was defined as the fraction of nuclei residing in cells containing three or more nuclei in May-Grunwald Giemsa-stained cells (Sigma, Saint Louis, MO). Myogenic differentiation was assessed biochemically via determination of muscle creatine kinase (CK) activity. Cells were washed twice in cold PBS, lysed in $0.5 \%$ Triton X-100 and scraped off the dish with a rubber policeman. Lysates were centrifuged for 2 minutes at $16,000 \mathrm{xg}$ and the supernatant was stored in separate aliquots at $-80^{\circ} \mathrm{C}$ for determination of protein content or $\mathrm{CK}$ activity. $\mathrm{CK}$ activity was measured using a spectro-photometric based (16) kit from Sigma (Sigma Diagnostics, Saint Louis, MO). Specific CK activity was calculated after correction for total protein, which was assessed by the Bradford method (17). For Western blotting of the fast twitch isotype of myosin heavy chain (MyHCf) or myogenin, cells were washed in PBS, 
and whole cell lysates were prepared by addition of lysis buffer, composed of $40 \mathrm{mM}$ Tris, $300 \mathrm{mM} \mathrm{NaCl}, 2 \%(\mathrm{v} / \mathrm{v})$ Nonidet P-40, $1 \mathrm{mM}$ DTT, $1 \mathrm{mM} \mathrm{Na} \mathrm{VO}_{4}, 1 \mathrm{mM}$ PMSF, $10 \mu \mathrm{g} / \mathrm{ml}$ Leupeptin and $1 \%(\mathrm{v} / \mathrm{v})$ Aprotinin. Lysates were incubated on ice for 30 minutes, followed by 30 minutes of centrifugation at $16000 \mathrm{xg}$. A fraction of the supernatant was saved for protein determination, and $2 \times$ Laemmli sample buffer $(2 \%(\mathrm{w} / \mathrm{v}) \mathrm{SDS}, 10 \%(\mathrm{v} / \mathrm{v})$ glycerol, $0.1 \mathrm{M}$ DTT and $0.01(\mathrm{w} / \mathrm{v})$ Bromophenol Blue) was added. Samples were then boiled for 5 minutes and stored at $-20^{\circ} \mathrm{C}$. Approximately $10 \mu \mathrm{g}$ of protein was loaded per lane and separated on a 7 or $10 \%$ polyacrylamide gel (Mini Protean System, Biorad, Hercules, CA), followed by transfer to a nitrocellulose membrane (Schleicher \& Schuell, Keene, NH) by semidry electroblotting. The membrane was blocked overnight for non specific binding in $5 \%(\mathrm{w} / \mathrm{v})$ non-fat, dried milk at $4^{\circ} \mathrm{C}$. Nitrocellulose blots were washed in PBS-Tween 20 $(0.05 \%)$, followed by a 1 h incubation with monoclonal antibodies specific for MyHCf (MY32. Sigma, Saint Louis, MO) or myogenin (M-225) (Santa Cruz, Santa Cruz, CA). After 3 wash steps of 20 minutes each, the blots were probed with a peroxidase conjugated secondary antibody, and visualized on X-ray film by chemiluminescense according to manufacturers instructions (KPL, Gaithersburg, MD). When applicable, protein abundance was semi-quantitated by densitometric analysis of the $X$-ray film, using a Fluor-S Multilmager, and Quantity One software (Bio-rad, Hercules, CA).

\section{Quantification of genomic DNA}

Cells were trypsinized and pelleted by a $10^{\prime}$ centrifugation at $4^{\circ} \mathrm{C}$ at $500 \mathrm{~g}$ and subjected to an overnight incubation at $55^{\circ} \mathrm{C}$ in the presence of $250 \mu \mathrm{ll}$ lysis buffer containing $50 \mathrm{mM}$ Tris $(\mathrm{pH} 8.0), 100 \mathrm{mM}$ EDTA, $100 \mathrm{mM} \mathrm{NaCl}, 1 \%(\mathrm{w} / \mathrm{v})$ SDS, and $0.1 \mathrm{mg} / \mathrm{ml}$ Proteinase $\mathrm{K}$. Nucleic acids were separated from the protein fraction by PCI extraction (Tris-saturated phenol:chloroform:isoamylalcohol in a $25: 24: 1$ ratio, added as an equal volume to the lysate). The genomic DNA was then precipitated by the addition of 0.1 volumes $5 \mathrm{M} \mathrm{NaCl}$ and 2.5 volumes $100 \%$ EtOH to the aqueous phase, followed by a 30 minute centrifugation at $16000 \mathrm{~g}$ at $4{ }^{\circ} \mathrm{C}$. Next, the precipitate was washed in $70 \% \mathrm{EtOH}$, and resolved in $50 \mu \mathrm{l} \mathrm{TE}$ buffer. Finally, genomic DNA was quantified by spectrophotometry at $260 \mathrm{~nm}$ (Biophotometer, Eppendorf, Westburg, NY) and expressed as the total amount of DNA per dish.

\section{Plasmids, transfections and stable cell lines}

For the assessment of transcriptional activation of the Troponin I ( TnI) gene during differentiation, stable cell lines were created, containing a TnI reporter plasmid, which encodes for the Till promoter linked to the luciferase gene, kindly provided by Dr. Albert Baldwin (University of North Carolina, Chapel Hill, NC). Cells, $8 \times 10^{5} / 400 \mu l$ in GM, were transfected by electroporation (Genepulser, Biorad, Hercules, CA) at $240 \mathrm{~V}$ in the presence of $2.5 \mu \mathrm{g}$ plasmid DNA of interest, and $0.7 \mu \mathrm{g}$ of a plasmid containing the neomycin resistance gene (pSV2-Neo, Stratagene, La Jolla, CA). For selection of positive clones, cells were cultured in GM containing $850 \mu \mathrm{g} / \mathrm{ml}$ Geneticin (Life Technologies, Rockville, MD, CA). To determine luciferase acitivity, cells were lysed in $1 x$ luciferase lysis buffer and stored at $-80^{\circ} \mathrm{C}$. Luciferase activity (Promega, Madison, WI) was measured according to manufacturers" instructions, and expressed relative to the soluble protein fraction. 


\section{Statistical analysis}

Raw data were entered into SPSS (version 8.0) for statistical analysis. Values were subjected to one-way analysis of variance, and the various Ireament groups were compared post-hoc with a Student-Newman-Keuls test $(\mathrm{P}<0.05)$.

\section{RESULTS}

\section{Enhanced myogenic differentiation by Marrigel as an extracellular matrix}

For the analysis of myogenic differentiation creatine kinase (CK) activity was monitored to determine the kinetics and degree of myogenesis, achieved by using one of the following protocols: cells plated on uncoated dishes cultured in $0.5 \%$ FBS containing media (UFBS), cells plated on uncoated dishes cultured in $2 \%$ HS containing media (UHS), cells plated on Matrigel-coated dishes cultured in $0.5 \%$ FBS containing media (MFBS), or cells plated on Matrigel-coated dishes cultured in $2 \%$ HS containing media (MHS). CK activity increased as of day 2 in all protocols, although a higher specific activity was apparent in the protocols in which a Matrigel coating was used, which was sustained throughout all of the later time points. Following 8 days of differentiation, the augmentation in $\mathrm{CK}$ activity by Matrigel was equal for the HS and FBS containing cultures (Figure 1A). Myosin heavy chain-f (MyHC-f) abundance was also evaluated after 5 days of differentiation using the 4 different protocols. Matrigel enhanced the expression of MyHC-f for the FBS- as well as the HS differentiation protocol, although the combination of Matrigel and FBS resulted in maximal expression $(100 \%)$ of MyHC-f (Figure 1B).

A

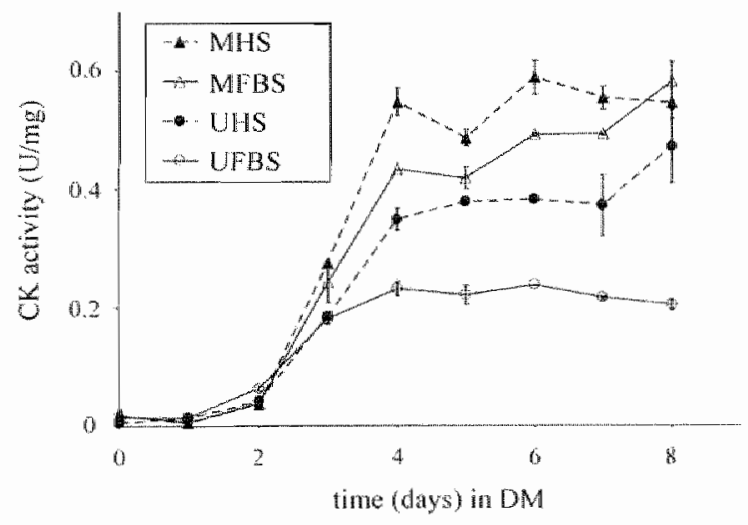

B

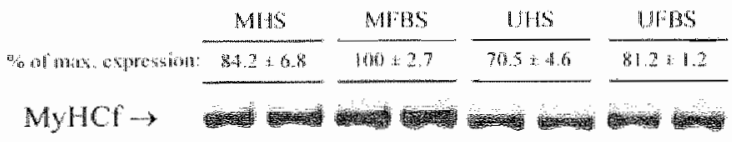

Figure 1: $\quad$ Increased creatine kinase activity (A) and myosin heavy chain expression (B) by differentiation on Matrigel. $\mathrm{C} 2 \mathrm{Cl} 2$ cells were grown on uncoated (U) or Matrigel-coaled dishes (M), and subsequently allowed to differentiate for the indionted limes it media containing $2 \% 115,040.5 \%$ FBS. Cell lysates were assessed for CK activity and lotal protein content Dephoted ist tho specific enzyme activity (mean 1 SEM) of triplicale samples (A). Allonintively, cqual amounts of: protein were separated by SDS-PACE, and assessed for MYHC-C abundance by Western blot analysis anter 5. days of differentiation (BB). MyHC-f abundanee was semi-quantitated msing chensitomeny, and expressed as a percentage (mean ts SEM) of maximal explassion $(\mathbb{M B B S}=100 \%)$. 
Therefore, the presence of Matrigel circunvented the requirement of HS for the myogenic program to proceed efficiently. Since it was our goal to induce optimal myogenic differentiation without introduction of any unrelated growth factors present in horse serum to the DM, and the UHS is the most commonly used differentiation protocol, the UHS protocol was further compared to the MFBS protocol.

\section{Myotube formation and spatial organization}

Using phase contrast microscopy, myogenic differentiation of C $2 \mathrm{C} 12$ cells was compared at different times using the UHS and MFBS protocols. Results in Figure 2 demonstrate a first appearance of small myotubes 3 days post-induction of differentiation using the UHS protocol, with a further increase in myotube size by day 5. Importantly, when we evaluated the ability of $\mathrm{C} 2 \mathrm{Cl} 2$ cells to differentiate using the MFBS protocol, extensive myotube formation was already observed at the 3 day time point, which increased further in time. Moreover, cells plated on Matrigel appeared to align in a coordinated fashion at day 2 , resulting in a more organized pattern of myotubes at the subsequent time points than observed in cultures differentiated according the UHS protocol.

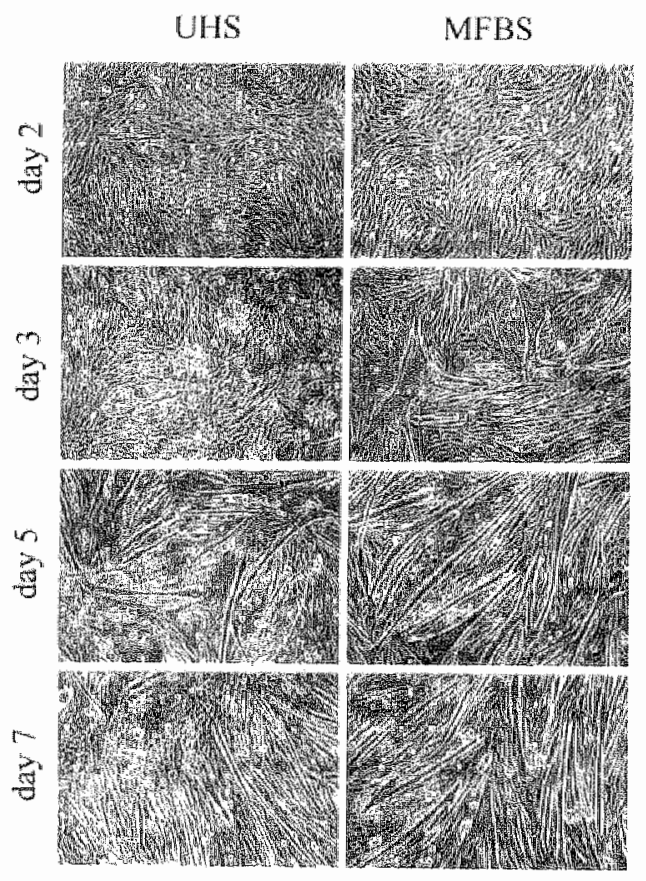

Figure 2:

Accelarated differentiation of myocyles into nyolubes, $\mathrm{C} 2 \mathrm{Cl} 2$ cells were growin on uncoated or Matrigel-coated dishes, and subsequendly allowed to differentiate in media containing $2 \%$ HS (UISS) or $0.5 \%$ FBS (MFBS), respectivety. Micrographs (x 100) were taken at the days indicated after induction of differentiation.

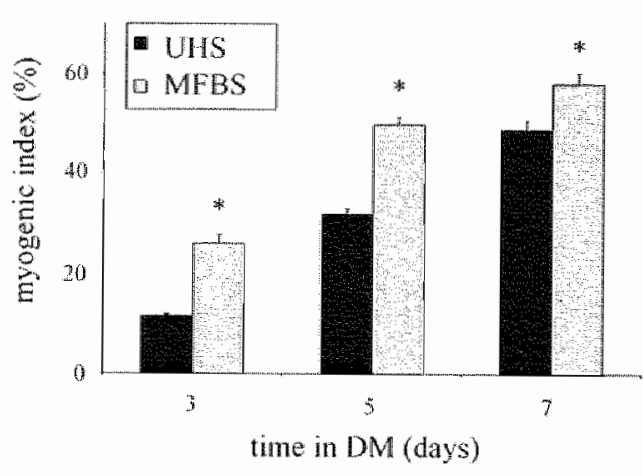

Figure 3: Accelerated fusion of myocytes into nyotubes. The myogenic index (mean 1 $\mathrm{SEM}, \mathrm{n}=3$ ) was determined after 3,5 , and 7 days after induction of differentation. Statistically significant differences $\left({ }^{*}=p<0.01\right)$ between UHS and MFBS differentiated cells were determined for each individual time point by oneWaY ANOVA. 
In addition, the shape and size of the myocytes was more homogeneous using the MFBS compared to the UHS protocol, and there appeared to be fewer unfused cells. The latter was illustrated by the myogenic index, which demonstrated that the MFBS protocol resulted in a higher percentage of nuclei residing in cells containing more than two nuclei for all time points, as compared to cultures that were induced to differentiate by UHS (Figure 3).

\section{Total DNA and protein during the differentiation process}

The higher incidence of unfused myoblasts observed using the UHS protocol, coincided with a marked, continuous increase in the amount of genomic DNA (Figure 4A) and protein (Figure $4 \mathrm{~B}$ ) during the first two days following serum reduction. These data suggest that not all the myoblasts had committed to terminal differentiation, but rather continued to proliferate when cultured in the $2 \%$ horse serum containing DM. This was followed by a marked temporal reduction in both, DNA and protein content, indicative of a loss of adherent cells. In contrast, for the MFBS protocol increases in total protein content only correlated with increases in DNA content during the first 24 hours. After day 3, total protein increased more than total DNA (Figure 4), consistent with the novel production of high abundance-muscle specific proteins.

A

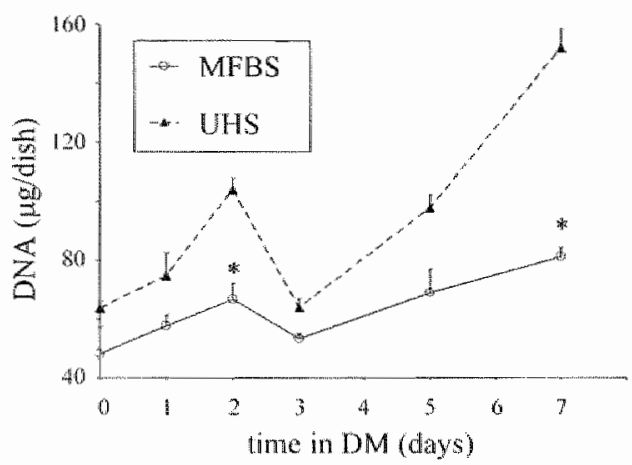

B

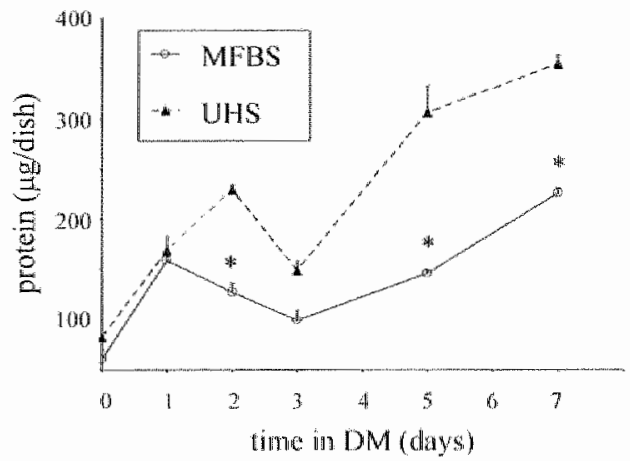

Figure 4: Analysis of total DNA (A) and protein (B) content per dish during differentiation. $\mathrm{C} 2 \mathrm{Cl} 2$ cells were grown on uncoated (UHS) or Matriget-coated (MFBS) dishes, and subsequenlly allowed to differentiate in media containing $2 \%$ HS (UHS) or $0.5 \%$ FBS (MFBS), respectively. Cell lysates were prepared for quantification of genomic DNA or total protein (mean \pm SEM, n $=3$ ) at the indicated times alter induction of differentiation. Note that comparisons for statistically significant differences $(*=040.05)$ in DNA content (A) or protein content (B) between UHS and MFBS differentated cells were made for each individual time point after correction for their respective values at time of induction of differentiation, and determined by one-way ANOVA.

\section{Accelerated muscle specific protein expression in the presence of Matrigel}

To evaluate whether the increase in total protein observed from day 3 on, involved the production of muscle specific proteins, the expression of the myofibrillar protein, myosin heavy chain (MyHCf, the fast isotype) was assessed, and compared between the MFBS and UHS protocols. As is shown in Figure $5 \mathrm{~A}$, MyHCF could clearly be demonstrated using both differentiation protocols. However, MyHCf expression kinetics were different between the 
protocols. Using the MFBS protocol, MyHCf could already be detected after 2 days in DM, and its expression levels were higher during day 3 and 5 , compared to $\mathrm{MyHCF}$ abundance observed using the UHS protocol, which is in line with data shown in Figure 1B. This finding suggested that the kinetics with which the myogenic differentiation process proceeded were different in the protocols tested here. Therefore, the abundance of myogenin, a key regulatory transcription factor in myogenesis, was evaluated during early differentiation. Western blot analysis demonstrated that myogenin could already be detected after 24 hours of differentiation when the MFBS protocol was used. Importantly, the expression of this myogenic regulatory factor (MRF) peaked much earlier (100\% expression after 48 hours), compared to myogenin expression in UHS cultured myocytes, which was not detectable at 24h in DM, with maximal expression only after 120h (Figure 5B).

A

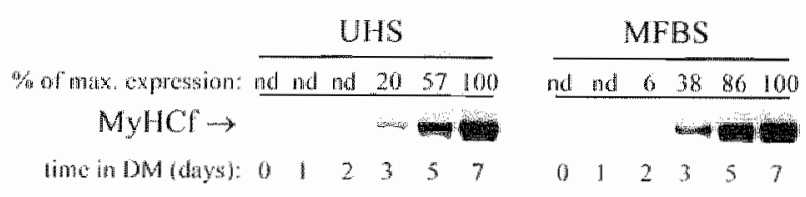

B

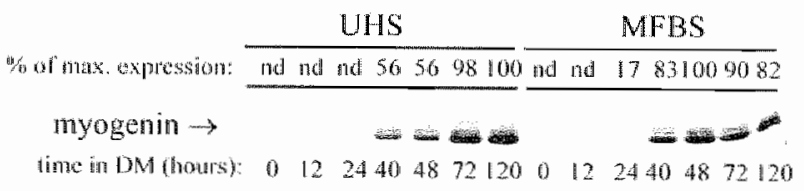

Figure 5: Accelerated expression of MyHCf (A) in presence of Matrigel correlates with the appearance of myogenin (B). $\mathrm{C} 2 \mathrm{C} 12$ cells were grown and differentiated according to the MFBS or UHS protocol, respectively. Cell lysates were prepared at the indicated limes after induction of differentiation, and expression of $\mathrm{MyHCf}$ (A), or myogenin (B) was assessed by Westerm blot analysis of 10ug protein lysate. MyHC-f and myogenin abundance were semi-guantitated using densitometry, and expressed as a percentage of the maximal expression observed in each differentiation protocol.

\section{Enhanced muscle gene expression by Matrigel is regulated at the transcriptional level}

Finally, we assessed whether the accelerated and enhanced appearance of muscle specific proteins observed using the MFBS protocol, would also be apparent at the transcriptional level. Muscle specific gene transcription was assessed using a $\mathrm{C} 2 \mathrm{C} 12$ cell line that stably expressed a troponin-luciferase reporter construct (as described in materials and methods).

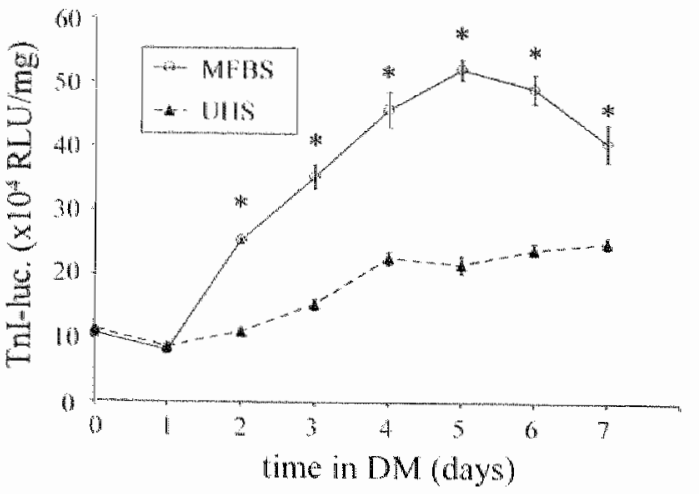

Figure 6: Enhanced muscle specific gene transcription. A line of $\mathrm{C} 2 \mathrm{Cl} 2$ cells, containing an integrated Thi-luciferase gene, was grown on uncoated (UHS) or Matrigel-coated (MFBS) dishes, and subsequently allowed to diflerentiate in media containing $2 \%$ HS or $0.5 \% \mathrm{FBS}$, respectively. Cells were harvested at the indicated times after the inducion of differentiation. Depicted is the total tuciferase activity per dish $(n=3$, mean \pm SEM). Statistically significant differences (* $=0<0.001$ ) between UHS and MFBS differentiated cells were determined for each individual time point by one-way ANOVA. 
As is demonstrated in Figure 6, transactivation of the roponin promoter was acoelerated following the induction of differentiation with the MFBS protocol. In addition, transactivation was markedly higher in cultures differentiated using the MFBS compared to the UHS protocol. Thus, consistent with the accelerated appearance of the transcription factor myogenin, the enhanced expression of muscle specific genes was apparent at the transcriptional level in cultures differentiated with the MFBS protocol.

\section{DISCUSSION}

Myogenic cell lines and primary cultures of skeletal muscle have extensively been used in the study of skeletal muscle development and to obtain insight in mechanisms of skeletal muscle homeostasis and disease at the cellular and molecular level. Regarding skeletal muscle development, the availability of these myogenic cell lines has contributed significantly to the identification and characterization of a number of transcription factors that regulate myogenesis, i.e. the muscle specific gene expression program, including myogenin. (3).

To obtain the differentiated characteristics of postnatal skeletal muscle, mumerous protocols have been described for the induction of myogenic differentiation of these cells, using a wide variety of serum sources, serum components or replacements, or other additives. As stated earlier, the broad spectrum of differentiation protocols may be responsible for discrepancies between various studies using differentiated cultures as a model, or investigating certain aspects of myogenic differentiation. Myogenic differentiation depends on the delicate interplay of several distinct signaling pathways that involve irreversible cell cycle exit, survival responses, activation of the myogenic transcriptional program, and the fusion into multinucleated myotubes. Thus, modulation of any of these signaling cascades by certain components of the DM may affect the kinetics of, and extent to which myogenic differentiation will occur. For example, cell cycle withdrawal relies on serum reduction in most protocols, but can be accelerated by the presence of retinoic acid (18). In addition, the presence of exogenous insulin like growth factors (IGF) may enhance the survival response in serum reduced DM, or promote myogenic transcription (19-21). Another, potentially confounding factor in most of the protocols, is the introduction of completely unratated growth factors, or other components to the DM, than are present in the GM. Therefore, we optimized a protocol in which the induction of myogenic differentiation can be accomplished by reduction of the serum content, and not the serum source of the DM.

Since satellite cells proliferate and differentiate during skeletal muscle development and regeneration in the context of an extracellular matrix (ECM) (15), we provided myocytes with a substratum that mimics their natural micro-environment (endomysium). This soluble basement membrane, Matrigel, contains laminin, collagen J $\mathrm{V}$, entactin, and heparan sullate proteoglycan (14). The culture of myogenic cell lines and primary skeletal muscle cells has been described for Matrigel itself (22), and for various componerts of this soluble basement membrane (23). Using a coating of diluted Matrigel and a DM containing $0.5 \%$ FBS (MFBS), we demonstrate in this study that myogenic differentiation can be induced to an equal or even higher extent, compared to a commonly used differentiation protocol that utilizes a DM containing $2 \%$ HS (UHS). 
Direct comparison of the MFBS and UHS protocol revealed a quicker and most extensive degrec of myogenic differentiation of myoblasts grown in Matrigel-coated dishes and differentiated in the presence of $0.5 \% \mathrm{FBS}$. For instance, assessment of myotube morphology and spatial organization showed the formation of larger and more homogeneously distributed myotubes when myocytes were cultured on a Matrigel coating and differentiated in the presence of $0.5 \%$ FBS (MFBS protocol). Furthermore, the myogenic index demonstrated that myocyte fusion was markedly promoted by the presence of Matrigel, in accordance with another study (23). The difference in the fusion capacity may be a function of a lower migratory ability of myoblasts differentiated according to the UHS protocol, since the motility of myoblasts depends to a large extent on the presence and composition of the ECM (24).

The higher incidence of unfused myoblasts using the UHS protocol coincided with a marked, initial increase in the amount of genomic DNA. The genomic DNA content per dish was assessed here as a measurement of total nuclei, since counting of cells would result in an incorrect estimate due to the cell fusion process, which is initiated approximately $48 \mathrm{~h}$ after induction of differentiation. The DNA content increased the initial 48 hours following serum withdrawal for both protocols, which corresponded with a twofold increase in cell number over that time period (data not shown). This residual proliferation despite the serum restricted conditions may be contributed to a fraction of asynchronously growing cells that has passed the restriction point at the moment of serum withdrawal and consequently is committed to complete another round of mitosis. In contrast to the MFBS protocol, DNA content continued to increase markedly using the UHS protocoll. This suggested that not all the myoblasts committed to terminal differentiation using the UHS protocol, but that a subpopulation continued to proliferate. Indeed, cyclin DI, a key mediator of cell cycle progression through the $\mathrm{Gl}$ checkpoint and therefore of proliferation, remained detectable up to 48 hours after the induction of differentiation in a study in which the DM contained $2 \%$ HS (25). Although we did not assess the expression of cyclin DI in our study, it is tempting to speculate that the composition of the DM determines whether myoblasts completely cease to proliferate or not. Further evidence of residual proliferation under differentiation-inducing conditions was provided in another study, in which a DM containing insulin, transferrin, sodium selenite and abumin was used (26). These slow cycling, undifferentiated, mononucleated myocytes were referred to as 'reserve cells', and believed to represent a population of cells that escapes terminal differentiation, in order to secure myogenic potential of skeletal muscle in response to a new stmulus, potentially reflecting the role of satellite cells during regeneration. In addition, another population of myoblasts undergoes apoptosis upon serum withdrawal, an event that was associated with deregulated cell cycle control (27). The dramatic loss in DNA and protein content (Figures $4 A$ and $4 B$ ) 3 days following induction of differentiation using the UHS protocol, suggested that the population of myoblasts that does not survive differentiation promoting conditions is larger in the UHS compared to the MFBS protocol.

The total protein content increased from day 3 on in both protocols. Although the magnitude of this increase was greater in the UIS protocol, it may not solely reflect muscle specific protein expression, but rather protein accumulation consequent to sustained proliferation, as the DNA content continued to increase past day 3 in the UHS protocol. Illustrative of the induction of muscle specific protein expression, creatine kinase (CK) activity increased dramatically on day 3 in both protocols, with the higbest specific activity present in the 
Matrigel cultures. This is in accordance with an earlier study, in which the stmulatory effect of a Matrigel coating on CK activity in differentianing rat primary satellite cells was demonstrated, although the DM used, contained 20\% HS (22). Another muscle specific protein, the myofibrillar protein myosin heavy chain (MyHCl, the fast isotype), was also expressed earlier during differentiation with the MFBS protocol. This suggested that the kinetics with which the myogenic differentiation process proceeded were different in the protocols tested here, which was illustrated by an accelerated appearance of the muscle transcription factor, myogenin in the MFBS protocol. In further support of this, the transactivation of the troponin promoter, assessed in a $\mathrm{C} 2 \mathrm{C} 12$ line with troponin reporter construct integrated in the genome, was markedly enhanced using the MFBS protocol. Although the presence of an ECM provided by Matrigel was found to be non-essential for the expression of myogenin (28), the accelerated and enhanced appearance of the various muscle proteins could still be the result of an increased activity of myogenin or other myogenic regulatory proteins. Alternatively, the lower serum percentage used in the MFBS protocol, combined with the presence of an ECM likely resulted in a nore rapid and complete cell cycle exit, ultimately leading to an accelerated induction of myogenesis.

In conclusion, we described here a protocol for the myogenic differentiation of skeletal muscle cells that does not require the introduction of any factors to the DM, other than those present in the GM, by providing the cells with a basal lamina that resembles their natural extracellular matrix, the endomysium. The enhancement of myogenic differentiation is apparent at the transcriptional level, and therefore regulated at the early stages of myogenesis. This protocol may aid studies aimed at elucidating mechanisms of myogenic differentiation, where a homogeneous population of myotubes is preferred.

\section{ACKNOWLEDGEMENTS}

The authors like to thank Adrianus van der Velden for technical assistance. 


\section{REFERENCES}

1. Blau, H. M., Pavlath, G. K., Hardeman, E. C., Chiu, C. P., Silberstein, L., Webster, S. G., Miller, S. C., and Webster, C. (1985) Plasticity of the differentiated state. Science $230,758-766$

2. Yaffe, D., and Saxel, O. (1977) Serial passaging and differentiation of myogenic cells isolated from dystrophic mouse muscle. Nature 270, 725-727

3. Olson, E. N. (1992) Interplay between proliferation and differentiation within the myogenic lineage. Dev Biol 154, 261-272

4. Yun, K., and Wold, B. (1996) Skeletal muscle determination and differentiation: story of a cone regulatory network and its context. Curr Opin Cell Biol 8, 877-889

5. Frost, R. A., Lang, C. H., and Gelato, M. C. (1997) Transient exposure of human myoblasts to tumor necrosis factor-alpha inhibits serum and insulin-like growth factor-I stimulated protein synthesis. Endocrinology 138, 4153-4159

6. Langen, R. C., Schols, A. M., Kelders, M. C., Wouters, E. F., and Janssen-Heininger, Y. M. (2001) Inflammatory cytokines inhibit myogenic differentiation through activation of nuclear factor-kappaB. Faseb $J 15,1169-1180$.

7. del Aguila, L. F., Claffey, K. P., and Kirwan, J. P. (1999) TNF-alpha impairs insulin signaling and insulin stimulation of glucose uptake in C2C12 muscle cells. Am $J$ Physiol 276, E849-855

8. Zentella, A., Manogue, K., and Cerami, A. (1993) Cachectin/TNF-mediated lactate production in cultured myocytes is linked to activation of a futile substrate cycle. Cytokine S, 436-447

9. Howard, P. L., Dally, G. Y., Ditta, S. D., Austin, R. C., Worton, R. G., Klamut, H. I., and Ray, P. N. (1999) Dystrophin isoforms DP7l and DP427 have distinct roles in myogenic cells. Muscle Nerve 22, 16-27

10. Buck, M., and Chojkier, M. (1996) Muscle wasting and dedifferentiation induced by oxidative stress in a murine model of cachexia is prevented by inhibitors of nitric oxide synthesis and antioxidants. Embo $J 15,1753-1765$

11. Guttridge, D. C., Mayo, M. W., Madrid, L. V., Wang, C. Y., and Baldwin, A. S., Jr. (2000) NF-kappaB-induced loss of MyoD messenger RNA: possible role in muscle decay and cachexia [see comments]. Science 289,2363-2366

12. Li, Y. P., Schwartz, R. J., Waddell, I. D., Holloway, B. R., and Reid, M. B. (1998) Sketetal muscle myocytes undergo protein loss and reactive oxygen-mediated NFkappaB activation in response to tumor necrosis factor alpha. Faseb $/ 12,871-880$

13. Gros, L., Riu, E., Montoliu, L., Ontiveros, M., Lebrigand, L., and Bosch, F. (1999) Insulin production by engineered muscle cells. Hum Gene Ther 10, 1207-1217.

14. Kleinman, H. K. MeGarvey, M. L., Hassell, J. R., Star, V. L., Cannon, F. B., Laurie, G. W. and Martin, G. R. (1986) Basement membrane complexes with biological activity. Brochemistry $25,312-318$

15. Godfrey, E. W., and Gradall, K. S. (1998) Basal lamina molecules are concentrated in myogenic regions of the mouse limb bud. Anat Embryol (Berd) 198, 481-486

16. Szasz, G., Gruber, W., and Bernt, E. (1976) Creatine kinase in serum: 1. Determination of optimum reaction conditions. Chin Chem 22, 650-656 
17. Bradford, M. M. (1976) A rapid and sensitive method for the guantitation of microgram quantities of protein utilizing the principle of protein-dye binding. Anal Biochem 72, 248-254

18. Halevy, O., and Lerman, O. (1993) Retinoic acid induces adult muscle cell differentiation mediated by the retinoic acid receptor-alpha. $J$ Cell Physiol $154,566-$ 572

19. Stewart, C. E., and Rotwein, P. (1996) Insulin-like growth factor-1l is an autocrine survival factor for differentiating myoblasts. J Biol Chem 271, 11330-11338

20. Stewart, C. E., James, P. L., Fant, M. E., and Rotwein, P. (1996) Overexpression of insulin-like growth factor-II induces accelerated myoblast differentiation. $J$ Cell Physiol 169, 23-32

21. Musaro, A., and Rosenthal, N. (1999) Maturation of the myogenic program is induced by postmitotic expression of insulin-like growth factor I. Mol Cell Biol 19. 3115-3124

22. Funanage, V. L., Smith, S. M., and Minnich, M. A. (1992) Entactin promotes adhesion and long-term maintenance of cultured regenerated skeletal myotubes. $J$ Cell Physiol 150, 251-257

23. Maley, M. A., Davies, M. J., and Grounds, M. D. (1995) Extracellular matrix, growth factors, genetics: their influence on cell proliferation and myotube formation in primary cultures of adult mouse skeletal muscle. Exp Cell Res 219, 169-179

24. Ocalan, M., Goodman, S. L., Kuh1, U., Hauschka, S. D., and von der Mark, K. (1988) Laminin alters cell shape and stimulates motility and proliferation of murine skeletal myoblasts. Dev Biol $125,158-167$

25. Guttridge, D. C., Albanese, C., Reuther, J. Y., Pestell, R. G., and Baldwin, A. S., Jr. (1999) NF-kappaB controls cell growth and differentiation through transcriptional regulation of cyclin D1. Mol Cell Biol 19, 5785-5799

26. Yoshida, N., Yoshida, S., Koishi, K., Masuda, K., and Nabeshima, Y. (1998) Cell heterogeneity upon myogenic differentiation: down-regulation of MyoD and Myf-5 generates 'reserve cells'. J Cell Sci 111, 769-779

27. Wang, J, and Walsh, K. (1996) Resistance to apoptosis conferred by Cdk inhibitors during myocyte differentiation. Science $273,359-361$.

28. Melo, F., Carey, D. J., and Brandan, E. (1996) Extracellular matrix is recuired for skeletal muscle differentiation but not myogenin expression. I Cell Biochen 62, 227. 239 


\title{
CHAPTER 4
}

\section{Inflammatory cytokines inhibit myogenic differentiation through the activation of nuclear factor kappa $B$}

\begin{abstract}
Muscle wasting is often associated with chronic inflammation. Since tumor necrosis factor$\alpha$ (TNFi $\alpha$ ) has been implicated as a major mediator of cachexia, its effects on C2C12 myocytes were examined. TNF $\alpha$ activated $N F-K B$ and interfered with the expression of muscle proteins in differentiating myoblasts. Introduction of a mutant form of $1 \mathrm{k} B \alpha$ restored myogenic differentiation in myoblasts treated with TNF $\alpha$ or $I L-1 \beta$. Conversely activation of $N F-K B$ by over-expression of IKK- $\beta$ was sufficient to block myogenesis, illustrating the causal link between $N F-\kappa B$ activation and inhibition of myogenic differentiation. The inhibitory effects of TNF $\alpha$ on myogenic differentiation were reversible, illustrating that the effects of the cytokine were not due to non-specific toxicity. Treatment of differentiated myotubes with TNF $\alpha$ did not result in a striking loss of muscle specific proteins, illustrating What myogenesis was selectively affected in the myoblast stage by TNFa. Importantly, NF$\mathrm{KB}$ was activated to the same extent in differentiating and differentiated cells, illustrating that once myocytes have differentiated, they become refractory to the effects of $N F-k B$ activation. These results demonstrate that inflammatory cytokines may contribute to muscle wasting through the inhibition of myogenic differentiation via a NF-KB dependent pathway.
\end{abstract}

Ramon C.J. Langen", Annemie M.W.J. Schols', Marco C.ll.M. Kelders', Emiel F.M. Wouters' and Yvonne M.W. Janssen-Heininger ${ }^{2}$. Departments of 'Respiratory Medicine, Maastricht University, Maastricht, The Netherlands, and Pathology, University of Vermont, Burlington VT, USA. Faseb vournal 2001; 15: 11691180. 


\section{INTRODUCTION}

Muscle wasting, defined as the loss of skeletal muscle tissue, commonly occurs in chronic wasting syndromes, such as acquired immune deficiency syndrome (AIDS) (1), cancer (2), chronic heart failure (3), and chronic obstructive pulmonary disease (COPD) (4-6), and is an independent predictor of mortality. Remarkably, in many of these conditions muscle wasting is associated with chronic elevations in circulating inflammatory cytokines, in particular tumor necrosis factor alpha (TNF $\alpha)(7-10)$. Generally, muscle wasting is believed to result from disturbances in the energy or anabolism-catabolism balance. For example, imbalances in myofibrillar protein synthesis and proteolysis have been demonstrated in experimental models of cancer cachexia $(11,12)$ or sepsis (13). Importantly, elevated levels of circulating inflammatory mediators, like TNF $\alpha$ and interleukin 1 (IL-1), were believed to trigger the events leading to muscle wasting in these models. In support of this, chronic administration of TNF $\alpha$ or IL-1 induced weight loss and skeletal muscle wasting in rats (14).

Alternatively, muscle wasting may result from a decrease of the number of fibers. In support of the latter, an increased prevalence in apoptotic myonuclei has been associated with the loss of skeletal muscle tissue in muscular dystrophies and inflammatory myopathies (1517). In addition, satellite cells form a reservoir of myogenic stem cells, which are essential in the replacement of damaged or degenerated myofibers. If inflammatory mediators interfere with the function of satellite cells by decreasing or blocking their ability to fuse with, or replace damaged myofibers, this could ultimately result in loss of skeletal muscle tissue.

Evidence for a direct role of inflammatory mediators in muscle wasting has been documented in in vitro studies. For example, administration of TNF $\alpha$ to primary cultures of differentiating human myoblasts inhibited the expression of $\alpha$-actin and myosin heavy chain (MyHC) (18). Others demonstrated the depletion of $\mathrm{MyHC}$ in differentiated myotubes in response to TNF $\alpha$, using the murine skeletal muscle cell line $\mathrm{C} 2 \mathrm{C} 12$ and primary cultures of rat skeletal muscle (19).

One well-studied pathway activated by TNF $\alpha$ involves signaling to the transcription factor nuclear factor kappa $B(N F-k B)$. Under normal conditions, $N F-k B$ is present within the cytoplasm in an inactive state, bound to its inhibitory protein $1 \mathrm{~K} B \alpha$. Upon stimulation with TNFa, an intracellular signaling cascade is initiated, resulting in the phosphorylation of $1 \kappa B \alpha$ on serine residues 32 and 36 by $1 \kappa B$ kinase (IKK). Phosphorylation and subsequent ubiquitination of these residues target $\llbracket \kappa B \propto$ for degradation by the 26S-proteasome complex. Once liberated from its inhibitory protein, NF- $k B$ translocates to the nucleus, where it orchestrates the transcription of a number of cytokine and chemokine, growth regulatory, and survival genes $(20,21)$.

The goal of the present study was to evaluate the effects of the inflammatory cytokines TNF $\alpha$ and $1 \mathrm{~L}-1 \beta$ on $\mathrm{C} 2 \mathrm{C} 12$ myocytes, and to explore the role of $\mathrm{NF}-\mathrm{KB}$ activation herein. We compared the effects of TNF $\alpha$ on myogenesis during or after the differentiation of myoblasts into myotubes, as studies have demonstrated that this cytokine can affect both undifferentiated myoblasts and differentiated myotubes $(18,19,22)$. In addition to TNF $\alpha$, the effects of $1 \mathrm{~L}-1 \beta$ on muscle specific gene expression were investigated, since a role for this cytokine has been suggested as a mediator of cachexia $(14,23)$. Finally, we evaluated 
whether the effects of TNF $\alpha$ and IL-1 $\beta$ on myogenic differentiation were mediated through the activation of $N F-k B$.

\section{MATERIALS AND METHODS}

\section{Cell culture}

The murine skeletal muscle cell line $\mathrm{C} 2 \mathrm{C} 12$ was obtained from the American Type Culture Collection (ATCCH CRL1772, Manassas, VA). These cells are able to undergo differentiation into spontaneously contracting myotubes upon growth factor withdrawal (24). Myoblasts were cultured in low glucose Dulbecco's Modified Eagle Medium (DMEM) containing antibiotics (50U/ml Penicillin and $50 \mu \mathrm{g} / \mathrm{ml}$ Streptomycin) and $9 \%$ $(v / v)$ Fetal Bovine Serum (FBS) (all from Life Technologies, Rockville, MD), referred to as growth media (GM). For experiments, 60mm dishes (Becton Dickinson Labware, Bedford, MA) were coated for 1 h at $37^{\circ} \mathrm{C}$ with diluted (1:50 in DMEM) Matrigel (Becton Dickinson Labware, Bedford, MA), which contains collagen IV, laminin, heparan sulfate proteoglycan and entactin, which are constituents of the natural extracellular matrix of skeletal muscle fibers (25). This plating protocol, resulted in enhanced and more consistent differentiation, compared to protocols that use $2 \%$ horse serum containing media to induce differentiation (manuscript in preparation). Cells were plated at $10^{4} / \mathrm{cm}^{2}$ and culltured in GM for $24 \mathrm{~h}$, allowing them to reach $\sim 60 \%$ confluency. To induce differentiation, cells were washed in Hank's balanced salt solution (HBSS) and further cultured in DMEM low glucose, containing antibiotics and $0.5 \%$ heat inactivated FBS, referred to as differentiation media (DM). To study the effects on differentiation, murine TNF $\alpha$ or $1 \mathrm{~L}-1 \beta$ (Calbiochem, La Jolla, CA), were added to the culture dishes directly after induction of differentiation. To study the susceptibility of differentiated myotubes to TNF $\alpha$, myoblasts were cultured in DM for 5 days and received fresh media every other day, prior to addition of the cytokine. Cells were examined with an inverted phase contrast microscope (Olympus CH40, Melville, NY), equipped with a camera (Nikon N6000).

\section{Assessment of myogenic differentiation}

As a morphological parameter of differentiation, the myogenic index was defined as the fraction of nuclei residing in cells containing three or more nuclei, following staining with May-Grunwald Giemsa (Sigma, Saint Louis, MO). Myogenic differentiation was assessed biochemically via determination of muscle creatine kinase (CK) activity. Cells were washed twice in cold PBS, lysed in $0.5 \%$ Triton X-100 and scraped off the dish with a rubber policeman. Lysates were centrifuged for 2 minutes at $16,000 \mathrm{xg}$ and the supernatant was stored in separate aliquots at $-80^{\circ} \mathrm{C}$ for determination of protein content or CK activity. CK activity was measured using a spectro-photometric based (26) kit from Sigma (Sigma Diagnostics, Saint Louis, MO). Specific CK activity was calculated after correction for total protein, which was assessed by the Bradford method (27). Expression of the fast twitch isotype of myosin heawy chain (MyHCf) or myogenin was evaluated by Western blotting. Cells were washed in PBS, and whole cell lysates were prepared by addition of lysis buffer, composed of $40 \mathrm{mM}$ Tris, $300 \mathrm{mM} \mathrm{NaCl}, 2 \%$ (v/v) Nonidet P-40, $1 \mathrm{mM} \mathrm{DTT}, 1 \mathrm{mM} \mathrm{Na}_{3} \mathrm{VO}_{4}$, $1 \mathrm{mM}$ PMSF, $10 \mu \mathrm{g} / \mathrm{ml}$ Leupeptin and $1 \%(\mathrm{v} / \mathrm{v})$ Aprotinin. Lysates were incubated on ice for 30 minutes, followed by 30 minutes centrifugation at $16000 \mathrm{xg}$. A fraction of the supernatant 
was saved for protein determination, and 2 L Lammli sample buffer (2\% (w/v) SDS, $10 \%$ $(\mathrm{v} / \mathrm{v}) \mathrm{glycerol}, 0.1 \mathrm{M}$ DTT and $0.01 \%$ (w/v) Bromophenol Blue) was added. Samples were then boiled for 5 minutes and stored at $-20^{\circ} \mathrm{C}$. Approximately $10 \mu g$ of protein was loaded per lane and separated on a 7 or $10 \%$ polyacrylamide gel (Mini Protean System, Biorad, Hercules, CA), followed by transfer to a nitrocellulose membrane (Schleicher \& Schuell, Keene, NH) by semidry electroblotting. The membrane was blocked overnight for non specific binding in $5 \%(\mathrm{w} / \mathrm{V})$ non-fat, dried milk at $4 \% \mathrm{C}$. Nitrocellulose blots were washed in PBS-Tween $20(0.05 \%)$, followed by a 1 in incubation with monoclonal antibadies specific for MyHCf (MY-32, Sigma, Saint Louis, MO) or myogenin (M-225) (Santa Cruz, Santa Cruz, CA). After 3 wash steps of 20 minutes each, the blots were probed with a peroxidase conjugated secondary antibody, and visualized by chemiluminescense according to manufacturers instructions (KPL, Gaithersburg, MD).

\section{Assessment of cell death}

Cell death was determined by measuring lactate dehydrogenase (LDH) actiwity in the supernatant of the culture media, using a spectrophotometric assay according manufacturers instructions (Promega, Madison, WI). Activity was expressed as percentage of maximal acitivity, i.e. the LDH activity following the total lysis of the cells of a control dish. Apoptosis was evaluated after pooling detached and adherent cells from each dish. Detached cells were collected from the culture media by centrifugation at $500 \mathrm{~g}$ for 10 minutes and resuspended in $200 \mathrm{pl}$ HBSS. Adherent cells were trypsinized, centrifuged (10 minutes, $500 \mathrm{~g}, 4^{\circ} \mathrm{C}$ ), and resuspended in $1 \mathrm{ml}$ of HBSS. $200 \mu \mathrm{l}$ was saved to determine adherent cell number and the remaining $800 \mu \mathrm{l}$ was pooled with the cells collected from the culture media. Cells were permeabilized in $0.1 \%$ Triton $X-100$ (in PBS) and stained with PBS solution containing $50 \mu \mathrm{g} / \mathrm{ml}$ propidium iodide (Sigma, Saint Louis, MO). After 30 minutes incubation on ice, cell cycle distribution was assessed to evaluate the sub- $\mathrm{G}_{0} / \mathrm{G}_{1}$ fraction, using flow cytometry (Coulter, EPICS Elite, Miami, FL). Total adherent cell number was determined using a Coulter particle counter, (Coulter Corporation, Miami, FL) after dilution of a suitable volume of cells in $10 \mathrm{ml}$ Isoton, and expressed as number of adherent cells per plate.

\section{Electrophoretic mobility shifi analysis (EMSA)}

To detemine DNA binding activity of $\mathrm{NF}-\mathrm{kB}$, complexes binding to an oligonucleotide containing a $K B$ consensus sequence were analyzed (Santa Cruz, Santa Cruz, CA). Nuclear extracts were prepared as described previously (28). $2 \mu \mathrm{g}$ of nuclear protein was used per binding reaction and protein-DNA complexes were resolved on a $5 \%$ polyacrylamide gel in $0.25 \times$ Tris-borate-EDTA buffer at $120 \mathrm{~V}$ for 2 hours. Gels were dried and exposed to film (X-Omat Blue XB-1, Kodak, Rochester, NY). Shifted complexes were quantitated by phospho-imager analysis (Bionad, Hercules, CA). To determine the sub-composition of the complexes. supershift reactions were performed by pre-incubation of the nuclear extracts with antibodies specific to the RelA or p50 subunits of NF-kB (Santa Cruz, Santa Cruz, CA). 


\section{Transfections and plasmids}

For the assessment of NF-KB transcriptional activity during differentiation, stable cell lines were created, containing either the $6 \mathrm{~KB}-\mathrm{TK}$ luciferase (NF-KB reporter) plasmid, or empty TK luciferase plasmid, both kindly provided by Dr. Patrick Baeuerle (Micromet, Germany). Cells, $8 \times 10^{5} / 400 \mu 1$ in GM, were transfected by electroporation (Genepulser, Biorad, Hercules, CA) at $240 \mathrm{~V}$ in the presence of $2.5 \mu \mathrm{g}$ plasmid DNA of interest, and $0.7 \mathrm{\mu g}$ of a plasmid containing the neomycin resistance gene (pSV2-Neo, Stratagene, La Jolla, CA). For selection of positive clones, cells were cultured in GM containing $850 \mu \mathrm{g} / \mathrm{ml}$ Geneticin (Life Technologies, Rockville, MD). Transient transfections were performed by calcium phosphate precipitation according to manufacturers" instructions (Specialty Media,

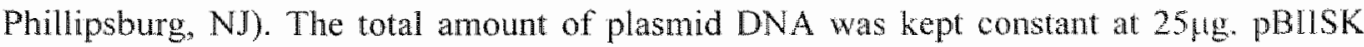
(Stratagene, La Jolla, CA) was used as carrier DNA and pSV-B-gal ( 1 Hg per transfection) (Promega, Madison, WI), was employed to correct for differences in transfection efficiency. The $6 \kappa \mathrm{k}$-TK luciferase or Troponin I (TnI)-luciferase plasmid, the latter kindly provided by Dr. Albert Baldwin (University of North Carolina, Chapel Hill, NC), were used as reporters for transcriptional activity of $\mathrm{NF}-\mathrm{kB}$ or muscle specific transcription factors, respectively

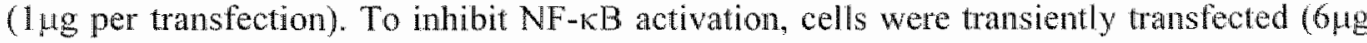
per transfection) with a plasmid encoding $I K B \alpha-S R$, which was constitutively expressed under control of the SFFV-LTR (pSFFV-NEO $I \kappa B \alpha-S R$ ), kindly provided by Dr. Rosa Ten (Mayo Clinic, Rochester, MN), or an empty vector as a control. For constitutive activation of NF-KB, cells were transiently transfected with a plasmid encoding IKK- $\beta$, kindly provided by Dr. Michael Karin (University of California, San Diego, La Jolla, CA). To determine luciferase and $\beta$-galactosidase acitivity, cells were lysed in $1 x$ luciferase lysis buffer and stored at $-80^{\circ} \mathrm{C}$. Luciferase (Promega, Madison, Wl) and B-gallactosidase (Tropix, Bedford, MA) were measured according to manufacturers' instructions.

\section{Immunofinorescence}

To assess the extent of myogenic differentiation in cells transfected with IKB $\alpha-S R$ or control vector following treatment with TNF $\alpha$, the expression of myogenin and IKB $\alpha-S R$ FLAG was assessed using immunofluorescence. Cells were grown, manipulated and fixed on glass coverslips. A biotinylated antibody $(10 \mu \mathrm{g} / \mathrm{ml}, \mathrm{M} 2$, Sigma, Saint Louis, MO), directed against the FLAG epitope, in combination with a streptavidin conjugated Alexa

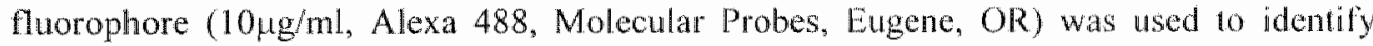
I $\mathrm{K} B \alpha-S R$ transfected cells. Simultaneously, an antibody recognizing myogenin $(10 \mu \mathrm{g} / \mathrm{ml}$, M225, Santa-Cruz, Santa-Cruz, CA) combined with an anti-rabbit Allophycocyanin conjugated antibody $(10 \mu \mathrm{g} / \mathrm{ml}$, Molecullar Probes, Eugene, OR) was applied. Immunoreactivity was evaluated using fluorescent microscopy (Olympus BX50) and analyzed for co-localization by confocal scanning laser microscopy (Biorad MRC 1024 ES).

\section{Statistical analysis}

Raw data were entered into SPSS (version 8.0) for statistical analysis. Values for CK activity, myogenic index, relative DNA-binding activity, LDH activity, and luciferase activity were subjected to one-way analysis of variance, and the various treatment groups were compared post-hoc with a Student-Newman-Keuls test $(P<0.05)$. Time dependent decrements in luciferase activity for $6 \mathrm{kB}$-TK-luciferase and TK-luciferase were assessed 
using multiple regression analysis. A two-way analysis of variance was employed to address whether myoblasts and myotubes activated NF-KB (assessed by EMSA and 6KB-TKluciferase activity) similarly in response to TNFa.

\section{RESULTS}

\section{Assessment of myogenic differentiation}

Intial experiments served to characterize the time frame of differentiation of $\mathrm{C} 2 \mathrm{C} 12$ cells following replacement of growth media (GM) with differentiation media (DM), by analysis of muscle specific protein expression. The activity of $\mathrm{CK}$, an enzyme expressed in mature skeletal and cardiac muscle (29), was found to increase with differentiation (Figure (A). Small increases in CK activity became apparent within 2 days after induction of differentiation and striking augmentation was observed between days 2 and 9 . Increases in $\mathrm{CK}$ activity corresponded with increases in expression of $\mathrm{MyHCF}$, a major myofibrillar protein $(29)$, and followed the expression of myogenin, a key muscle specific transcription factor (30) (Figure $1 \mathrm{~B}$ and $1 \mathrm{C}$, respectively).

A

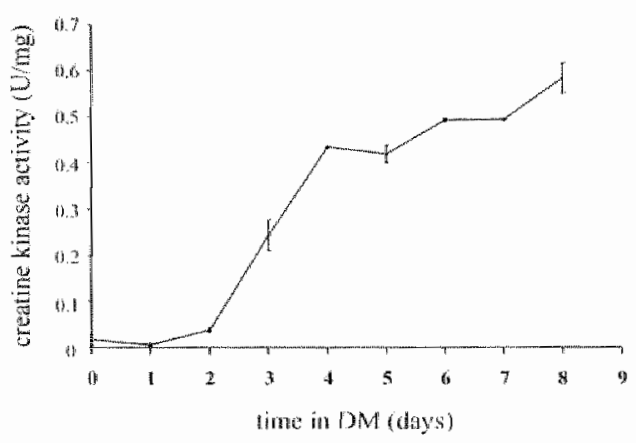

B

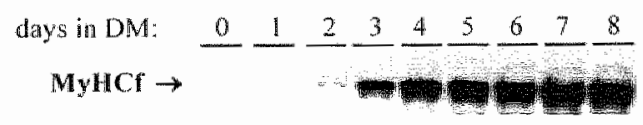

$\mathrm{C}$

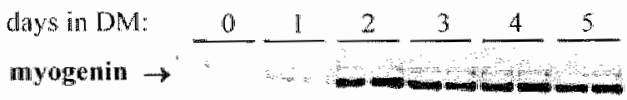

Figure 1: Biochemical assessment of the differentiation state of $\mathrm{C} 2 \mathrm{Cl} 2$ cells. Myoblasts were grown $10-60 \%$ confluency and allowed to differentiste by switching the culture media from GM to DM. CK activity was measured in cell lysates and normalized for total protein. Depicted is the average $+S E M(n-2)$ for each time point (A). The expression of MyHCF (B) or myogenin (C) was analyzed in 10 ag of protem lysate by Western bloting. Data are representative of $2-3$ independent experiments.

\section{Effect of TNF $\alpha$ on differentiated myorubes}

To investigate the effect of the inflammatory cytokine TNF $\alpha$ on the abundance of muscle specific proteins in differentiated myotubes, cells were cultured in DM for five days, followed by an additional 24 or 72 h incubation in the presence or absence of TNFa. Since catabolic effects of TNF $\alpha$ are well-documented (19), we determined total protein content per dish following exposure to the cytokine. However, total protein content was not altered after $24 \mathrm{~h}$ of culture in the presence of the cytokine (data not shown). In fact, $72 \mathrm{~h}$ after the addition of TNF $\alpha$ to the myotube cultures, a dose dependent increase in total protein content 
became apparent (Table 1), indicating that TNF $\alpha$ did not exert a catabolic effect in myotubes. CK activity was decreased $72 \mathrm{~h}$ after exposure to TNFa (Figure 2A). In addition. slight reductions in MyHCf content were detected in lysates of myotubes treated with TNFo for 24h (Figure 2B). Overall, the effects of TNF $\alpha$ on differentiated myotubes were manginal and only occurred at the highest dose $(50 \mathrm{ng} / \mathrm{ml})$ of cytokine.

Table 1: Decreased myoblast and increased myotube protein content in response to TNFa

\begin{tabular}{|c|c|c|}
\hline \multirow[b]{2}{*}{ treatment } & \multicolumn{2}{|c|}{ protein concent ( $\mu g$ protein/plate) (mean \pm sem) } \\
\hline & myoblasts ${ }^{b}$ & myotubes \\
\hline control & $359 \pm 6$ & $612 \pm 24$ \\
\hline TNF $\alpha(0.1 \mathrm{ng} / \mathrm{ml})$ & $344 \pm 10$ & - \\
\hline $\mathrm{TNF} \alpha(1.0 \mathrm{ng} / \mathrm{ml})$ & $309 \pm 29$ & $599 \pm 8$ \\
\hline $\mathrm{TNF} \alpha(10 \mathrm{ng} / \mathrm{ml})$ & $286 \pm 32$ & $651 \pm 21$ \\
\hline$T N F \alpha(50 \mathrm{ng} / \mathrm{ml})$ & - & $774 \pm 17^{*}$ \\
\hline
\end{tabular}

"Values were tested for significant differences (*: $p<0.05$ compared to control) using one-way ANOVA.

"Myoblasts were induced to differentiate in the presence of various concentrations of TNFa. "Total protein was determined after $72 \mathrm{~h}$ and expressed per plate. "Myoblasts were allowed to differentiate for 5 days to form myotubes before the addition of various concentrations of TNFa. Tolal protein was determined $72 \mathrm{~h}$ after the addition of the cytokine and expressed per plate.

A

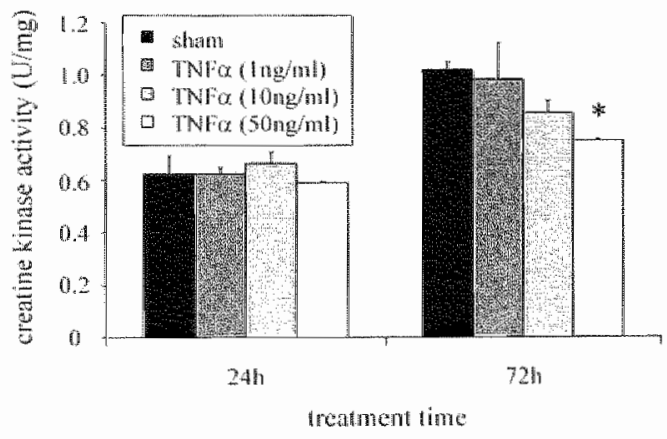

B

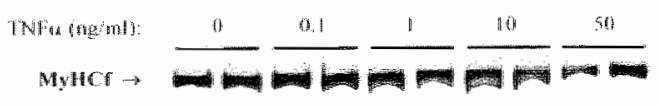

Figure 2: Assessment of $\mathrm{CK}$ activity and MyHCf abundance in differentiated myotubes treated with $\mathrm{TNF} \alpha$.

Cells were grown for $24 \mathrm{~h}$ in GM and allowed to differentiate for 5 datys by incubation in DM. TNFC (1-50ng/ml) was added, and cells wore cultured for an additional 24 or $72 \mathrm{~h}$. CK activity was determined in cell lysates and corrected for total protein. Depicted are the average \pm SEM $(n=2)$ for each treatment group (A). $\mathrm{MyHCl}$ expression was assessed in 10ug of protem lysate by Western blot anatysis (B). Statistically significan differences $(*=0<0.05)$ between the various treatment groups and their respective control wero determined by one-way ANOVA for each separate time point.

\section{Effect of TNF $\alpha$ on differentiating myobasts}

We next assessed the effects of TNF $\alpha$ during the myogenic differentiation process. As shown in Figure 3A, addition of TNF $\alpha$ immediately after induction of differentiation, markedly inhibited the formation of myotubes. This effect of the cytokine was further evidenced by a dose dependent decrease of the myogenic index (Figure 3B). In addition, total protein per dish was lower when myoblasts were cultured in DM for $72 \mathrm{~h}_{1}$ in the presence of TNFa (Table 1). The appearance of biochemical differentiation markers was 
also blocked by TNFa. For instance, $\mathrm{CK}$ activity (Figure 3C), MyHCf content (Figure 3D), or myogenin expression (Figure $3 \mathrm{E}$ ) were dose-dependently suppressed in differentiating myocytes treated with the cytokine, even though all of these parameters were normalized for total protein. These results illustrate that TNF $\alpha$ preferentially affects myogenesis in differentiating myoblasts, whereas differentiated myotubes are more refractory to the effects of TNF $\alpha$ on muscle protein expression. Concentrations of TNF $\alpha$ that interfere with myogenic differentiation here have been documented in the circulation of patients with cachexia (9).

$A$

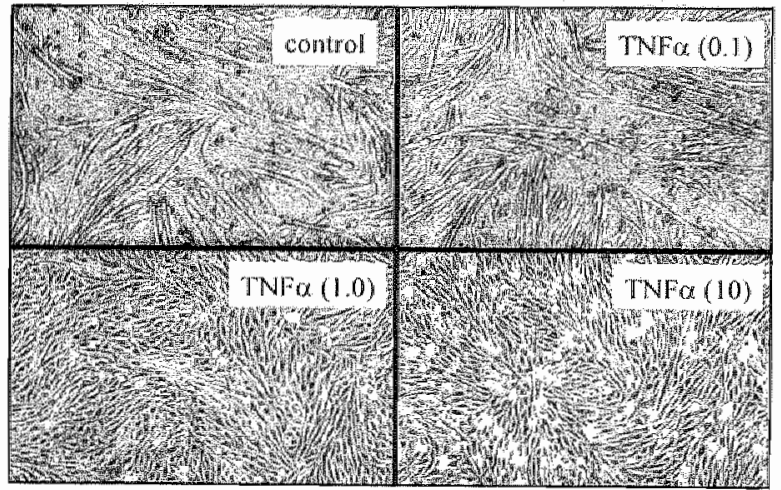

D

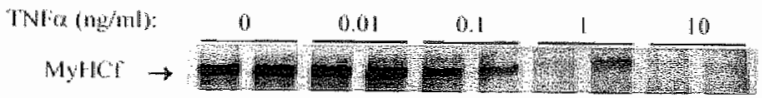

E

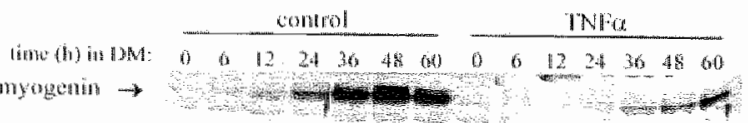

B

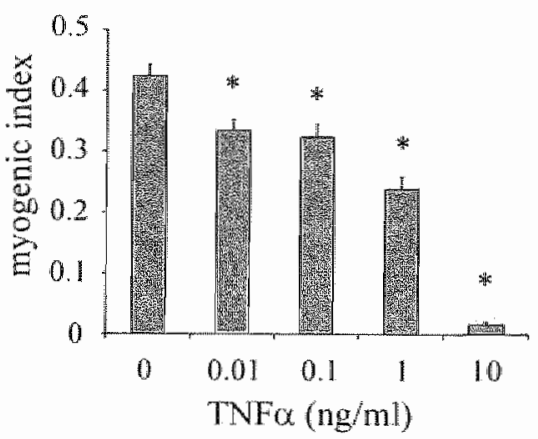

C

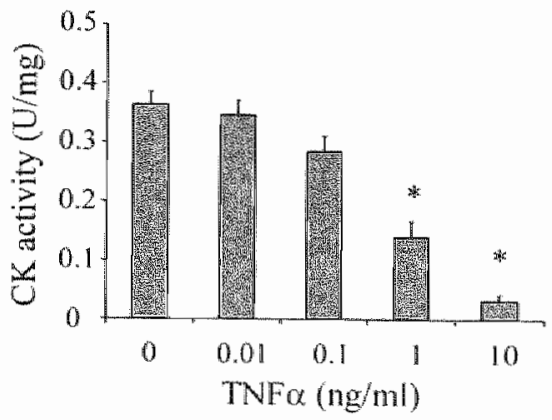

Figure 3: TNFa interferes with myogenic differentiation. Cells were induced to differentiate in the presence or absence of TNF $(0.1-10 \mathrm{ng} / \mathrm{ml})$ for $72 \mathrm{~h}$ by incubation in DM. Morphology was evaluated by phase contrist microscopy (A) or by assessment of the myogenic index (B). Data are expressed as the average 1 SEM of hive random fields trom duplicate samples. Biochemical indicators of differentiation were determined in control or TNFa-exposed cells. CK activity (average \pm SEM) was assessed in duplicate troated samples and corrected for total protein (C). Expression of MyHCf (D), or myogenin (E) was assessed by Westem blot analysis of $10 \mu \mathrm{g}$ protein lysate. Data are representative of 3 independent experiments. Statistically significant differences $(*=0<0.03)$ between the various treatment groups and control were determined for $C K$ activity and myogenic index by one-way ANOVA. Linear trends over dose were also tested and demonstrated a dose dependent effect of TNFo for both, the myogenic index and CK activity (p<0.001). 


\section{TNF $\alpha$ cytotoxicity and reversibility}

To investigate whether the loss of myogenesis in differentiating myoblasts was the result of cytotoxicity by TNFo, cell death was assessed. Lactate dehydrogenase (LDH) activity in the culture media, resulting from its release by necrotic cells, was determined as a measure of cell death. Increasing LDH activity was found in control cells during the differentiation process, reflecting a population of cells that appears to be incapable of survival under growth restricting conditions. The presence of TNF $\alpha$ dose dependently increased LDH release during differentiation (Figure $4 \mathrm{~A}$ ).

A

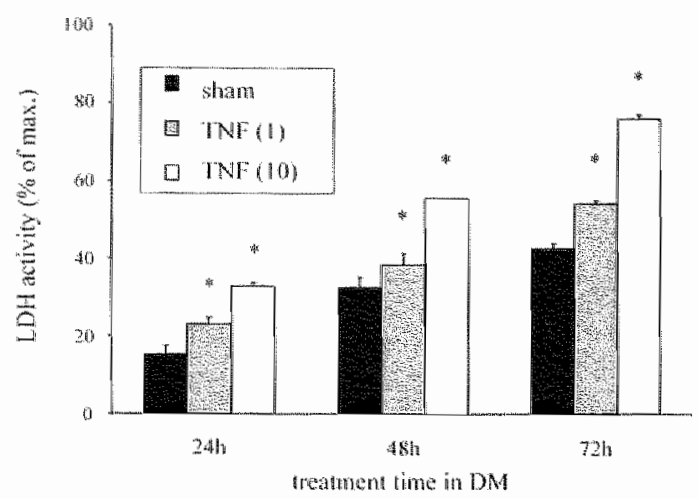

C

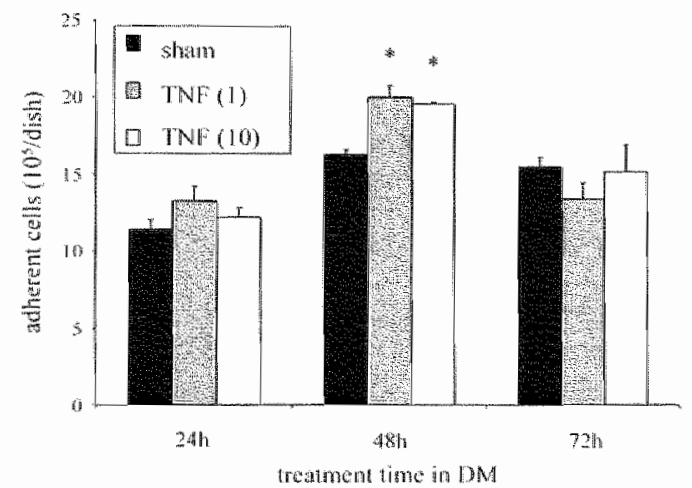

B

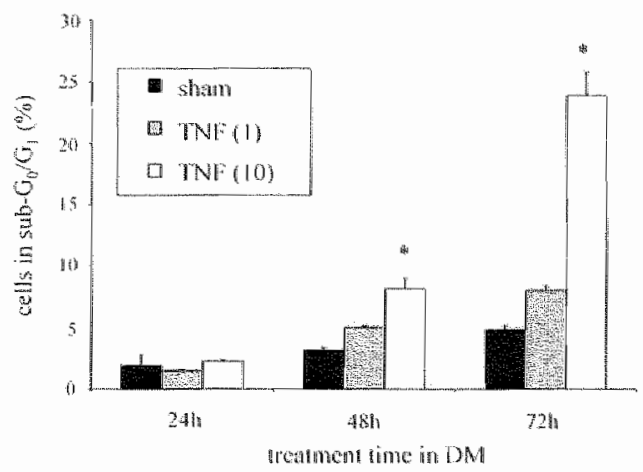

Figure 4: Increased cell death during differentiation by TNF $\alpha$ coincides with a prolitiontive response. $\mathrm{C} 2 \mathrm{Cl} 2$ myoblasts were allowed to differentiate in the absence or presence of TNFa. After $24 \mathrm{~h}$, $48 \mathrm{~h}$, and $72 \mathrm{~h}$ cell death was deternined as LDH activity in the media and expressed as of maximal activity (A). Apoptosis was assessed for the same time points as the sub-Gigi fraction of the total (adherent and detached) cell population (B). In addition, the adherent cells were counted and expressed as number per disth

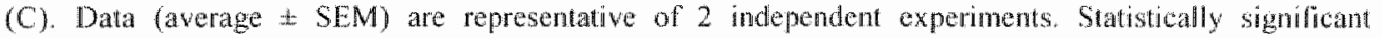
differences $(*=p<0.05$ ) between the TNFo treated groups and control were determined for each separate time point by oneway ANOVA. Linear trends were tested over time and dose. Control cells demonsirated a time dependent increase in $\mathrm{LDH}$ activity and sub- $\mathrm{G}_{\mathrm{ij}} / \mathrm{G}_{1}$ fraction $(\mathrm{p}<0.002)$. Dose dependent increases were fontrof for $L D H$ activity at all time poinis $(\mathrm{p}<0.005)$ and for the $\%$ of cells in sub-G/ $/ \mathrm{G}_{1}$ fraction at $48 \mathrm{gh}$ and 72 h $(\mathrm{p}<0.005)$ following exposure to TNF $\alpha$. 
Analysis of cell death by flow cytometry, using the fluorimetric exclusion dye Sytox, confirmed the rise in cell death inherent to differentiation and the additional increase following TNFa (data not shown). Further investigation revealed that the observed necrosis could be secondary to an apoptotic mechanism, as myoblasts treated with TNFa for 48 and 72 hours demonstrated a dose dependent elevation in the sub- $\mathrm{G}_{0} / \mathrm{G}_{1}$ fraction, when stained with propidium jodide and analyzed by flow cytometry (Figure 4B). Surprisingly, the total number of adherent cells increased after 48 hours of exposure to TNF $\alpha$, illustrating that this cytokine causes proliferation in the first 48 hours of myogenic differentiation (Figure $4 \mathrm{C}$ ). After $72 \mathrm{~h}$ however, cell numbers following TNFa treatment were equal to control cell numbers again, which had remained constant, suggesting that additional cell death observed in the presence of TNFa during this period (Figures $4 \mathrm{~A}$ and $4 \mathrm{~B}$ ) may in fact result from apoptosis of these myocytes that are initially proliferating.

A

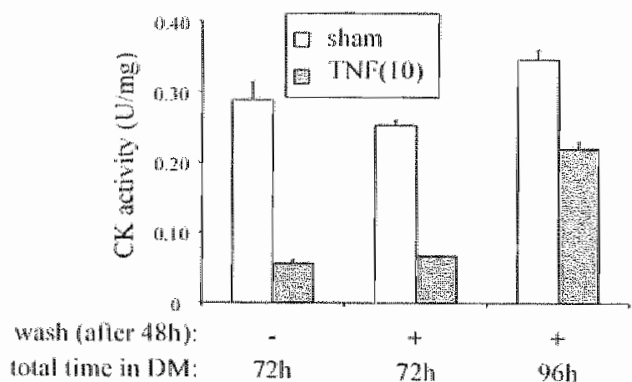

C

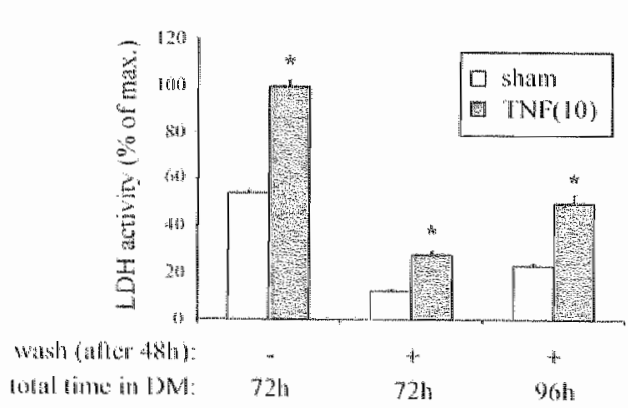

wath athen that total timen 1 in 1 M :

721

961
B

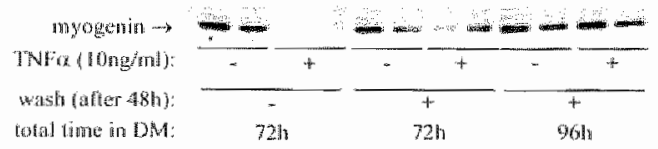

Figure 5: Inhibition of myogenic differentiation by TNF $\alpha$ is reversible. Myoblasts were induced to differentiate in the absence or presence of TNF $(10 \mathrm{ng} / \mathrm{ml})$. After $48 \mathrm{~h}$, TNF $\alpha$ was washed out and the cells were cultured for an additional $24 \mathrm{~h}$ ( $72 \mathrm{~h}$ total) or $48 \mathrm{~h}$ (96h total) in DM. CK activity (A) and myogenin expression (B) were determined in cell extracts and LDH activity $(C)$ in the media. The $C K$ activity of control (72h) and washed (96h) myocytes following TNF $\alpha$ was compared by two-way ANONA. Removal of TNFo after $48 \mathrm{~h}$ significantly $(p<0.01)$ restored $C K$ activity. For LDH activily, statistically significant differences $(*=0<0.001)$ between the TNF $\alpha$ treated groups and control were determined for each separate time point by one-way ANOVA.

We next tested whether the effect of TNF $\alpha$ on differentiation was reversible, which would not expected to be the case for a non-specific cytotoxic signal. TNF $\alpha$ was washed out after $48 \mathrm{~h}$ of culture and fresh DM was added to the myocytes. Although LDH activity persisted to increase following the removal of the cytokine (Figure 5C), myogenesis was restored completely and rapidly, as was demonstrated for CK activity (Figure 5A) and myogenin (Figure 5B). These results confirm that the inhibitory effects of TNF $\alpha$ on myogenic differentiation are not due to a non-specific toxic effect. 


\section{$N F-K B$ in myoblasts and myotubes}

To investigate potential mechanisms responsible for the observed inhibition of myogenic differentiation, we focused on $\mathrm{NF}-\mathrm{kB}$, a transcription factor that has a central role in inflammatory responses, and is known to be activated by inflammatory cytokines like TNF $\alpha$ and IL-1B (21). Exposure to TNF $\alpha$ caused a marked and sustained activation of NF-KB DNA binding activity (Figure 6A) and transactivation (Figure 6B) in response to TNF $\alpha$. Analysis of the sub-composition of the retarded complexes by supershift assay, using antibodies directed against the RelA and p50 subunits of $\mathrm{NF}-\kappa \mathrm{B}$, revealed that the major complex induced by TNF $\alpha$ (upper band) was composed of a RelA-p50 heterodimer, and possibly another RelA hetero- or homodimer, since pre-incubation with the p50 antibody did not result in a complete shift of this band (Figure 6A). As expected, NF-kB DNA binding activity and transactivation in response to TNF $Q$ was preceded by rapid degradation of $\mathrm{I} \kappa \mathrm{B} \propto$ (Figure $6 \mathrm{C}$ ), as determined by Western Blotting using an antibody directed against I $\mathrm{B} \propto$ (sc371, Santa Cruz, Santa Cruz, CA).

A

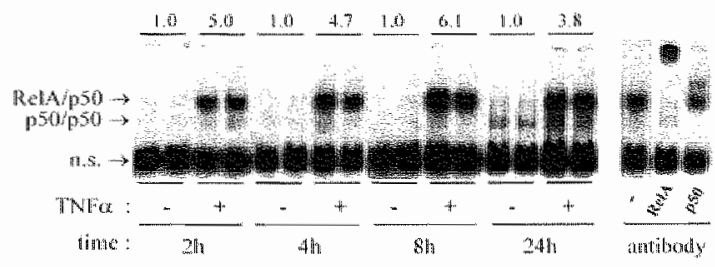

B

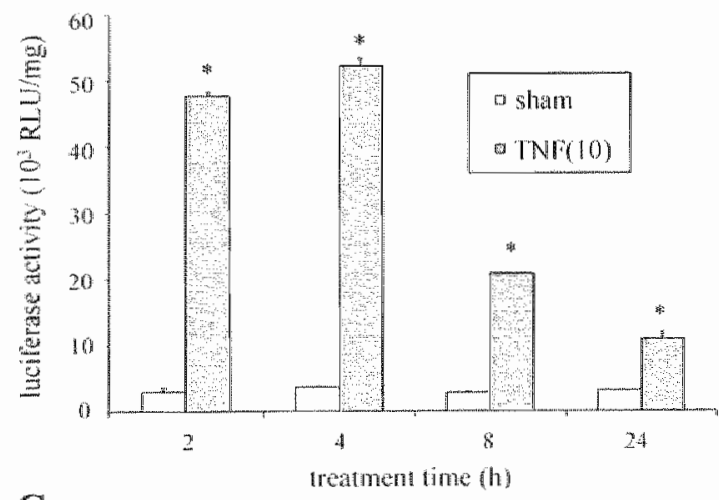

$\mathrm{C}$

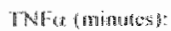

$\ln \mathrm{B} x \rightarrow$
Figure 6: Activation of $\mathrm{NE}-\mathrm{B}$ by TNFa. $\mathrm{C} 2 \mathrm{C} 12$ cells were allowed to differentate for $2-24 \mathrm{~h}$ in the presence or absence of TNF $\alpha(10 \mathrm{ng} / \mathrm{ml})$. Nuclear extracts wore prepared at the indicated thmes and assessed for DNA binding activity to a consensus NF-KB oligonucleotide by EMSA. Relative DNA-binding activity was determined by phospho-imager analysis and expressed as fold increase over control for each time point. Complex subconposition was assessed in an extract of TNFa exposed cells $(10 \mathrm{ng} / \mathrm{ml}$, 4h), by supershift malysis using antibodies against RelA or p50 (A). Transeriptional activation of $\mathrm{NF}-K \mathrm{~B}$ was determined in $\mathrm{C} 2 \mathrm{C} / 2$ cells stably expressing the 6r-B-TK-lucterase construct Lysates from untrealed and trealed cells were prepared 2,4 , 8 and 24 hours after induction of differentiation for assessment of luciforse activity (B). NF-KB metivation by TNFo is preceded by degradation of $\mathrm{kB}$. TNF (long/ml) treated colls were havested at the indicatud exposure lime, and 10 hy of protem lysate was analyzed by Westem bluting (C). Data are represertalive of $2-3$ independent experimants. Stalishically difherences (* p<0.05) between treated and contuol gronps were determined for each individual mime point by one-way ANOVA. 
A

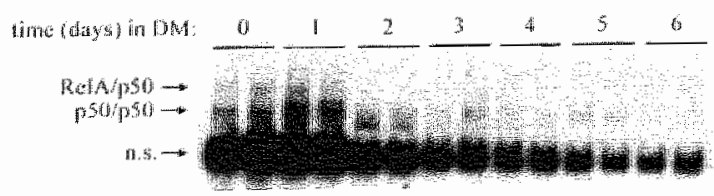

B

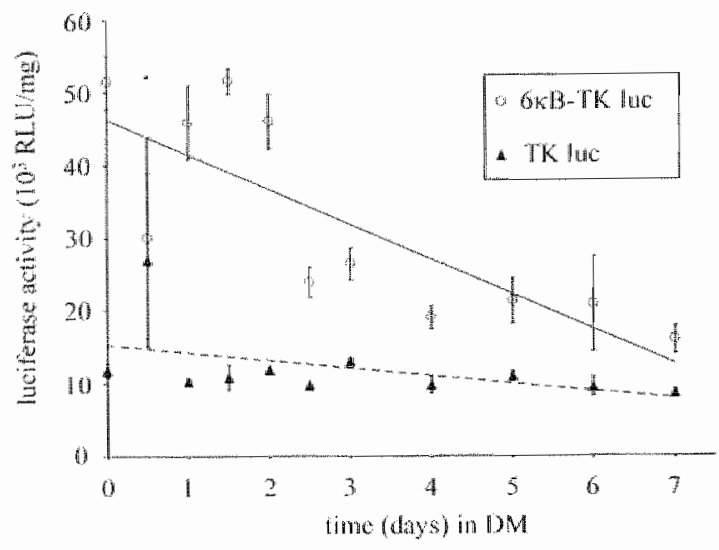

C

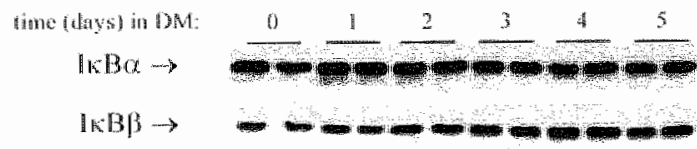

Figure 7: $\quad \mathrm{NF}-\mathrm{KB}$ DNA binding and transcriptional activity decreases during differentiation. C2C12 cells were induced to differentiate by incubation in DM, and nuclear extracis were prepared at subsequent days of incubation in DM for analysis of binding activity to a consensus $N F-K B$ oligonticleotide by EMSA. Indicated are the sub-compositions of the various retarded complexes; n.s. =non-specific (A). Assessment of $\mathrm{NH}-\mathrm{kB}$ iransactivation in a the of $\mathrm{C} 2 \mathrm{Cl} 2$ cells stably expressing $6 \mathrm{~KB}$ TK-luciferase. Cells were harwested after the indicated times of culture in $\mathrm{DM}\left(\mathrm{n}^{-2}-2\right)$ for the determination of luciferase activity (average \pm SEM). As a control. C2C12 cells were stably transfected with an enply TK-huciferase construct, which does not respond to $\mathrm{NF}-\mathrm{B}$ activation. Multiple regression analysis demonstrated a significant difference in the slopes of $6 \mathrm{kB}$-TK-luc and TK-lne (p 0,002). Moreover, huciferase activity decreased significantly over time for $6 \mathrm{~K} B-T K-\mathrm{lue}(\mathrm{p}<0,0001)$, whereas no significantl decrease was found for TK-luc $(\mathrm{p}=0.08)(\mathrm{B})$. IKBo abundance romains stable and levels of $1 \mathrm{~K} B(3$ increase during differentiation. Cell extracts were prepared at the indicated times afler induction of differentiation and assessed for $1 \mathrm{~KB}$ Ba and $\mathrm{IKB} B$ by Western blot andlysis (C). Similar activation of NF-KB by TNFa in myoblasts and myotubes. NF-KB DNA binding aclivity was determined by EMSA in nuclear extracts of myoblasts and myotubes that had been exposed to TNFa (10ng/ml) for 4h. Retative binding activity of the RelAap50 dimer, quantified by phospho-imaging analysis, was expressed as fold increase over untreated control and indicated above each set of lanes (D. upper panel). NF-KB transactivation was assessed in nyoblasts or myotubes of the $\mathrm{C} 2 \mathrm{Cl} 26 \mathrm{~KB}-\mathrm{TK}$ lucilevase cell line, after 6 of TNFo treatnent. Luciferase units were normalized to protein content, and data are expressed as lold increase over sham (D, lower panel). The response of myoblasts and nyotubes to TNFo was compared and found to be identical by employing a wo-way ANOVA, which showed no interaction between differentiation status and treatment. 
We next determined how NF-KB activity correlated with myogenic differentiation. Results in Figure 7 demonstrate baseline DNA binding activity of NF-KB complexes composed of both. RelA-p50 and p50 homodimers in unstimulated, undifferentated cells. Basal levels of NF $K B$ DNA binding activity decreased during myogenic differentiation, after an initial increase in binding by the p50 homodimer (Figure $7 \mathrm{~A}$ ). The use of $\mathrm{C} 2 \mathrm{Cl} 2$ cells that were stably transfected with $6 \mathrm{~KB}$ TK-luciterase, revealed that basal transcriptional activity of $\mathrm{NF}$ $\mathrm{kB}$ also decreased during muscle differentiation. In contrast, no changes were observed in a cell line containing the (control) TK-luciferase construct (Figure 7B). The decrease in NF$\kappa B$ activity was accompanied by increasing levels of the inhibitory protein $\llbracket k B \beta$, whereas IKB $\alpha$ abundance remained constant during differentiation (Figure 7C). However, the inducibility of $N F-K B$ was the same during or after diferentiation, as exposure to TNF $\alpha$ increased NF-KB DNA-binding activity (Figure 7D, upper panel) and transcriptional activity (Figure 7D, lower panel) to a similar extent in myoblasts and differentiated myotubes. These results demonstrated an inverse relation between basal NF- $\mathrm{KB}$ activity and myogenic differentiation. Since $L-1$, like TNF $\alpha$ is known to activate $N^{-}-k B$, differentiating myoblasts were treated with this cytokine (IL-1 $\beta, 0.1-10 \mathrm{ng} / \mathrm{ml}$ ). Similar as observed for "TNF $\alpha$, TL-1 $\beta$ dose dependently inhibited myogenic differentiation, as was revealed by measurement of CK activity and assessment of MyHCf expression (data not shown).

A

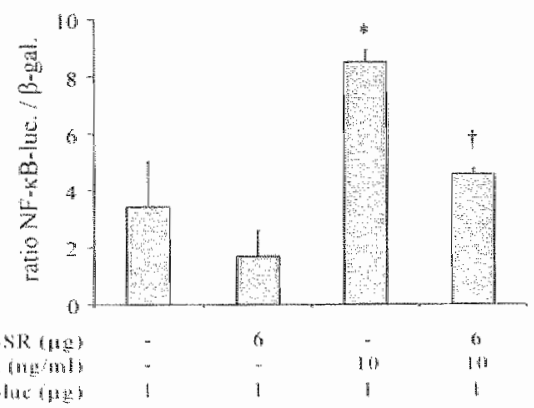

B

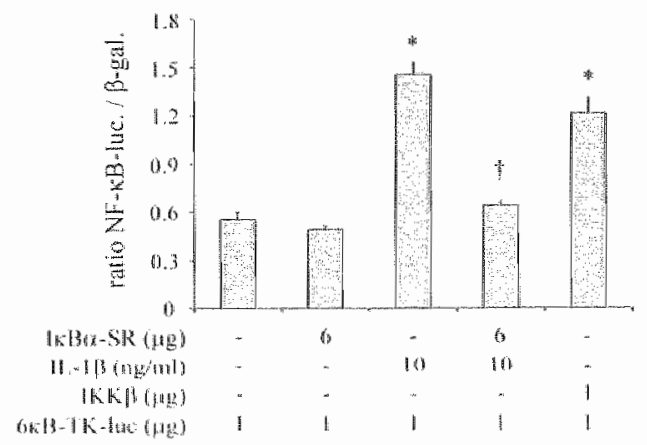

Figure 8: Expression of $1 K B \alpha-S R$ inhibits and $1 K K B$ induces $N F-k B$ transactivation. $C 2 C 12$ cells were

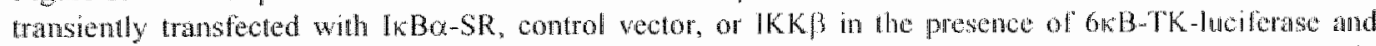
pSV-B-Gal. 16 hours post transfection, cells were allowed to recover for $12 \mathrm{~h}$ in $6 \mathrm{M}$ ind subsequently induced to differentiate in presence or absence of TNF $\alpha(A)$ or $I L-I \beta(B)$, to evaluate if $K B \alpha-S R$ expression could block $N F-K B$ transactivation. IKK. $B$ was over-expressed for the constitutive activation of $N F-k B(A)$. Cells were harvested 6 hours after treatment (in DM) for evalwation of lociferase and p-galactosidase acrivity, of which the latter served to correct for differences in transfection efficiency. Stalistically significant differences were determined by one-way ANOVA. * p 0.05 compared to untreated cells, that did not contain IKB $B-S R$; + p 0.05 compared to TNFO $(A)$ or IL-IB (B) treated cells that did nod contain IKB $\alpha-S R$. 


\section{$N F-$ B inhibits myogenic differentiation}

To determine whether $N_{F} \times B$ activation was causally involved in the inhibition of myogenic differentiation in response to TNF $\alpha$ or $I L-1 \beta$, cells were transiently transfected with $I K B \alpha-S R$, a non-degradable mutant of $I K B \alpha$, and a troponin promoter-luciferase reporter plasmid (Tnl-luciferase), that is only expressed in differentiated muscle. As expected, the expression of $J K B \alpha-S R$ reduced NF- $K B$ transactivation by TNF $\alpha$ (Figure $8 \mathrm{~A}$ ) or IL-1 $\beta$ (Figure 8B).

A

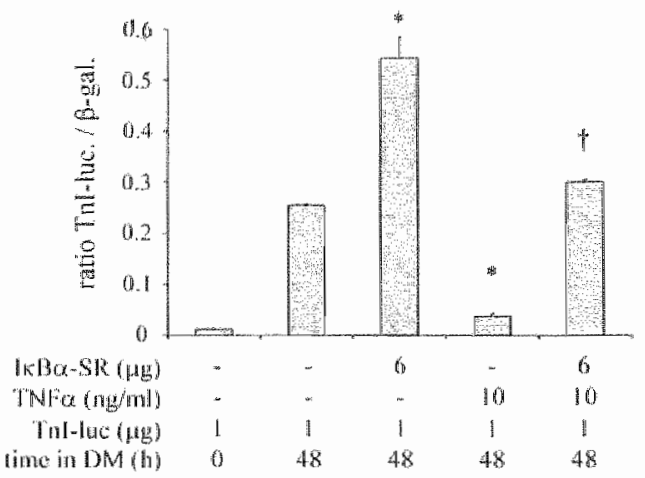

B

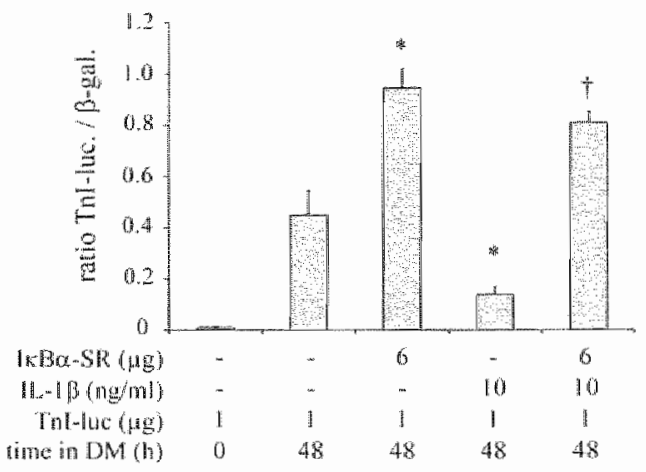

C

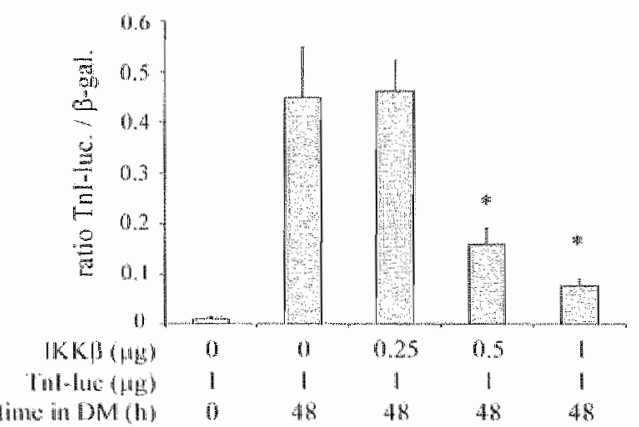

Figure 9: Blockade of NF-KB activation reverses the inhibitory effects of TNF $\alpha$ or $\mathrm{LL}-1 / 3$ on myogenic diflerentiation. Cells were co-transfected with IkB $\alpha-S R$ or control vector, and TnI-luciferase, to assess if blocking NF-KB activation reversed inlibition of differentiation by TNF $\alpha$ or IL-1B. 16 hours pos! transfection, cells were allowed to recover for $12 \mathrm{~h}$ in $\mathrm{GM}$, and subsequently induced to differentiate in presence or absenve of TNF $\alpha$ (A) or IL-1B (B). After 48h in DM, cell lysates were prepared for evaluation of luciferase and $\beta$-galactosidase activity. Alternatively, cells were co-transfected with IKKB and TnI-luciferase for $16 \mathrm{~h}$, allowed to recover for $12 \mathrm{~h}$, and harvested after $48 \mathrm{~h}$ of subsequent incubation in DM (C). Luciferase activity was expressed relative to $\beta$-galactosidase activity to account for differences in transfection efficiency. Shown are the representative data of $2-3$ independent experiments. Statistically significant differences were determined by one-way ANOVA. * $p<0.05$ compared to untreated cells (48DM), that did not contain $\mid \kappa B \alpha-S R ; \uparrow p<0.05$ compared to TNF $\alpha(A)$ or IL-1B (B) treated cells that did not contain $1 k B \alpha-$ $S R$. Linear trends over dose were also tested and demonstrated a dose dependent effect of IKK $\beta$ for Thlluciferase ( $\mathrm{p}<0.001$ ). 
Importantly, over-expression of $\mathrm{K} \mathrm{KB} \alpha-\mathrm{SR}$ enhanced myogenic differentiation and restored the loss of troponin-huciferase expression in response to exposure to these cytokines (Figures 9A and 9B, respectively). The causal role of $\mathrm{NF}-\mathrm{B}$ in the TNFa-induced inhibition of myogenic differentiation was also illustrated by immunolluorescence, which revealed that only $\mathbb{I} K B \alpha-S R$ positive cells expressed myogenin when cultured in DM in the presence of TNF $\alpha$ (Figure 10). Finally, over-expression of IKK $\beta$. which resulted in constitutive activation of NF-KB (Figure 8B), dose dependently blocked troponin-luciferase expression (Figure 9C), further emphasizing the causal role of $\mathrm{NF}-\mathrm{kB}$ activation in the inhibition of myogenic differentiation.
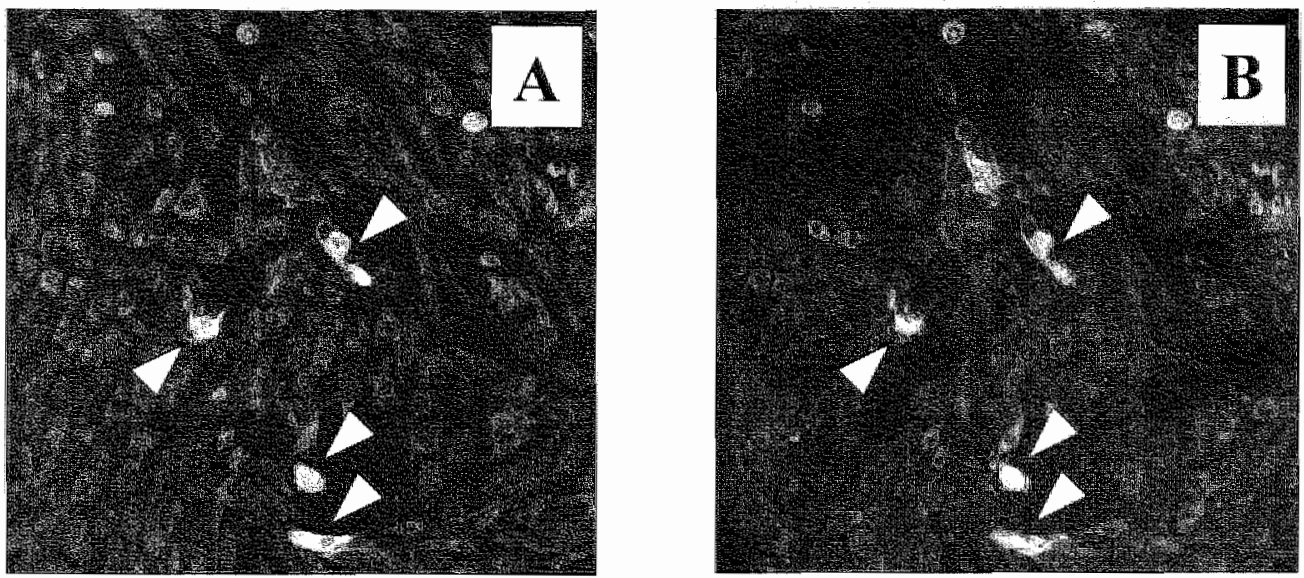

Figure 10: Inhibition of NF- $\mathrm{KB}$ restores myogenin expression in differentiating myoblasts exposed to TNFa. Cells were grown on glass coverslips and transfected with FLAG-tagged $/ \kappa B \alpha-S R$ or control vector and allowed to differentiate in the presence or absence of TNF $\alpha$. After $48 \mathrm{~h}$ in DM, cells were fixed, stained and analyzed for myogenin (Panel A) and IKB $\alpha$-SR (FLAG) (Panel B) by immunofluoresence using confocal scanning laser microscopy. Positive cells are indicated by arrowheads.

\section{DISCUSSLON}

Cachexia has been associated in many chronic wasting diseases with elevated levels of circulating inflammatory mediators, including TNFa (7-10, 31). Furthermore, chronic administration of TNF $\alpha$ or $I L-1 \beta(14)$, or the implantation of a TNF $\alpha$ producing tumor (12), results in muscle wasting. Since the involvement of catabolic hormones or other mediators could not be ruled out in those studies, it is not clear whether muscle wasting is mediated through a direct effect of these inflammatory cytokines on skeletal muscle. In the present study, the effects of TNF on $\mathrm{C} 2 \mathrm{Cl} 2$ cells during or after their differentation were analyed. Undifferentiated $\mathrm{C} 2 \mathrm{C} 12$ cells, or myoblasts, are the in viro equivalent of satellite cells, which constitute the myogenic stem cell population in postnatal skelchl muscle (32). Although present as a low percentage of total myonuclei in adult skeletal muscle, satellite cells are indispensable in the maintenance of functional muscle, since they possess the 
capacity to proliferate and differentiate to replace lost or injured muscle fibers. Our findings demonstrate dramatically different responses to TNFa in differemtiating myoblasts versus fully differentiated myotubes. First of all, when cultured in the presence of TNFo, differentiating myoblasts demonstrated a decreased protein content per dish compared to control, whereas differentiated myotubes contained more protein per dish. The latter is in contrast to a study in which a catabolic effect of TNFa on total protein content of differentiated myotubes was reported (19). Secondly, although some loss in MyHCF content and $C K$ activity was observed after exposure of myotubes to TNFo, these decreases were marginal. In contrast, addition of TNFo to differentiating myoblasts completely inhibited myogenic differentiation at concentrations of $1-10 \mathrm{ng} / \mathrm{ml}$, which have been reported in the circulation in chronic inflammatory diseases $(31,33,34)$. In support of our findings, others have also reported marked inhibitory effects of TNFa on myogenic differentiation $(18,22$, $35,36)$, and failed to demonstrate effects in differentiated myotubes (18,35). A recent study also demonstrated this differential effect of TNFo, but showed that myotubes became susceptible to TNFa once Interferon $\gamma$ was administered in addition to TNF $\alpha$ (37). This strongly indicates that a secondary signaling event is required in the sensitization of myotubes to TNF $\alpha$ and could involve the activation of STAT-1 (38).

TNFa has been shown to evoke toxic effects in a variety of cell types $(39,40)$, and proliferative responses in other cell types (41). Our study also demonstrates that in presence of TNF $\alpha_{n}$ a sub-population of myoblasts undergoes cell death when cultured in DM, which is evidenced by increased LDH levels in the medium. However, the inhibition of myogenesis was completely reversible after removal of the cytokine, indicative of a specific inhibitory effect of TNFo. We speculate that the observed cell death here may involve apoptosis of the fraction of myoblasts, which initially responded to TNF $\alpha$ by inappropriate proliferation.

In addition to TNFa, exposure of differentiating myocytes to $1 \mathrm{~L}-1 \beta(0.1-10 \mathrm{ng} / \mathrm{ml})$ allso impaired myogenesis, as indicated by decreased CK activity and MyHCf expression (data not shown). Therefore we propose that the inhibition of myogenic differentiation of satellite cells, resulting from a sustained elevation in the levels of circulating inflammatory cytokines, may constitute an important mechanism leading to muscle wasting in chronic inflammatory conditions, through impairment of the regeneration process.

Binding of TNFa and $1 \mathrm{~L}-1$ to their respective receptors can trigger multiple pathways which, dependent upon the adaptor complexes that are associated with the cytoplasmic domain, can converge at the level of the IKB-kinase (IKK) complex, resulting in the activation of $N F-K B(20)$. We tested here whether TNF $\alpha$ or IL-l-induced activation of NF$\mathbb{K} B$ was causally involved in the inhibition of myogenic differentiation. First, we demonstrated that baseline DNA binding and transcriptional activity of $N F^{-}-K B$ markedly decreased during differentiation, in agreement with findings of others $(42,43)$. More detailed analysis revealed that the overall decrease in DNA binding activity was preceded by an initial increase in $p 50$ homodimer binding acitivity. Such a transient rise of $N F-k B$ DNA binding activity during the initial phase of myogenic differentiation has been described (44). In that study it was concluded, based on additional data demonstrating a loss of myogenesis following the addition of non-specific NF-kB inhibitors, that $N F-\kappa B$ activation is required for myogenic differentiation to occur. However, $N F-k B$ transactivation was not assessed during any phase of differentiation, nor was the 
composition of the NF- $\mathrm{KB}$ complex contributing to the increased DNA binding activity identified. Since the DNA binding activity of the p50 homodimer was selectively incrensed in the initial phase of differentiation in our system, we believe that it may in fact function as a repressor of NF- $\mathrm{kB}$ dependent transcription, as the p50 subunit does not contain a transactivation domain, but is still able to occupy $N F-K B$ binding sites (45). This idea is further supported by the observation that NF- $\mathrm{KB}$ transactivation decreased during differentiation (Figure $7 B$ ). In addition, $I k B \beta$ levels increased during differentiation, whereas $I \kappa B \alpha$ abundance remained constant. The decrease in NF-kB DNA binding and transcriptional activity during differentiation coincided with increasing expression of muscle specific proteins and fusion of cells into myotubes. Others have reported that reduction of basal NF-KB activity, via retroviral transfer of $I K B \alpha-S R$ or by addition of the NF-KB inhibitor curcumin, enhanced myogenic differentiation $(43,46)$. These observations led us to further investigate the link between TNF $\alpha$ or IL-I $\beta$-induced NF- $\mathrm{KB}$ activation and the observed inhibition of myogenic differentiation. We report here that expression of $I \kappa B \alpha-S R$ in differentiating myoblasts abrogated TNF $\alpha$ or IL-1 $\beta$-induced NF- $\mathrm{kB}$ transactivation, and more importantly, restored myogenic differentiation in the presence of these cytokines, demonstrating that TNF $\alpha$ and IL-1 $\beta$ block myogenic differentiation through the activation of NF-KB. Despite equivalent activation of NF-KB in myoblasts and myotubes (Figure 7D), only myoblasts appear to be adversely affected by TNF $\alpha$, illustrating the cells are capable of responding to TNF $\alpha$ in both stages, and that the lack of effects of TNF $\alpha$ in myotubes is not the result of a loss of TNF $\alpha$ signaling. These observations are in contrast to a report that demonstrated enhanced activation of $\mathrm{NF}-\mathrm{KB}$ in $\mathrm{C} 2 \mathrm{C} 12$ myotubes compared to myoblasts, presumably due to the higher expression of TRAF-2 in the myotubes (47). Possibly, these discrepancies can be attributed to the different protocols to allow differentiation of the $\mathrm{C} 2 \mathrm{C} 12$ cells, or differences in the transfection procedures that were used. An explanation of why myocytes are uniquely susceptible to TNF $\alpha$ during differentiation may be linked to the cell cycle machinery. For example, it has been demonstrated that cyclin DI is transcriptionally regulated by $\mathrm{NF}-\mathrm{KB}$ (43). Initiation of myogenic differentiation is preceded by exit from the cell cycle, an event that requires down-regulation of cyclin D1. Therefore, activation of NF-KB by TNF $\alpha$ and subsequent expression of cyclin DI may inhibit myogenesis in myoblasts by preventing cell cycle exit, whereas expression of cyclin DI is irrelevant in myotubes, since they irreversibly reside in $\mathrm{G}_{0} / \mathrm{G}_{1}$ (48). In support of this, we observed an increase in cell number after 24 and 48 hours of culture in DM when TNFa was present (Figure 4D), which coincided with an increased fraction of cells residing in the $S$ and $G_{2} / M$ phase of the cell cycle (data not shown). Alternatively, the activity of the muscle specific basic helix loop helix transcription factors MyoD and Myl-5, which have been proven to be indispensable for myogenic differentiation (49), could be repressed as a direct consequence of $\mathrm{NF}-\mathrm{KB}$ activation. In support of the latter, it has been shown that the catalytic subunit of Protein Kinase A (PKAc) is associated with active NF- $k B$ (50), whereas another study demonstrated that PKA is capable of inactivating MyoD and Myf-5 (51). Another mechanism by which MyoD may be inhibited by NF-KB has been described very recently. In this study it was demonstrated that the MyoD mRNA half life decreased in differentiating myoblasts following TNF $\propto$ exposure, and that this depended on NF-KB regulated gene expression (37). 
In summary, we have demonstrated that the inflammatory cytokines TNF $\alpha$ and IL-1 $\beta$ interfere with myogenic differentiation. Once skeletal muscle cells have differentiated, they appear to be become relatively resistant. Therefore, it is possible that the loss of skeletal muscle associated with chronic inflammatory disease states, is the result of an inability of satellite cells to differentiate into functional fibers following damage or degeneration. Although therapeutic interventions for skeletal muscle wasting are usually designed to restore imbalances in protein anabolism and catabolism, our results suggest that intervention strategies should also be focussed on stimulation or restoration of satellite cell differentiation, since this process may be compromised under conditions of chronic inflammation. Besides the administration of agents that have been demonstrated to increase muscle mass in healthy individuals, like specific nutritional supplements, hormonal treatment or IGF-1, specific intra-cellular pathways like the activation of NF-K.B, may have to be modulated in cachectic patients for these agents to have an effect.

\section{ACKNOWLEDGEMENTS}

We thank Dr. Pam Vacek for assistance with the statistical analysis. Dries Testelmans is thanked for excellent technical support and Colette Charland (Flow Cytometry Facility, University of Vermont) for technical assistance with the flow cytometry analysis. Dr. Patrick Bauerle (Micromet, Germany), Dr. Albert Baldwin Jr. (University of North Carolina, Chapel Hill, NC), Dr. Rosa Ten (Mayo Clinic, Rochester, MN), and Dr. Micheal Karin (University of California, San Diego, La Jolla, CA) are thanked for kindly providing us with the necessary plasmids. 


\section{REFERENCES}

1. Koller, D. P., Tierney, A. R., Wang, J., and Pierson, R. N., Ir. (1989) Magnitude of bodymcell-mass depletion and the timing of death from wasting in AIDS. Aw $J$ Clin Nutr 50, 444-447

2. Argiles, J. M. and Lopez-Soriano, F. J. (1999) The role of cytokines in cancer cachexia. Med Res Rev 19, 223-248

3. Anker, S. D., Ponikowski, P., Varney, S., Chua, T. P., Clark, A. L. Webb-Peploe, K. M., Harrington, D., Kox, W. J., Poole-Wilson, P. A., and Conts, A. J. (1997) Wasting as independent risk factor for mortality in chronic heart fallure [published ematum appears in Lancet 1997 Apr 26;349(9060):1258]. Lancet 349, 1050m-1053

4. Schols, A. M., Slangen, J., Volovics, L., and Wouters, E. F. (1998) Weight loss is a reversible factor in the prognosis of chronic obstructive pulmonary disease. $A m I$ Respir Crit Care Med 157, 1791-1797

5. Wilson, D. O., Rogers, R. M., Wright, E. C., and Anthonisen, N. R. (1989) Body weight in chronic obstructive pulmonary disease. The National Institutes of Health Intermittent Positive-Pressure Breathing Trial. Am Rev Respir Dis 139, 1435-1438

6. Morrison, W. L., Gibson, J. N., Scrimgeour, C., and Rennie, M. J. (1988) Muscle wasting in emphysema. Clin Sci $75,415-420$

7. Belec, L., Meillet, D., Gresenguet, G., and Gherardi, R. K. (1995) Increased tumor necrosis factor-alpha serum levels in patients with HIV wasting syndrome and euthyroid sick syndrome [letter; comment]. I Acquir Immune Defic Syndr Hum Retrovirol $8,212-214$

8. Nakashima, J., Tachibana, M., Ueno, M., Miyajima, A., Baba, S., and Murai, M. (1998) Association between tumor necrosis factor in serum and cachexia in patients with prostate cancer. Clin Cancer Res 4, 1743-1748

9. Zhao, S. P., and Zeng, L. H. (1997) Elevated plasma levels of tumor necrosis factor in chronic heart failure with cachexia. Int J Cardiol 58, 257-261

10. Di Francia, M., Barbier, D., Mege, J. L., and Orehek, J. (1994) "Tumor necrosis factor-alpha levels and weight loss in chronic obstructive pulmonary disease. Am $J$ Respir Crit Care Med 150, 1453-1455

11. Llovera, M., Garcia-Martinez, C., Agell, N., Marzabal, M., Lopez-Soriano, P. J., and Argiles, I. M. (1994) Ubiquitin gene expression is increased in skeletal muscle of tumour-bearing rats. FEBS Lev $338,311-318$

12. Buck, M., and Chojkier, M. (1996) Muscle wasting and dedifferentiation induced by oxidative stress in a murine model of cachexia is prevented by inhibitors of nitric oxide synthesis and antioxidants. Embo $J 15,1753-1765$

13. Vary, T. C., Owens, E. L., Beers, I. K., Vener, K., and Cooney, R. N. (1996) Sepsis inhibits synthesis of myoribrillar and sarcoplasmic proteins: modulation by interleukin-1 receptor antagonist. Shock $6,13-18$

14. Fong, Y., Moldawer, L. L., Marano, M., Wei, H., Barber, A., Manogue, K., Tracey, K. J., Kuo, G., Fischman, D. A. Cerami, A., and et al. (1989) Cachectin/TNF or IL-1 alpha induces cachexia with redistribution of body proteins. Am I Physiol 256, R659665

15. Tews, D. S., and Goebel, H. H. (1997) Apoptosis-related proteins in skeletal muscle fibers of spinal muscular atrophy. J Newropathol Exp Neurol $56,150-156$ 
16. Tews, D. S., and Coebel, H. H. (1997) DNA-fragmentation and expression of apoptosis-telated proteins in muscular dystrophies. Newropathol Appl Newrobiol 23 , 331-338

17. Sugiura, T., Murakawa, Y., Nagai, A., Kondo, M., and Kobayashi, S. (1999) Fas and Fas ligand interaction induces apoptosis in inflammatory myopathies: CD4+ $\mathrm{T}$ cells cause muscle cell injury directly in polymyositis. Arthritis Rheum 42, 291-298

18. Miller, S. C.. Ito, H., Blau, H. M. and Torti, F. M. (1988) Tumor necrosis factor inhibits human myogenesis in vitro. Mol Cell Biol 8, 2295-2301

19. L.i, Y. P., Schwartz, R. J., Waddell, I. D., Holloway, B. R., and Reid, M. B. (1998) Skeletal muscle myocytes undergo protein loss and reactive oxygen- mediated NFkappaB activation in response to tumor necrosis factor alpha. Faseb $J 12,871-880$

20. Karin, M. (1999) The beginning of the end: IKappaB kinase (IKK) and NF-kappaB activation. I Biol Chem 274, 27339-27342

21. Pahl. H. L. (1999) Activators and target genes of Rel/NF-kappaB transcription factors. Oncogene 18,6853-6866

22. Layne, M. D., and Farmer, S. R. (1999) Tumor necrosis factor-alpha and basic fibroblast growth factor differentially inhibit the insulin-like growth factor-I induced expression of myogenin in C2C12 myoblasts. Exp Cell Res $249,177-187$

23. Cooncy, R., Owens, E., Jurasinski, C., Gray, K., Vannice, J., and Vary, T. (1994) Interleukin-1 receptor antagonist prevents sepsis-induced inhibition of protein synthesis. Am J Physiol 267, E636-641

24. Yaffe, D., and Saxel, O. (1977) Serial passaging and differentiation of myogenic cells isolated from dystrophic mouse muscle. Nature 270, 725-727

25. Kleinman, H. K., McGarvey, M. L., Hassell, J. R., Star, V. L., Cannon, F. B., Laurie, G. W., and Martin, G. R. (1986) Basement membrane complexes with biological activity. Biochemistry $25,312-318$

26. Szasz, G., Gruber, W., and Bernt, E. (1976) Creatine kinase in serum: 1. Determination of optimum reaction conditions. Clin Chem 22,650-656

27. Bradford, M. M. (1976) A rapid and sensitive method for the quantitation of microgram quantities of protein utilizing the principle of protein-dye binding. Anal Biochem 72, 248-254

28. Janssen, Y. M., Matalon, S., and Mossman, B. T. (1997) Differential induction of clos, c-jun, and apoptosis in lung epithelial cells exposed to ROS or RNS. Am $f$ Physiol 273, L. $789-796$

29. Kirchberger, M. (1991) Exitation and contraction of skeletal muscle. In Physiological Biasis of Medical Practice (West, I. B., ed) pp. 62-102, Williams \& Wilkins, Batlimore, MD

30. Molkentin, J. D., and Olson, E. N. (1996) Defining the regulatory networks for muscle development. Cur Opin Genet Dev 6, 445-453

31. Roubenoff, R., Roubenof,, R. A., Ward, L. M., Holland, S. M., and Hellmann, D. B. (1992) Rheumatoid cachexia: depletion of lean body mass in rheumatoid arthritis. Possible association with tumor necrosis factor. J Rheumatol 19, 1505-1510

32. Yablonka-Reuveni, $Z$. (1995) Development and postnatal regulation of adult myoblasts. Microsc Res Tech 30, 366-380 
33. Vreugdenhil, G., Lowenberg, B., Van Eijk, H. G., and Swak, A. I. (1992) Tumor necrosis factor alpha is associated with disease activity and the degree of anemia in patients with rheumatoid arthritis. Eur J Clin Invest 22, 488-493

34. Nakashima, J., Tachibana, M., Ueno, M., Baba, S., and Tazaki, H. (1995) Tumor necrosis factor and coagulopathy in patients with prostate cancer. Cancer Res 55 , $4881-4885$

35. Ji, S. Q., Neustrom, S., Willis, G. M., and Spurlock, M. E. (1998) Proinflammatory cytokines regulate myogenic cell proliferation and fusion but have no impact on myotube protein metabolism or stress protein expression. I Interferon Cytokine Res $18,879-888$

36. Szalay, K., Razga, Z., and Duda, E. (1997) TNF inhibits myogenesis and downregulates the expression of myogenic regulatory factors myoD and myogenin. Eur J Cell Biol 74, 391-398

37. Guttridge, D. C., Mayo, M. W., Madrid, L. V., Wang, C. Y., and Baldwin, A. S., Jr. (2000) NF-kappaB-induced loss of MyoD messenger RNA: possible role in muscle decay and cachexia [see comments]. Science 289, 2363-2366

38. Wang, Y., Wu, T. R., Cai, S., Welte, T., and Chin, Y. E. (2000) Statl as a component of tumor necrosis factor alpha receptor 1-TRADD signaling complex to inhibit NFkappaB activation. Mol Cell Biol 20, 4505-4512

39. Wallach, D., Varfolomeev, E. E., Malinin, N. L., Goltsev, Y. V., Kovalenko, A. V., and Boldin, M. P. (1999) Tumor necrosis factor receptor and Fas signaling mechanisms. Annu Rev Immunol 17, 331-367

40. Tartaglia, L. A., Rothe, M., Hu, Y. F., and Goeddel, D. V. (1993) Tumor necrosis factor's cytotoxic activity is signaled by the p55 TNF receptor. Cell 73, 213-216

41. Cornelius, P., Marlowe, M., Lee, M. D., and Pekala, P. H. (1990) The growth factorm like effects of tumor necrosis factor-alpha. Stimulation of glucose transport activity and induction of glucose transporter and immediate early gene expression in 3T3-L/ preadipocytes [published erratum appears in J Biol Chem 1991 Feb 25;266(6):4023]. $J$ Biol Chem 265, 20506-20516

42. Lehtinen, S. K., Rahkila, P., Helenius, M., Korhonen, P., and Salminen, A. (1996) Down-regulation of transcription factors $\mathrm{AP}-1, \mathrm{Sp}-1$, and $\mathrm{NF}$-kappa $\mathrm{B}$ precedes myocyte differentiation. Biochem Biophys Res Commun 229, 36-43

43. Guttridge, D. C., Albanese, C., Reuther, J. Y., Pestell, R. G., and Baldwin, A. S., Jr. (1999) NF-kappaB controls cell growth and differentiation through transcriptional regulation of cyclin D1. Mol Cell Biol 19, 5785-5799

44. Kaliman, P., Canicio, J., Testar, X., Palacin, M., and Zorzano, A. (1999) Insulin-like growth factor-1I, phosphatidylinositol 3-kinase, nuclear factor-kappaB and inducible nitric-oxide synthase define a common myogenic signaling pathway. $f$ Biol Chem $274,17437-17444$

45. Ghosh, S., May, M. J., and Kopp, E. B. (1998) NF-kappa B and Rel proteins: evolutionarily conserved mediators of immune responses. Annu Rev Immunol 16, 225-260

46. Thaloor, D., Miller, K. I., Gephart, J., Mitchell, P. O., and Pavlath, G. K. (1999) Systemic administration of the NF-kappaB inhibitor curcumin stimulates muscle regeneration after traumatic injury. Am J Physiol 277, C320-329 
47. MacLachlan, T. K., and Giordano, A. (1998) TRAF2 expression in differentiated muscle. J Cell Biochem 71, 461-466

48. Olson, E. N. (1992) Interplay between proliferation and differentiation within the myogenic lineage. Dev Biol 154, 261-272

49. Rudnicki, M. A., Schnegelsberg, P. N., Stead, R. H., Braun, T., Arnold, H. H., and Jaenisch, R. (1993) MyoD or Myf-5 is required for the formation of skeletal muscle. Cell 75, 1351-1359

50. Zhong, H., SuYang, H., Erdjument-Bromage, H., Tempst, P., and Ghosh, S. (1997) The transcriptional activity of NF-kappaB is regulated by the IkappaB-associated PKAc subunit through a cyclic AMP-independent mechanism. Cell 89, 413-424

51. Winter, B., Braun, T., and Arnold, H. H. (1993) cAMP-dependent protein kinase represses myogenic differentiation and the activity of the muscle-specific helix-loophelix transcription factors Myf-5 and MyoD. J Biol Chem 268, 9869-9878 


\title{
CHAPTER 5
}

\section{Tumor necrosis factor alpha inhibits myogenesis through redox dependent and independent pathways}

\begin{abstract}
Muscle wasting accompanies diseases that are associated with chronic elevated levels of circulating inflammatory cytokines and oxidative stress. We previously demonstrated that tumor necrosis factor alpha (TNF $\alpha$ ), inhibits myogenic differentiation via the activation of Nuclear Factor kappa B (NF-kB). The goal of the present study was to determine whether this process depends on the induction of oxidative stress. We demonstrate here that TNF $\alpha$ causes a decrease in reduced glutathione (GSH) during myogenic differentiation of $\mathrm{C} 2 \mathrm{Cl} 2$ cells, which coincides with an elevated generation of reactive oxygen species (ROS). Supplementation of cellular GSH with $\mathrm{N}$-acetyl-L-cysteine (NAC) did not reverse the inhibitory effects of TNF $\alpha$ on troponin I (Tnl) promoter activation, and only partially restored creatine kinase (CK) activity in TNF $\alpha$-treated cells. In contrast, the administration of NAC prior to treatment with TNFa almost completely restored the formation of multinucleated myotubes. NAC decreased TNF $\alpha$-induced activation of NF-kB only marginally, indicating that the redox-sensitive component of the inhibition of myogenic differentiation by TNF $\alpha$ occurred independently, or downstream of NF-kB. Our observations suggest that the inhibitory effects of TNF $\alpha$ on myogenesis can be uncoupled in a redox sensitive component affecting myotube formation, and a redox independent component affecting myogenic protein expression.
\end{abstract}

Ramon C.J. Langen', Annemie M.W.J. Schols', Marco C.J.M. Kelders', Jos L.J. van aler Velden', Emich F.M. Wouters' and Yvonne M.W. Janssen-Heininger ${ }^{2}$. Departments of 'Respiratory Medicine, Maastricht University, Mastricht, The Netherlands, and "Pathology, University of Vermont, Burlington VT, USA. Am of Physiol Cell Physiol 2002; 283: C714 721. 


\section{INTRODUCTION}

Muscle wasting (cachexia), a syndrome characterized by the disproportional loss of skeletal muscle, is a frequent complication in many chronic diseases, including chronic obstructive pulmonary disease (COPD) (1-3), cystic fibrosis (4), chronic heart failure (CHF) (5), renal failure (review) (6), AIDS (7), and cancer (8). There is increasing interest in improving the treatment of cachexia, since it is an independent predictor of morbidity and mortality in many of these disease states. Targeted treatment strategies however, require insight into the etiology of muscle wasting. Imbalances in protein anabolism/catabolism and muscle injury and repair have been hypothesized to be involved. Inflammatory cytokines appear to be critical mediators of cachexia, based upon observations that muscle wasting syndromes are often accompanied by elevated levels of tumor necrosis factor alpha (TNF $\alpha$ ) and interleukin-1 (IL-1) (9-12). Furthermore, administration of these cytokines is sufficient to induce muscle wasting in rodents (13, 14). Previously we demonstrated that TNF $\alpha$ or IL-1 inhibit myogenic differentiation in a mouse line of myoblasts $(\mathrm{C} 2 \mathrm{C} 12$ cells), which suggested that inhibition of muscle regeneration may contribute to cachexia (15). The cytokine-induced inhibition of myogenic differentiation was causally linked to the activation of the transcription factor, Nuclear Factor kappa $B(N F-\kappa B)$.

$N F-k B$ is considered the master regulator of inflammatory responses. It transcriptionally activates many genes important in inflammation, immune function, anti-apoptotic responses, proliferation and matrix turnover (16). NF- $\mathrm{kB}$ resides in a latent form in the cytoplasm where it is bound to the inhibitory protein of NF-kB, IKB. Upon stimulation, a rapid and transient activation of $I K B$ kinases (IKK) occurs which phosphorylate $\mathbb{I} K \mathbb{B}$, resulting in subsequent ubiquitination and rapid degradation via the $26 \mathrm{~S}$ proteasome pathway. The liberation from $1 \kappa B$ unmasks the nuclear localization sequence of $N F-\kappa B$ permitting it to translocate to the nucleus, causing it to bind its recognition sequence and activate transcription (17).

Oxidative stress has also been implicated in the activation of $\mathrm{NF}-\mathrm{kB}$, based upon many studies demonstrating that antioxidants or metal scavengers prevent cytokine induced activation of NF-KB and that the addition of oxidants to certain cell types, including skeletal muscle is sufficient to induce its activation $(18,19)$. In addition, exposure of cultured skeletal myocytes to inflammatory cytokines resulted in the generation of reactive oxygen and nitrogen species $(20,21)$. Importantly, oxidative stress also may play a role in muscle weakness and wasting, since it has been reported to affect skeletal muscle in various ways. For instance, reactive oxygen species (ROS) may contribute to fatigue and decreased force generation through modification of sarcoplasmic reticulum function, alterations in mitochondrial respiration, and even direct oxidation of critical sulfhydryl groups on contractile proteins, which may in turn result in the enhanced degradation of these myofibrillar proteins $(22,23)$. Moreover, nitric oxide appears to contribute to muscle wasting in an experimental model using the implantation of TNF $\alpha$ producing Chinese Hamster Ovary (CHO) cells that resulted in up regulation of inducible nitric oxide synthase (iNOS). Consequently, chemical inhibitors of iNOS reversed the loss of muscle specific gene expression observed in cachectic mice (13).

The goal of the present study was to determine whether oxidative stress plays a role in the inhibition of myogenic differentiation following treatment with TNF $\alpha$, and whether this 
occurs wia the activation of NF-kB. We explored these questions by using the glutathone precursor and antioxidant, $\mathrm{N}$-acetyl-L-cysteine (NAC), which is known to reduce the activation of $\mathrm{NF}-\mathrm{KB}$ in response to TNF $\alpha$ (18). Our results demonstrate that momphological aspects of myogenic differentiation, i.e. the formation of myotubes could be restored by NAC following exposure to TNF $\alpha$, and that this occurred independently of NF-KB.

\section{MATERIALS AND METHODS}

\section{Cell culture}

The murine skeletal muscle cell line C 2 C 12 was obtained from the American Type Culture Collection (ATCC + CRL 1772, Manassas, VA). These cells are capable of differentiating into contracting myotubes upon withdrawal of growth factors following cell cycle exit (24). Myoblasts were cultured in growth medium (GM) consisting of low glucose Dulbecco" Modified Eagle Medium containing antibiotics $(50 \mathrm{U} / \mathrm{ml}$ Penicillin and $50 \mu \mathrm{g} / \mathrm{ml}$ Streptomycin) and 9\% (v/v) Fetal Bovine Serum (FBS) (all from Life Technologies, Rockville, MD). For experiments, $60 \mathrm{~mm}$ dishes (Becton Dickinson Labware, Bedford, MA) were coated with Matrigel (Becton Dickinson Labware, Bedford, MA), which contains collagen IV, laminin, heparan sulfate proteoglycan and entactin. Plating on Matrigel resulted in enhanced and more consistent differentiation, compared to frequently used protocols that employ $2 \%$ horse serum containing media (manuscript submitted for publication). Cells were plated at $10^{4} / \mathrm{cm}^{2}$ and cultured in $\mathrm{GM}$ for $24 \mathrm{~h}$, allowing them to reach $\sim 60 \%$ confluency. To induce differentiation, cells were washed in Hank's balanced salt solution (HBSS) and cultured in differentiation media (DM) containing DMEN low glucose, antibiotics and $0.5 \%$ heat inactivated. FBS. To study the effects on differentiation, one single dose of murine TNF $\alpha$ (Calbiochem, La Jolla, CA) was added to the culture dishes directly after induction of differentiation. To study the effects of oxidative stress per se, cells were treated with $20-200 \mu \mathrm{M} \mathrm{H}_{2} \mathrm{O}_{2}$ (Sigma), which was added as a bolus directly after induction of differentiation. Cells were examined with an inverted phase contrast microscope (Olympus CH40, Melville, NY), equipped with a camera (Nikon N6000).

\section{Treatment with N-Acetyl-L-Cysteine (NAC) and determination of redaced glurathione and oxygen radical generation}

For the supplementation of cellular glutathione (GSH) levels, cells were cultured in GM with various concentrations of NAC 16-24h prior to induction of differentiation. For determination of cellular GSH, cells were collected by trypsinization, centrifuged for 10 minutes at $500 \times \mathrm{g}$ at $4^{\circ} \mathrm{C}$, and washed twice in ice cold PBS. Next, pelleted cells were resuspended in $\mathrm{PBS}$, and an aliquot was taken for determination of total protein. The remaining fraction was centrifuged and the pelleted cells were lysed in 25\% TCA-phosphate buffer. The cell llysate was further diluted in 3 volumes of phosphate buffer and centrifuged at $16000 \mathrm{x} \mathrm{g}$ at $4^{\circ} \mathrm{C}$ for 2 minutes. $1 / 20$ volume of $O$-Phtalaldehyde $(\mathrm{OPT}, 1 \mathrm{mg} / \mathrm{ml}$ in methanol, Sigma, Saint Louis, MO) was added to a suitable volume of supernatant, and total GSH was measured as a fluorescent product of the reaction with OPT as described by Cohn and Lyle (25). To normalize for potential differences in cell numbers, glutathione values were corrected for total protein. ROS production was assessed by the use of the oxidant sensitive fluorescent probe 2",7'-dichlorofluorescein diacetate, $\mathrm{H}_{2} \mathrm{DCF}-\mathrm{DA}$ (Molecular 


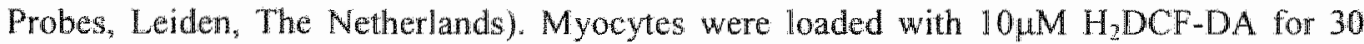
minutes, washed twice in ice-cold PBS and lysed in the dark in 200 ul luciferase lysis buffer (Promega, Madison, WI). The lysate was further diluted in $800 \mu \mathrm{H}_{2} \mathrm{O}$ and centrifuged for 3 minutes $(49 \mathrm{C}, 12000 \mathrm{xg})$. Fluorescence was determined in the supernatants at $\lambda_{\text {nex }} 500 / \lambda_{\text {enn }}$ $530 \mathrm{~nm}$.

\section{Assessment of myogenic differentiation}

To assess the extent of myogenic differentiation morphologically, the myogenic index, which is defined as the fraction of nuclei residing in cells containing three or more nuclei, was assessed following staining with May-Grunwald Giemsa (Sigma, Saint Louis, MO). Additionally, we determined muscle creatine kinase (CK) activity and the expression of the fast twitch isotype of myosin heavy chain (MyHCf) or myogenin as markers differentiation by Western Blotting, according to procedures described previously (15). Monoclonal antibodies specific for MyHCf $(\mathrm{MY}-32)$ or myogenin (M-225) were obtained from Sigma, (Saint Louis, MO) and Santa Cruz, (Santa Cruz, CA), respectively.

\section{Electrophonetic mobility shift analysis (EMSA)}

The ability of $\mathrm{NF}-\mathrm{KB}$ to bind to its consensus recognition sequence was evaluated in electrophoretic mobility shift assays (EMSA) as described previously (15). $2 \mu \mathrm{g}$ of nuclear protein was used per binding reaction and protein-DNA complexes were resolved on a $5 \%$ polyacrylamide gel in $0.25 X$ Tris-borate-EDTA buffer at $120 \mathrm{~V}$ for 2 hours. Gels were dried and exposed to film (X-Omat Blue XB-1, Kodak, Rochester, NY). Shifted complexes, indicative of NF-KB complexes were evaluated by phospho-imager analysis (Biorad, Hercules, CA) and their sub-composition was verified using antibodies recognizing p50 and RelA subunits of NF-kB (Santa Cruz, Santa Cruz, CA).

\section{Transfections and plasmids}

For the assessment transcriptional activity of NF-kB during differentiation, stable cell lines were created, as is described elsewhere (15). Using identical procedures we also created a cell line that stably expresses the Troponin I (TnI) promoter driven luciferase reporter in order to assess muscle specific gene transcription. To determine luciferase acitivity, cells were lysed in luciferase lysis buffer and stored at $-80^{\circ} \mathrm{C}$. Luciferase activity was measured according to manufacturers' instructions (Promega, Madison, Wh) and values were corrected for total protein content.

\section{Strotistical analysis}

Raw data were entered into SPSS (version 8.0) for statistical analysis. Values for CK activity, myogenic index, and luciferase activity were subjected to one-way analysis of variance, and the various treatment groups were compared post-hoc with a StudentNewman-Kauls test $(\mathbb{P}<0.05)$. 


\section{RESULTS}

\section{TNF $\alpha$ inhibits myogenic differentiation and affects cellular redox status}

Myogenic differentiation of $\mathrm{C} 2 \mathrm{C} 12$ cells is a process characterized by the expression of muscle specific genes, like myosin heavy chain (MyHC), creatine kinase (CK), myogenin, and the fusion of myocytes into multinucleated myotubes. We previously established that the cytokine, TNF $\propto$ inhibits myogenic differentiation of $\mathrm{C} 2 \mathrm{Cl} 2$ cells (15). To illustrate this effect, CK activity was assessed $72 \mathrm{~h}$ following induction of differentiation, as we determined earlier that $\mathrm{CK}$ activity is markedly induced at this time point (15). In addition, measuring Troponin I Tnl) promoter activation using a $\mathrm{C} 2 \mathrm{C} 12$ cell line containing a Tnlluciferase reporter gene, provided us with an earlier marker of myogenesis.

A

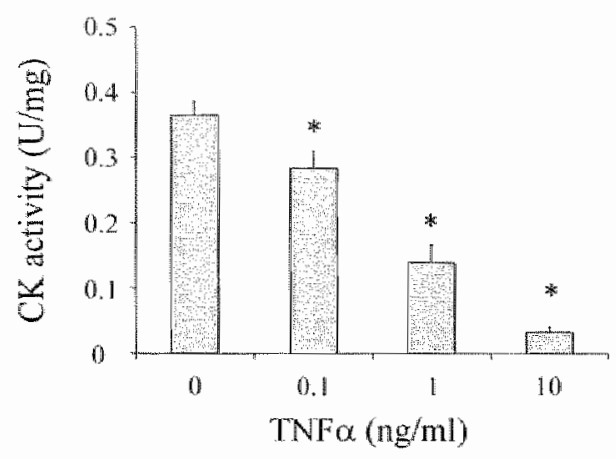

C

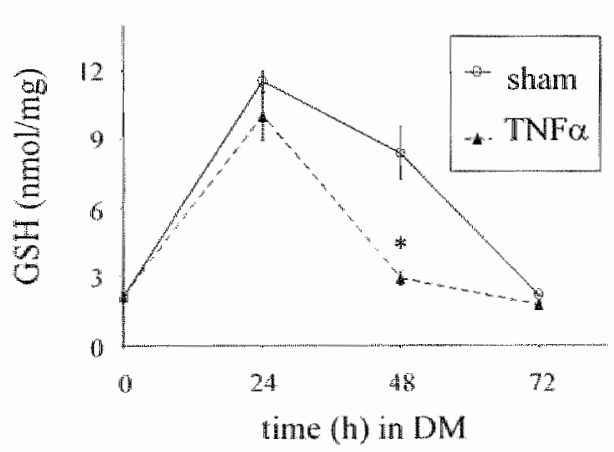

B

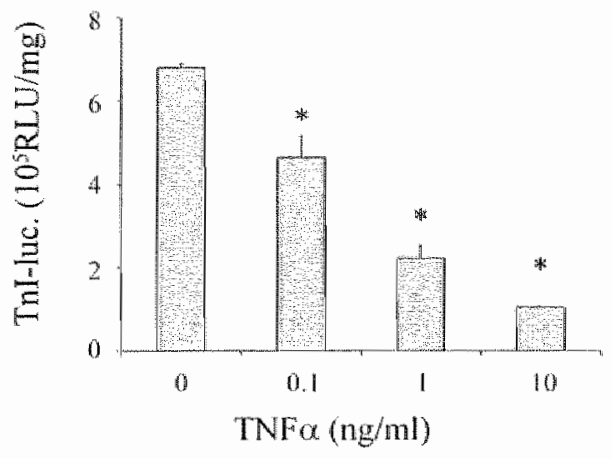

D

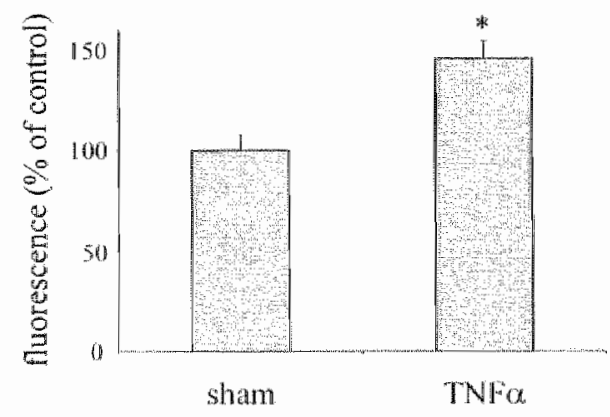

Figure 1: TNFa inhibits myogenic differentiation and affects cellular redox status. Myoblasts were allowed to differentiate in presence or absence of TNFo, administered once at the indicated concentrations. After $72 \mathrm{~h}$, CK activity was determined and expressed per $\mathrm{mg}$ protein $\left(n=3 \pm S E M_{*}, p<0.001\right)(\mathrm{A})$. Alternatively, Tnl promoter activation was measured in a $\mathrm{Tnl}$ reporter line (sec materials and methods) as luciferase activity $(n=2+S E M, *=0.01)$ and normalized to protein after 48 h of culture in DM with or without TNFa (B). GSH levels were assessed and nomalized to protein every $24 \mathrm{~h}$ during differentiation $(\mathrm{n}=3 \pm \mathrm{SEM}, * \mathrm{p}<0.001)$ in parental $\mathrm{C} 2 \mathrm{C} 12$ cells that were cultured in the presence or absence of TNFa $(10 \mathrm{ng} / \mathrm{ml})(\mathrm{C})$. Myocytes were loaded with DCF (10 HM for 30 minutes) after $24 \mathrm{~h}$ of differentiation in presence or absence of TNF $\alpha(10 \mathrm{ng} / \mathrm{ml})$. Fluorescence was determined in the supernatants of the cell lysates and expressed as \% of control $(n=3 \pm S E M, *=0<0.02)$ (D). Shown are representative graphs of 3 or more indenendent exneriments. 
Potent induction of luciferase activity is already apparent $48 \mathrm{~h}$ after induction of differentiation ( $21.5 \pm 4.4^{*} 10^{5} \mathrm{RLU} / \mathrm{mg}$ protein vs. $3.8 \pm 1.0^{*} 10^{5} \mathrm{RLU} / \mathrm{mg}$ protein in cultures maintained in GM). The results in Figure 1 demonstrate an extensive decrease in creatine kinase activity (IA), as well as the inhibition of transactivation of the troponin I (TnI) promoter (IB) when TNFa was administered at the onset of the differentiation process.

Since TNF $\alpha$ is known to cause oxidative stress, we next assessed the reduced glutathione (GSH) content of $\mathrm{C} 2 \mathrm{C} 12$ cells in presence or absence of TNFa. During the first 24 hours of differentiation, a three-fold increase in GSH levels occurred (Figure IC). This increase was transient, and after 72 hours of differentiation, levels of GSH returned to baseline. Importantly, in the presence of $10 \mathrm{ng} / \mathrm{ml}$ of TNF $\alpha$, GSH levels also increased during the first 24 hours, but decreased more rapidly compared to sham controls, almost completely returning to baseline by 48 hours. This coincided with increased DCF oxidation in the myocytes differentiated in the presence of TNF $\alpha$ (Figure 1D), further indicative of oxidative stress following TNF $\alpha$ treatment.

A

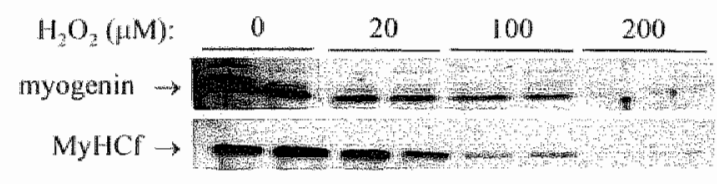

B

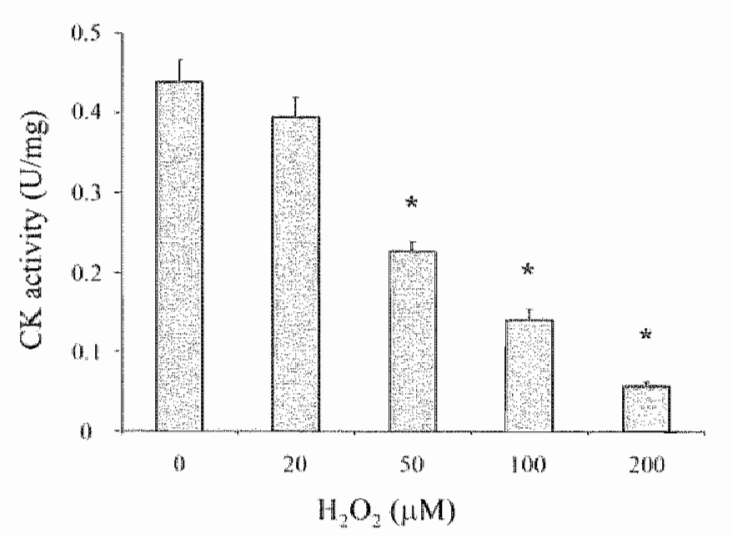

C

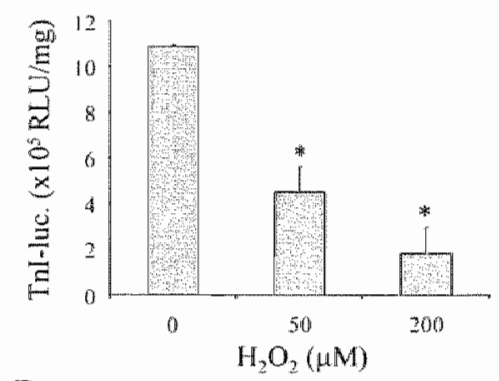

D

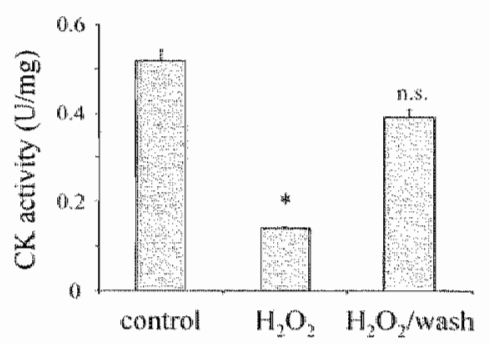

Vigure 2: Induction of oxidative stress by hydrogen peroxide inhibits myogenic differentiation. Myocytes were cultured in the presence or absence of increasing concentrations of $\mathrm{H}_{2} \mathrm{O}_{2}$, which was added directly after induction of differentiation. After $72 \mathrm{~h}$, lysates were prepared and equal amounts of protein were separated by SDS-PAOE and subjected to Western blot analysis for myogenin and MyHCF expression (A). Separate lysates were prepared for determination of CK activity ( $n=3 \pm S E M ; *=p<0.001$ ), which was normalized to total protein (B). Alternatively, myocytes of the Tnl reporter line were allowed to differentiate for 484 in various concentrations of $\mathrm{H}_{2} \mathrm{O}_{2}$, after which lysates were prepared to assess Tnl promoter activation. Luciferase activity $(\mathrm{n}=2 \pm \mathrm{SEM} ; * \mathrm{p}<0.00 \mathrm{l})$ was expressed per mg protein (C). Myocytes were cultured in DM in absence or presence of $200 \mu \mathrm{M} \mathrm{H}_{2} \mathrm{O}_{2}$ for $72 \mathrm{~h}$ (control and $\mathrm{H}_{3} \mathrm{O}_{3}$, respectively). Alternatively. the DM of $\mathrm{H}_{2} \mathrm{O}_{2}$-treated myocytes was replaced after $48 \mathrm{~h}$ with fresh $\mathrm{DM}$, followed by an additional $72 \mathrm{~h}$ incubation ( $\mathrm{H}_{2} \mathrm{O}_{2} /$ wash) after which $\mathrm{CK}$ was determined $(\mathrm{n}=3 ; *=\mathrm{p}<0.04$ and $\mathrm{n} . \mathrm{s}=\mathrm{non}$ significant compared to control). Shown are representative graphs of 3 or more independent experiments. 


\section{Induction of oxidative stress by hydrogen peroxide imhibits myogenic differentation}

We next determined whether the induction of oxidative stress by the addition of the oxidant, hydrogen peroxide $\left(\mathrm{H}_{2} \mathrm{O}_{2}\right)$ mimicked the inhibitory effects of TNFo on differentiation. As is demonstrated in Figure 2, $\mathrm{H}_{2} \mathrm{O}_{2}$ administered as a bolus in concentrations ranging from 20 $200 \mu \mathrm{M}$ decreased myosin heavy chain-fast and myogenin expression (Figure $2 \mathrm{~A}$ ), inhibited $\mathrm{CK}$ activity and TnI-gene transcription (Figure $2 \mathrm{~B}$ and $\mathrm{C}$ ), and blocked myotube formation (Figure $3 \mathrm{C}$ below), illustrating that the process of myogenic differentiation is blocked by oxidative stress per se. To assure that the lack of differentiation is not the result of nonspecific toxicity of $\mathrm{H}_{2} \mathrm{O}_{2}$, the DM of myocytes treated with $\mathrm{H}_{2} \mathrm{O}_{2}$ was replaced after $48 \mathrm{~h}$ and CK activity was evaluated after an additional $72 \mathrm{~h}$ in DM. As shown in Figure 2D, $72 \mathrm{~h}$ after replacing the DM medium CK activity was almost equal to that of control myocytes that had differentiated for $72 \mathrm{~h}$, illustrating that the inhibition of differentiation by $\mathrm{H}_{2} \mathrm{O}_{2}$ was not the result of non-specific cell death.

A

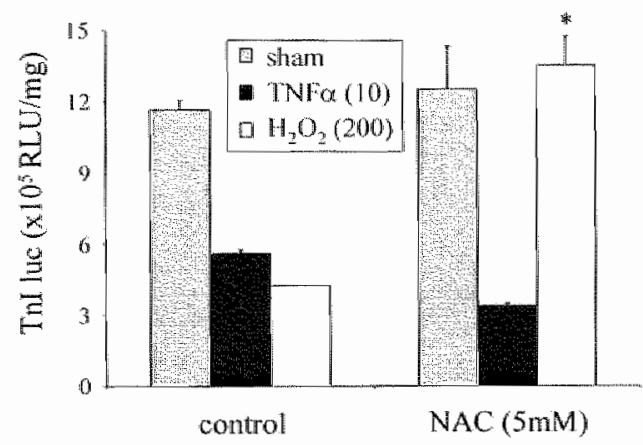

B

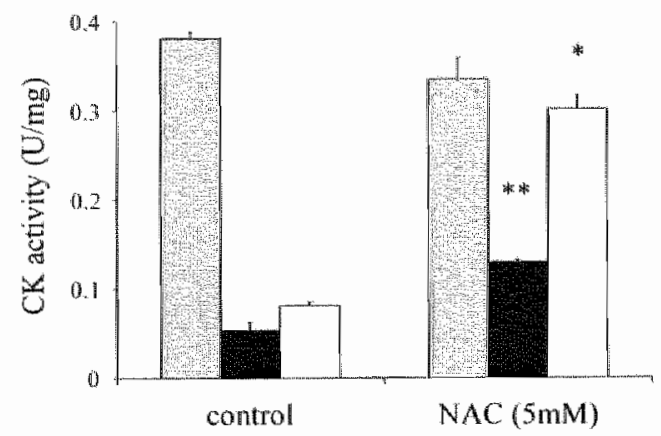

$\mathbb{C}$
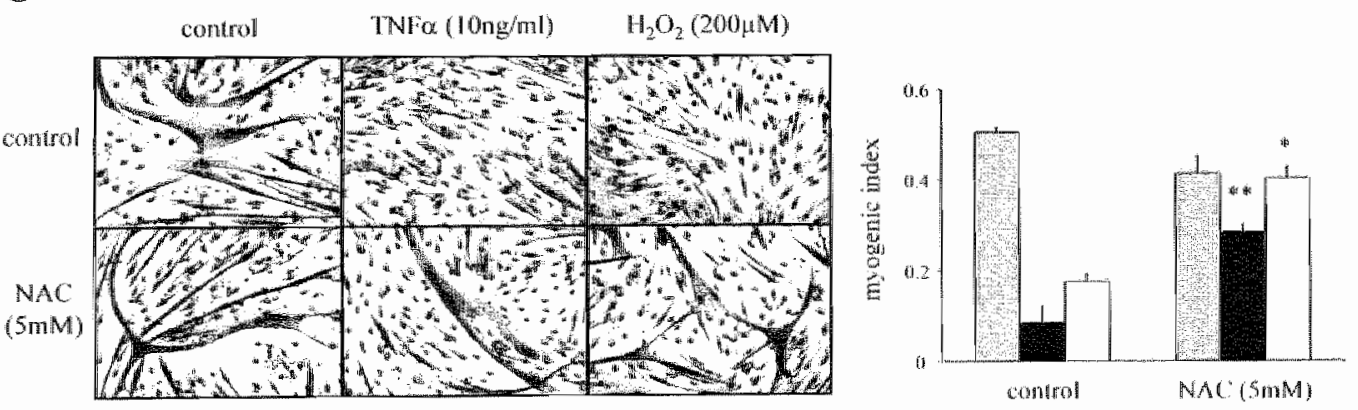

Figure 3: NAC reverses certain aspects of the inhibition of myogenesis by TNFa. Cells were cultured in GM in presence or absence of $5 \mathrm{mM} \mathrm{NAC} \mathrm{(a} \mathrm{concentration} \mathrm{that} \mathrm{did} \mathrm{not} \mathrm{affect} \mathrm{myogenic} \mathrm{differentiation).}$ After $24 \mathrm{~h}$, myocytes were washed and allowed to differentiate in the presence or absence of TNF $(10 \mathrm{ng} / \mathrm{ml})$, or $\mathrm{H}_{2} \mathrm{O}_{2}(200 \mu \mathrm{M})$ as a positive control to test the efficacy of $\mathrm{NAC}$ supplementation to prevent oxidative stress. For the assessment of Thil promoter activation, myocytes of the Thl reporter line were lysed after $48 \mathrm{~h}$ in DM and corrected for total protein $(\mathrm{n}=2 \pm \mathrm{SEM})$. (A). Parental $\mathrm{C} 2 \mathrm{C} 12$ cells were assessed for CK. activity after $72 \mathrm{~h}$ in DM ( $\mathrm{n}=2 \pm \mathrm{SEM}$ ) (B), or micrograpths ( $\times 200)$ were taken and the myogenic index was determined $(\mathrm{n}=3 \pm \mathrm{SEM})(\mathrm{C})$. Statistical analysis by 2 -way ANOVA demonstrated the following interactions: for Tnl-lue (A)*: $p=0.019$; for $\mathrm{CK}$ activity $(\mathrm{B}) *: \mathrm{p}=0.001$, and **: $\mathrm{p}=0.01$; for the myogenic index (C) *: $p=0.003$, and $* * 0=0.003$. Shown are representative graphs of 3 or more independent experiments. 


\section{Redox modulation reverses certain aspects of TNFa-mediated inhibition of myogenesis}

Next, we investigated whether boosting cellular GSH prior to induction of differentiation would restore myogenic differentiation in cells exposed to TNFa or $\mathrm{H}_{2} \mathrm{O}_{2}$. To this end, the myoblasts were incubated in GM for $24 \mathrm{~h}$ with the glutathione precursor $\mathrm{N}$-acetyl-L-cysteine (NAC) at a $5 \mathrm{mM}$ concentration, which did not modulate myogenesis (Figure 3), but enhanced intracellular glutathione levels (control vs. $5 \mathrm{mM}$ NAC: $8.4 \pm 0.8$ vs. $28.1 \pm 2.5$ nmol GSH/mg protein). As demonstrated in Figure 3, NAC completely restored all aspects of myogenic differentiation in cells treated with $\mathrm{H}_{2} \mathrm{O}_{2}$. However, pre-incubation with $\mathrm{NAC}$ did not restore Tnl promoter activation following treatment of TNF $\alpha$ (Figure $3 \mathrm{~A}$ ) and only marginally attenuated TNF $\alpha$ dependent inhibition of CK (Figure 3B). Surprisingly, the ability to fuse into multinucleated myotubes was almost completely restored in TNF $\alpha$ treated cells following pre-treatment with NAC (Figure $3 \mathrm{C}$ ). These results illustrate that the inhibition of myogenic differentiation observed after TNF $\alpha$ exposure is partially dependent on alterations in cellular thiol pools.

A

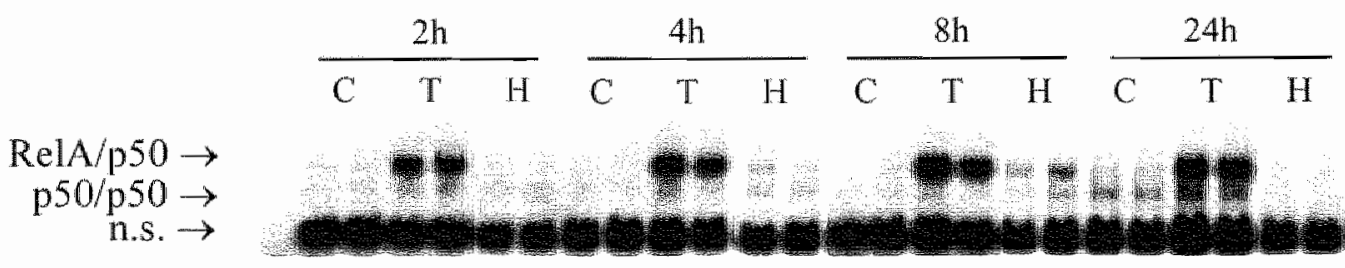

B

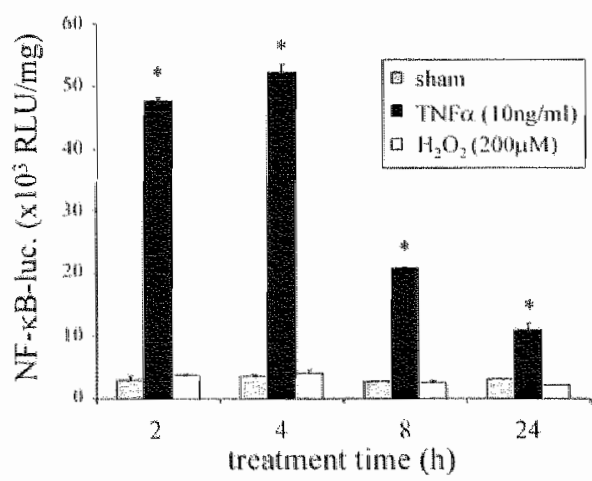

$\mathrm{C}$

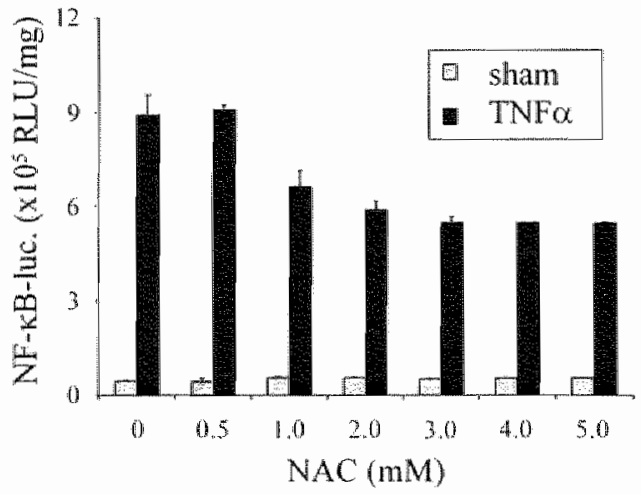

Figure 4: $\quad \mathrm{NF}-\mathrm{kB}$ activation in $\mathrm{C2Cl} 2$ myocytes is redos-independent. Directly after induction of differentiation, $\mathrm{C} 2 \mathrm{C} 12$ cells were treated for the indicated time frames with $10 \mathrm{ng} / \mathrm{ml}$ TNFo ('T') or $200 \mu \mathrm{M}$ $\mathrm{H}_{2} \mathrm{O}_{2}\left(\mathrm{H}^{\circ}\right)$, and compared to controls $\left(\mathrm{C}^{\circ}\right)$ for DNA binding activity using EMSA $(\mathrm{A})$; n.s. is non-specific binding. Myocytes of a $\mathrm{NF}-\mathrm{kB}$ reporter cell line ( $6 \mathrm{kB}$ TK-luciferase) were treated with TNFon $\mathrm{H}_{2} \mathrm{O}_{2}$, and assessed for NF $-\mathrm{K} B$, transactivation ( $\mathrm{n}=2 \pm \mathrm{SEM}, *=\mathrm{p}<0.00 \mathrm{I})$ (B). Alternatively, myoblasts were cultured in the presence of NAC for $24 \mathrm{~h}$, and subsequently stimulated with TNFo $(10 \mathrm{ng} / \mathrm{ml})$. Lysates were prepared to assess $\mathrm{NF}-\mathrm{k} B$ dependent luciferase activity (C). Shown are representative graphs of 2 or more independent experiments. 


\section{NF-KB activation in C2C12 myocyles is redox-independent}

Since NF-KB has been shown to be redox sensitive, and its activation frequently is preventable by $\mathrm{NAC}$ (26), we next determined whether the ability of NAC to reverse the inhibition of myogenic differentiation following exposure to $\mathrm{H}_{2} \mathrm{O}_{2}$ or TNF $\alpha$ was related to the modulation of $\mathrm{NF}-\mathrm{KB}$. We first determined the ability of $\mathrm{NF}-\mathrm{kB}$ to bind to its cognate DNA sequence and transactivate gene expression in cells treated with TNF $\alpha$ or $\mathrm{H}_{2} \mathrm{O}_{2}$. Results in Figure 4 demonstrate a marked binding of RelA and $550 \mathrm{NF}-K B$ subunits to DNA following exposure to TNFa which coincided with transactivation of a NF-KB dependent luciferase reporter gene. Surprisingly, $\mathrm{H}_{2} \mathrm{O}_{2}$ concentrations that interfered with myogenic differentiation induced no, or small increases in NF-KB DNA binding (Figure 4A). Only at 4 and 8 hours following $\mathrm{H}_{2} \mathrm{O}_{2}$ a minor induction ( 1.3 and 2.2 fold over control, respectively) could be detected. However, this was not reflected in $N F_{-k B}$ transcriptional activation, as luciferase activity demonstrated no changes following $\mathrm{H}_{2} \mathrm{O}_{2}$ over the time frame examined (Figure 4B). These data illustrate that oxidative stress inhibits myogenic differentiation via a pathway independent or downstream of NF-KB. Lastly, we determined whether NAC was able to inhibit NF-KB activation in ceils exposed to TNFa. Importantly and consistent with its inability to fully restore myogenic differentiation in presence of TNF $\alpha$, NAC only partially prevented $N F-\kappa B$ activation in TNFo-exposed cells (Figure $4 \mathrm{C}$ ).

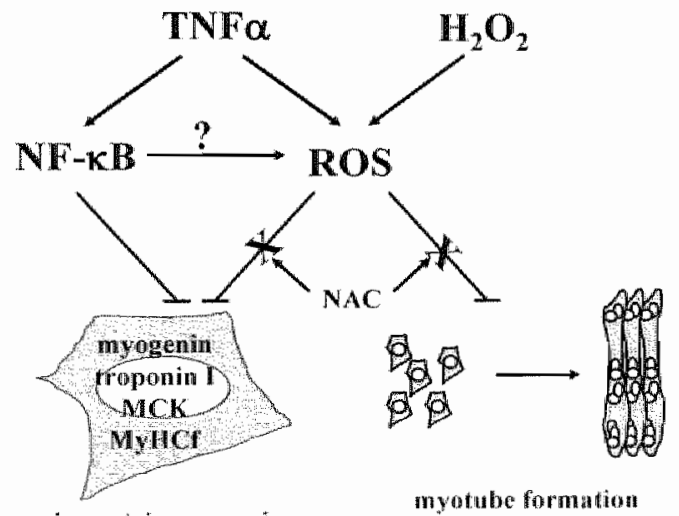

myogenic protein expression
Figure 5. Multiple redox dependent and independent pathways inhibit myogenic differentiation. Oxidative stress induced by hydrogen peroxide inhibits myogenesis at both, the level of muscle specific protein expression and nyotube fusion, in the absence of $\mathrm{NF}-\mathrm{K} \mathrm{B}$ activation. In contrast, inhibition of muscle protein expression by TNFo does not depend on oxidative stress but requires $N F-K B$ activalion. The mechanism by which TNFa blocks myotube formation does involve the generation of ROS, since it can be reversed by NAC, but it remains unclear whether this is independent or downstrean of $\mathrm{NF}^{-k B}$, activation.

\section{DISCUSSION}

The etiology of cachexia remains to be elucidated and likely involves multiple processes, including imbalances in anabolism/catabolism and musele injury and repair. Previous work by our laboratories and other groups revealed that skeletal muscle differentiation is inhibited by TNFa $(15,27-31)$, which was confirmed in the present study by the lack of myotube formation, CK activity and TnI promoter activation. Importantly, this effect of TNF $\alpha$ is not due to non-specific toxicity, as the inhibition of differentiation proved to be reversible. The implications of these findings are that myogenic differentiation, as part of the regenerative 
response of skeletal muscle, may be impaired in the presence of inflammatory mediators, ultimately contributing to cachexia.

Many signaling pathways mvolved in proliferation, apoptosis and differentiation are modulated by the cellular redox state $(32,33)$. Therefore we investigated in the present study whether the inhibition of myogenic differentiation by TNFor was accompanied by alterations in reduced glutathione (GSH) levels. Importantly, we demonstrated a 5 -fold increase in the content of $\mathrm{GSH}$ during the first 24 hours on myogenic differentiation. The functional significance of this increase is unclear, but may provide necessary protection against oxidative stress associated with enhanced mitochondrial respiratory activity, which occurs during myogentc differentiation (34). In this perspective it is interesting to note that a 5 -fold increase in DCF oxidation could be detected in myocytes that had been cultured in DM for $24 \mathrm{~h}$, compared to GM (data not shown). The transient increase in GSH observed during the first $24 \mathrm{~h}$ of differentiation was not affected by the presence of TNF $\alpha$. However, compared to control cultures, GSH concentrations were reduced the following $48 \mathrm{~h}$ in TNF $\alpha$-ex posed cells. Moreover, the presence of TNF $\alpha$ increased DCF oxidation, suggesting that the reduction of GSH levels may be due to increased reactive oxygen species (ROS) generation. A potential source of these TNFo-induced ROS may be the mitochondria, as a recent study demonstrated that ROS generation following TNFo (measured as DCF oxidation) required functional mitochondria (35). In fact, TNF $\alpha$ is known to elicit the generation of reactive oxygen and nitrogen species (ROS and RNS, respectively) by several cell types, including skeletal muscle $(20,21)$. Therefore, we investigated whether the prototypical $\mathrm{ROS}, \mathrm{H}_{2} \mathrm{O}_{2}$ was able to block myogenic differentiation and mimick the inhibitory effect of TNF $\alpha$. Expression of MyHCf and myogenin, the activity of CK and the Tnl promoter, and the ability of the cells to form multinucleated myotubes, were all inhibited by $\mathrm{H}_{2} \mathrm{O}_{2}$ in a dose-dependent fashion, illustrating that oxidative stress per se is sufficient to block myogenic differentiation. Importantly, the inhibition of myogenic differentiation by $\mathrm{H}_{2} \mathrm{O}_{2}$ was reversible, illustrating that the absence of differentiation markers was not due to non-specific toxicity.

If the inhibition of myogenic differentiation by TNF $\alpha$ also would depend on the induction of oxidative stress, modulation of the cellular redox status by supplementing reduced glutathione levels would be expected to restore myogenesis. We demonstrated in the present study that cellular GSH concentrations were effectively raised using NAC. However, only centain aspects of myogenesis were partially restored by $\mathrm{NAC}$ when cells were differentiated in the presence of TNFa. Specifically, Tnl promoter activation was still inhibited by TNFa, despite the use of NAC concentrations that completely reversed the inhibitory elfect of $\mathrm{H}_{2} \mathrm{O}_{2}$. Whereas $\mathrm{NAC}$ fully restored $\mathrm{CK}$ activity in presence of $\mathrm{H}_{2} \mathrm{O}_{2}$, it only partially rescued $\mathrm{CK}$ activity following exposure to TNF $\alpha$. In contrast, myotube formation was almost completely restored in $\mathrm{H}_{2} \mathrm{O}_{2}$ or TNF $\alpha$ treated cells when intracellular thiol levels were augmented using NAC. These observations suggest that a redox dependent mechanism is important in the block of myotube formation associated with exposure to oxidants or cytokines, whereas myogenic protein expression can be regulated in a redox dependent or independent manmer based upon the stimulus present.

Recently, our group (15) and others (31), demonstrated that TNF $\alpha$ or IL-1 inhibit myogenesis through the activation of the transcription factor $N F-\kappa B$. In fact, the activation of $N F-\kappa B$ is sufficient to inhibit myogenesis, as constitutive activation of $N F-\kappa B$ by over- 
expression of $I K K \beta$ inhibits myogenesis. The redox sensitivity of the transeription factor $N F-k B$ has been described in many cell types, including skeletal muscle $(18,19)$. Therefore, we evaluated whether inhibition of myogenesis by $\mathrm{H}_{2} \mathrm{O}_{2}$ coincided with the activation of $\mathrm{NF}-\mathrm{\kappa B}$, and conversely, whether the use of $\mathrm{NAC}$ modulated the activation of $\mathrm{NF}-\mathrm{KB}$ by TNF $\alpha$, as it restored some aspects of myogenic differentiation. Surprisingly, $\mathrm{H}_{2} \mathrm{O}_{2}$, at concentrations that inhibited myogenesis, did not induce significant NF-kB DNA binding, nor transactivation at any of the time points. The absence of $N F-K B$ activation was not the result of methodological problems, as TNF $\alpha$ induced a robust activation in NF $-\kappa B$ DNA binding activity and reporter gene transcription. Our findings are in contrast with studies by others in which $\mathrm{H}_{2} \mathrm{O}_{2}$ induced $\mathrm{NF}-\mathrm{KB}$ DNA binding in $\mathrm{L} 6$ and $\mathrm{C} 2 \mathrm{Cl} 2$ skeletal myocytes $(18,19)$. However, this discrepancy may be attributed to differences in antioxidant enzyme activity, since $\mathrm{NF}-\mathrm{kB}$ activation by $\mathrm{H}_{2} \mathrm{O}_{2}$ in the latter study was assessed in fully differentiated myotubes and antioxidant enzyme activities significantly decrease during myogenic differentiation (36). Therefore, the inhibition of biochemical aspects of myogenesis by TNF $\alpha$ did not appear to require the induction of oxidative stress. In contrast, the inhibition of morphological myogenic differentiation, i.e. myotube formation, by TNF $\alpha$, involved a redox sensitive component. Fusion into myotubes is a process regulated by cellmatrix and cell-cell interactions, and involves the formation of functional $\beta$-catenin-adherin complexes proximate to the cell membrane $(37,38)$. Potentially, disruption of these complexes, which is shown to occur in response to oxidative stress, is responsible for the inhibition of myotube formation (39).

The signaling pathways that mediate the $\mathrm{H}_{2} \mathrm{O}_{2}$-dependent inhibition of myogenic differentiation remain elusive, but may involve the members of the MAPK family. Activities of extracellular signal regulated kinase (ERK) and c-Jun N-terminal kinase (JNK) are increased in response to treatment with oxidants (40). In fact, we have detected enhanced ERK phosphorylation following treatment with $\mathrm{H}_{2} \mathrm{O}_{2}$ in $\mathrm{C} 2 \mathrm{Cl} 2$ myoblasts (unpublished observations), indicative of ERK activation. Furthermore, it has been demonstrated that ERK is a critical regulator of myogenic differentiation (41).

In summary, we have demonstrated in the present study that in response to TNF $\alpha$ myotube formation is inhibited in a redox dependent manner, but that the inhibition of other aspects of myogenic differentiation and the activation of $\mathrm{NF}-\mathrm{KB}$ occurred largely independently of cellular thiol levels. In contrast, NAC completely rescued the inhibition of myogenic differentiation that occurred following treatment with $\mathrm{H}_{2} \mathrm{O}_{2}$, without modulation of $\mathrm{NF}-\mathrm{K} B$ activity. Thus, dependent upon the stimulus that myoblasts encounter, multiple $N F-k B$ dependent and independent and redox sensitive and insensitive pathways contribute to the loss of myogenic differentiation, as is illustrated in Figure 5. These observations may have implications for the treatment of cachexia and suggest the use of combined antiinflammatory and antioxidant therapies. 


\section{REFERENCES}

1. Morrison, W. L., Gibson, J. N., Scrimgeour, C., and Rennie, M. J. (1988) Muscle wasting in emphysema. Clin Sci 75, 415-420

2. Wilson, D. O., Rogers, R. M., Wright, E. C., and Anthonisen, N. R. (1989) Body weight in chronic obstructive pulmonary disease. The National Institutes of Health Intermittent Positive-Pressure Breathing Trial. An Rev Respir Dis 139, 1435-1438

3. Schols, A. M., Slangen, J., Volovics, L., and Wouters, E. F. (1998) Weight loss is a reversible factor in the prognosis of chronic obstructive pulmonary disease. Am $I$ Respir Crit Care Med 157, 1791-1797

4. Elborn, J. S., Cordon, S. M., Western, P. J., Macidonald, 1. A., and Shale, D. J. (1993) Tumour necrosis factor-alpha, resting energy expenditure and cachexia in cystic fubrosis. Clim Sci (Colch) 85, 563-568.

5. Anker, S. D., Ponikowski, P., Vamey, S., Chua, T. P., Clark, A. L., Webb-Peploe, K. M., Harrington, D., Kox, W. d., Poole-Wilson, P. A., and Coats, A. J. (1997) Wasting as independent risk factor for mortality in chronic heart failure [published erratum appears in Lancet 1997 Apr 26:349(9060):1258]. Lancet 349, 1050-1053

6. Mitch, W. E. (1998) Robert H Herman Memorial Award in Clinical Nutrition Lecture, 1997. Mechanisms causing loss of lean body mass in kidney disease. Am $J$ Clin Nutr 67, 359-366.

7. Kotler, D. P., Tierney, A. R., Wang, J., and Pieison, R. N., Jr. (1989) Magnitude of body-cell-mass depletion and the timing of death from wasting in AIDS. Am $J$ Clin Nutr $50,444-447$

8. Argiles, J. M., and Lopez-Soriano, F. J. (1999) The role of cytokines in cancer cachexia. Med Res Rev 19,223-248

9. Belec, L., Meillet, D., Gresenguet, G., and Gherardi, R. K. (1995) Increased tumor necrosis factor-alpha serum levels in patients with HIV wasting syndrome and euthyroid sick syndrome [letter; comment]. I Acquir Immune Defic Syndr Hum Rerrowinol 8, 212-214

10. Di Francia, M., Barbier, D., Mege, J. L., and Orehek, J. (1994) Tumor necrosis factor-allpha levels and weight loss in chronic obstructive pulmonary disease. $A \mathrm{~m} J$ Respir Crit Care Med 150, 1453-1455

11. Nakashima, I., Tachibana, M., Ueno, M., Miyajima, A., Baba, S., and Murai, M. (1998) Association between tunor necrosis factor in serum and cachexia in patients with prostate cancer. Clin Cancer Res 4, 1743-1748

12. Zhao, S. P., and Zeng, L. H. (1997) Elevated plasma levels of tumor necrosis factor in chronic heart failure with cachexia. Int J Cardiol 58, 257-261

13. Buck, M., and Chojkier, M. (1996) Muscle wasting and dedifferentiation induced by oxidative stress in a murine model of cachexia is prevented by inhibitors of nitric oxide synthesis and antioxidants. Embo $J 15,1753-1765$

14. Fong, Y.. Moldawer, L. L., Marano, M., Wei, H., Barber, A., Manogue, K., Tracey, K. J., Kuo, G., Fischman, D. A., Cerami, A., and et al. (1989) Cachectin/TNF or IL-1 alpha induces cachexia with redistribution of body proteins. Am J Physiol 256, R659. 665 
15. Langen, R. C., Schols, A. M., Kelders, M. C., Wouters, E. F., and Janssen-Heininger, Y. M. (2001) Inflammatory cytokines inhibit myogenic differentiation through activation of nuclear factor-kappaB. Faseb J 15, 1169-1180.

16. Pahl, H. L. (1999) Activators and target genes of Rel/NF-kappaB transcription factors. Oncogene 18,6853-6866

17. Ghosh, S., May, M. J., and Kopp, E. B. (1998) NF-kappa B and Rel proteins: evolutionarily conserved mediators of immune responses. Anmu Rev Immumol 16, $225-260$

18. Sen, C. K., Khanna, S., Reznick, A. Z., Roy, S., and Packer, L. (1997) Gllutathione regulation of tumor necrosis factor-alpha-induced NF-kappa $B$ activation in skeletal muscle-derived L6 cells. Biochem Biophys Res Commun 237, 645-649

19. Li, Y. P., Schwartz, R. J., Waddell, 1. D., Holloway, B. R., and Reid, M. B. (1998) Skeletal muscle myocytes undergo protein loss and reactive oxygen- mediated NFkappaB activation in response to tumor necrosis factor alpha. Faseb J12, 871-880

20. Li, Y. P., Atkins, C. M., Sweatt, J. D., and Reid, M. B. (1999) Mitochondria mediate tumor necrosis factor alpha/NF-kappaB signaling in skeletal muscle myotubes. Antioxidants \& Redox Signaling 1, 97-104

21. Williams, G., Brown, T., Becker, L., Prager, M., and Giroir, B. P. (1994) Cytokineinduced expression of nitric oxide synthase in $\mathrm{C} 2 \mathrm{Cl} 2$ skeletal muscle myocytes. $\mathrm{Am}$ J Physiol 267, R1020-1025

22. Reid, M. B. (2001) Nitric oxide, reactive oxygen species, and skeletal muscle contraction. Med Sci Sports Exerc 33, 371-376.

23. Supinski, G. (1998) Free radical induced respiratory muscle dysfunction. Mol Cell Biochem 179, 99-110.

24. Yaffe, D., and Saxel, O. (1977) Serial passaging and differentiation of myogenic cells isolated from dystrophic mouse muscle. Nature 270, 725-727

25. Cohn, V. H., and Lyle, J. (1966) A fluorometric assay for glutathione. Anal Biochem $14,434-440$.

26. Li, N., and Karin, M. (1999) Is NF-kappaB the sensor of oxidative stress? Faseb J $13,1137-1143$

27. Miller, S. C., Ito, H., Blau, H. M., and Torti, F. M. (1988) Tumor necrosis factor inhibits human myogenesis in vitro. Mol Cell Biol 8, 2295-2301

28. Szalay, K., Razga, Z., and Duda, E. (1997) TNF inhibits myogenesis and downregulates the expression of myogenic regulatory factors myoD and myogenin. Eur J Cell Biol 74, 391-398

29. Ji, S. Q., Neustrom, S., Willis, G. M., and Spurlock, M. E. (1998) Proinflammatory cytokines regulate myogenic cell proliferation and fusion but have no impact on myotube protein metabolism or stress protein expression. $J$ Interferon Cyrokine Res $18,879-888$

30. Layne, M. D., and Farmer, S. R. (1999) Tumor necrosis factor-alpha and basic fibroblast growth factor differentially inhibit the insulin-like growth factor-I induced expression of myogenin in C2C12 myoblasts. Exp Cell Res 249, 177-187

31. Guttridge, D. C., Albanese, C., Reuther, J. Y., Pestell, R. G., and Baldwin, A. S., Ir. (1999) NF-kappaB controls cell growth and differentiation through transcriptional regulation of cyclin D1. Mol Cell Biol 19, 5785-5799 
32. Kamata, H, and Hirata, H. (1999) Redox regulation of cellular signalling. Cell Signal 11, 1-14.

33. Chuth, P. J. (2000) Cell membrane redox systems and transformation. Antioxid Redox Signal 2, 177-187.

34. Rochard, P., Rodier, A., Casas, F., Cassar-Malek, I., Marchal-Victorion, S., Daury, L., Wrutniak, C., and Cabello, G. (2000) Mitochondrial activity is involved in the regulation of myoblast differentiation through myogenin expression and activity of myogenic factors. $J$ Biol Chem 275, 2733-2744.

35. Chandel, N. S., Schumacker, P. T., and Arch, R. H. (2001) Reactive oxygen species are downstream products of TRAF-mediated signal transduction. $J$ Biol Chem 276, 42728-42736

36. Franco, A. A., Odom, R. S., and Rando, T. A. (1999) Regulation of antioxidant enzyme gene expression in response to oxidative stress and during differentiation of mouse skeletal muscle. Free Radic Biol Med 27, 1122-1132

37. Kaufmann, U., Kirsch, J., Irintchev, A., Wernig, A., and Starzinski-Powitz, A. (1999) The M-cadherin catenin complex interacts with microtubules in skeletal muscle cells: implications for the fusion of myoblasts. $/$ Cell Sci $112,55-68$.

38. Goichberg, P., Shtutman, M., Ben-Ze'ev, A., and Geiger, B. (2001) Recruitment of beta-catenin to cadherin-mediated intercellular adhesions is involved in myogenic induction. $J$ Cell Sci 114, 1309-1319.

39. Parrish, A. R., Catania, J. M., Orozco, J., and Gandolfi, A. J. (1999) Chemically induced oxidative stress disrupts the E-cadherin/catenin cell adhesion complex. Toxicol Sci 51, 80-86.

40. Janssen, Y. M., Matalon, S., and Mossman, B. T. (1997) Differential induction of cfos, c-jun, and apoptosis in lung epithelial cells exposed to ROS or RNS. Am J Physiol 273, L789-796

41. Bennett, A. M., and Tonks, N. K. (1997) Regulation of distinct stages of skeletal muscle differentiation by mitogen-activated protein kinases. Science 278, 1288-1291 


\title{
CHAPTER 6
}

\section{Tumor necrosis factor-alpha inhibits myogenic differentiation through MyoD protein destabilization}

\begin{abstract}
Tumor necrosis factor alpha (TNF $\alpha$ ) has been implicated as a mediator of muscle wasting through nuclear factor kappa $B(N F-k B)$-dependent inhibition of myogenic differentiation. The aim of the present study was to identify the regulatory molecule(s) of myogenesis targeted by TNF $\alpha / N F-K B$ signaling. TNF $\alpha$ interfered with cell cycle exit and repressed the accumulation of transcripts encoding muscle specific genes in differentiating $\mathrm{C} 2 \mathrm{C} 12$ myoblasts. Over-expression of a p65 (RelA) mutant lacking the transcriptional activation domain attenuated the TNF $\alpha$-mediated inhibition of muscle specific gene transcription. In addition, the ability of the Muscle Regulatory Factor, MyoD to induce muscle specific transcription in 10T1/2 fibroblasts was also disrupted by wild type p65, demonstrating that NF-kB transcriptional activity interferes with the function of MyoD. Inhibition of muscle specific gene expression by TNFa was restored by over-expression of MyoD, whereas endogenous MyoD protein abundance and stability were reduced by TNF $\alpha$ through increased proteolysis of MyoD by the ubiquitin proteasome pathway. Lastly, the inhibitory effects of TNF $\alpha$ on myogenic differentiation were demonstrated in a mouse model of skeletal muscle regeneration, in which TNF $\alpha$ also caused a delay in myoblast cell cycle exit. These results implicate that TNF $\alpha$ inhibits myogenic differentiation through destabilizing MyoD protein in a $\mathrm{NF}-\kappa \mathrm{B}$ dependent manner, which interferes with skeletal muscle regeneration and may contribute to muscle wasting.
\end{abstract}

Ramon C.J. Langen', Jos L.J van der Velden', Annemie M.W.J. Schols', Marco C.I.M. Kelders', Eimiel F.M. Wouters' and Yvonne M.W. Janssen-Heininger'. Departments of 'Respiratory Medicine, Matastriclut University, Maastricht, The Netherlands, and ${ }^{2}$ Pathology, University of Vermont, Burlingion VT, USA. Faseb $J 2003$, in revision. 


\section{INTRODUCTION}

Muscle wasting, defined as the loss of skeletal muscle tissue, commonly occurs in chronic wasting syndromes, such as acquired immune deficiency syndrome (AIDS) (1), cancer (2), chronic heart failure (3), and chronic obstructive pullmonary disease (COPD) (4), and is an independent predictor of mortality. Remarkably, in many of these chronic conditions muscle wasting is associated with elevations in circulating inflammatory cytokines, in particular tumor necrosis factor alpha (TNF $\alpha$ ) (5-8). Chronic administration of TNF $\alpha$ or interleukin-1 (IL-1) induced weight loss and skeletal muscle wasting in rats (9) further illustrating the important role these cytokines may play in muscle loss. Generally, muscle wasting is believed to result from disturbances in the energy or protein anabolism-catabolism balance. For example, imbalances in myofibrillar protein synthesis and proteolysis have been demonstrated in experimental models of cancer cachexia $(10,11)$ or sepsis (12).

Alternatively, imbalances in processes that govern the maintenance of skeletal muscle and muscle plasticity, such as skeletal muscle fiber degeneration, apoptosis and regeneration, may be an important determinant of muscle wasting associated with chronic disease. Muscle regeneration occurs constantly during normal muscle use (13), but is increased in response to muscle damage, increased muscle load, or resumed muscle use following inactivity (14). The recruitment of a reservoir of muscle precursor cells named satellite cells is crucial in this process. Upon activation satellite cells are stimulated to proliferate (and are called myoblasts at this stage), followed by exit from the cell cycle to engage in the myogenic differentiation program (14). Impaired satellite cell function as a result of interference with their ability to proliferate, differentiate or fuse could ultimately result in loss of skeletal muscle tissue.

Myogenic differentiation involves cell cycle exit, the expression of muscle specific genes, and myotube formation. Previously, our group $(15,16)$ and others $(17-21)$ have demonstrated that TNF $\alpha$ interferes with all of these aspects of myogenic differentiation. Inhibition of myotube formation by TNF $\alpha$ involves the induction of oxidative stress (15), whereas TNF $\alpha$-induced activation of NF- $\mathrm{KB}$ is responsible for impaired muscle specific gene expression in differentiating myoblasts $(16,20,21)$. Interestingly, this differentiation deficient phenotype was accompanied by sustained proliferation in response to TNF $\alpha$.

MyoD is the chief regulatory molecule of myogenic differentiation and belongs, together with Myf5, myogenin and MRF4, to the muscle regulatory factors (MRFs), a family of basic helix-loop-helix transcription factors. MyoD plays an important role in cell cycle exit of differentiating myoblasts $(22,23)$, muscle specific gene expression (24-26), and myotube formation (27). Therefore, the aim of this study was to explore whether the inhibition of myogenesis observed in response to TNF $\alpha$ was mediated through impairment of MyoD function, and determine the role of $\mathrm{NF}-\kappa \mathrm{B}$ activation herein. Importantly, as myogenic differentiation is essential to skeletal muscle regeneration, we evaluated the effect of TNF $\alpha$ on myoblast cell cycle exit in regenerating hind limb muscle. 


\section{MATERIALS AND METHODS}

\section{Cell culture}

The murine skeletal muscle cell line C2C12 and 10T1/2 fibroblasts were obtained from the American Type Culture Collection (ATCC CRL 1772, and CCL-226, respectively, Manassas, VA), and cultured in growth media (GM), composed of low glucose Dulbecco's Modified Eagle Medium (DMEM) containing antibiotics $(50 \mathrm{U} / \mathrm{m} \|$ Penicillin and $50 \mu \mathrm{g} / \mathrm{m} /$ Streptomycin) and 9\% (w/v) Fetal Bovine Serum (FBS) (all from Life Technologies, Rockvilie, MD), or differentiation media (DM), which contained DMEM with $0.5 \%$ heatinactivated FBS and antibiotics (DM). Both cell types were grown on Matrigel (Becton Dickinson Labware, Bedford, MA) coated (1:50 in DMEM) disthes as described previously (16). Cells were plated at $10^{4} / \mathrm{cm}^{2}$ and cultured in GM for $24 \mathrm{~h}$, before transfection or induction of differentiation. When applicable, murine TNF $\alpha$ (Calbiochem, La Jolla, CA) was added once to the culture dishes directly after induction of differentiation. For determination of MyoD protein half-life, the protein synthesis inhibitor cycloheximide (CHX) (Calbiochem) was dissolved in HBSS and used at a final concentration of $50 \mu \mathrm{M}$. In separate experiments, the proteasome inhibitor MG-132 (Calbiochem, La Jolla ${ }^{\text {CA) }}$ diluted in DMSO, was added to cell cultures at a final concentration of 100 uM.

\section{Ribonuclease Protection Assay}

RNA probe design

Mouse muscle or C2C12 RNA was used to amplify the various fragnents of interest by RTPCR, using the primers summarized in Table 1 . When possible, probes were designed corresponding to splice boundaries to prevent hybridization with contaminating genomic DNA. To facilitate subcloning into the pBluescript II SK $(+/-)$ phagemid (Stratagene, La Jolla, CA) in the correct orientation, forward primers were extended with a 3 " EcoR restriction site, whereas the reverse primers contained a 5 ' HindIII and Bg/II site. The latter allowed to screen for the presence of the insert by a single restriction enzyme digestion of plasmid isolated from colonies of transformed XL2-Blue MRF' ultra-competent bacteria (Stratagene, La Jolla, CA). Amplified plasmids were isolated using Endofree Plasmid Maxi Kit (Qiagen, Valencia, CA), and sequence analysis was perfomed to verify the sequence of the inserted fragment.

\section{RNA isclation}

C2C12 cells were washed twice with PBS and lysed using $4 \mathrm{ml}$ solution-D (6.4 M guanidine thiocyanate, $40 \mathrm{mM}$ Na-citrate, $0.8 \%$ sarcosyl, $100 \mathrm{mM}$ B-mercaptoethanol) per $100 \mathrm{~mm}$ dish. Alternatively, for soleus muscle RNA isolation, tissue was homogenized (Polytron, Kinematica, Switzerland) in $0.75 \mathrm{ml}$ solution-D. RNA was extracted by adding 0.1 vol. $2 \mathrm{M}$ sodium acetate $\mathrm{pH} 5.0,1$ vol. of water saturated phenol, and 0.2 vol. of chloroform:isoamyl alcohol (50:1). After 15 minutes incubation and centrifugation, RNA was precipitated with an equal volume of isopropanol. The pellet was resuspended in $0.5 \mathrm{~m} l$ solution $\mathrm{D}$ and precipitated again with isopropanol. After a wash step in $70 \%$ ethanol, the RNA was dissolved in nuclease free water and stored at $-80^{\circ} \mathrm{C}$ in small aliquots.

Probe synthesis and ribonuclease protection asway

Panels containing multiple probes were prepared by subjecting EcoRI-linearized constructs, mixed in equal concentrations (the GAPDH probe was prepared separately), to a transcription reaction using T7 RNA polymerase in the presence of excess unlabeled 
nucleotides and $50 \mu \mathrm{Ci}\left[\alpha-{ }^{32} \mathrm{P}\right] \cup \mathrm{TP}$ (800Cimmol), according to the manufacturers Maxiscript kit instructions (Ambion, Houston, TX). The protection reaction was performed after 18 h hybridization at $42^{\circ} \mathrm{C}$ of a mix containing $10 \mu \mathrm{g}$ RA per sample, $8 \times 10^{4} \mathrm{CPM}$ per probe with the exception for glyceraldehyde-3-phosphate dehydrogenase (GAPDH, at 3.2 $\times 10^{3} \mathrm{CPM}$ ), after $3^{*}$ of denaturation at $95^{\circ} \mathrm{C}$, according to manufacturers RPA III kit instructions (Ambion, Houston, TX). The amount of probe used was determined to be saturating in optimization experiments performed for each individual mRNA species. The next day, unprotected fragments were removed by RNase digestion (1:100 diluted RNase A/RNase T1 cocktail) followed by centrifugation. Precipitated, protected fragments were dissolved in $5 \mu l$ loading buffer, denatured at $95^{\circ} \mathrm{C}$, and separated on a $5 \%$ denaturing polyacrylamide gel. Gels were dried and exposed to film (Biomax MR-1, Kodak), or an imaging screen for quantification in a Personal Molecular Imager FX (Bio-Rad, Hercules, $\mathrm{CA}$ ), and band intensity was analyzed using Quantity One software (Bio-Rad).

\section{Transfections and plasmids}

Transient transfections were performed using Lipofectamine $2000 T \mathrm{M}$ (Invitrogen, Carlsbad, CA) according to manufacturers' instructions. Briefly, cells were incubated with the Lipofectamine-DNA mix for 3 h (total amount of DNA $1.5 \mu \mathrm{g}$ for C2C12 cells and $2.0 \mu \mathrm{tg}$ for $10 \mathrm{~T} 1 / 2$ cells), followed by overnight (typically $16 \mathrm{~h}$ ) recovery in GM, prior to induction of differentiation. Troponin I (TnI)-luciferase plasmid, kindly provided by Dr. Albert Baldwin (University of North Carolina, Chapel Hill, NC), was used as a reporter for the activity of muscle specific transcription factors $(0.25 \mu g$ per transfection). pSV- $\beta$-gal $(0.25 \mu \mathrm{g}$ per transfection), was employed to correct for differences in transfection efficiency (Promega, Madison, WI). pEMSV-MyoD was a kind gift from Dr. Barbara Winter (University of Braunschweig, Germany). Plasmids encoding IKK- $\beta$, IKK $\alpha$, or $p 65$, kindly provided by $\mathrm{Dr}$. Michael Karin (University of California, San Diego, La Jolla, CA), were used to activate $N F-k B$. Altematively, $N F-k B$ activation was imhibited by co-transfection of a plasmid encoding $1 \mathrm{~KB} \alpha-\mathrm{SR}$, which was constitutively expressed under control of the SFFV-LTR (pSFFV-NEO IKB $\alpha-S R$ ), kindly provided by Dr. Rosa Ten (Mayo Clinic, Rochester, MN), or p65-ATD, which was a gift from Dr. Sankar Ghosh (Yale University, New Haven, CT). To determine luciferase and $\beta$-galactosidase acitivity, cells were lysed in $1 x$ luciferase lysis buffer and stored at $-80^{\circ} \mathrm{C}$. Luciferase (Promega, Madison, WI) and $\beta$-galactosidase (Tropix, Bedford, MA) were measured according to manufacturers' instructions.

\section{Western blot analysis}

MyoD and B-actin protein abundance was evaluated by Western bloting. Cells were washed in PBS, and whole cell lysates were prepared by addition of lysis buffer (40mM Tris, $300 \mathrm{mM} \mathrm{NaCl}, 2 \%$ (v/v) Nonidet P.40, $1 \mathrm{mM} \mathrm{DTT,} 1 \mathrm{mM} \mathrm{Na} \mathrm{VO}_{4}, 1 \mathrm{mM}$ PMSF, $10 \mu \mathrm{g} / \mathrm{ml}$ leupeptin and $1 \%(\mathrm{w} / \mathrm{v})$ aprotinin). Lysates were incubated on ice for 30 minutes, followed by 30 minutes centrifugation at $16000 \mathrm{xg}$. A fraction of the supernatant was saved for protein determination, and $2 \times$ Laemmli sample buffer $(2 \%(w / v) \operatorname{SDS}, 10 \%(\mathrm{v} / \mathrm{v}) \mathrm{glycerol}$, $0.1 \mathrm{M}$ DTT and $0.01 \%(\mathrm{w} / \mathrm{v})$ Bromophenol Blue) was added, followed by boiling of the samples for 5 minutes and storage at $-20^{\circ} \mathrm{C}$. Total protein was assessed by the Bradford method (28), and $20 \mu \mathrm{g}$ of protein was loaded per lane and separated on a $10 \%$ polyacrylamide gel (Mini Protean System, Bio-Rad, Hercules, CA), followed by transfer to 
a nitrocellulose membrane (Schleicher \& Schuell, Keene, NH) by semidry electroblotting. The membrane was blocked overnight for non-specific binding in $5 \%(w / v)$ non-fat, dried milk at $4^{\circ} \mathrm{C}$. Nitrocellulose blots were washed in PBS-Tween $20(0.05 \%)$, followed by an 1 h incubation with a polyclonal antibody specific for MyoD (Santa Cruz, Santa Cruz, CA), or $\beta$-actin (Sigma) to evaluate for equal loading after stripping. After 3 wash steps of 20 minutes each, the blots were probed with a peroxidase conjugated secondary antibody, and visualized by chemiluminescense according to manufacturers instructions (KPL, Gaithersburg, MD). For the determination of MyoD half-life, MyoD band intensity was determined using the CCD camera of a Molecular Imager system (Bio-Rad, Hercules, CA).

\section{Immunoffuorescence}

Fibroblasts grown on glass coverslips and transfected with MyoD, GFP, and p65 WT or p65- $\triangle T D$ were stained after $24 \mathrm{~h}$ of culture in DM for myogenin using a polyclonal antibody (M225, Santa Cruz, Santa Cruz, CA), and a Alexa-568 fluorophore conjugated anti-rabbit secondary antibody (Molecular Probes, Leiden, The Netherlands). Transfected (GFP positive) fibroblasts were visualized using a camera-equipped fluorescent microscope (Nikon Eclipse E800), and assessed for myogenin reactivity, by scoring 10 separate fields at $100 x$ magnification.

Alternatively, $\mathrm{C} 2 \mathrm{C} 12$ myoblasts grown on glass coverslips were fixed after 24,48 , or $72 \mathrm{~h}$ of culture in DM in presence or absence of TNFo, and stained for MyoD using a monoclonal antibody (BD, Bedford, MA) in combination with a Alexa-488 fluorophore-conjugated antimouse secondary antibody (Molecular Probes, Leiden, The Netherlands). Nuclei were counter-stained with propidium iodide $(20 \mu \mathrm{g} / \mathrm{ml})$. Images were obtained at $200 \mathrm{x}$, using a confocal scanning laser (Bio-Rad MRC 1024 ES) coupled to fluorescent microscope (Olympus BX 50).

\section{Animals}

Male C57/bl6 mice were purchased from Jackson Laboratories (Bar Harbor, ME) and were housed in a temperature controlled room on a 12:12h light-dark cycle with food pellets and water provided ad libitum. All procedures were performed with approval of the University of Vermont's Institutional Animal Care and Use Committee. Four months old mice were randomly assigned to one of two groups ( $n=8$ for each group): 1) hindlimb suspension (HS)/reloading (RL) with intra-muscular (IM) PBS injections, or 2) HS/RL with IM TNF $\alpha$ injections. The HS/RL model has been described previously, and evokes regeneration of postural muscles, which involves myoblast proliferation and differentiation (29). HS was accomplished using a tail suspension device, which consisted of a plastic coated iron wire taped around the mouse's tail and connected to a swivel hook to allow circular motility. The latter was attached to $a$ Teflon coated PVC ring, which slid over a iron rod spanning the length of the cage to allow longitudinal motility. The tail harness was placed while mice were lightly anesthetized using halothane inhalation, and mice were sufficiently raised so as to prevent the hindlimbs from touching the cage floor or sides. This way four HS mice could be housed in one standard cage. After a 2 weeks period of HS, mice were anesthetized and released from the tail harness, and allowed to resume normal cage activity. At this point, and every subsequent $24 \mathrm{~h}$ for 5 days, mice of group 1 received IM injections with PBS (50 1 l) delivered to the gastrocnemius-soleus area of both hindlimbs using a 30 gauge needle (Ultra-Fine II, Becton Dickinson, NJ), while lightly anesthetized. Mice of group 2 


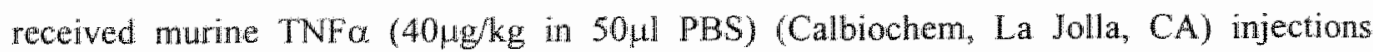
instead of PBS, and showed no signs of fever or loss of appetite compared to animals of group 1. After 5 days of reloading, mice were euthamized by halothane overdose. Soleus and gastrocnemius muscles were collected using standardized dissection methods, cleaned of excess fat and comnective tissue, blotted dry, weighed on an analytical balance, snap frozen in liquid nitrogen and stored at $-80^{\circ} \mathrm{C}$ for $\mathrm{RNA}$ extraction.

\section{Statistical analysis}

Raw data were entered into SPSS (version 8.0y for statistical analysis. Values for the ratio Juciferase/ $\beta$-galactosidase activity, or \% of myogenin positive transfected fibroblasts, or H3.2 mRNA signal normalized for GAPDH were subjected to one-way analysis of variance, and the various treatment groups were compared post-hoc with a Student-Newman-Keuls test $(\mathrm{P}<0.05)$. Where applicable, a two-way analysis of variance was employed.

\section{RESULTS}

\section{TNFC imhibits accumulation of muscle specific gene transcripts and cell cycle exit in differentiating myoblasts}

To assess whether the inhibitory effect of TNFo on myogenesis was apparent at the mRNA Jevel, differentiating C $2 C 12$ myoblast cultures were analyzed for the accumulation of various muscle specific mRNA species by Ribonuclease Protection Assay (RPA) (Figure 1A). Increasing mRNA levels of myogenin, troponin I-slow and fast (Tnl-s॥, and Tnl-f, respectively), muscle creatine kinase (MCK) and myoglobin (Mb) could be observed as myogenesis progressed following the induction of differentiation, whereas mRNA levels of housekeeping genes such as histone 3.3 (H3.3), and GAPDH remained constant. However, up-regulation of muscle specific mRNA levels was markedly attenuated in myocytes differentiated in the presence of TNFa. In addition, MyoD mRNA levels were clearly reduced, whereas Myf5 was increased after $48 \mathrm{~h}$ of culture in the presence of TNF $\alpha$. Data normalized to the housekeeping gene H3.3 are shown in Figure 1B. H3.3 was chosen as a housekeping gene as its abundance remains constant during myogenic differentiation (30). Similar responses were obtained after normalization to GAPDH as housekeeping gene (not shown). These data illustrate that the inhibitory effects of TNF $\alpha$ on the myogenic differentiation process are apparent at the level of muscle specific gene expression.

As myogenic differentiation requires irreversible exit from the cell cycle, number of prolileration markers was assessed. First, histone 3.2 (H3.2) mRNA abundance was evaluated. A 3-fold decrease in 13.2 mRNA levels could be observed 24 h after induction of differentiation in control cultures compared to proliferation supportive conditions, which was absent in the TNF $\alpha$ treated cultures (Figure $\mathbb{A}$ A and B). Evaluation of cyclin D1, a protein inwolved in progression from the $\mathrm{Gl}$ - to S-phase of the cell cycle, also suggested impaired cell cycle exit in response to TNF $\alpha$, as the reduction in cyclin DI abundance observed with differentiation was incomplete in TNFa treated myoblasts (Figure 1C). Lastly, the number of cells recovered from dishes incubated with TNF $\alpha$ in DM for 48 has signilicantly higher than in control dishes after $48 \mathrm{~h}$ in DM $(126.7 \pm 8.6 * 10 \%$ dish in control 
vs $177.8 \pm 11.1 * 10^{4} /$ dish in TNF $\alpha ; p<0.01$ ), indicating that impaired cell cycle exit was associated with sustained cell proliferation.

A

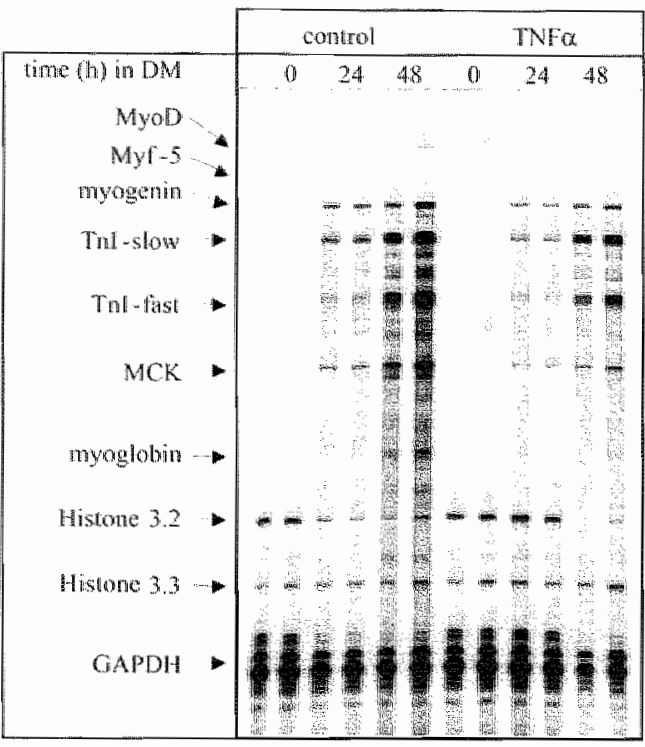

C
B

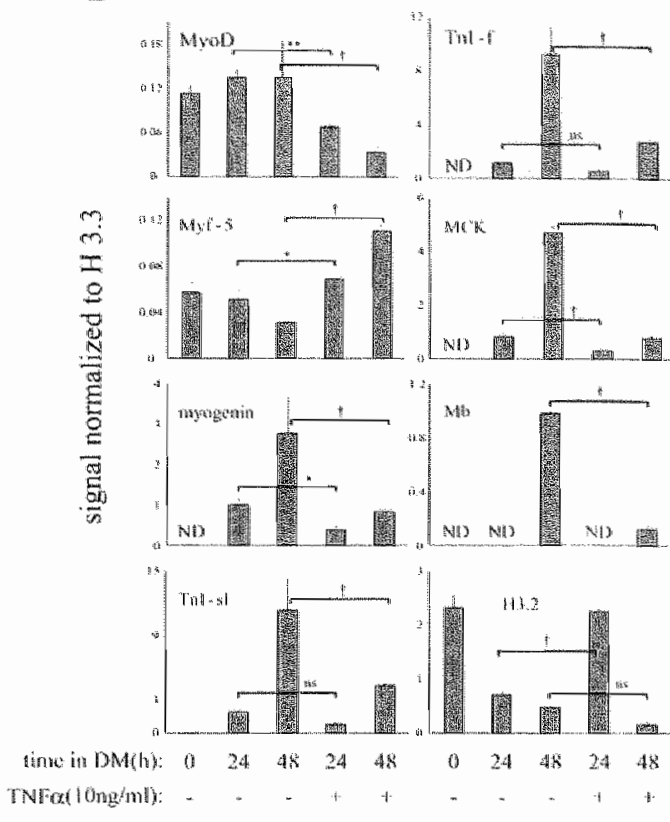

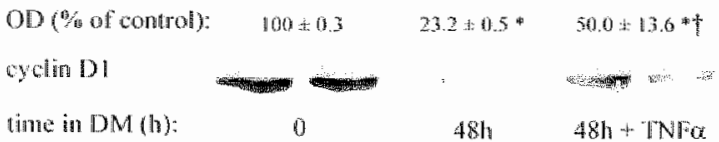

Figure 1: TNF $\alpha$ inhibits accumulation of muscle specific gene transeripts and cell cycle exil in differentiating $\mathrm{C} 2 \mathrm{Cl} 2$ cells. Myoblasts were indwed to differentiate in the presence or absence of TNFo (10ng/mi) for $24 \mathrm{~h}$ or $48 \mathrm{~h}$. Total RNA was isolated and subjected to Ribonuclease Protection Assay (RPA) using a panel containing the indicated anti-sense probes. Shown is a representative example of 3 independent experiments (A). Signal intensity of the various mRNA bands shown in IA were determined with Phosphorlmager analysis, normalized to the housekeeping gene H3.3, and expressed in relative units as the mean \pm sem. Differences between DM and DM+TNFa were determined at 24 and $48 \mathrm{~h}$, with $* 00.05$, ** $p<0.01,+p<0.001$, and ns non-significant. N.D.: not detected (B). Cyclin DI protein abundance was determined in protein lysates $(20 \mu \mathrm{g})$ of proliferating or differentiating ( $48 \mathrm{~h} \mathrm{DM}$ ) myoblasts cultured in presence or absence of TNFa ( $10 \mathrm{ng} / \mathrm{ml})$. Shown is representative data of 3 independent experiments of which Cyclin DI signal intensity was determined, and expressed as $\%$ (mean \pm sem) of the signal measurted in proliferating myoblasts. * $\mathrm{p}<0.001$ for both DM and DM TNFo compared to $G M ;$ DM+TNF $\alpha$ compared 1o DM (C) Statistically significant differences were determined by one-way ANOVA. 
A

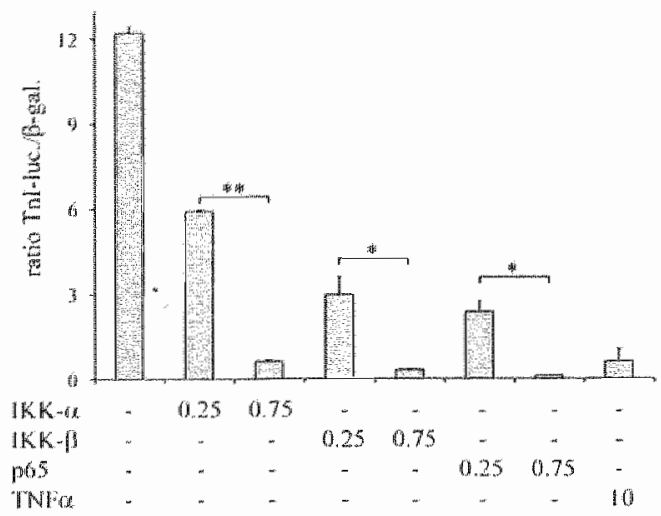

C

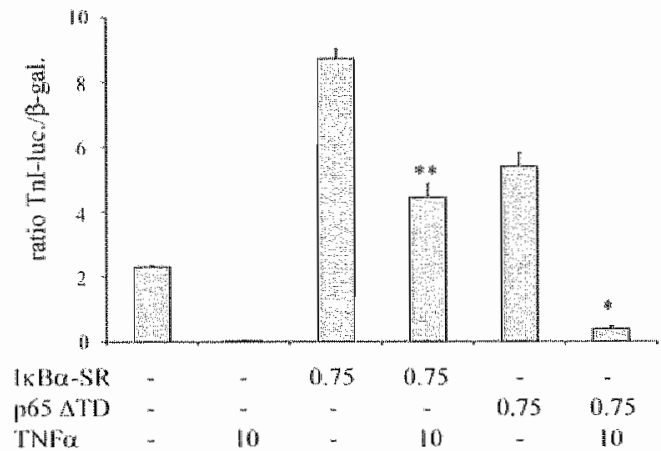

B

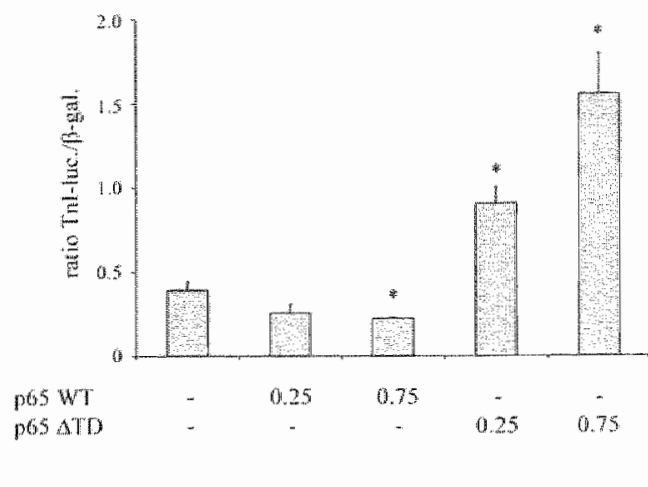




\section{Inhibition of myogenic differentiation by TNF a requires transcriptional activation of $N F-\alpha$}

$\mathrm{NF}-\mathrm{KB}$ activity is inversely related to myogenesis, but required for myoblast proliferation $(16,20)$. To test the effects of $\mathrm{NF}-\mathrm{KB}$ activation on differentiation, C2C 12 cells were transiently transfected with a Troponin 1 promoter-reporter construct (Thl-luc) as a marker of myogenesis (31). TnI promoter transactivation in differentiating $\mathrm{C} 2 \mathrm{C} 12$ cells was markedly inhibited when $N F-K B$ was activated by either TNF $\alpha$ or over-expression of $I K K B$ * IKK $\alpha$ or p65 (Figure 2A). In contrast to wild type (WT) p65, expression of a p65 mutant lacking both transcriptional domains (p65- $\triangle \mathrm{TD}$ ) in $\mathrm{C} 2 \mathrm{Cl} 2$ myocytes resulted in a dose dependent increase in TnI-promoter transactivation (Figure $2 \mathrm{~B}$ ). Inhibition of basal $N F-\kappa B$ activity by a mutant form of $\mathrm{I} K \mathrm{~B} \alpha(\mathrm{K} \mathrm{KB} \alpha-\mathrm{SR})$ also stimulated Tnl-reporter activity (Figure 2C). Expression of p65-ATD in TNFa treated cultures elicited a 10 -fold increase of this myogenic reporter gene compared to TNF $\alpha$ alone, although it did not restore the inhibitory effect of TNF $\alpha$ on TnL-promoter activity to control values as observed for IKB $\alpha$-SR (Figure 2C). Collectively, these data demonstrate that basal or TNF $\alpha$-induced p65 transcriptional activity is involved in the inhibition of myogenesis.

\section{MyoD dependent myogenesis is modulated by $N F-\kappa B$ activity}

To elucidate the identity of the regulatory molecules affected by $N F-K B$ activation, $M y o D$ function was evaluated by measuring transactivation of the Tin promoter in $10 \mathrm{~T} 1 / 2$ fibroblasts. Transcriptional activation of muscle specific promoters only occurs in these cells if MyoD (or another MRF) is over-expressed (Figure 3A, compare first and second bar) (25). Activation of the $N F-\kappa B$ pathway by co-expression of $\mathbb{K} K \alpha$, IKK $\beta$, or $p 65$ inhibited MyoD-dependent Tnl-promoter transactivation in a dose dependent fashion (Figure 3A). Moreover, the integrity of the transactivation domain of $p 65$ was critical for inhibition of MyoD function, as co-expression of p65- $\triangle T D$ actually enhanced MyoD dependent transactivation, in contrast to wild-type (WT) p65 (Figure 3B). Identical to the observations in $\mathrm{C} 2 \mathrm{C} 12$ cells, expression of IKB $\alpha-\mathrm{SR}$ also facilitated MyoD dependent myogenic transcriptional activation (Figure 3B). Importantly, co-transfection of WT $\mathrm{p} 65$ with MyoD in 10T1/2 cells also strongly inhibited myogenin expression in transfocted (GFP-marked) cells, whereas expression of p65- $\mathrm{TD}$ did not significantly reduce the number of transfected cells that stained positive for myogenin compared to control (MyoD only) cultures (Figure 3C). 
A

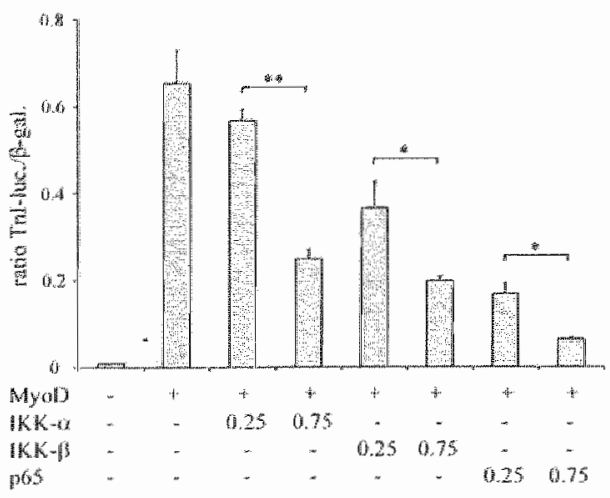

$\mathrm{C}$

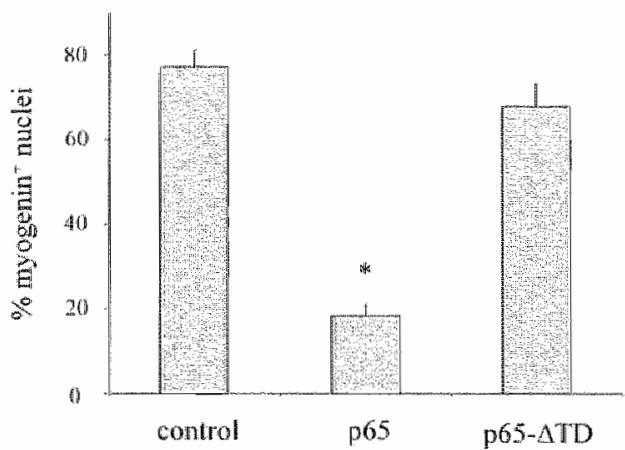

B

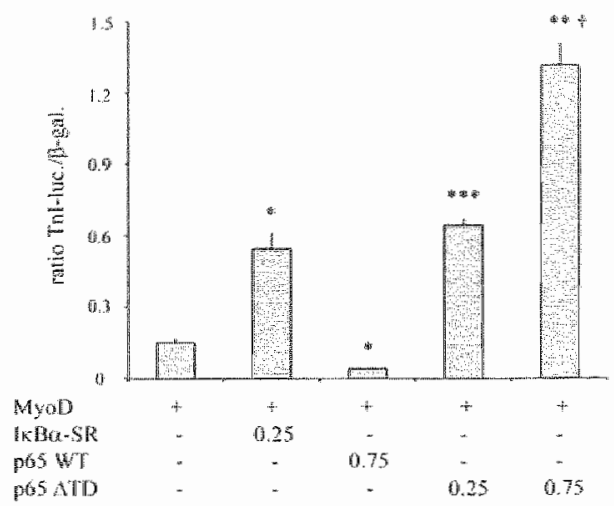

Figure 3: MyoD dependent myogenesis is modulated by NF-kB activity. MyoD $(0.5 \mu \mathrm{g})$ was expressed in $10 \mathrm{TI} / 2$ fibroblasts together with plasmids encoding IKK $\alpha, \mathbb{L K K} \beta$, p65, or vector control, and Tnl-

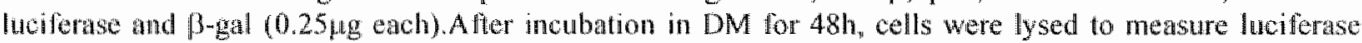
and $\beta$-gal activity. All itreatments were found different from control: $p<0.05$, with the exception of $0.25 \mu \mathrm{g}$ $1 K K \alpha$. In addition, ${ }^{*}<0.05$, and $* * 0<0.01$ illustrate dose dependent effects (A). Alternatively, plasmids encoding WT $\mathrm{T} 65$, or transertptionally inactive p65 (ATD-p65), IKBd-SR, or vector control were coIransfected with MyoD, Tnl-luc and $\beta$-gal $(0.25 \mathrm{\mu g}$ each) followed by incubation in DM for $48 \mathrm{~h}$, after which cells were harvested to measure luciferase and $\beta$-gal activity. ${ }^{*} p<0.05, * * 0.01$, and *** $p<0.001$ compared to control; $+p<0.02$ illustrates a dose dependent effect of $A T D-p 65$ (B). Shown are representative data of three independent experiments $(n=3, \mathrm{SEM})$. Statistically significant differences were determined by one-way ANOVA.

Fibroblasts grown on coverslips were transfected with MyoD $(0.5 \mu g)$ and GFP $(0.25 \mu \mathrm{g})$ encoding plasmids, together with emply vector, WT p65, or p65-ATD (1.0ng each). After $24 \mathrm{~h}$ in DM cells were fixed, and transfected cells (GPP-positive) were evaluated for myogenin expression. Transfected fibroblasts were scored for myogenin expression at $100 \times, 10$ separate fields per sample ( $n=3$ ), and the results expressed as the percentage myogenin positive nuctei of the total number of GFP-positive nuclei. Values were tested for significant differences relative to control (* p<0.001) using one-way ANOVA (C). 


\section{TNF a decreases $M y o D$ abundance in differentiating myoblosts}

As our results implied that basal and TNFa-induced NF-KB transactivation interfered with MyoD function, MyoD protein expression levels were assessed during differentiation. MyoD abundance remained constant in control cultures after $24 \mathrm{~h}$ of culture in DM (Figure 4A), whereas myocytes differentiated in the presence of TNF a consistently demonstrated a striking reduction in MyoD abundance after $72 \mathrm{~h}$ (Figure $4 \mathrm{~A}$ ). Inmunostaining confirmed the reduction of MyoD protein by TNF $\alpha$, and revealed that only a fraction of the TNF $\alpha$ treated cells stained faintly for MyoD at 24 and $48 \mathrm{~h}$, with all MyoD immunoreactivity lost after $72 \mathrm{~h}$ of culture in DM (Figure $4 \mathrm{~B}$ ). Thus, these data demonstrate that the presence of TNF $\alpha$ during differentiation resulted in reduced MyoD abundance, in particular in the later phases of myogenic differentiation.

A

\begin{tabular}{|c|c|c|c|c|c|}
\hline \multicolumn{2}{|c|}{ lime in DM $(h)$ : } & 0 & 24 & 48 & 72 \\
\hline \multirow{2}{*}{$\bar{E}$} & Myod & & & & \\
\hline & IEation & $15 x 0.1$ & $1.6 \pm 0.2$ & $1.6 \pm 0.1$ & 2.11002 \\
\hline \multirow{2}{*}{$\frac{8}{4}$} & Myod & & & & as \\
\hline & Tatio & $1.3 \pm 0.1$ & $1.3 \div 0.1$ & $5.1 \div 0.1^{\circ}$ & $0.290 .1 \%$ \\
\hline
\end{tabular}

B

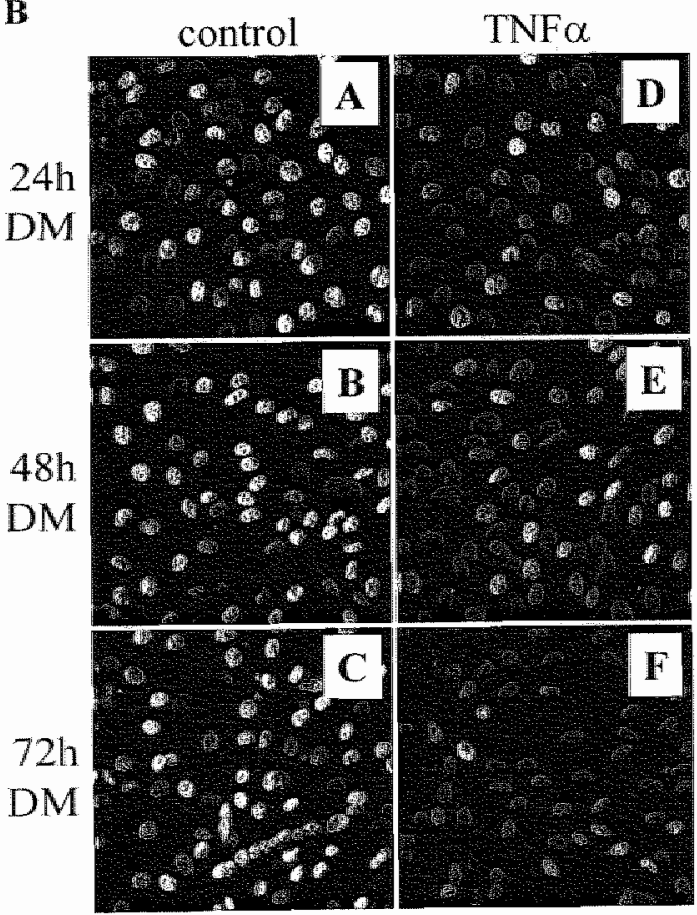

Figure 4: TNF $\alpha$ decreases MyoD abundance in differentiating myocytes. $\mathrm{C} 2 \mathrm{Cl} 12$ cells were cultured in DM in the presence or absence of TNFo, and cell lysates were evaluated for MyoD or B-actin protein levels at the indicated time points. Shown is representative data of 4 independent experiments. MyoD and $\beta$-actin band intensity was measured and expressed as a ratio (mean \pm sem), with $* \mathrm{p}<0.01$ between DM control and $D M+T N F a$ at $48 \mathrm{~h}$ and $72 \mathrm{~h}$, as determined by 1 way ANOVA (A). In addition, confocal scanning laser microscopy was used to evaluate MyoD abundance and localization. Myocytes were grown on coverslips and subsequently differentiated in the presence (panel D-F) or absence (panel A-C) of TNF $\alpha$ for 24 h (panel A, D), 48h (panel B, E), or $72 \mathrm{~h}$ (panel C, F). MyoD was visualized by immunohistochernistry (green) and the nuclei were stained using propidium iodide (red). Due to co-focalization of the green and red signal, Myod-positive nuclei show up yellow. A renresentative of 3 experiments is shown (B) 


\section{TNF a affects MyoD protein stability}

The half-life of MyoD protein has only been calculated for ectopically expressed MyoD in proliferating fibroblasts and HeLa cells $(32,33)$. Therefore, we determined the stability of endogenous $\mathrm{MyOD}$ in $\mathrm{C} 2 \mathrm{Cl} 2$ myocytes cultured in growth (GM) or differentiation conditions (DM), using the protein synthesis inhibitor, cycloheximide (CHX). MyoD halfIlfe in proliferating myoblasts (in GM) was calculated to be $66 \pm 15$ minutes (not shown), and increased to $130 \pm 13$ minutes after 24 h in DM. In contrast, MyoD stabilization did not occur in cultures differentiated in the presence of TNFo, as its half-life was only $86 \pm 17$ minutes $(p<0.05)$. A representative experiment of $M y o D$ half-life determination is shown in Figure 5A, with corresponding calculations in Figure 5B.

A

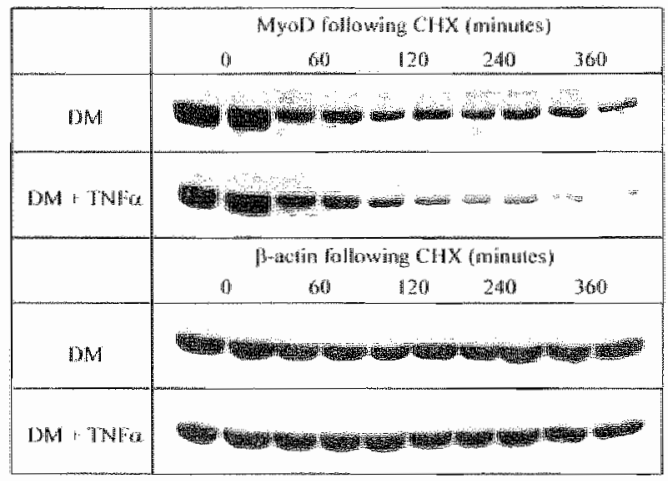

B

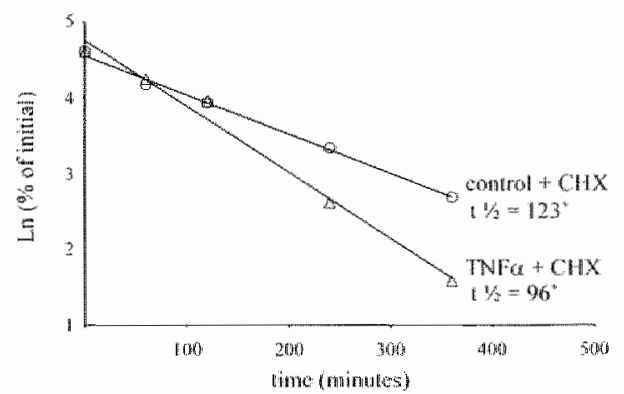

Figure 5: TNFa decreases MyoD protein half-life in differentiating myoblasts. CHX (50uM) was added to myocytes after $24 \mathrm{~h}$ of culture in DM in the presence or absence of TMF $\alpha$. At the indicated time points cell lysates were prepared for SDS-PAGE and Western Blot analysis of MyoD protein abundance, or $\beta$-actin as loading control $(A)$. Band intensity was measured and nomalized to $t=0$ (100\%). For each time point, the natural logarithm (In) of the band intensity (in \%) was plotted versus time, and MyoD half-life (t1/2) was calculated as the time point corresponding to the In of $50 \%$. Shown is a representative calculation out of 3 independent experiments, which culminated in average half-live of $130^{\prime}+13^{\prime}$ in DM vs $86^{\prime} \pm 17^{\prime}$ in $D M+T N F(p<0,05)(B)$.

In agreement with previous reports $(33,34)$, inhibition of the ubiquitin-proteasome pathway stabilized MyoD in the absence of protein synthesis (Figure 6A). Importantly, the reduction in MyoD protein stability resulting from TNF $\alpha$ was almost completely restored to control levels by inhibition of the $26 \mathrm{~S}$ proteasome pathway, by pre-incubation with either MG-132 (Figure 6A), or $2.5 \mu \mathrm{M}$ clasto-lactacystin $\beta$-lactone (data not shown). If insufficient MyoD protein levels due to increased degradation were the mechanism by which TNF $\alpha$ inhibited myogenic differentiation, increasing MyoD abundance could be expected to restore myogenesis. Indeed, over-expression of MyoD restored TnI promoter transactivation in differentiating $\mathrm{C} 2 \mathrm{C} 12$ myoblasts in the presence of TNFa (Figure 6B). Collectively, these data indicate $\mathrm{MyoD}$ as the putative myogenic regulatory molecule targeted by TNF $\alpha$, leading to impaired myogenic differentiation. 
A

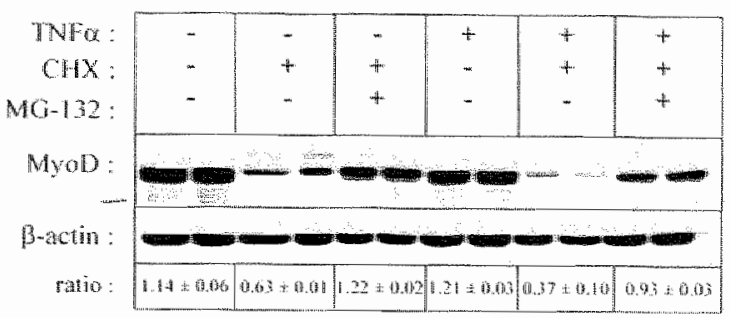

B

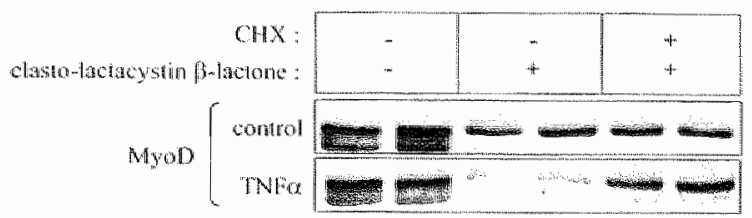

$\mathrm{C}$

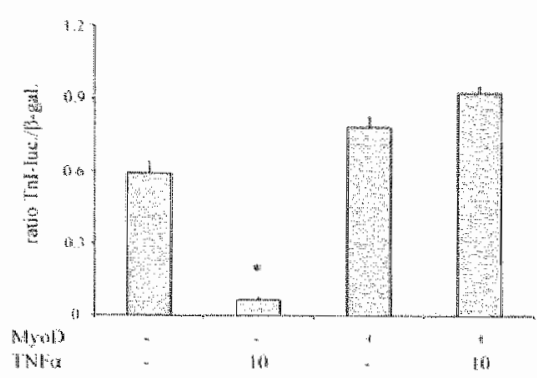

Figure 6: TNF $\alpha$ increases MyoD degradation through the ubiquitin proteasome pathway. $62 \mathrm{Cl} 2$ myoblasts were cultured in DM for 241 in the presence or absence of TNFa, followed by incubation with $\mathrm{CHX}(50 \mu \mathrm{M})$, or vehicle, separate or together with $\mathrm{MG}-132(100 \mu \mathrm{M})$, or clasto-lactacystin $\beta$-lactone (2.5.M) for 4 hours. MyoD and $\beta$-actin were determined as in ' $5 B^{\prime}$, and band intensity was assessed and expressed as a ratio. Shown is representative blots of $3(A)$, and 2 (B) independent experiments.

Inhibition of myogenesis is prevented by overexpression of MyoD, C2C12 myoblasts were transfected with a MyoD (or empty) expression vector and cultured in DM in the presence or absence of TNF $\alpha$ (10ng/ml). After $48 \mathrm{~h}$ Tnl-luciferase and $\beta$ mall activity were detemined and expressed as a ratio. Shown are representative data of three independent experiments $(n=3 \pm$ SEM). The inflaence of constitutive MyoD expression on TNFa dependent inhibition of Tnl-luc was evaluated by two-way ANOVA, which showed at significant interaction between MyoD and TNFo $(p<0.005)(\mathrm{c})$.

\section{TNF $\alpha$ impairs myoblast cell cycle exit in regenerating skeletal muscle}

In order to investigate the significance of TNF $\alpha$ dependent inhibition of myogenic differentiation in intact skeletal muscle, a mouse model of muscle regeneration was adopted. In a separate experiment, two weeks of hind limb suspension (HS) resulted in atrophy of the soleus and gastrocnemius muscles, evidenced by a reduction in muscle weight of approximately $40.3 \pm 2.2 \%$, and $23.4 \pm 1.6 \%$, respectively ( $n=8$ per group, $p<0.001$ by $\|$ way ANOVA). Reloading (RL) of the hind limb musculature caused muscle regeneration. which was complete after 14 days, judged by muscle weight, which had returned to baseline values (not shown). Muscle regeneration in this model involves satellite cell activation, proliferation and differentiation (29), which prompted us to evaluate the inhibitory effect of TNF $\alpha$ on cell cycle exit observed in vitro. Compared to mice that had received intritmuscular (IM) injections with PBS during the 5 day RL-phase, H3.2 mRNA levels were markedly elevated in the gastrocnemius (Figure 6A and B) and soleus (not shown) of mice that had received IM injections with TNF $\alpha$ every $24 \mathrm{~h}$ during reloading. TNF $\alpha$ also reduced myogenin mRNA levels in regenerating skeletal muscle when normalized to $\mathrm{H} 3.3$ (Figure 6B), although no difference could be detected after correction for GAPDH (not shown). The 
latter may be due to a reduction of GAPDH levels by TNF $\alpha$, which was consistently observed in vivo and in vitro (Figure $1 \mathrm{~A}$ ). These results confirm the inhibition of cell cycle exit observed myoblast cultures in response to TNF $\alpha$, and illustrate the inhibitory effects of TNFa on skeletal muscle regeneration in the mouse.

A

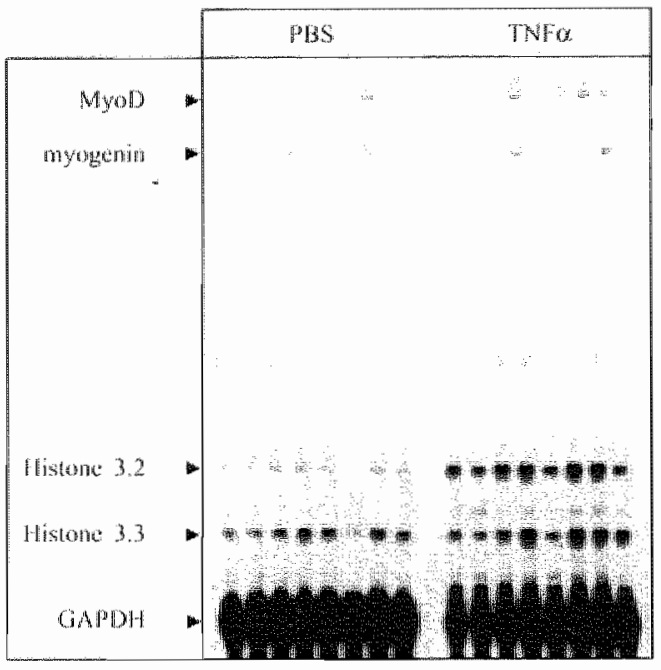

B

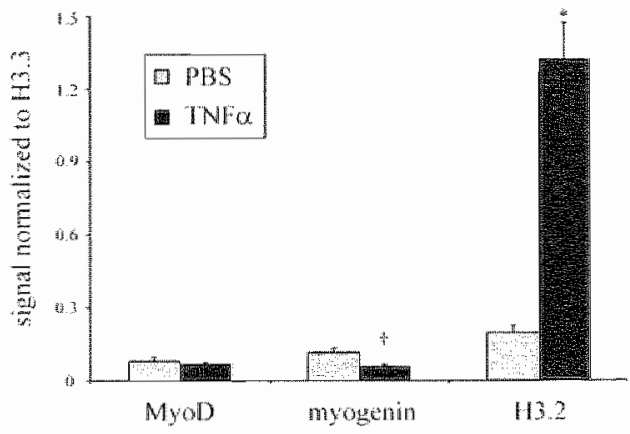

Figure 7: TNFa inhibits myoblast cell cycle exit in regenerating skeletal muscle. RNA extracted from gastrocnemius muscle excised from PBS- or TNFa-injected HS/RL animals ( $n=8$ for each group) was subjected to RPA analysis to determine mRNA abundance of MyoD and myogenin, the proliferation marker H3.2 and housekeeping genes H3.3 and GAPDH (A). MyoD, myogenim, and H3.2 mRNA signal intensity was normalized to $H 3.3$ levels (B). $n=8$ per group; $*=p<0.001$, or $\dagger=p<0.01$ for PBS vs TNFo, as determined by 1 -bay ANOVA.

\section{DISCUSSION}

Previously, we and others demonstrated inhibition of myogenic differentiation by inllammatory cytokines such as TNFa and $\mathrm{L}-1$, through activation of $N F-K B(16,21)$. We also demonstrate in the present study that the inhibitory effects of TNF $\alpha$ on myogenesis involved impaired mRNA accumulation of transcripts encoding muscle specific genes, and coincided with a failure of myoblasts to exit the cell cycle. The latter was evidenced by the sustained xpression of cyclin-D1 protein by TWFa, as shown previously (20). In addition. MRNA of the H3.2 variant, which is restricted to the S-phase of the cell cycle (35), and absent once myoblasts differentiate (30), remained detectable in myoblasts differentiated in the presence of TNF $\alpha$ (Figure 1 A and IB). Inhibition of myogenesis by TNF $\alpha$ required NE$\mathrm{KB}$ activation $(16,21)$, and, as shown in this study relied on impairment of MyoD function (Figure 3). Importantly, the integrity of the transactivation domain (TD) of p65 proved critical for this response, as expression of a mutant protein lacking the TD (p65- $\Delta T D$ ) 
enhanced myogenesis and reversed the inhibitory effects of TNFa, albeit incompletely. The recruitment of a residual pool of WT $p 65$ in response to TNF $\alpha$, which might not have been completely replaced with mutant 165 due to the transient nature of the transfection method, may have been responsible for this remaining inhibitory effect of TNF $\alpha$. This may also explain the differential effect of p65- $\triangle T D$ expression on MyoD-dependent Tnl-promoter transactivation (Figure 3B) and myogenin expression (3C), as the replacement of endogenous with mutant $\mathrm{p} 65$ may have been more complete at the time of analysis for the Tnl reporter, which was performed $72 \mathrm{~h}$ post-transfection vs $48 \mathrm{~h}$ for myogenin expression. Nonetheless, the myogenesis-stimulatory effect of inlubition of basal $N F-K B$ was also observed by over-expression of a mutant form of $\mathrm{K} B \alpha(\mathrm{KB} \alpha-\mathrm{SR})$ (Figure 2C), and is in line with the finding that $\mathrm{NF}-\mathrm{kB}$ activity declines as myogenic differentiation progresses $(16,20)$. Collectively, these findings suggest that a NF-kB regulated gene product may be responsible for impaiment of MyoD function, in response to TNFa.

MyoD is regarded as the key regulator of myogenic differentiation, as MyoD deficient myoblasts are incapable of completing the differentiation program successfully (27). An additional role for MyoD has been described in the regulation of cell cycle exit, including the transcriptional activation of the cell cycle inhibitor p21 $(22,23)$. Therefore, functional inhibition of MyoD may not only result in loss of muscle specific gene expression; it may also be responsible for the perturbation of cell cycle exill in response to TNFa. Myol. activity is regulated at multiple levels, including the interaction with inthibitory molecules or chromatin remodeling proteins, or the availability of dimerization partners (for review see (36)). However, ectopic expression of MyoD restored myogenesis in C2CI2 cells in the presence of TNFa, suggesting that the defect in myogenesis is not the result of a limited availability of cofactors required for MyoD activity, but may rather be due to insufficient levels of functional MyoD protein itself. MyoD protein levels decreased following TNF $\alpha$ treatment, as described previously (18), whereas in control cultures MyoD protein abundance increased within 24h post-induction of differentiation. Moreover, the increase in MyoD protein abundance in control cultures observed during the first 24 following transition from GM to DM was not accompanied by increases at the mRNA level. Apart from transcriptional regulation, MyoD protein abundance is, as for any other protein, also regulated by its stability. This study demonstrates that the hallife of endogenous MyoD protein in $\mathrm{C} 2 \mathrm{C} 12$ myoblasts doubled when cultures were shifted from GM to DM, suggesting that MyoD abundance during differentiation is governed by protein slabilization rather than transcriptional regulation. Therefore, the reduced MyoD protein stability observed with TNFa is likely the primary contributor to the decrease in MyoD protein abundance. The reduction in MyoD transcripts following TNF $\alpha$ may be secondary to MyoD protein instability, as the expression of MyoD is in part controlled by an aulomegulatory mechanism, in which MyoD is involved in its own transcription (37).

Myod destabilization in response to TNFa is potentially regulated by a NF-KB dependent gene product. As inhibition of the proteasome almost completely restored MyoD protein stability in the presence of TNFa, candidate genes responsible for increased proteolysis of MyoD include components of the ubiquitin proteasome pathway. Previously. TNFo was found to induce mRNA transcripts encoding the poly-ubiquitin gene in skeletal muscle (38). 
In addition, the expression of the ubiquitin conjugating enzyme $\mathrm{UbcH} 2$ was induced in skeletal myotubes by TNF $\alpha$ in a NF- $\mathrm{KB}$ dependent manner (39). Moreover, mRNA encoding the ubiquitin ligases (E3 proteins), Muscle RING Finger I (MURFI) and Muscle Atrophy F-box (MAFbx) were strongly induced in skeletal muscle by IL-1 $(40,41)$. Importantly, proteasomal degradation of MyoD is dependent on E3 ubiquitin ligase activity $(42,43)$. These observations make it tempting to speculate that NF- $\mathrm{kB}$ dependent induction of specific ubiquitin conjugating enzymes or ligases by inflammatory cytokines may contribute to muscle wasting through the targeted proteolysis of myogenic regulators like MyoD, in addition to the more ubiquitous proteolysis of myofibrillar proteins.

The pivotal role of MyoD during in vivo myogenesis has been demonstrated in models of skeletal muscle regeneration (44). Our data suggest that TNF $\alpha$ may interfere with muscle regeneration, as $\mathrm{H} 3.2 \mathrm{mRNA}$ after 5 days of reloading of disuse-atrophied soleus and gastrocnemius muscle was still markedly elevated in animals receiving TNFa injections. This is reminiscent of continued satellite cell proliferation, as the proliferative response of satellite cells due to increased muscle activity returns to baseline after 4 days (45). Although this corresponds with the in virro data in which TNF $\alpha$ perturbed myoblast cell cycle exit, the possible contribution of other cell types besides satellite cells to the increased H3.2 expression in the regenerating muscles cannot be excluded. However, in other models of muscle regeneration, proliferation markers were clearly associated with myoblasts $(46,47)$. In addition, systemic administration of TNF $\alpha$ in adult mice was found to induce 5-bromo2'-deoxyuridine incorporation specifically in satellite cells, indicative of the proliferation stimulating effect of TNFa on skeletal muscle (48). Based on our in vitro data, one could expect the inhibitory effect of TNF $\alpha$ on myoblast cell cycle exit to coincide with impaired myogenic differentiation. Indeed, TNF $\alpha$ reduced myogenin mRNA expression in regenerating skeletal muscle, indicating that TNF $\alpha$ may interfere with muscle regeneration in vivo. There is precedent for the notion that TNFR-signaling may result in impaired muscle regeneration, as TNF Receptor Interacting Protein 2 (RIP-2) expression is decreased in regenerating muscle (49). The reduction in RIP-2 expression may contribute to decreased $N F-\kappa B$ activity during muscle regeneration, which may be recuired as inhibition of NF-KB stimulated muscle regeneration following traumatic injury (50).

In summary, our data suggests that TNF $\alpha$ reduces $M y o D$ protein stability in a $N F-k B$ dependent manner, which results in sustained myoblast proliferation and inhibition myogenic differentiation. These findings may provide important novel insights into the mechanisms involved in inflammation-associated muscle wasting. 


\section{REFERENCES}

1. Kotler, D. P., Tiemey, A. R., Wang, J, and Pierson, R. N., It. (1989) Magninde of body-cell-mass depletion and the timing of death from wasting in ADS. Am $I$ Clin Nutr 50, 444-447

2. Argiles, J. M., and Lopez-Soriano, F. I. (1999) The role of cytokines in cancer cachexia. Med Res Rev 19, 223-248

3. Anker, S. D., Ponikowski, P., Varney, S., Chua, T. P., Clark, A. L., Webb-Peploe, K. M., Harrington, D., Kox, W. J., Poole-Wilson, P. A., and Coats, A. J. (1997) Wasting as independent risk factor for mortality in chronic heart failure [published erratum appears in Lancet 1997 Apr 26;349(9060):1258]. Lancer 349,1050-1053

4. Schols, A. M., Slangen, J., Volovics, L., and Wouters, E. F. (1998) Weight loss is a reversible factor in the prognosis of chronic obstructive pulmonary disease. Am $J$ Respir Crit Care Med 157, 1791-1797

5. Belec, L., Meillet, D., Gresenguet, G., and Gherardi, R. K. (1995) Increased tumor necrosis factor-alpha serum levels in patients with MIV wasting syndrome and euthyroid sick syndrome [letter; comment]. I Acquir Immme Defic Symdr Hum Retrovirol 8, 212-214

6. Nakashima, J., Tachibana, M., Ueno, M., Miyajima, A., Baba, S., and Murä, M. (1998) Association between tumor necrosis factor in serum and cachexia in patients with prostate cancer. Clin Cancer Res 4, 1743-1748

7. Zhao, S. P., and Zeng, L. H. (1997) Elevated plasma levels of tumor necrosis factor in chronic heart failure with cachexia. Int J Cardiol 58, 257-261

8. Di Francia, M., Barbier, D., Mege, J. L., and Orehek, I. (1994) Tumor necrosis factor-alpha levels and weight loss in chronic obstructive pulmonary disease. $A m J$ Respir Crit Cone Med 150, 1453-1455

9. Fong, Y., Moldawer, L. L., Marano, M., Weï, H., Barber, A., Manogue, K., Tracey, K. J., Kuo, G., Fischman, D. A., Cerami, A., and et al. (1989) Cachectin/TNF or IL-1 alpha induces cachexia with redistribution of body proteins. Am \& Physiol 256, R659665

10. Buck, M., and Chojkier, M. (1996) Muscle wasting and dedifferentiation induced by oxidative stress in a murine model of cachexia is prevented by inhibitors of nitric oxide synthesis and antioxidants. Embo $J 15,1753-1765$

11. Llovera, M., Garcia-Martinez, C., Agell, N., Marzabal, M., Lopez-Soriano, F. J., and Argiles, J. M. (1994) Ubiquitin gene expression is increased in skeletal muscle of tumour-bearing rats. FEBS Len $338,311-318$

12. Vary, T. C., Owens, E. L. Beers, J. K., Verner, K., and Cooney, R. N. (1996) Sepsis inhibits synthesis of myofibrillar and sarcoplasmic proteins: modulation by interleukin-1 receptor antagonist. Shock $6,13-18$

13. Wanek, L. J., and Snow, M. H. (2000) Activity-induced fiber regeneration in rat soleus muscle. Anat Rec 258, 176-185

14. Hawke, T. J., and Garry, D. J. (2001) Myogenic satellite cells: physiology to molecular biology. J Appl Physiol 91, 534-551

15. Langen, R. C., Schols, A. M., Kelders, M. C., Van Der Velden, J. L., Wouters, E. F., and Janssen-Heininger, Y. M. (2002) Tumor necrosis factor-alpha inhibits 
myogenesis through redox-dependent and-independent pathways. Am J Physiol Cell Physiol 283, C7 14-721

16. Langen, R. C., Schols, A. M., Kelders, M. C., Wouters, E. F., and Janssen-Heininger, Y. M. (2001) Inflammatory cytokmes inhibit myogenic differentiation through activation of nuclear factor-kappaB. Faseb $/ 15,1169-1180$

17. Miler, S. C., Ito, H., Blau, H. M., and Tort, F. M. (1988) Tumor necrosis factor inhibits human myogenesis in vitro. Mol Cell Biol 8, 2295-2301

18. Szalay, K., Razga, Z., and Duda, E. (1997) TNF inhibits myogenesis and downtegulates the expression of myogenic regulatory factors $m y o D$ and myogenin. Eur J Cell Biol 74, $391-398$

19. Layne, M. D., and Farmer, S. R. (1999) Tumor necrosis factor-alpha and basic fibroblast growth factor differentially inhibit the insulin-like growth factor-I induced expression of myogenin in C2C12 myoblasts. Exp Cell Res $249,177-187$

20. Gutridge, D. C., Albanese, C., Reuther, J. Y., Pestell, R. G., and Baldwin, A. S., Jr. (1999) $\mathrm{NF}$-kappaB controls cell growth and differentiation through transcriptional regulation of cyclin DI. Mol Cell Biol 19,5785-5799

21. Gutridge, D. C., Mayo, M. W., Madrid, L. V., Wang, C. Y., and Baldwin, A. S., Jr. (2000) NF-kappaB-induced loss of MyoD messenger RNA: possible role in muscle decay and cachexia [see comments]. Schence 289, 2363-2366

22. Guo, K., Wang, J., Andres, V., Smith, R. C., and Walsh, K. (1995) MyoD-induced expression of $\mathrm{p} 2 \mathrm{l}$ inhibits cyclin-dependent kinase activity upon myocyte terminal differentiation. Mol Cell Biol 15, 3823-3829

23. Halevy, O., Novitch, B. G., Spicer, D. B., Skapek, S. X., Rhee, J., Hannon, G. J., Beach, D., and Lassar, A. B. (1995) Correlation of terminal cell cycle arrest of skeletal muscle with induction of 21 by MyoD. Science 267, 1018-1021

24. Tapscott, S. J., Davis, R. L., Thayer, M. J., Cheng, P. F., Weintraub, H., and Lassar, A. B. (1988) MyoD 1: a nuclear phosphoprotein requiring a Myc homology region to convert fibroblasts to myoblasts. Science 242, 405-411

25. Weintraub, H., Tapscott, S. J., Davis, R. L., Thayer, M. J., Adam, M. A., Lassar, A. B., and Miller, A. D. (1989) Activation of muscle-specific genes in pigment, nerve, fat, liver, and fibroblast cell lines by forced expression of MyoD. Proc Natl Acad Sci US. $486,5434-5438$

26. Rudnicki, M. A., Schnegelsberg, P. N., Stead, R. H., Braun, T., Arnold, H. H., and laenisch, R. (1993) MyoD or Myf-5 is required for the formation of skeletal muscle. Cell $75,1351-1359$

27. Comelison, D. D., Olwin, B. B., Rudnicki, M. A., and Wold, B. J. (2000) MyoD(-/-) satellite cells in single-fiber culture are differentiation defective and MRF4 deficient. Dev Biol 224, 122-137

28. Bradford, M. M. (1976) A rapid and sensitive method for the quantitation of microgram quantitics of protein utilizing the principle of protein-dye binding. Anal Biochen 72, 248-254

29. Mitchel], P. O., and Pavlath, G. K. (2001) A muscle precursor cell-dependent pathway contributes to muscle growth after atrophy. Am I Physiol Cell Physiol 281 , C. $1706-1715$

30. Wunsch, A. M., and Lough, J. (1987) Modulation of histone H3 variant synthesis during the myoblast-myotube transition of chicken myogenesis. Dev Biol 119, 94-99 
31. Langen, R. C., Schols, A. M. Kelders, M. C., Wouters, B. F. and Janssen-Heininger. Y. M. (2003) Enhanced Myogenic Differentiation by Extracellular Matrix is Regulated at the Early Stages of Myogenesis. In Vitro Cell Dev Biol Amin 39, 163. 169

32. Reynaud, E. G., Pelpel, K., Guillier, M., Leibovitch, M. P., and Leibovitch, S. A. (1999) p57(Kip2) stabilizes the MyoD protein by inhibiting cyclin E-Cdk2 kinase activity in growing myoblasts. Mol Cell Biol 19, 7621-7629

33. Lingbeck, J. M. Trausch-Azar, J. S., Ciechanover, A., and Schwartz, A. L. (2003) Determinants of nuclear and cytoplasmic ubiquitin-mediated degradation of MyoD. $J$ Biol Chem 278, 1817-1823

34. Song, A., Wang, Q., Goebl, M. G., and Harrington, M. A. (1998) Phosphorylation of nuclear MyoD is required for its rapid degradation. Mol Cell Biol 18, 4994-4999

35. Wu, R. S., Tsai, S., and Bonner, W. M. (1982) Patterns of histone variant synthesis can distinguish $\mathrm{G} 0$ from $\mathrm{G} 1$ cells. Cell $31,367-374$

36. Puri, P. L., and Sartorelli, V. (2000) Regulation of muscle regulatory factors by DNA-binding, interacting proteins, and post-transcriptional modifications. $I$ Cell Physiol $185,155-173$

37. Thayer, M. J., Tapscott, S. J., Davis, R. L., Wright, W. E., Lassar, A. B., and Weintraub, H. (1989) Positive autoregulation of the myogenic determination gene MyoD 1. Cell 58, 241-248

38. Garcia-Martinez, C., Agell, N., Llovera, M., Lopez-Soriano, F. J., and Argiles, J. M. (1993) Tumour necrosis factor-alpha increases the ubiquitinization of rat skeletal muscle proteins. FEBS Leit 323, 211-214

39. Li, Y. P., Lecker, S. H., Chen, Y., Waddell, 1. D., Goldberg, A. L., and Reid, M. B. (2003) TNF-alpha increases ubiquitin-conjugating activity in skeletal muscle by upregulating UbcH2/E220k. Faseb $J 17,1048-1057$

40. Bodine, S. C., Latres, E., Baumhueter, S., Lai, V. K., Nunez, L., Clarke, B. A., Poueymirou, W. T., Panaro, F. J., Na, E., Dhamarajan, K., Pan, Z. Q. Valenzuela, D. M., DeChiara, T. M., Stitt, T. N., Yancopoulos, G. D., and Glass, D. J. (2001) Identification of ubiquitiu ligases required for skeletal muscle atrophy. Science 294 , $1704-1708$

41. Gomes, M. D., Lecker, S. H., Jagoe, R. T., Navon, A., and Goldberg, A. L. (2001) Atrogin-1, a muscle-specific fi-box protein highly expressed during muscle atrophy. Proc Nall Acad Sc: US A $98,14440-14445$

42. Gonen, H, Stancovski, 1., Shkedy, D., Hadari, T., Bercovich, B., Bengal, E., Mesilati, S., Abu-Hatoum, O., Schwartz, A. L., and Ciechanover, A. (1996) ISolation, characterization, and partial purification of a novel ubiquitin-protein ligase, E3. Targeting of protein substrates via multiple and distinct recogmition signals and conjugating enzymes. I Biol Chem 271, 302-310

43. Abu Hatoum, O., Gross-Mesilaty, S., Breitschopt, K., Hoflman, A., Gonisn, H., Cicchanover, A., and Bengal, E. (1998) Degradation of myogenic transcription factor MyoD by the ubiquitin pathway in vivo and in vitro: regulation by specific DNA binding. Mol Cell Biol 18, 5670-5677

44. Megeney, L. A., Kablar, B., Garrett, K., Anderson, J. E., and Rudnicki, M. A. (1996) MyoD is required for myogenic stem cell function in adult skeletal muscle. Genes Dev $10,1173-1183$ 
45. Smith, H. K.. Maxwell, L., Rodgers, C. D., McKee, N. H., and Plyley, M. J. (2001) Exercise-enhanced satellite cell proliferation and new myonuclear accretion in rat skeletal muscle. J Appl Physiol 90, 1407-1414

46. Kami, K., and Senba, E. (2002) In vivo activation of STAT3 signaling in satellite cells and myofibers in regenerating rat skeletal muscles. J Histochem Cytochern 50, $1579-1589$

47. Duguez, S., Bihan, M. C., Gouttefangeas, D., Feasson, L., and Freyssenet, D. (2003) Myogenic and nonmyogenic cells differentially express proteinases, $\mathrm{Hsc} / \mathrm{Hsp} 70$, and BAG-1 during skeletal muscle regeneration. Am J Physiol Endocrinol Metab 285, E206-215

48. Li, Y. P. (2003) TNF-alpha is a mitogen in skeletal muscle. Am J Physiol Cell Physiol 285, C370-376

49. Munz, B., Hildt, E., Springer, M. L., and Blau, H. M. (2002) RIP2, a checkpoint in myogenic differentiation. Mol Cell Biol 22, 5879-5886

50. Thaloor, D., Miller, K. J., Gephart, J., Mitchell, P. O., and Pavlath, G. K. (1999) Systemic administration of the NF-kappaB inhibitor curcumin stimulates muscle regeneration after traumatic injury. Am J Physiol 277, C320-329 


\title{
CHAPTER 7
}

\section{Inhibition of myogenic differentiation by tumor necrosis factor alpha or protein kinase $A$ is associated with aberrant regulation of MyoD protein stability}

\begin{abstract}
Tumor necrosis factors alpha (TNF $\alpha$ ) has been implicated as a mediator of skeletal muscle wasting. We recently demonstrated that TNF $\alpha$ inhibits myogenic differentiation via the activation of Nuclear factor Kappa $B(N F-K B)$. The activity of Protein Kinase $A(P K A)$ is linked to the transcriptional activity of $N F-K B$ and is associated with inhibition of myogenesis. Therefore, we investigated in the present study whether inhibition of myogenic differentiation by TNF $\alpha$ occurred through a PKA dependent mechanism, and whether this involved the function of $\mathrm{MyOD}$, a pivotal regulator of myogenic differentiation. Inhibition of myogenic promoter transactivation by TNFa coincided with increased phosphorylation, and decreased protein abundance and half-life of MyoD. Importantly, reduced MyoD protein stability was associated with impaired MyoD-dependent transactivation in myoblasts treated with TNF $\alpha$. Pharmacological activation of PKA by forskolin, or overexpression of the catalytic subunit of PKA was sufficient to inhibit MyoD-dependent myogenic promoter transactivation. Whereas a phosphorylation-resistant mutant of MyoD (S200A), displayed a markedly enhanced stability, inhibition of MyoD transcriptional activity by TNF $\alpha$ or PKA signaling could not be reversed by expression of the $\mathrm{S} 200 \mathrm{~A}$ MyoD mutant, indicating that phosphorylation of MyoD Ser 200 is not involved in TNF $\alpha$ NF-KB-, nor PKA-dependent inhibition of myogenic differentiation. Lastly, the pharmacological inhibitor of PKA, H89 did not amelionate the inhibitory effects of "TNF on myogenic differentiation, whereas PKA activation, in contrast to TNFa actually increased MyoD half-life. Collectively, our data indicate that PKA and TNFo signaling unhibit myogenesis via distinct mechanisms that are associated with aberrant regulation of MyoD protein stability.
\end{abstract}

Ramon C.J. Langen', Annemie M.W.J. Schols', Jos L.J. van der Velden', Lmicl F.M. Wouters' and Ywonne M.W. Janssen-Heininger? Departments of 'Respiratory Medicine, Maastricht University, Maastrich, "The Netherlands, and "Pathology, University of Vermont, Butlington VT, USA An I Physiol Cell Physiol 2003, submitted. 


\section{INTRODUCTION}

Imbalances in processes that goverm the maintenance of skeletal muscle and muscle plasticity, such as skeletal muscle fiber degeneration, apoptosis and regeneration, may be an important determinant of muscle wasting associated with chronic disease. Differentiation of myoblasts in to skeletal muscle fibers is a process that occurs during embryogenesis, but also during postnatal muscle growth and regeneration. Muscle regeneration occurs during normal muscle use (1), but is increased in response to muscle damage, increased muscle load, or restimed muscle use following inactivity (2). Impaired muscle growth or regeneration as a result of interference with the ability of myoblasts (or satellite cells in post-natal skeletal muscle) to proliferate, differentiate or fuse, could ultimately result in loss of skellal muscle tissue.

Myogenic differentiation is a complex process, which is to a large extent dependent on the Muscle Regulatory Factors (MRFs), which include MyoD, Myf5, myogenin and MRF4 (3). In particular MyoD has been implicated in the orchestration of myogenesis, and its functions include cell cycle withdrawal, muscle specific gene transcription, and the fusion of myoblasts into myotubes or myofibers (4). MyoD is a phospho-protein, and it has been demonstrated that MyoD stability is governed by its phosphorylation status, as the phosphorylation of one specific amino acid residue (Ser 200 ) is required for its proteolysis $(5,6)$.

Previously, we have shown that the pro-inflammatory cytokine, Tumor Necrosis Factor alpha (TNF $\alpha$ ) inhibits myogenic differentiation, through a mechanism that depends on activation of the Nuclear Factor kappa $B(N F-k B)$ and involves destabilization of MyoD (manuscript in revision). Induction of $N F-k B$ dependent transcription requires its nuclear localization following degradation of the inhibitory protein IKBo (7). Recently, it has been reported that under basal conditions the $I K B \alpha N F-K B$ complex also contains the catalytic subunit of Protein Kinase A (PKAc) (8). Elevated PKA activity was observed directly following $N F-K B$ induction in response to various stimuli, and occurred independently of the PKA regulatory subunit. Instead, PKA activity was dependent on the degradation of $\mathrm{IKB \alpha}$. It is possible that PKAc release following $I K B$ a degradation in response to TNFo is involved in the inhibitory effect of TNF $\alpha$ on myogenic differentiation. In fact, PKA activation per se resulted in the inhibition of myogenesis, although the mechanism remained elusive $(9,10)$. As MyoD contains three consensus PKA phosphorylation motives (11), it was the focus of this work to explore whether inhibition of myogenic differentiation by TNFa occurred through PKA-dependent modulation of MyoD protein stability. 


\section{MATERIALS AND METHODS}

\section{Cell culture}

The murine skeletal muscle cell line $\mathrm{C} 2 \mathrm{C} 12$ and $10 \mathrm{r} 12$ fibroblasts were obtained from the American Type Culture Collection (ATCC \# CRL1772, and $\mathrm{CCL}_{2} 226$, respectively, Manassas, VA), and cultured in growth media (GM), composed of low glucose Dulbecco's Modified Eagle Medium (DMEM) containing antibiotics $(50 \mathrm{U} / \mathrm{ml}$ Penicillin and $50 \mu \mathrm{g} / \mathrm{m}$ l Streptomycin) and $9 \%(\mathrm{v} / \mathrm{v})$ Fetal Bovine Serum (FBS) (all from Life Technologies, Rockville, MD), or differentiation media (DM), which contained DMEM with $0.5 \%$ heatinactivated FBS and antibiotics (DM). Both cell types were grown on Matrigel (Becton Dickinson Labware, Bedford, MA) coated (1:50 in DMEM) dishes as described previously (12). Cells were plated at $10^{4} / \mathrm{cm}^{2}$ and cultured in GM for $24 \mathrm{~h}$, before transfection or induction of differentiation. When applicable, murine TNF $\alpha$ (Calbiochem, La Jolla, CA), forskolin (Sigma), or H-89 (Calbiochem), were added to the culture dishes directly after induction of differentiation. For the determination of MyoD protein half-life, the protein synthesis inhibitor cycloheximide (CHX) (Calbiochem) was dissolved in HBSS and used at a final concentration of $50 \mu \mathrm{M}$.

\section{Transfections and plasmids}

Transient transfections were performed using Lipofectamine 2000TM (Invitrogen, Carlsbad, CA) according to manufacturers' instructions. Troponin I (TnI)-luciferase plasmid, kindly provided by Dr. Albert Baldwin (University of North Carolina, Chapel Hill, NC), was used as a reporter for the activity of muscle specific transcription factors $(0.25 \mu \mathrm{g}$ per transfection). pSV- $\beta$-gal $(0.25 \mu \mathrm{g}$ per transfection), was employed to correct for differences in transfection efficiency (Promega, Madison, WI). pEMSV-MyoD was a kind gift from Dr. Barbara Winter (University of Braunschweig, Germany). A plasmid encoding p65, provided by Dr. Michael Karin (University of California, San Diego, La Jolla, CA), was used to activate NF-kB. A PKAc encoding plasmid was a kind gift from Dr. Sankar Ghosh (Yale University, New Haven, CT). A stable cell line containing the Tnl reporter plasmid has been described (13). To determine luciferase and $\beta$-gallactosidase acitivity, cells were lysed in $1 x$ luciferase lysis buffer and stored at $-80^{\circ} \mathrm{C}$. Luciforase (Promega, Madison. Wh) and $\beta$ galactosidase (Tropix, Bedford. MA) were measured according to manufacturers" instructions.

\section{Western blot analysis}

MyoD and $\beta$-actin protein abundance was evaluated by Westem bloting. Cells were washed in PBS, and whole cell lysates were prepared by addition of lysis buffer $(40 \mathrm{mM}$ Tris, $300 \mathrm{mM} \mathrm{NaCl}, 2 \%(\mathrm{v} / \mathrm{v})$ Nonidet P-40, $7 \mathrm{mM}$ DTT, $1 \mathrm{mM} \mathrm{Na} \mathrm{VO}_{4}, 1 \mathrm{mM}$ PMSF, $10 \mu \mathrm{g} / \mathrm{ml}$ leupeptin and $1 \%(\mathrm{v} / \mathrm{v})$ aprotinin). Lysates were incubated on ice for 30 minutes, followed by 30 minutes centrifugation at $16000 \mathrm{xg}$. A fraction of the supernatant was saved for protein determination, and $2 x$ Laemmli sample buffer (2\% (w/v) SDS, $10 \%(\mathrm{v} / \mathrm{v})$ glycerol, $0.1 \mathrm{M}$ DTT and $0.01 \%$ (w/v) Bromophenol Blue) was added, followed by boiling of the samples for 5 minutes and storage at $-20^{\circ} \mathrm{C}$. Alternatively, cell lysates were prepared and subjected to calf intestinal phosphatase (CIAP, Sigma) treatment in presence or absence of $100 \mathrm{mM} \mathrm{PO}_{4}$, for th at $30^{\circ} \mathrm{C}$, prior to protein denaturation. Total protein was assessed by the 
Bradford method (14), and $10 \mu \mathrm{g}$ of protein was loaded per lane and separated on a $10 \%$ polyacrylamide gel (Mini Protean System, Bio-Rad, Hercules, CA), followed by transfer to a nitrocellulose membrane (Schleicher \& Schuell, Keene, $\mathrm{NH}$ ) by semidry electroblotting. The membrane was blocked overnight for non specific binding in $5 \%(\mathrm{w} / \mathrm{v})$ non-fat, dried milk at $4{ }^{\circ} \mathrm{C}$. Nitrocellulose blots were washed in PBS-Tween $20(0.05 \%)$, followed by a 1 h incubation with a polyclonal antibody specific for MyoD (Santa Cruz, Santa Cruz, CA). After 3 wash steps of 20 minutes each, the blots were probed with a peroxidase conjugated secondary antibody, and visualized by chemiluminescense according to manufacturers instructions (KPL, Gaithersburg, MD). For the determination of MyoD half-life, MyoD band intensity was determined using the CCD camera of a Molecular Imager system (BioRad, Hercules, CA). Blots were stripped and reprobed for $\beta$-actin to assure equal loading.

\section{RESULTS}

\section{TNF $\alpha$ inhibits myogenic transcriptional activation and alters MyoD phosphorylation and abundance}

We first determined the effects of TNF $\alpha$ on myogenic differentiation and MyoD. Transactivation of a genomically integrated troponin-l promoter in differentiating $\mathrm{C} 2 \mathrm{Cl} 2$ myoblasts (DM, (13)) was induced over 50-fold compared to cells cultured in growth media (GM), whereas the presence of TNF $\alpha$ in DM inhibited this myogenic response (Figure 1). In line with previous reports (manuscript in revision)(15), inhibition of myogenic differentiation by TNF $\alpha$ was associated with a reduction in MyoD protein abundance in differentiating myoblasts, which was most pronounced after $72 \mathrm{~h}$ (Figure $2 \mathrm{~A}$ and $2 \mathrm{~B}$ ). MyoD is a phospho-protein, and when evaluated by Western Blot analysis, two distinct bands can be detected. The slower migrating band represents phosphorylated MyoD, as illustrated by phosphatase treatment, which yielded only the lower immunoreactive signal (Figure 2C). Analysis of the phosphorylated fraction of MyoD revealed a sustained increase in MyoD phosphorylation 24h following TNF $\alpha$ treatment (Figure 2D), which corresponded with the reduction of total MyoD abundance. Thus, the inhibition of myogenic differentiation and reduction in MyoD abundance in response to TNF $\alpha$ coincided with increased MyoD phosphorylation, suggesting the induction of MyoD-directed kinase (or inactivation of MyoD-directed phosphatase) activity by TNFo.
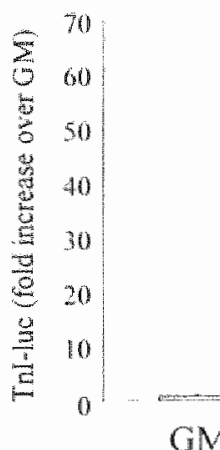

GM

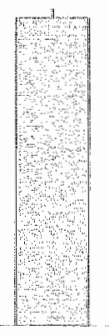

DM
$\mathrm{DM}+\mathrm{TNF} \alpha$
Figure 1: Transactivation of the Troponin-1 promoter is inhibited in the pesence of TWFo or gromth medium. $\mathrm{C} 2 \mathrm{C} / 2$ myoblasts were transiently transfected with plasmids enooding Troponin l-iuciferase and $\beta$-galactosidase; to avaluate the effect of TNFo (10ng/ml) on myogenio differentiation. Tnl-luciferase and B-gal activity were determined in lysates prepared from cels after $48 \mathrm{~h}$ of culture in DM $(+\%$ TNFo $)$, and were expressed as a ratio 10 nomalize for transfection efficiency. Shown are representative data of three independent experiments $(n=3$ is SENH. 
A

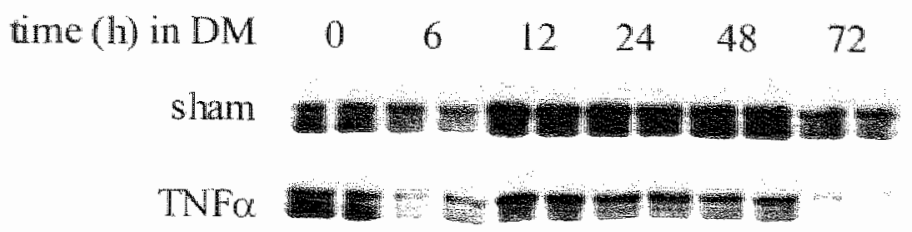

C

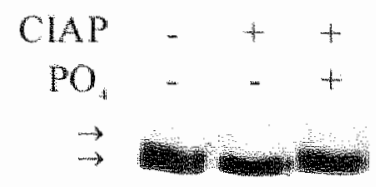

$\mathbf{B}$

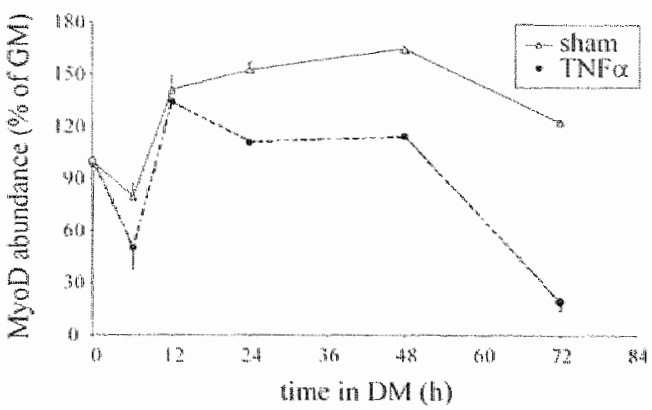

$\mathrm{D}$

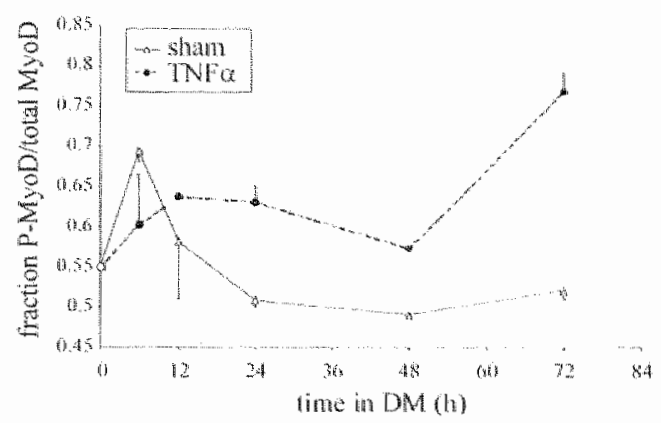

Figure 2: TNFa reduces MyoD abundance and increases phosphorylation of MyoD in differentiating myoblasts. C2C12 cells were culcured in DM in the presence or absence of TNFo (10ng/ml), and cell lysates were evaluated for MyoD protein levels by SDS-PAGE/Western blot analysis at the indicated time points (A). MyoD signal intensity was analyzed by densitometry and expressed as total MyoD (B). Altematively, $\mathrm{C} 2 \mathrm{Cl} 2$ myoblast lysates were prepared and subjected to CIAP (5U/20ug protein) treatment (to denonstrate selectivity $100 \mathrm{mM} \mathrm{PO}_{4}$ was used to inhibit C(AP), prior to Western blot analysis. The arrows indicate phosphorylated and unphosphorylated MyoD (C). After densitometric analysis of the Westem blot shown in A, phosphorylated MyoD (upper band) was expressed as a fraction of total MyoD (D).

\section{Activation of PKA inhibits myogenic differentiation and MyoD dependent transcription}

PKA is the only kinase activated in response to TNFa, which is known to phosphorylate MyoD $(9,10)$. Therefore, we next addressed whether the activation of PKA per se inhibited myogenesis. PKA activation by forskolin (FK) inhibited myogenesis, illustrated by the dose-dependent decrease of Tnl-promoter activation (Figure $3 \mathrm{~A}$ ). This effect was specific for PKA activation, as over-expression of the catalytic subunit of PKA (PKAc) also resulted in inhibition of Tnl-promoter transactivation in differentiating $\mathrm{C} 2 \mathrm{C} 12$ myoblasts (Figure $3 \mathrm{~B}$, left panel). In addition, the ability of MyoD to induce myogenesis in 10T//2 fibroblasts was also blocked by over-expression of PKAc (Figure 3B, right panel), suggesting that MyoD function may be directly affected by PKA activity.

\section{MyoD proteolysis is preceded by phosphorylation and is increased by TNF $\alpha$}

We next determined the half-life of MyoD in $\mathrm{C} 2 \mathrm{C} 12$ myoblasts using the protein synthesis inhibitor, cycloheximide (CHX). Coinciding with its gain of function (Figure 1), MyoD protein half-life increased, from $65 \pm 15^{\prime}$ in GM to $130 \pm 14^{\prime}$ in DM. In contrast, MyoD protein stabilization did not occur (half-life $86 \pm 14^{\prime}$ ) when myoblasts were differentiated in presence of TNF $\alpha$ (Figure $4 \mathrm{~A})$. 


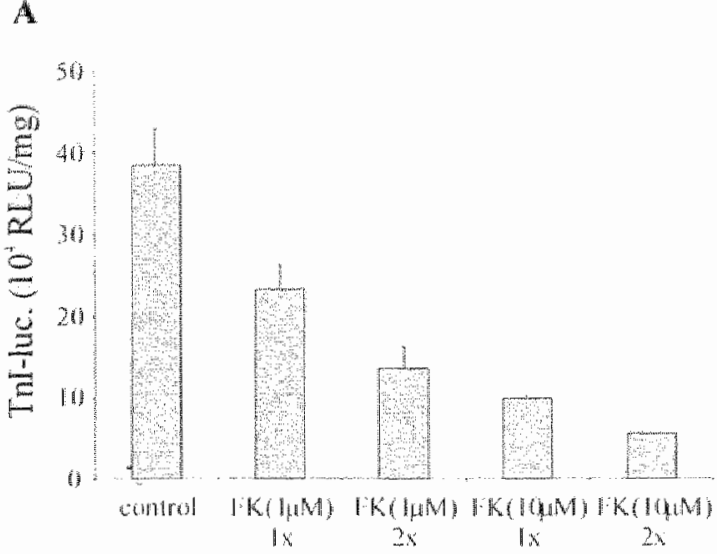

B

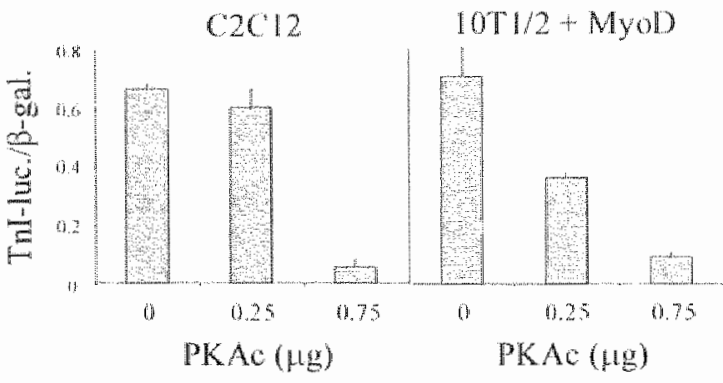

Figure 3: Activation of PKA inhibits myogenic differentiation. Myoblasts of a $\mathrm{C} 2 \mathrm{Cl} 2$ cell line stably expressing a luciferase reporter gene under the control of the Tnl-promoter (13) were cultured in DM in the presence or absence of Forskolin, added to the DM once ( $1 x)$, or every $24 \mathrm{~h}$ (2x). After $48 \mathrm{~h}$ in DM cells were lysed and luciferase activity was determined and corrected for total protein to evaluate myogenic differentiation (A). The catalytic subunit of PKA (PKAc) was expressed together with a Tnl-promoter reporter construct $(0.25 \mu \mathrm{g})$ in either $\mathrm{C} 2 \mathrm{Cl} 2$ myoblasts ( $\mathrm{B}$, left panel), or $10 \mathrm{~T} / 2$ fibroblasts transfected with a MyoD encoding plasmid (0.5\%g) (3B, right panel) Cells were coutransfected with a plasmid encoding $\beta$-galactosidase $(0.25 \mu \mathrm{g})$ to correct for transfection efficiency. Thl-luciferase and $\beta$-gal activity were determined in cell lysates $48 \mathrm{~h}$ after induction of differentiation and expressed as a ratio to evaluate myogenic differentiation. Shown are representative data of three or more independent experiments $(n=3 \pm S E M)$.

In both proliferating and differentiating myoblasts, the intensity of the top band (phosphorylated MyoD) did not start to decrease until all unphosphorylated MyoD (lower band) had disappeared (Figure 4A), suggesting that MyoD phosphorylation preceded its degradation. The significance of MyoD phosphorylation on protein stability was further illustrated by the expression of a plasmid encoding for MyoD with a Ser $\rightarrow$ Ala substitution on amino acid residue 200 (MyoD-S200A) in fibroblasts. This MyoD mutant protein was aimost completely refractory to phosphorylation, as only a single (lower) MyoD band could be detected by Western blot analysis (Figure 4B). Importantly, the stability of this MyoD mutant protein was markedly enhanced when compared to WT MyoD expressed at similar levels in fibroblasts (Figure 4B), suggesting that MyoD protein stability may be regulated by its phosphorylation.

\section{Phosphorylation of MyoD $S 200$ is not involved in inhibition of myogenic differentiation caused by $N F-$ - $B$ or PKA activation}

Illustrative of the pivotal role of NF-KB in TNF $\alpha$-dependent inhibition of myogenesis, overexpression of $\mathrm{p} 65$ was sufficient to inhibit MyoD dependent transcriptional activation, which was also observed following over-expression of PKAc (Figure 5A). To address the potential role of MyoD Ser200 phosphorylation in TNF $\alpha$ signaling, or PKA dependent inhibition of myogenesis, fibroblasts were transfected with S200A MyoD. Functional inactivation of MyoD by either p65, or PKAc was not reversed following S200A MyoD 
expression, indicating that neither TNF $\alpha$ NF-KB signaling, nor PKAc required MyoD $\$ 200$ phosphorylation to inhibit MyoD-dependent gene transcription (Figure 5B). To investigate whether the inhibitory effect of TNF $\alpha$ on myogenic differentiation was mediated through PKA, a specific PKA inhibitor H-89 (16) was used at concentrations that were previously shown to inhibit PKA stimulation of NF- $\mathrm{KB}$ activation (8). Pre-incubation of TNFa-treated myoblasts with H-89 did not reverse the inhibitory effect of TNFo on myogenesis (data not shown).

A

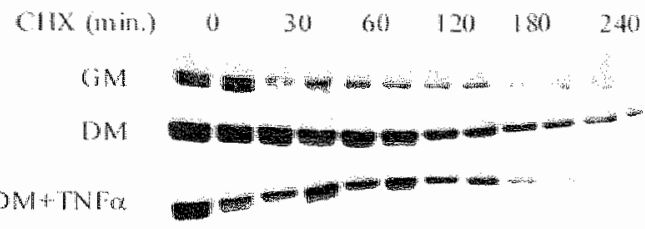

B

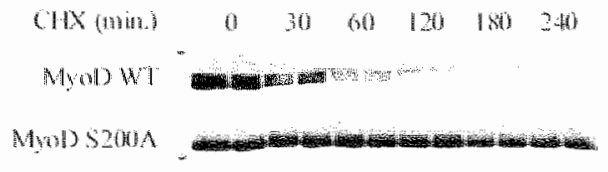

Figure 4: $\quad$ MyoD degradation is preceded by phosphorylation and MyoD protein hall-life is reduced in the presence of TNF $\alpha$ or growth medium. C2C12 myoblasts cultured in GM. DM (24h) or DM contaming TNFa ( $10 \mathrm{ng} / \mathrm{ml}, 24 \mathrm{~h})$ were treated with the protein synthesis inhibitor, cyclohexinnde (CHX, $50 \mu \mathrm{M})$. Al the indicated times, cell extracts were prepared to determine MyoD half-life by Westem blot analysis (A). Protein half-life of wild-type (WT) or mutant MyoD containing a Ser $\rightarrow$ Ala substitution at amino acid position $200(\mathrm{~S} 200 \mathrm{~A})$ was evaluated in fibroblasts transiently transfected with the respective MyoD constructs (I Hg each) (B).

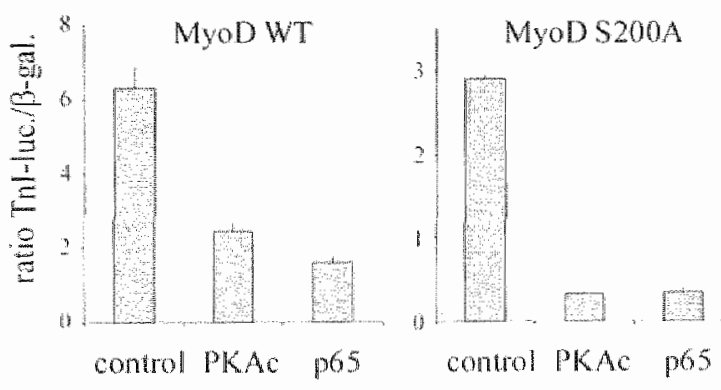

\begin{abstract}
Figure 5: Inhibinon of myogenic differentiation by PKA or NF-H.B activation does not require MyoD $\$ 200$ phosphorylation. PKAc or p65 $(0.75 \mu \mathrm{g}$ each) were axpressed in 10T/2 libroblasts

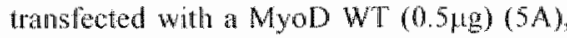

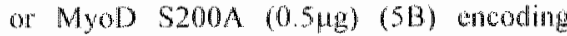
plasmid. Determination of co-translected Tonlwaciferase and [3-gatactosidase antivity

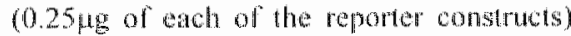
allowed evaluation of Myod function (n-3 t. SEM).
\end{abstract}

\title{
Activation of PKA increases MyoD protein half-life
}

Lastly, we explored the possibility that PKA interfered with MyoD function through destabilization of MyoD protein, in analogy to the GM or TNFo-induced destabilization and functional impairment of MyoD (Figures $I$ and $4 A$ ). In contrast to TNF $\alpha$, activation of PKA by FK actually enhanced MyoD half-life from 130 minutes (control) to 211 minutes (Figure 6A). This finding was confirmed in fibroblasts transfected with MyoD, in which cotransfected PKAc elicited a striking increase of MyoD protein half-life (Figure 6B). 
A.

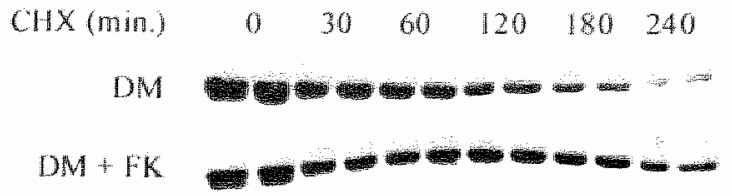

B

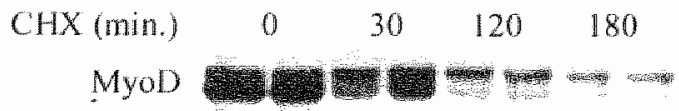

$\mathrm{PKAc}+\mathrm{MyoD}$
Figure 6: Activation of PKA increases

MyoD protein stability. MyoD protein stability was assessed in $\mathrm{C} 2 \mathrm{Cl} 2$ myoblasis as described in Figure 4 after 24 th of culture in DM. PKA was activated by the addition of $10 \mu \mathrm{M}$ Forskolin (dissolved in DMSO) at the onset of differentiation and one hour prior to CHX (A). Evaluation of MyoD stability in fibroblasts transfected with MyoD $(\mathbb{H} \mu \mathrm{g})$ in presence of vector control or PKAc $(2 \mu g)$ encoding plasmids (B).

Collectively, these data demonstrate that TNF $\alpha$ or PKA mediated inhibition of myogenic differentiation is associated with aberrant regulation of MyoD stability through distinct mechanisms, and that PKA activation likely is not involved in TNFo-induced functional impairment of MyoD.

\section{DISCUSSION}

Myogenic differentiation of muscle precursor cells into skeletal muscle fibers is a process that occurs during embryogenesis, but also during postnatal muscle growth and regeneration (2). Earlier studies have shown that the pro-inflammatory cytokine, TNFa inhibits myogenesis $(12,17-19)$, suggesting that TNF $\alpha$ may impair muscle growth and regeneration. In this work we attempted to further elucidate the signaling pathways underlying the inhibitory effect of TNFa on myogenesis, as it may have implications for inflammationassociated skeletal muscle wasting.

Evaluation of "Troponin-I promoter transactivation revealed that TNF $\alpha$ inhibited myogenic differentiation. Previously we demonstrated that this occurred through the activation of NF$\kappa B$, as the expression of a non-degradable mutant of $I \kappa B \alpha$ restored myogenesis in the presence of TNF $\alpha$ (12). TNF $\alpha$-induced degradation of $I \kappa B \alpha$, which leads to the release and nuclear translocation of NF-KB dimers, is a well-described process (7). In fact, NF-KB activation by over-expression of p65 was sufficient to inhibit myogenesis (Figure 5A). The exact mechanism by which TNFa inhibits myogenesis is still subject to debate, but occurs in early differentiation and involves loss of function and abundance of the key muscle regulatory factor (MRF), MyoD $(15,18)$. Although MyoD function is regulated at multiple levels (4), little is known about the relationship between MyoD protein stability, which determines its abundance, and $\mathrm{MyoD}$ function. MyoD protein stability is thought to be regulated by phosphorylation, based on studies performed in fibroblasts, which suggested that the phosphorylation of a specific amino acid residue (Ser 200) of MyoD target it for proteolysis $(5,6)$. Our study demonstrates that the disappearance of unphosphorylated 
MyoD preceded that of phospho-MyoD in myoblasts, strengthening the notion that proteolysis of (endogenous) MyoD is regulated by phosphorylation. Interestingly, MyoD destabilization in response to TNFo coincided with a shift in MyoD phosphorylation status to predominanty phospho-MyoD, suggesting that MyoD-destabilization by TNFo involved induction of kinase activity directed to MyoD.

In addition to NF-KB, the catalytic subunit of PKA (PKAc) is also associated with $1 k B \alpha$. and released upon stimuli leading to $\mathbb{K} B \alpha$ degradation (8). Precedent for inhibition of myogenic differentiation in response to $\mathrm{PKA}$ activation stemmed from experiments demonstrating impaired Tnl-promoter transactivation in differentiating $\mathrm{C} 2 \mathrm{C} 12$ myoblasts through activation of PKA by forskolin, or the over-expression of PKAC (Figures $3 \mathrm{~A}$ and B). Similar to our observations with TNFa (manuscript in revision), the inhibitory effect of PKA activation on myogenic differentiation also appeared to involve functional impairment of MyoD, as the ability of this MRF to induce muscle specific gene transcription in $10 \mathrm{~T} / 2$ fibroblasts was inhibited by PKAc over-expression. However, the data described here do not support an important role for PKA in TNFa-dependent inhibition of myogenic differentiation, as inhibition of PKA activity did not reverse the impaired Tul-promoter activation caused by TNFo. Moreover, if direct phosphorylation of MyoD is required for: the inhibition of myogenesis in response to TNFa or PKA, it will likely involve a residue distinct from Ser 200, as the $\mathrm{S} 200 \mathrm{~A}$ MyoD mutant was not refractory to TNFa/NF- $\mathrm{B}$ or PKA mediated inhibition of myogenic transcription.

Although both TNF $\alpha$ and PKA appeared to affect MyoD function and protein stability directly, it is unlikely that this occurred through an identical signaling pathway, as TNFa caused MyoD instability, whereas pharmacological on "genetic' activation of PKA actually increased MyoD protein half-life. As MyoD-dependent transactivation of a myogenic promoter was completely inhibited by activation of PKA, this implies that MyoD protein stabilization alone does not assure functionality of MyoD. The mechanism that may account for the inhibitory actions of PKA on myogenesis remains unclear. Inhibition of myogenic differentiation by PKA activation has been shown previously, and was postulated to involve impaired MyoD and Myfs function (10). Although PKA was found to phosphorylate MyoD in vitro in that study, the functional consequences remained unclear, as the DNA-binding ability of MyoD was unaffected. The phosphorylation of one single serine residue (Ser 200) appears to determine MyoD protein stability (Figure 4B)(5). Considering the increased stability of MyoD upon activation of PKA, and the fact that the S200A mutant was not refractory to PKAc-mediated inhibition of myogenic transcription, it is unlikely that $\$ 200$ is subject to phosphorylation by PKA. However, direct phosphorylation of MyoD itsell by PKA can not be excluded, since MyoD contains three PKA consensus motives (1 i), which may constitute another level of functional regulation of $M y o D$, distinct from serving as a degradation signal.

Although it has been shown that MyoD phosphorylation by PKA does not alter its abillty lo bind DNA (10), it may repress MyoD dependent transactivation by interfering with the recruiment of cofactors, analogous to the effect of PKA on the yeast transcription factor ADR 1 (20). Alternatively, PKA mediated phosphorylation of MyoD may cause aberrant localization to a cellular compartment which lacks MyoD-directed proteolytic activity but does not support MyoD dependent transcription. For instance, nuclear export of MyoD upon phosphorylation could not only explain the inhibition of MyoD-dependent gene 
transcription by PKA, but also the stabilization of MyoD following PKA activation, as the proteolysis of MyoD is thought to occur in the nucleus (21). However, endogenous PKA activity has been implicated in the nuclear translocation of MyoD, although this was not mediated through direct phosphorylation of $\mathrm{MyOD}$ (11). Nevertheless, phosphorylation of another transcriptional regulator, Nuclear Factor of Activated T-cells (NFAT) constitutes a nuclear export signal (22), thereby disabling NFAT-dependent gene transcription. In fact, a role for PKA has been suggested as a 'priming' kinase involved in the phosphorylation and nuclear export of NFAT (23). Interestingly, specific NFAT isoforms have been identified as positive regulators of muscle gene transcription (22), suggesting that inactivation of NFAT may represent a mechanism by which PKA impairs myogenesis.

In conclusion, the data presented here demonstrate that TNF $\alpha$ or PKA mediated inhibition of myogenic differentiation is associated with aberrant regulation of MyoD stability through distinct mechanisms. 


\section{REFERENCES}

1. Wanek, L. J., and Snow, M. H. (2000) Activity-induced fiber regeneration in rat soleus muscle. Anat Rec $258,176-185$

2. Hawke, T. J., and Garry, D. J. (2001) Myogenic satellite cells: physiology to molecular biology. J Appl Physiol $91,534-551$

3. Rudnicki, M. A., and Jaenisch, R. (1995) The MyoD family of transcription factors and skeletal myogenesis. Bioessays 17, 203-209

4. Li, L., and Olson, E. N. (1992) Regulation of muscle cell growth and differentiation by the MyoD family of helix-loop-helix proteins. Ad Cancer Res 58, 95-1 19

5. Song, A., Wang, Q., Goebl, M. G., and Harrington, M. A. (1998) Phosphorylation of muclear MyoD is required for its rapid degradation. Mol Cell Biol 18, 4994-4999

6. Kitzmann, M., Vandromme, M., Schaeffer, V., Camac, G., Labbe, J. C., Lamb, N., and Fernandez, A. (1999) cdkl-and edk2-mediated phosphorylation of MyoD Ser200 in growing $\mathrm{C} 2$ myoblasts: role in modulating MyoD half-life and myogenic activity. Mol Cell Biol 19,3167-3176

7. Karin, M. (1999) The beginning of the end: IkappaB kinase (IKK) and NF-kappaB activation. J Biol Chem 274, 27339-27342

8. Zhong, H., SuYang, H., Erdjument-Bromage, H., Tempst, P., and Ghosh, S. (1997) The transcriptional activity of $\mathrm{NF}$-kappaB is regulated by the $1 \mathrm{kappaB}$-associated PKAc subunit through a cyclic AMP-independent mechanism. Cell 89, 413-424

9. Li, L., Heller-Harrison, R., Czech, M., and Olson, E. N. (1992) Cyclic AMPdependent protein kinase inhibits the activity of myogenic helix-loop-helix proteins. Mol Cell Biol 12, 4478-4485

10. Winter, B., Braun, T., and Amold, H. H. (1993) cAMP-dependent protein kinase represses myogenic differentiation and the activity of the muscle-specific helix-loophelix transcription factors Myf-5 and MyoD. J Biol Chem 268, 9869-9878

11. Vandromme, M., Carnac, G., Gauthier-Rouviene, C., Fesquet, D., Lamb, N., and Fernandez, A. (1994) Nuclear import of the myogenic factor MyoD requires CAMP. dependent protein kinase activity but not the direct phosphorylation of MyoD. J Cell Sci 107 ( Pt 2), 613-620

12. Langen, R. C., Schols, A. M., Kelders, M. C., Wouters, E. F., and Janssen-Heininger, Y. M. (2001) Inflammatory cytokines inhibit myogenic diferentiation through activation of nuclear factor-kappaB. Faseb,J15, 1169-1180

13. Langen, R. C. I., Schols, A. M. W. J., Kelders, M. C. J. M., Woulters, E. F. M., and Janssen-Heininger, Y. M. W. (in press) Enhanced myogenic ditrerentiation by extracellular matrix is regulated at the early stages of myogenesis. In firro Celular and Developmental Biology-Animal

14. Bradford, M. M. (1976) A rapid and sensitive method for the quantitation of microgram quantities of protein utilizing the principle of protein-dye binding. Anat Biochem 72, 248-254

15. Gutridge, D. C. Mayo, M. W., Madrid, L. V., Wang, C. Y., and Baldwin, A. S., Ir. (2000) NF-kappaB-induced loss of MyoD messenger RNA: possible role in muscle decay and cachexia [see comments]. Science $289,2363-2366$ 
16. Davies, S. P., Reddy, H., Caivano, M., and Cohen, P. (2000) Specificity and mechanism of action of some commonly used protein kinase inhibitors. Biochem $J$ $351,95-105$

17. Miller, S. C., Ito, H., Blau, H. M., and Torti, F. M. (1988) Tumor necrosis factor inhibits human myogenesis in vitro. Mol Cell Biol 8, 2295-2301

18. Szalay, K., Razga, Z, and Duda, E. (1997) TNF inhibits myogenesis and downregulates the expression of myogenic regulatory factors myoD and myogenin. Eur J Cell Biol 74, 391-398

19. Guttridge, D. C., Albanese, C., Reuther, J. Y., Pestell, R. G., and Baldwin, A. S., Jr. (1999) NF-kappaB controls cell growth and differentiation through transcriptional regulation of cyclin D1. Mol Cell Biol 1.9, 5785-5799

20. Cherry, J. R., Johnson, T. R., Dollard, C., Shuster, J. R., and Denis, C. L. (1989) Cyclic AMP-dependent protein kinase phosphorylates and inactivates the yeast transcriptional activator ADR 1. Cell 56, 409-4 119

21. Floyd, Z. E., Trausch-Azar, J. S., Reinstein, E., Ciechanover, A., and Schwartz, A. L. (2001) The nuclear ubiquitin-proteasome system degrades MyoD. J Biol Chem 276, 22468-22475

22. Crabtree, G. R., and Olson, E. N. (2002) NFAT signaling: choreographing the social lives of cells. Cell 109 Suppl, S67-79

23. Sheridan, C. M., Heist, E. K., Beals, C. R., Crabtree, G. R., and Gardner, P. (2002) Protein kinase A negatively modulates the nuclear accumulation of NF-ATel by priming for subsequent phosphorylation by glycogen synthase kinase-3. $J$ Biol Chem $277,48664-48676$ 


\section{CHAPTER 8}

General discussion and future directions 


\section{PROLOCUE}

Therapeutic interventions in chronic inflammatory diseases such as chronic obstructive pulmonary disease (COPD), chronic/congestive heart falure (CHE), inflammatory bowel disease (IBD), and rheumatoid arthritis ( $\mathrm{RA}$ ) have traditionally been focused on treatment of primary organ impairment. Treatment options in these conditions are often limited, and due to irreversible damage, at best prevent further functional deterioration. However, according to World Health Organization definitions, chronic diseases are characterized not onlly by their local impaiment, but also by disability and handicap (1). Impaired exercise performance is a major disabling factor these conditions, and can be attributed to muscle dysfunction independently of primary organ impaiment (2-5). Muscle function is determined by strength and endurance. In particular, the reduction in strength is the result of a decrease in muscle mass. Muscle atrophy frequently occurs in chronic inflammatory disease independently of primary organ failure (6-9), implying that this shared "systemic" pathology may result from a common factor in these conditions. Understanding the mechanism responsible for skeletal muscle atrophy associated with COPD, CHF, IBD, and RA would allow a generalized therapeutic approach aimed at reversal of the systemic aspects of these diseases.

Increased levels of circulating inflammatory mediators have been associated with skeletal muscle atrophy in these conditions (10-18). To elucidate whether and how inflammation contributes to skeletal muscle atrophy associated with chronic disease, investigation of the effects of inflammation on skeletal muscle using in viro and animal models is essential. The overall aim of the studies in this thesis was to explore potential mechanisms of inflammation-associated skeletal muscle atrophy, in order to improve the understanding and treatment of skeletal muscle atrophy in chronic inflammatory diseases.

\section{NF-KB ACTIVATION IN SKELETAL MUSCLE}

The transcription factor Nuclear Factor kappa $B\left(N^{3}-K B\right)$ is a pivotal, intra-cellular integrator of inflammatory stimuli and responses (19). To investigate whether exposure to inlammatory cytokines would affect skeletal muscle, activation of NF- $K B$ was evaluated in culured skeletal muscle cells in Chapter 4. Tumor Necrosis Factor alpha (TNFa) potently induced NF-KB activation in both, myoblasts and myotubes, which was apparent by the rapid dectease of the inhibitory protein $1 k B a$, increased DNA binding of the RelA-p50 heterodimer, and $N F-k B$ dependent transactivation of a promoter-reporter construct. In addition. Interleukin- $(\mathrm{IL}-1)$ as well as the over-expression of $1 \mathrm{~KB}$-kinase (IKK) resulted in $N F-K B$ activation. This suggested that skeletal muscle utilizes the classical pathway to activate $N F=K B$, in which ligand-dependent activation of cytokine receptors, located at the cell membrane results in the recruitment of adaptor molecules, which are responsible for the activation of $1 \mathrm{KK}$, subsequent degradation of the inhibitory protein $\mathrm{IkB} \alpha$ and nuclear translocation of $N F-K B$. A role for oxidative stress in $N F-K B$ activation has been described (20), and therefore the effect of TNFa addition on Reactive Oxygen Species (ROS) production in myoblasts was examined in Chapter 5. Alhough TNF $\alpha$ increased the generation of ROS (Figure 1), ROS did not appear to be required for NF-KB activation, as 
supplementation with the antioxidant precursor $\mathrm{N}$-acelyl cyteine (NAC) did not affect TNFa-induced NF-KB activation. Conversely, the addition of ROS to myoblasts did not induce NF-KB activation.

The finding that skeletal muscle is capable of activating NF-KB may suggest an active role for skeletal muscle in inflammatory responses. This may either be in response to the primary stimulus, or as amplification step secondary to an inflammatory signal of local or systemic origin. This intrinsic ability of skeletal muscle to participate in inflammatory signaling merits further characterization and elucidation of the signaling pathways involved in order to understand the significance of these events in muscle physiology and pathology. Still, the activation of $\mathrm{NF}-\mathrm{KB}$ has direct consequences for skeletal muscle as well, as it impaired all aspects of the differentiation process of myoblasts into multinucleated myotubes.

\section{INHIBITION OF MYOGENIC DIFFERENTIATION BY NF-KB ACTIVATION}

The effect of inflammatory mediators on skeletal muscle was evaluated by monitoring the expression of muscle specific genes in differentiating myoblasts, or fully differentiated myotubes in presence of TNFa or IL-1. As described in Chapter 4. TNF $\alpha$ or IL-1 each inhibited the formation of myotubes, as well as the expression of nuscle specific proteins such as creatine kinase (CK), myosin heavy chain (MyHC), and myogenin in differentiating myoblasts. This inhibitory effect of these cytokines was dependent on NF-KB activation, as disabling the capability of the cells to activate $N F-K B$ restoned myogenic differentiation in the presence of TNF $\alpha$. However, despite similar activation of $N F-K B$ in differentiated myotubes, these multinucleated cells were refractory to TNFa, as expression of myosin heavy chain and creatine kinase was unaffected by the cytokine. This may have important implications for the mechanism of inflammation-induced muscle wasting. It nay indicate that activation of distinct inflammatory signal transduction pathways in concert with $N F-k B$ signaling may be required to affect myofibers directly, as has been shown for the JAK/STAT pathway. Simultaneous activation of JAK/STAT and NF-KB signaling by intramuscular injections of a cocktail of Interforon gamma (IFNy) and TNFa reduced muscle specific protein expression in myofibers, whereas. TNFa alone did not (21). Allernatively, inflammatory cytokines may not affect muscle protein expression in myofibers directly, but require an additional, endocrine signal. This notion is illustrated by the synergistic offect of combined administration of TNF $\alpha$ and corticosteron in experimental models of muscle atrophy $(22,23)$. However, the latter may preferentially concern conditions of acule muscle wasting, such as associated with sepsis, in which amino acids derived of increased proteolytic breakdown of myofibrillar protein serve to fual the synthesis of acute phase reactants in the liver. The mechanism of this atrophic response involves an imbalance in myofiber proten synthesis and proteolysis. This ma be distinet from the mechanism underlying muscle atrophy associated with chronic disease, in which factors that govern muscle plasticity, apart from an imbalance in muscle protein metabolism may be responsible for muscle atrophy.

Further analysis of the inhibitory response of TNF $\alpha$ on myogenic differentiation described in Chapter 6 revealed that the expression of muscle specific genes was also reduced at the 
mRNA level. In addition, inhibition of muscle specific promoter activation, and impaired cell cycle exit of differentiating myoblasts in response to TNF $\alpha$, suggested that the function of the key myogenic regulator MyoD (24) was affected (Figure 1). MyoD function was impaired by TNF $\alpha$ in a NF- $\mathrm{kB}$ dependent manner, but could be restored by over-expression of MyoD. The functional inhibition of MyoD by TNF $\alpha$ coincided with a marked decrease in MyoD protein levels, which resulted from increased proteolysis through the ubiquitin proteasome pathway. Many regulatory proteins are subject to proteolysis through this pathway following specific post-translational modifications, like phosphorylation, oxidation or hydroxylation, which elicit their subsequent ubiquination, marking the protein for degradation by the proteasome (25).

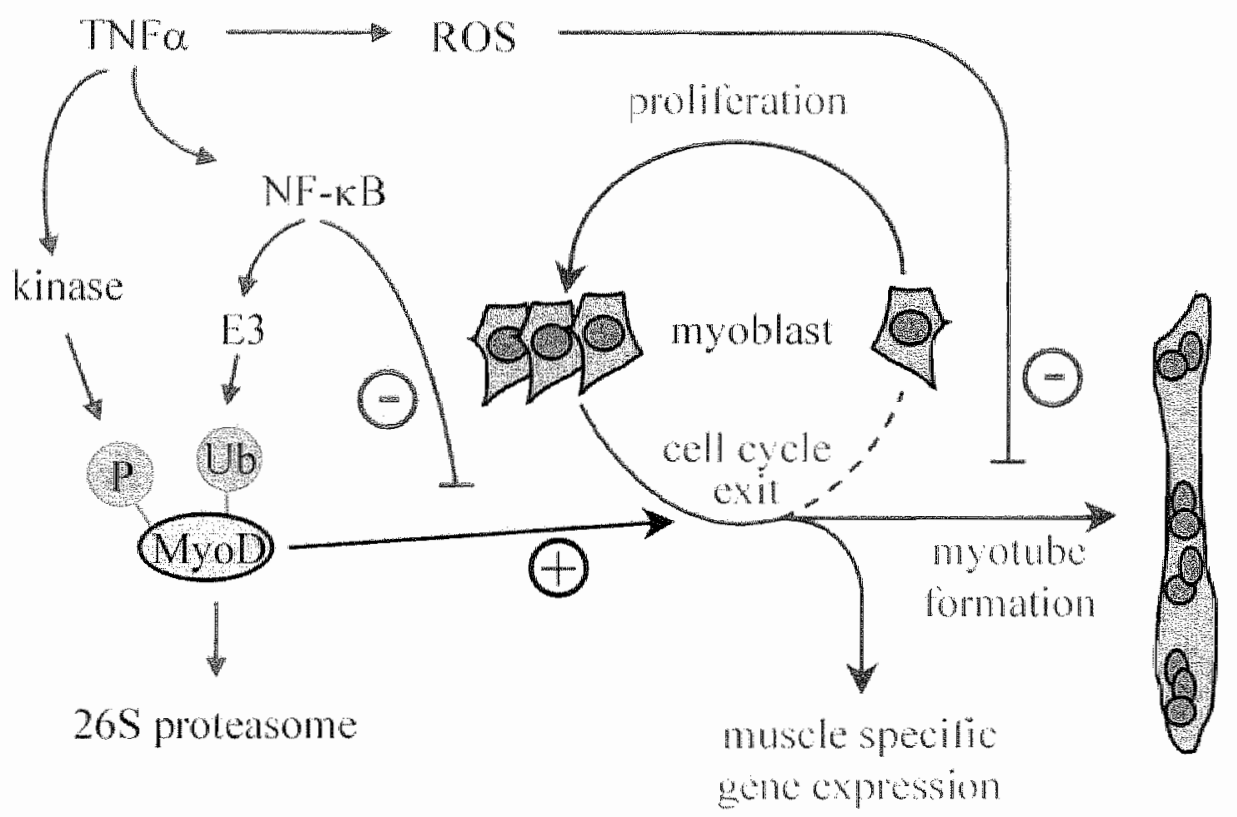

Figure /: Inhibition of myogenic differentiation by TNF $\alpha$. TNF $\alpha$ induces NF-KB activation and ROS production independently in sketetal muscle. ROS formation by TNFo specifically affected myotube formation, whereas NF-KB activation by TNFo was responsible for the inhibition of muscle specific gene expression. This occurred llurough interference with MyoD function as a result of MyoD protein destabilization, which involved increased MyoD phosphorylation and proteolysis through the ubiquitin proteasome pathway.

The potential involvement of MyoD phosphorylation in increased MyoD proteolysis in response to TNF $\alpha$ was explored in Chapter 7. Although the phosphorylation rate was not directly determined, the presence of TNF $\alpha$ resulted in an increase in the fraction of phosphorylated MyoD (Figure 1). However, if TNF $\alpha$-induced MyoD phosphorylation is involved in inhibition of myogenic differentiation, it does not rely on Ser 200 phosphorylation, which governs the stability of MyoD in proliferating cells (26), as a Ser $200 \rightarrow$ Ala mutant of MyoD was not resistant to $\mathrm{NF}-\mathrm{kB}$ signaling. In addition, Protein 
Kinase A (PKA) activation, which impared myogenesis and has been shown to phosphorylate MyoD (27), was not required for TNFa mediated inhibition of myagenic differentiation. Whether inhibition of myogenesis by TNF $\alpha$ depends on phosphorylation of MyoD on some other residue(s), by a kinase other than PKA remains to be detemined.

An altemative mode to cause selective degradation of regulatory proteins through the ubiquitin proteasome pathway relies on the inducible expression of ubiquitin conjugating enzymes (E2 proteins), and ubiquitin ligases (E3 proteins), of which the latter have a high substrate specificity. In this perspective, it is interesting to note that inhibition of myogenic differentiation by $N F-k B$ appeared to rely on an intact transcription domain of RelA. suggesting that an $N F-k B$ regulated gene product may be responsible for the increased proteolysis of MyoD (Figure 1). Evidence for a role of the wbiquitin proteasome pathway in inflammation-associated skeletal muscle afrophy has been demonstrated in various experimental models (28), which mainly encompassed the acute loss of muscle mass due to myofibrillar protein degradation, as referred to earlier. Muscle specific ubiquitin conjugating enzymes (29) and ubiquitin ligases $(30,31)$ involved in this proteolytic response have recently been identified, and it will be interesting to investigate whether their substrate specificity includes $M y o D$, and to analyze their transcriptional regulation for $N F$ KB responsiveness.

\section{INHIBITION OF MYOGENIC DIFFERENTIATION: IN WIVO IMPLICATIONS}

As most of the work described in this chapter was performed in vitro, it was important to investigate its relevance using an in vivo model, in order to understand the implications for skeletal muscle physiology and pathology. Myogenic differentiation is a process that occurs not only in skeletal muscle development during embryogenesis, but also during post-natal muscle growth or regeneration, which are essential determinants of skeletal muscle plasticity (32). Therefore, the effects of TNFo were verified in a mouse model of skeletal muscle regeneration in Chapter 6. Confirming the observations in the in wiro model, intramuscular TNF $\alpha$ injections during regeneration resulted in a sustained proliferation signal and a decrease in myogenin expression, indicative of impaired myogenic differentiation. Based on these findings, a mechanism distinct from an imbalance in protein metabolism is proposed to be involved in skeletal muscle atrophy in chronic inflammatory conditions.

The accretion of new myonuclei by satellite cell activation, myoblast proliferation and myogenic differentiation is essential for post-natal skeletal muscle growh and regeneration, since, analogous to an increase in myofiber number, an increase in myofiber size requires the addition of new myonuclei (33). This is due to a limitation of the sarcoplasmic volume controlled by one myonucleus, designated the myonuclear domain (32). Consequently, an uncompensated loss of myonuclei will invariably result in a decreased myofiber size. Therefore, in addition to a balance in protein metabolism, skeletal muscle plasticity is likely to be governed at another level, i.e. the balance in the accretion and loss of myonuclei, or myonuclear turnover (Figure 2). Skeletal muscle atrophy observed with muscle disuse can be regarded as an imbalance in myonuclear tumover, and depends on a mechanism that appears to involve apoptosis, or programmed cell death (34), as the myonuclear mumber decreased with muscle mass. Recently, increased apoptosis in skelletal muscle has been associated with muscle wasting in COPD (35) and CHF (36). Although uncompensated 
myonuclear apoptosis would certainly result in muscle atrophy according to the myonuclear turnover hypothesis (Figure 2), great care must be taken with the interpretation of these studies, as important questions remained unanswered regarding the cellular origin and the extreme magnitude of the apoptotic signal. A fundamental understanding of the apoptotic mechanism in skeletal muscle is currently lacking, as apoptosis has mostly been studied in mononuclear cells, and not in multinucleated myofibers. Whether and how a single myonucleus of a myofiber can undergo apoptosis, which intracellular molecules are involved, and which stimuli (inflammatory cytokines?) can induce apoptosis will be the focus of future investigations. Armed with this knowledge, the contribution of apoptosis to skeletal muscle atrophy associated with chronic disease can truly be evaluated.

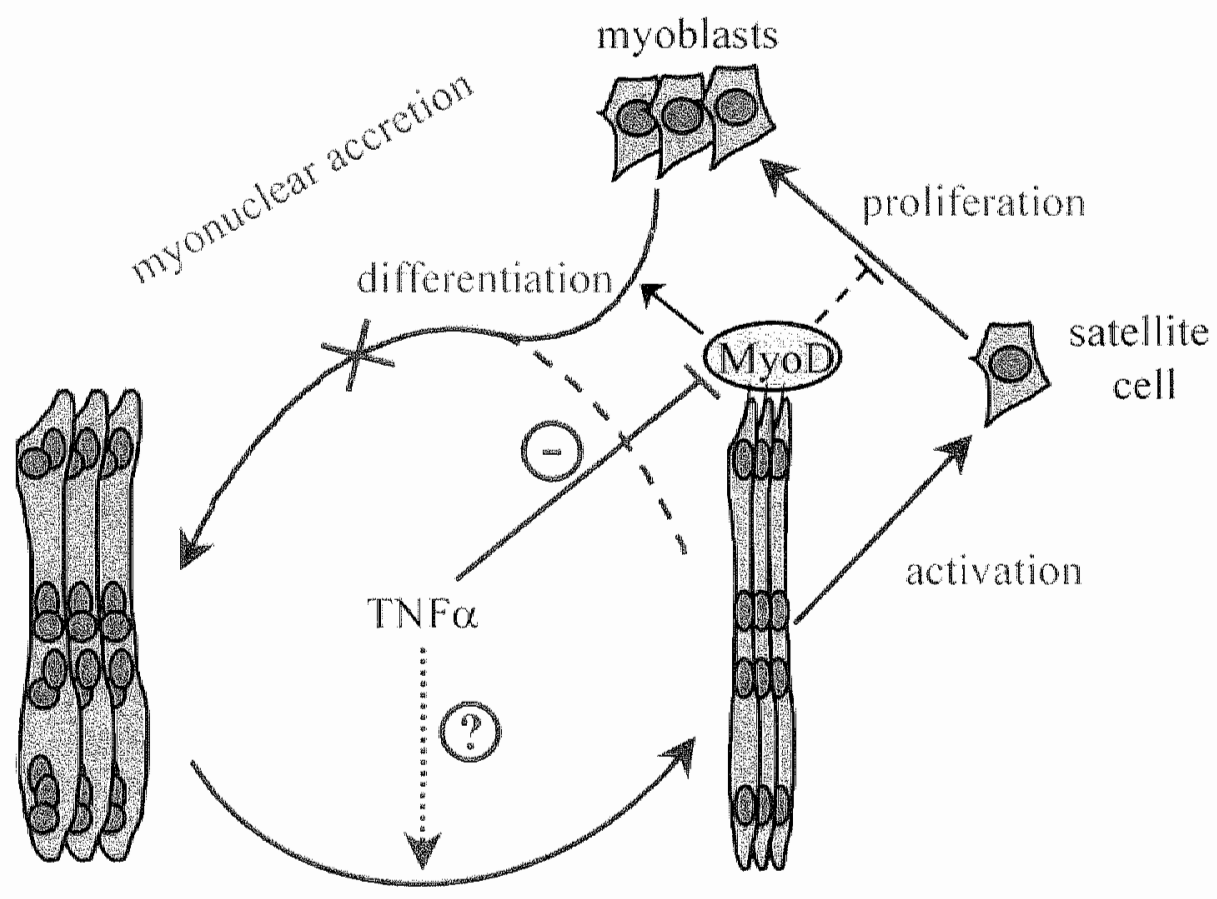

nyonuclear apoptosis

Figure 2: Interlerence with myonuclear turnover by TNFo impaits skeletal muscle plasticity and causes muscle atrophy. Basal or regeneration induced myonuclear accretion is blocked by TNF $\alpha$ through inhibition of MyoD function in differentiating myoblasts and subsequent interference with myogenesis. Whether of not amplified by TNFa, basal or damage-induced myonuclear apoptosis proceeds while uncompensated, resulting in an imbalance in myonuclear turnover, and ultimately leading to sketetal muscle atroply.

Still, myonuclear turnover, and therefore muscle plasticity is also governed by changes in myonuclear accretion. The latter depends on the activation of a resident pool of muscle precursor cells, named satellite cells (Figure 2). Upon activation, these cells, now called myoblasts proliferate, and differentiate to fuse with existing myofibers. This mode of 
myonuclear accretion is essential for post-natal growth of skeletal muscle, as inhibition of satellite cells activation and proliferation impaired growth-related or regeneration induced gain of muscle mass $(33,34)$. This has major implications for the findings described in this thesis, as myogenic differentiation is an essential part of satellite cell dependent accretion of myonuclei. Inhibition of myogenic differentiation by inflammatory mediators may impair muscle regeneration in response to injury, or may even disturb basal myonuclear turnover in favor of a loss of myonuclei, ultimately resulting in skeletal muscle atrophy (Figure 2). Obviously, muscle growth stimulation in absence of myogenic differentiation is also expected to be compromised, which may explain the lack of responsiveness of a population of COPD patients with an increased inflammatory serum profile to an anabolic stimulus (37). A more fundamental understanding of the intra-cellular processes that govern skeletal muscle plasticity in response to hypertrophic and regeneration stimuli will also allow the identification of the signaling pathways that are interfered with by inflammatory mediators. In this perspective, attention will be focussed on the role of Glycogen Synthase Kinase-3 beta (GSK-3 3 ) in skeletal muscle regeneration and hypertrophy, as this kinase is involved muscle Insulin-like Growth Factor I (IGF-1) signaling (38), embryonal muscle development (39), and cardiac hypertrophy (40).

It will also be important to examine if the balance in myonuclear turnover is disturbed in skeletal musele atrophy as it occurs in chronic disease, especially as it provides an explanation for the slow progression of muscle atrophy in these conditions. In future studies, myonuclear number and regeneration markers should be determined in muscle biopsies obtained from patients suffering from inflammation-associated muscle atrophy, as well as 'signatures' of an inflammatory response of the skeletal muscle itself, e.g. NF-KB activation. In addition, experimental models of chronic inflammation associated muscle atrophy will aid further understanding of this condition, and may provide molecular markers that can be used for diagnostic purposes. With regard to this approach it is interesting to note that SP-C/TNF $\alpha$ transgenic mice, which demonstrate an emphysematous phenotype associated with chronic pulmonary inflammation (41), have a reduced skeletall muscle mass (unpublished data). The skeletal muscle of these mice, as well as its response to muscle growth or regeneration protocols awaits further analysis of critical constituents of myogenic differentiation. The use of transgenic $\mathrm{NF}-\mathrm{KB}$ or $\mathrm{MyoD}$ reporter mice, and conditional knockout mice will provide further insight in the role of MyoD and NF-KB in inflammation associated skeletal muscle atrophy.

Finally, just as the work of this thesis started out, the in vitro culture of skeletal muscle will play an essential role in further elucidation of the signal transduction involved in muscle atrophy. Using this model, the proteolysis of MyoD will be further investigated to identify the kinase(s) and ubiquitin ligase(s) responsible for the increased proteolysis of $\mathrm{MyoD}$ in response to TNF $\alpha$, with their causal involvement assessed by exiting, new technicues like RNA interference.

The integrated approach of basal research in experimental models as presented in this thesis, and careful analysis of muscle biopsies obtained from well-designed clinical studies, will provide a platform for therapeutic interventions focused at the prevention or teversal of skeletal muscle atrophy associated with chronic disease. 


\section{REFERENCES}

1. Wood, P. H. (1980) Appreciating the consequences of disease: the intemational classification of impairments, disabilities, and handicaps. WHO Chron 34, 376-380

2. Baarends, E. M. Schols, A. M. Mostert, R., and Wouters, E. F. (1997) Peak exercise response in relation to tissue depletion in patients with chronic obstructive pulmonary disease. Eur Respir J 10, 2807-2813

3. Harrington, D., Anker, S. D., Chua, T. P., Webb-Peploe, K. M., Ponikowski, P. P., Poole-Wilson, P. A... and Coats, A. J. (1997) Skeletal muscle function and its relation to exercise tolerance in chronic heart failure. J Am Coll Cardiol 30, 1758-1764

4. Brevinge, H., Berglund, B., Bosaeus, I., Tolli, J., Nordgren, S., and Lundholm, K. (1995) Exercise capacity in patients undergoing proctocolectomy and small bowel resection for Crohn's disease. $B r J$ S $w$ rg $82,1040-1045$

5. Stucki, G., Bruhlmann, P., Stoll, T., Stucki, S., Willer, B., and Michel, B. A. (1996) Low serum creatine kinase activity is associated with muscle weakness in patients with rheumatoid arthritis. I Rhewmatol 23, 603-608

6. Schols, A. M., Slangen, J., Volovics, L., and Wouters, E. F. (1998) Weight loss is a reversible factor in the prognosis of chronic obstructive pulmonary disease. Am of Respir Crit Care Med 157, 1791-1797

7. Anker, S. D., Ponikowski, P., Varney, S., Chua, T. P., Clark, A. L., Webb-Peploe, K. M., Harrington, D., Kox, W. J., Poole-Wilson, P. A., and Coats, A. J. (1997) Wasting as independent risk factor for mortality in chronic heart failure. Lancet 349,1050 1053

8. Tjellesen, L., Nielsen, P. K., and Staun, M. (1998) Body composition by dual-energy $X$-ray absorptiometry in patients with Crohn's disease. Scand $J$ Gastroenterol 33 , $956-960$

9. Roubenoff, R., Roubenoff, R. A., Ward, L. M., Holland, S. M., and Hellmann, D. B. (1992) Rheumatoid cachexia: depletion of lean body mass in rheumatoid arthritis. Possible association with tumor necrosis factor. $J$ Rheumatol 19, 1505-1510

10. Di Francia, M. Barbier, D., Mege, J. L., and Orehek, J. (1994) Tumor necrosis factor-alpha levels and weight loss in chronic obstructive pulmonary disease. Am I Respir Cril Care Med 150, 1453-1455

11. Schols, A. M., Buurman, W. A., Staal van den Brekel, A. J., Dentener, M. A., and Wouters, E. F. (1996) Evidence for a relation between metabolic derangements and increased levels of inllammatory mediators in a subgroup of patients with chronic obstructive pulmonary disease. Thoran 51,819-824

12. Eid, A. A. lonescu, A. A., Nixon, L. S., Lewis-Jenkins, V., Matthews, S. B., Grifliths, T. L., and Shale, D. J. (2001) Inflammatory response and body composition in chronic obstructive pulmonary disease. Am I Respir Crit Care Med 164, 14141418

13. Levine, B., Kalman, J., Mayer, L., Fillit, H. M., and Packer, M. (1990) Elevated circulating levels of tumor necrosis factor in severe chronic heart failure. $N E n g l J$ Med $323,236-241$ 
14. Ferrari, R., Bachetti, T., Confortini, R., Opasich, C., Febo, O., Conti, A., Cassani, O., and Visioli, $O$. (1995) Tumor necrosis factor soluble receptors in patients with various degrees of congestive heart failure. Cifculation 92, 1479-1486

15. Murch, S. H., Lamkin, V. A., Savage, M. O., Walker-Snith, I. A., and MacDonald. T. T. (1991) Serum concentrations of tumour necrosis factor alpha in childhood chronic inflammatory bowel disease. Gut 32, $913-917$

16. Mazlam, M. Z., and Hodgson, H. J. (1992) Peripheral blood monocyte cytokine production and acute phase response in inflammatory bowel disense. Gu 33, 773-778

17. Altomonte, L., Zoli, A., Mirone, L., Scolieri, P., and Magaro, M. (1992) Serum levels of interleukin- $1 b$, tumour necrosis factor-a and interleukin-2 in rheumatoid arthritis. Correlation with disease activity. Clin Rhemmatol 11,202-205

18. Roubenoff, R., Roubenoff, R. A., Cannon, J. G., Kehayias, I. J., Zhuang, H., Dawson-Hughes, B., Dinarello, C. A., and Rosenberg, 1. H. (1994) Rheumatoid cachexia: cytokine-driven hypemetabolism accompanying reduced body cell mass in chronic inflammation. $J$ Clin Invest $93,2379-2386$

19. Pahl, H. L. (1999) Activators and target genes of Rel/NF-kappaB transcription factors. Oncogene 18, 6853-6866

20. Karin, M., Takahashi, T., Kapahi, P., Delhase, M., Chen, Y., Makris., C., Rothwarl, D., Baud, V., Natoli, G., Guido, F., and Li, N. (2001) Oxidative stress and gene expression: the AP-1 and NF-kappaB connections. Biofactors 15,87-89

21. Guttridge, D. C., Mayo, M. W., Madrid, L. V., Wang, C. Y., and Baldwin, A. S., Ir. (2000) NF-kappaB-induced loss of MyoD messenger RNA: possible role in muscle decay and cachexia. Science 289, 2363-2366

22. Hall-Angeras, M., Angeras, U., Zamir, O., Hasselgren, P. O., and Fischer, J. E. (1990) Interaction between corticosterone and tumor necrosis factor stimulated protein breakdown in rat skeletal muscle, similar to sepsis. Swrgery 108, 460-466

23. Raina, N., and Jeejeebhoy, K. N. (1998) Changes in body composition and dietary intake induced by tumor necrosis factor alpha and corticosterone--individually and in combination. Am J Clin Nutr 68, 1284-1290

24. Wei, Q., and Paterson, B. M. (2001) Regulation of MyoD function in the dividing myoblast. FEBS Ler $490,171-178$

25. Pickart, C. M. (2000) Ubiquitin in chains. Trends Biochem Sci 25, 544-548

26. Song, A., Wang, Q., Goebl, M. G., and Harrington, M. A. (1998) Phosphorylation of nuclear MyoD is required for its rapid degradation. Mol Cel/ Biol 18, 4994-4999

27. Winter, B., Braun, T., and Amold, H. H. (1993) cAMP-dependent protein kinase represses myogenic differentiation and the activity of the muscle-specific helix-loophelix transcription factors Myl-5 and MyoD.J Biol Chem 268, 9869-9878

28. Jagoe, R. T., and Goldberg. A. L. (2001) What do we really know about the ubiquitin-proteasome pathway in muscle atrophy? Cur Opin Clin Nur Metah Care 4. $183-190$

29. Li, Y. P., Lecker, S. H., Chen, Y., Waddell, I. D., Goldberg, A. L., and Reid, M. B. (2003) TNF-alpha increases ubiquitin-conjugating activity in skeletal musele by upregulating UbcH2/E220k. Faseb J 17, 1048-1057

30. Bodine, S. C., Latres, E., Baumhueter, S., Lai, V. K., Nunez, L., Clarke, B. A., Poueymirou, W. T., Panaro, F. J., Na, E., Dharmarajan, K., Pan, Z. Q. Valenzuela., D. M., DeChiara, T. M. Stitt, T. N., Yancopoulos, G. D., and Glass, D. I. (2001) 
Identification of ubiquitin ligases required for skeletal muscle atrophy. Science 294 , $1704-1708$

31. Gomes, M. D., Lecker, S. H., Jagoe, R. T., Navon, A., and Goldberg, A. L. (2001) Atrogin-1, a muscle-specific F-box protein highly expressed during muscle atrophy. Proc Nat Acad Sci US A 98, 14440-14445

32. Allen, D. L., Roy, R. R., and Edgerton, V. R. (1999) Myonuclear domains in muscle adaptation and disease. Muscle Nerve 22, 1350-1360

33. Mozdziak, P. E., Schultz, E., and Cassens, R. G. (1997) Myonuclear accretion is a major determinant of avian skeletal muscle growth. Am J Physiol 272, C565-571

34. Mitchell, P. O., and Pavlath, G. K. (2001) A muscle precursor cell-dependent pathway contributes to muscle growth after atrophy. Am J Physiol Cell Physiol 281, C1706-1715

35. Agusti, A. G., Sauleda, d., Miralles, C., Gomez, C., Togores, B., Sala, E., Batle, S., and Busquets, X. (2002) Skeletal muscle apoptosis and weight loss in chronic obstructive pulmonary disease. Am J Respir Crit Care Med $166,485-489$

36. Adams, V., Jiang, H., Yu, J., Mobius-Winkler, S., Fiehn, E, Linke, A., Weigl, C, Schuler, G., and Hambrecht, R. (1999) Apoptosis in skeletal myocytes of patients with chronic heart failure is associated with exercise intolerance. $J \mathrm{Am} \mathrm{Coll} \mathrm{Cardiol}$ $33,959-965$

37. Creutzberg, E. C., Schols, A. M., Weling-Scheepers, C. A., Buurman, W. A., and Wouters, E. F. (2000) Characterization of nonresponse to high caloric oral nutritional therapy in depleted patients with chronic obstructive pulmonary disease. Am $J$ Respir Crit Care Med 161, 745-752

38. Rommel, C., Bodine, S. C., Clarke, B. A., Rossman, R., Nunez, L., Stitt, T. N., Yancopoulos, G. D., and Glass, D. J. (2001) Mediation of IGF-1-induced skeletal myotube hypertrophy by $\mathrm{PI}(3) \mathrm{K} / \mathrm{Akt} / \mathrm{mTOR}$ and $\mathrm{PI}(3) \mathrm{K} / \mathrm{Akt} / \mathrm{GSK} 3$ pathways. Nat Cell Biol 3, 1009-1013

39. Cossu, G., and Borello, U. (1999) Wht signaling and the activation of myogenesis in mammals. Embo J 18, 6867-6872

40. Antos, C. L., Mckinsey, T. A., Frey, N., Kutschke, W., McAnally, J., Shelton, J. M., Richardson, J. A., Hill, J. A., and Olson, E. N. (2002) Activated glycogen synthase-3 beta suppresses cardiac hypertrophy in vivo. Proc Narl Acad Sci U S A 99, 907-91.2

41. Miyazaki, Y., Araki, K., Vesin, C., Garcia, I., Kapanci, Y., Whitsett, J. A., Piguet, P. F., and Vassalli, P. (1995) Expression of a tumor necrosis factor-alpha transgene in murine lung causes lymphocytic and fibrosing alveolitis. A mouse model of progressive pulmonary fibrosis. J Clin Invest 96, 250-259 
SUMMARY 
Skeletal muscle atrophy accompanies many chronic inflammatory disease states, such as chronic obstructive pulmonary disease (COPD), chronic heart failure, inflammatory bowel disease, and rheumatoid arthritis, and results in impaired exercise performance, increased morbidity and mortality. The balance (homeostasis) in muscle growth (myogenesis) and muscle breakdown is governed by the ability of skeletal muscle to adapt (muscle plasticity) to altered muscle loading, or regenerate in response to muscle damage. The mechanism underlying muscle atrophy is still unclear, and may result from imbalances in the loss and gain of myonuclei, i.e. myonuclear turn-over. This thesis describes the inhibitory effects of inflammatory cytokines on skeletal muscle differentiation, and its potential relevance in the etiology of muscle atrophy.

Skeletal muscle atrophy in acute and chronic inflammatory disease states may be governed by distinct mechanisms. Acute inflammatory conditions, such as sepsis, are associated with muscle catabolism. The loss of muscle tissue may be consequent to a decrease in protein synthesis, which is apparent at the transcriptional and translational level of muscle protein expression. Alternatively, a cytokine-driven increase in protein degradation, involving the ubiquitin-proteasome pathway has been demonstrated in acute loss of muscle mass. Considering the slow progression of muscle atrophy in chronic inflammatory conditions, muscle homeostasis and plasticity may also be deregulated at levels other than muscle protein metabolism. Loss of myonuclei by apoptosis and gain by muscle growth and regeneration have been described in experimental conditions. Certain cytokines may elicit apoptotic responses of myonuclei, or conversely, inhibit myonuclear accretion during muscle regeneration and growth. Eventually, such an imbalance in myonuclear turnover, and disruption of muscle plasticity at the cellular level could result in muscle atrophy.

Myonuclear accretion during muscle regeneration or growth requires the activation, proliferation and differentiation of residing muscle precursor cells, known as satellite cells. Myogenic differentiation of these mononuclear cells (myoblasts) involves the expression of skeletal muscle specific proteins and the fusion with existing, or new myofibers. This process can be modelled in vitro, using a cell line of cultured mouse skeletal muscle myoblasts as described in Chapter 3. In this system myoblasts grow and divide (proliferate) in the presence of a culture medium containing a high concentration of growth factors. To allow activation of the differentiation programme, the myoblasts have to cease proliferating (exit the cell cycle). This can be accomplished by reducing the concentration of growth factors in the medium. Culture media composed of a wide variety of growth factors and other additives have been used to this end. Since the diversity in these components may modulate the differentiation process differentially, a differentiation protocol was developed and optimized that does not require the introduction of any factors to the differentiation media (DM), other than those present in the growth media. By culturing C2C12 skeletal myocytes on a coating of diluted Matrigel, a soluble basement membrane, consisting of collagen IV, laminin, heparan sulfate proteoglycans and entactin, myogenic differentiation was accomplished by mere serum reduction. Assessment of myotube formation (in vitro myofiber formation through myoblast fusion), creatine kinase activity, myosin heavy chainfast and myogenin, revealed that the kinetics and extent of myogenic differentiation were superior using this protocol, compared to a commonly used differentiation protocoll, in which an extracellular matrix is not provided and the DM contains horse serum. In addition, 
the elevated transactivation of the troponin-1 has promoter stggested that myogenesis was enhanced at the transcriptional level. Finally, assessmant of genomic DNA content demonstrated that the Matrigel differentiation protocol resulted in lowered proliferation. As this protocol may aid studies aimed at the elucidation of mechanisms of (interference with) myogenic differentiation, it was used throughout the rest of the experiments described in this thesis.

In Chapter 4 the response and consequences of inflammatory cytokines on skeletal muscle were investigated. Myotubes and differentiating myoblasts were exposed to intlammatory cytokines, including tumor nectosis factor alpha (TNF $\alpha$ ) and interleukin 1B (IL-1B). Both, TNF $\alpha$ and IL-I $\beta$ activated nuclear factor-kappaB (NF-KB), which is a pivotal transcriptional regulator of intlammatory stimuli and responses. Importantly, TNF $Q$ and IL. $1 \beta$ interfered with the expression of muscle proteins in differentiating myoblasts. Introduction of a mutant form of inhibitory protein $\kappa B \propto(I \kappa B \alpha)$, which blocked $N F-k B$ activation, restored myogenic differentiation in myoblasts treated with TNF $\alpha$ or $\|L-\| \beta$. Conversely, activation of $\mathrm{NF}-\kappa \mathrm{B}$ by over-expression of $\llbracket k \mathrm{~B}$ kinase was sufficient to block myogenesis, illustrating the causal link between NF-KB activation and inhibition of myogenic differentiation. The inhibitory effects of TNF $\alpha$ on myogenic differentiation were reversible, indicating that the effects of the cytokine were not due to non-specific toxicity. Treatment of differentiated myotubes with TNFa did not result in a striking loss of musclespecific proteins, which shows that myogenesis was selectively affected in the myoblast stage by TNF $\alpha$. An important finding was that $N F-\kappa B$ was activated to the same extent in differentiating and differentiated cells, illustrating that once myocytes have differentiated they become refractory to the effects of $N F-k B$ activation.

Besides NF-KB activation, TNFa is also known to induce oxidative stress. As described in Chapter 5, this also occurred in $\mathrm{C} 2 \mathrm{C} 12$ cells in which TNFa caused a decrease in reduced glutathione (GSH) during myogenic differentiation, which coincided with an elevated generation of reactive oxygen species (ROS). Supplementation of cellular GSH with $N$ acetyl-L-cysteme (NAC) did not reverse the inhibitory effects of TNFa on troponin I (TnI) promoter activation, and only partially restored creatine kinase (CK) activily in "TNFatreated cells. In contrast, the administration of NAC prior to treatment with TNF $\alpha$ almost completely restored the formation of multinucleated myotubes. NAC decreased TNF $\alpha$ induced activation of $\mathrm{NF}-\mathrm{K} \mathrm{B}$ only marginally, indicating that the redox-sensitive component of the inhibition of myogenic differentiation by TNFa occurred independently, or downstream of NF-KB. These observations suggested that the inhibitory effects of TNF $\alpha$ on myogenesis can be uncoupled in a redox sensitive component affecting myotube formation, and a redox independent component affecting myogenic protein expression.

Chapter 6 was focussed on the identification of the regulatory molecule(s) of myogenesis targeted by TNFo/NF-KB signaling. TNF $\alpha$ interfered with cell cycle exit and repressed the accumulation of mRNA transcripts encoding muscle specific genes in differentiating $\mathrm{C} 2 \mathrm{C} / 2$ myoblasts. Over-expression of a mutant of the $N F-k B$ subunit $p 65$ (RelA), which lacked the transcriptional activation domain, attenuated the TNFa-mediated inhibition of muscle specific gene transcription. This indicated that $N F-K B$ transcriptional activity was requited 
for the inhibitory effect of TNFa/NF-KB signalling on myogenesis. In addition, the ability of the Muscle Regulatory Factor MyoD to induce muscle specific transcription in 10T1/2 fibroblasts was also disrupted by wild type p65, demonstrating that NF-kB transeriptional activity interferes with the function of MyoD. Inhibition of muscle specific gene expression by TNF $\alpha$ was restored by over-expression of $M y o D$, whereas endogenous $M y o D$ protein abundance and stability were reduced by TNFo through increased proteolysis of MyoD by the ubiquitin proteasome pathway. Lastly, the inhibitory effects of TNFa on myogenic differentiation were demonstrated in a mouse model of skeletal muscle regeneration, in which TNF $\alpha$ also caused a delay in myoblast cell cycle exit and a decrease in myogenin expression.

The activity of Protein Kinase A (PKA) is linked to the transcriptional activity of NF- $K B$ and is associated with inhibition of myogenesis. Therefore, in Chapter 7 the question was addressed whether inhibition of myogenic differentiation by TNFa occurred through a PKA dependent mechanism, affecting MyoD function. Decreased MyoD protein abundance and half-life caused by TNFo coincided with increased phosphorylation of this myogenic regulatory molecule. Similar to TNF $\alpha$, pharmacological activation of PKA by forskolin, or over-expression of the catalytic subunit of PKA was sufficient to inhibit MyoD-dependent myogenic promoter transactivation. Whereas a phosphorylation-resistant mutant of MyoD (S200A), displayed a markedly enhanced stability, inhibition of MyoD transcriptional activity by TNF $\alpha$ or PKA signaling could not be reversed by expression of the S200A MyoD mutant, indicating that phosphorylation of MyoD Ser 200 is not involved in TNF $\alpha$ NF-KB-, nor PKA-dependent inhibition of myogenic differentiation. Lastly, the pharmacological inhibitor of PKA, H89 did not ameliorate the inhibitory effects of TNF $\alpha$ on myogenic differentiation, whereas PKA activation, in contrast to TNF $\alpha$ actually increased MyoD half-life. Collectively, our data indicate that PKA and TNF $\alpha$ signaling inhibit myogenesis via distinct mechanisms that are associated with aberrant regulation of MyoD protein stability.

In conclusion, the studies described in this thesis demonstrate that inflammatory cytokines like TNF $\alpha$, and IL-1 inhibit myogenic differentiation through the activation of NF-KB. An intact transactivation domain of the $p 65$ subunit of NF-KB appeared to be required for this response, suggesting the involvement of a $N F-K B$ regulated gene. MyoD was identified as the myogenesis-regulatory molecule targeted by TNF $\alpha / N F-K B$ signalling. The loss of MyoD function was caused by its reduction in protein abundance, and coincided with increased phosphorylation and a reduction in MyoD protein stability. The latter was reversible by inhibition of the $26 \mathrm{~S}$-proteasome, indicating that induction of one or multiple components of the ubiquitin proteasome pathway by TNF $\alpha$ appear to be responsible for the increased degradation of MyoD. Therefore, the NF-kB regulated gene responsible for inhibition of myogenic differentiation may concern an ubiquitin conjugating enzyme of ubiquitin ligase responsible for enhanced proteolysis of MyoD by TNFa. Importantly, the relevance of the in vitro findings described in this thesis was demonstrated in a murine model of reloading-induced skeletal muscle regeneration, in which intra-muscular TNF $\alpha$ injections resulted in a sustained proliferation signal and a decrease in myogenin expression, indicative of impaired myoblast differentiation. 
Based on these findings, a perturbation in myonuclear turnover caused by the inhibition of myogenic differentiation and subsequent myonuclear accretion is proposed as a mechanism by which impaired muscle plasticity contributes to skeletal muscle atrophy in chronic inflammatory conditions. 


\section{SAMENVATTING}


Atrofie van skeletspieren treed vaak op bij chronische inflammatoire ziektebeelden, waaronder chronische obstructieve longziekten (COPD), chronisch hartfalen, inflammatoire darmziekten, en reumatoide artritis. Atrofie leidt tot spierzwakte, een verminderde lichamelijke conditie en zelfs tot een verhoogd sterfterisico. De gezonde skeletspier heeft een enorm vermogen om zich aan te passen (ook wel spierplasticiteit genoemd) aan veranderingen in het type - en de intensiteit van spieractiviteit, zuurstofverbruik en zich te herstellen na spierschade (spierregeneratie). Spierplasticiteit komt bijvoorbeeld tot uiting bij krachttraining, waarbij door toegenomen gebruik van bepaalde spieren na een bepaalde periode een vergroting van de betreffende spieren valt waar te nemen. Op celniveau betekent dit meestal dat de spiervezees in grootte zijn toegenomen. Opvallend hierbij is dat het aantal celkernen in de spiervezels (myonucleï) ook toeneemt en er is bewijs dat spiergroei (myogenese) niet of onvolledig plaatsvindt wanneer de toename in myonuclei wordt geblokkeerd. Het lijkt zelfs zo te zijn dat er in de gezonde spier continu spierkernen bijkomen en verdwijnen (myonucleaüre turn-over), maar de spiermassa niet toe- of afneemt omdat dit proces in evenwicht is. Een verstoring van deze balans door een toegenomen verlies van myonucleï, of een verminderde aanwas van spierkernen resulteert in spieratrofie. De onderliggende mechanismen van spieratrofie bij chronische inflammatoire ziektebeelden zijm nog onduidelijk. In dit proefschrift is onderzocht of en hoe ontstekingseiwitten (cytokinen) die voorkomen bij deze ziektebeelden de omvorming (differentiatie) van enkelkernige spiercellen (myoblasten) in meerkernige spiervezels kunnen remmen, omdat dit proces een essentieel onderdeel is van de aanwas van spierkernen en dus van het behoud van spiermassa.

Dit differentiatieproces kan in een petrischal (in vitro) worden nagebootst, gebruik makend van een cellijn van muizenskeletspier myoblasten $(\mathrm{C} 2 \mathrm{Cl} 2)$. In dit systeem worden myoblasten aangezet tot celdeling door de aanwezigheid van hoge concentraties groeifactoren in het kweekmedium. Om het differentiatieprogramma van de myoblasten te activeren moet de proliferatie eerst worden stopgezet zodat de cellen uit de celcyclus kunnen treden. Dit wordt bewerkstelligd door de concentratie aan groeifactoren in het kweekmedium te reduceren. Dit celkweeksysteem is geoptimaliseerd en vervolgens gebruikt in de experimenten die in dit proefschrift zijn beschreven. Spierdifferentiatie wordt hierbij steeds gemeten aan de hand van het verschijnen (expressie) van specifieke spiereiwitten en de fusie van de enkelkernige myoblasten tot meerkernige spiervezels (ook wel myotubes genoemd in wirro).

Uit de experimenten blijkt dat het differentieproces van de myoblasten geremd wordt door ontstekingseiwitten zoals tumor necrosis factor alfa (TNF $\alpha$ ) en interleukine $1 \beta$ (IL-1 $\beta$ ). Daarthast activeren TNF $\alpha$ en IL- $1 \beta$, een belangrijk regulerend eiwit van ontstekingsreacties, nuclear factor kappa $B(N F-K B)$, in myoblasten en myotubes. Activatie van $N F-\kappa B$ is op zichzelf al genoeg on differentiatie te blokkeren. Daar staat tegenover dat TNF $\alpha$ en IL-1 $\beta$ spierdifferentiatie niet ontregelen als $N F-\kappa B$ activatie wordt voorkomen. De remmende werking van $N F-k B$ op spierdifferentiatie is gericht tegen een eiwit dat van groot belang is in het differentiatieproces, MyoD. Celcyclus uittreding, de expressie van spierspecifieke eiwitten en myotube vorming, elk processen die voor een belangrijk deel worden gereguleerd door MyoD, zijn verstoord als gevolg van NF-kB activatie door TNFa. Daarnaast verliest $M y o D$ ook de eigenschap om niet-spiercellen een spierkarakter te laten aannemen als NF-KB geactiveerd is. Het dysfunctioneren van MyoD door TNF $\alpha / N F-k B$ signaal-transductie is het gevolg van een verminderde hoeveelheid en halfwaarderijd 
(stabiliteit) van het MyoD eiwit, omdat het versneld wordt afgebroken (gedegradeerd) door een eiwit-afbrekend complex, het $26 \mathrm{~S}$-proteasoom. Omdat de door TNFo verhoogde MyoD degradatie kan worden genormaliseerd door remming van het $26 \mathrm{~S}$-proteasoom, zijn ubiquitine conjugatie en ligatie enzymen van de ubiquitine-proteasome pathway kandidaatNF- $k B$ gereguleerde genen, die specifiek worden geinduceerd door stimuli zoals TNF $\alpha$. Tenslotte wordt de relevantie van deze celkweek bevindingen onderstreept door de reproduceerbaarheid wan de myogenese-onderdrukkende effecten van TNF $\alpha$ in cen muizenmodel van skeletspier regeneratie.

Gebaseerd op bovenstaande bevindingen wordt geconcludeerd dat een verstoring van de spierplasticiteit door inflammatoire cytokinen ten grondslag kan liggen aan skeletspieratrofie. Hierbij betreft het onderliggende mechanisme een imballans in myonucleaïre turnover, die wordt veroorzaakt door een verminderde myonuclaïre aanwas als gevolg van onderdrukking van spierdifferentiatie. 


\section{DANKWOORD / ACKNOWLEDGEMENTS}


Eindelijk. Dat is het eerste woord dat me te binnen schiet nu ik aan het dankwoord van mijn proefschrift begin. Eindelijk, omdat de maanden van achter de computer gekluisterd te zitten hiermee geheel tot het verleden behoren (...) en ik weer het lab in kan. Maar vooral eindelijk, ondat ik nu op fatsoenlijke wijze een behoorlijk aantal mensen eens kan bedanken voor al hun steun en hulp in de afgelopen jaren, iets dat er gaandeweg het proces wel eens bij inschiet.

Om te beginnen bij mijn promoter, Professor Wouters. Alhoewel ik u bij mijn sollicitatiegesprek -destijds nog met lang haar-heb moeten overtuigen mijn wilde haren in Antwerpen te hebben verloren, werd ik gelukkig toch aangesteld als AIO. Ik wil u daarom ook bedanken voor uw vertrouwen on mij, samen met Yvonne en Annemie vorm aan het project te laten geven. Vanuit uw brede visie heeft u waar nodig bijgestuurd met een detailistische kennis van de cellulaire sigaal-transductie die een doorgewinterd celbioloog doet verbleken. Ook heeft u mij de kracht doen inzien van de "verdeel en heers strategie" bij het publiceren van onderzoek. Maar vooral wil ik u bedanken voor de plats waar u mij naartoe heeft gestuurd voor mijn onderzoek en waar ik een geweldige tijd heb mogen doorbrengen: Vermont.

Daar heb ik mogen werken onder de begeleiding van een begaafd cel- en moleculair biologe. Yvonne, heel erg bedankt voor jouw mentorschap. Als 'hands-on' co-promoter heb je me enorm veel geleerd; van het werk aan de labtafel tot het schrijven van artikelen en het presenteren van het onderzoek. Gedurende de tijd dat ik er was is jouw lab qua personele bezetting explosief gegroeid, maar toch was er altijd de mogelijkheid om bij je binnen te lopen met een vraag of je enthousiasme te prikkelen met de laatste nieuwe data. Je bent een echt voorbeeld voor mij en ik hoop dat we in de toekomst nog lang zullen samenwerken.

Natuurlijk ook Annemie, als mijn 'trans-Atlantic' co-promoter enorm bedankt voor je begeleiding en thet vertrouwen dat je me hebt gegeven. Ondanks de afstand stond je altijd klaar om interessante resultaten te bespreken, de bevindingen in een klinisch-relevant perspectief te plaatsen en manuscripten kritisch na te kijken. Daamaast werden de congressen altijd extra goed benut om weer eens flink te brainstormen. Nu ik terug ben in Maastricht hoop ik nog veel te kunnen leren van jouw management- en netwerkcapaciteiten en samen nog veel, maar vooral spannend onderzoek te kunnen verrichten.

Ook gaal mijn dank uit naar de beoordelingscommissie van mijn proefschrift, onder voorzitterschap van Prof. Dr. M. Daemen en verder bestande uit Prof. Dr. M. Hofker, Prof. Dr. G.J. van der Vusse. Prof. Dr. M. Decramer en Prof. Dr. M.B. Reid-Michael, thank you very much for your critical review of my thesis and your efforts to attend the defence.

Since I have started of in English now anyway, I will first continue to thank all the people I have worked with at the University of Vermont. There are so many people that have helped me in some way or another that I am bound to forget someone. But if this happens to be YOU, let me know by e-mail, include your address and I will make it up by sending you a postcard from Holland.

Starting in the Janssen lab. a really big thank you to everyone for all the quality time in the lab, but also outside work. To begin with my buddy Rebecca. It was great having you as my 
fellow grad student. We've had lots of laughs and learned a lot from each other (except Dutch). Also thanks to Wendy, our ever patient technician. Matt, I still can't believe all the lab facts you have stored in your head (the full name for PMSl, wasn't it?). You have taught me lots of stuff, not only in the lab, but also about working on cars. Thanks for all that. Other post-docs and fellow (grad) students I like to thank are Dries, Katie, Heather, Marleen, Solange, Isak, Brian (did you injure anyone playing UVM soccer last season?). Roy (tot binnenkort), the four sisters Christen (been kidnapped lately?), Niki (Ajax - Club Brugge 2:0), Karina (are you leaving or cold?), and Punya (what happened to your wig?). Of course Amy, thanks for your patience and rush-ordering. Kim (we have someone just like you here in our lab in Maastricht), thanks for keeping up with me (and Jos). I also owe a big thank you to my friends and partners in crime Jos and Marco, although the more serious version can be found in the Dutch section.

I would also like to thank Dr. Brooke Mossman, and all the people (that have worked) in her lab, including Cindy. A special "thank you" for Dr. Charles Irvin and Dr. Jason Bates for all their support and in particular for their help with the SP-C/TNF $\alpha$ mice. Also thanks to the people of the Heintz, Dostman, Taatjes, Toth, and Rincon lab, and of course the respective PI's. I also definitely would like to thank all the secretaries in the Pathology office, and in particular Laurie Sabens.

And last, but certainly not least thanks to Tom "Toolman" Teel, and of course the ladies from the kitchen, Betty and Linda, who I still consider as my sugar aunts.

Dan weer terug in Nederland aangekomen wil ik de medewerkers van onze vakgroep bedanken ondat ze het toch voor elkaar gekregen hebben dat ik me hier (weer) thuis voel. Juanita, Mieke, Mariëlle en Eva, jullie waren er al toen ik hier begon waama het contact vervolgens hoofdzakelijk beperkt was tot verplicht cafébezoek tijdens congressen, wambij de Margarita's niet werden geschuwd (door jullie). Ook gaat mijn dank uit naar de "nieuwtjes" Roelinka (uut Terschelling), Erica, Kirsten en Evi (uit het buitenland), Suzanne, Carmen en Petra en alle dames wan het secretariaat, met in het bijzonder Wimnie, Fabięnne, Manon en natuurlijk France.

Gelukkig staat er tegenover al dat vrouwelijk geweld nog een team van ferme manskerels om de boel een beetje in balans te houden. Frits (binnenkort weer eens squashen?), ik heb jo maar even mee mogen maken voordat je gerekruteerd werd voor het leger van de witle jassen, maar wel het paranimfschap met je mogen delen in die tijd. Jij ook succes met de laatste loodjes van je onderzoek.

Dan natururlijk Mareo, alias Kobus (voor vrienden). Na jarenlange radiostilte was jij bereid analist te komen spelen in Vermont, hetgeen ondermeer heeft mogen resulteren in je eigen RPA probe panel (Kobus ${ }^{\mathrm{M}}$ ). In de Green Mountains hebben we menige hike afgelogd en in de winter de skihellingen onveilig gemaakt (met name jij dan eigenlijk). Bedankt voor je collegialiteit en vriendschap gedurende die periode en ik voorzie een goede voorlzelling ervan hier in Maastricht.

Daamaast wil ik ook jou, Jos, bedanken woor de goede samenwerking en alle lol die we in Vermont gehad hebben, watr je eerst als stagiair en later als analist met mij het spieronderzoek bent ingedoken. Zo stond het in ieder geval op papier, mar in werkelijkheid heb je daar eigenlijk met de inzet en het unicht van een AlO in het kwadraat gewerkt. Daarom ben ik ook erg blij dat je nu hier in Mastricht in ons lab al weer een jaar op een AIO project bent aangesteld. Ik hoop dat we samen nog veel leuk onderzoek gaan verrichten 
en dat jij nou eens opschiet zodat het voor jou wel binnen 4 jaar in cen boekje resulteert. Verder hoop ik voor je dat je me binnenkort weer eens serieuze tegenstand biedt met squash, want de uitdaging begint er voor mij een beetje af te raken.

Tenslotte dan nog Harry, enorm bedankt voor al je (met name computertechnische) hulp. Al vanaf de eerste dag dat ik hier rondliep (in ' 97 nog) voelde jij je (gelukkig) geroepen mij door de ontberingen wan het computertijdperk heen te loodsen. Ik ben er nog steeds niet uit of dat nu kwam doordat ik aan jou vroeg "of dat ene apparaat daar de printer was". Het bleek de airconditioner te zijn. Maar natuurlijk vooral bedankt voor alle vriendschap en je steun met de laatste loodjes van het proefschrift.

Naast al mijn vrienden en collega"s nog een woord aan mijn familie.

Daar schaar ik jou ook onder Ronald. Het was geweldig dat je ons nog bent komen opzoeken in de VS, alwaar je natuurlijk als gelouterd cameraman direct een natuurdocumentaire hebt kunnen schieten en materiaal hebt vergaard voor "Wuld Policecar Chases III'.

Willem en Ada Bleijenberg en Rudi en Sabine Ovaa, bedankt voor al jullie steun en bezoekjes in de VS en dat jullie je dochter/(schoon)zus met me mee hebben laten gaan naar de andere kant van de oceaan voor zo'n lange periode.

$\mathrm{Pa}$, ma en Eno, bedankt dat jullie er altijd waren. Er is veel gebeurd gedurende de 4 jaar dat we niet in Nederland waren. Maar dankzij jullie steun zijn we ook door de moeilijkere tijden heen gekomen en hebben we toch vooral kunnen genieten van onze tijd in de VS. Gelukkig zijn jullie ook op bezoek geweest om mee te kunnen maken hoe we daar hebben gewoond, gewerkt en onze vrije tijd hebben besteed (met bijvoorbeeld stevige hikes op besneeuwde bergtoppen, iets wat jij niet snel zal vergeten hé pa?).

En dan tenslotte de ene persoon die met mij in het diepe is gesprongen. Zonder te twijfelen zij je ' $j a$ ' ... toen ik je vroeg of je het zag zitten om mee te gaan naar de VS. Dit zonder enige garantie of, en wat voor werk we voor je zouden kunnen vinden en hoe en waar we zouden komen te wonen. Maar ondanks al die onzekerheden ben je meegegaan en hebben we een onvergetelijke tijd gehad. Je hebt jezelf helemaal kunnen ontplooien in je baan als case manager van daklozen in Burlington, en toen we na uiteindelijk 4 jaar weer terugkeerden naar Nederland was dit voor jou misschien nog wel moeilijker dan voor mij. Weer opnieuw leuk en uitdagend werk en een woning zoeken in, voor ons toch, weer een beetje buitenland, maar dat is toch weer gelukt.

Mariska, bedankt voor al je steun, geduld en vooral liefde. Samen gaan we, waar dan ook een mooie toekomsi tegemoet! 


\section{PUBLICATIONS}


1. van Helden, H. P., Küupers, W. C., Langerwerf, P. E., Langen, R. C., Haagsman, H. P. and Bruinzed, P. L. (1998) Efficacy of Curosurf in a rat model of acute respiratory distress syndrome. Eur Respir J12,533-539.

2. Langen, R. C., Schols, A. M., Kelders, M. C., Wouters, E. F., and Janssen-Heininger, Y. M. (2001) Inflammatory cytokines inhibit myogenic differentiation through activation of nuclear factor-kappaB. Faseb $J 15,1169-1180$.

3. Langen, R. C., Schols, A. M., Kelders, M. C., Van Der Velden, J. L., Wouters, E. F., and Janssen-Heininger, Y. M. (2002) Tumor necrosis factor-alpha inhibits myogenesis through redox-dependent and -independent pathways. Am J Physiol Cell Physiol 283, C714-721.

4. Janssen-Heininger, Y. M., Persinger, R. L., Korn, S. H., Pantano, C., McElhinney, B., Reymaert, N. L.. Langen, R. C., Ckless, K., Shrivastava, P., and Poynter, M. E. (2002) Reactive nitrogen species and cell signaling: implications for death or survival of lung epithelium. Am J Respir Crit Care Med 166, S9-S16.

5. Langen, R. C. J. (2003) Effects of inflammation on skeletal muscle. In European Respiratory Monograph (Wouters, E. F. M., ed) 8, 68-85. European Respiratory Society Joumals Lidd, Sheffield, UK.

6. Langen, R. C. J., Kom, S. H., and Wouters, E. F. M. (2003) Reactive oxygen species in the local and systemic pathogenesis of Chronic Obstructive Pulmonary Disease. Free Radic Biol Med 35(3), 226-35.

7. Langen, R. C. J., Schols, A. M. W. J., Kelders, M. C. J. M., Wouters, E. F. M., and Janssen-Heininger, Y. M. W. (2003) Enhanced myogenic differentiation by extracellular matrix is regulated at the early stages of myogenesis. In Vitro Cellula. and Developmental Biology-Animal 39, 163-169.

8. Langen, R. C. I., v. d. Velden., A.L.J., Schols, A. M. W. J., Kelders, M. C. J. M., Wouters, E. F. M., and Janssen-Heininger, Y. M. W. (2003) Tumor necrosis alpha inhibits myogenic differentiation through MyoD protein destabilization. Faseb $J$. (in revision).

9. Langen, R. C. I., Schols, A. M. W. J., .. d. Velden., A.L.J., Wouters, E. F. M., and Janssen-Heininger, Y.M. W.(2003) lnhibition of myogenic differentiation by tumor nectosis factor alpha or protein kinase $A$ is associated with aberrant regulation of MyoD protein stability. Am J Physiol Cell Physiol (submitted). 
CURRICULUM VITAE 
Ramon Langen was bom on the aleventh of October 1972 in Etten-Leur (NL). After he finished high school in 1991 at the Katholieke Scholengemeenschap Etten-Leur (KSE), he studied medicine for two years at the University of Antwerp, Belgium (RUCA). In 1993 he switched to the biomedical laboratory education (HLO, Hogeschool West-Brabant). He did an internship at the Laboratoires Francais du Biotechnologie (LFB) in Lille, France, where he participated in the characterization of monoclonal antibodies to the Rhesus $\mathrm{D}$ antigen. $\mathrm{He}^{*}$ graduated after having completed his thesis on a research project he conducted during a nine month period as an intern at the Prins Maurits Laboratory (PML) of the institute of applied ${ }^{1}$ scientific research (TNO) in Rijswijk. During this periad he studied the role of TNF $\alpha^{k}$ secretion by alveolar macrophages in an animal model of ARDS. In October 1997 he joined the Department of Respiratory Medicine of the Maastricht University as a PhD student. Most of the experimental work described in this thesis was performed during his four yeart stay in the United States, where he worked in the department of Pathology at the University" of Vermont. His project was aimed on elucidation of the mechanisms by which ${ }^{1}$ inflammation modulates skeletal muscle plasticity, and contributes to muscle atrophy. Currently, in his position as post-doctoral fellow at the Department of Respiratory' Medicine, his research will focus on the regulation of skeletal muscle plasticity in health and disease. 